Florida International University FIU Digital Commons

$11-16-2010$

\title{
Engagement Experiences of Hispanic Generation 1.5 English Language Learners at a Massachusetts Community College
}

Jacqueline Peña

Florida International University, jpena017@fiu.edu

DOI: $10.25148 /$ etd.FI10122202

Follow this and additional works at: https://digitalcommons.fiu.edu/etd

Part of the Community College Education Administration Commons, Curriculum and Instruction Commons, and the First and Second Language Acquisition Commons

\section{Recommended Citation}

Peña, Jacqueline, "Engagement Experiences of Hispanic Generation 1.5 English Language Learners at a Massachusetts Community College" (2010). FIU Electronic Theses and Dissertations. 337.

https://digitalcommons.fiu.edu/etd/337 


\title{
FLORIDA INTERNATIONAL UNIVERSITY
}

Miami, Florida

ENGAGEMENT EXPERIENCES OF

HISPANIC GENERATION 1.5 ENGLISH LANGUAGE LEARNERS

AT A MASSACHUSETTS COMMUNITY COLLEGE

\author{
A dissertation submitted in partial fulfillment of the \\ requirements for the degree of \\ DOCTOR OF PHILOSOPHY \\ in \\ CURRICULUM AND INSTRUCTION \\ by \\ Jacqueline Peña
}

2010 
To: Dean Delia C. Garcia

College of Education

This dissertation, written by Jacqueline Peña, and entitled Engagement and Membership Experiences of Hispanic Generation 1.5 English Language Learners at a Massachusetts Community College, having been approved in respect to style and intellectual content, is referred to you for judgment.

We have read this dissertation and recommend that it be approved.

Benjamin Baez

Teresa Lucas

Joan Wynne

Eric Dwyer, Major Professor

Date of Defense:November 16, 2010

The dissertation of Jacqueline Peña is approved.

Dean Delia Garcia College of Education

Interim Dean Kevin O'Shea University Graduate School

Florida International University, 2010 
C Copyright 2010 by Jacqueline Peña

All rights reserved. 


\section{DEDICATION}

First, I dedicate this dissertation to my mother, who paved the road towards my degree and supported me during my journey on that path. She made extraordinary sacrifices to ensure that my brother and I had a safe home and the best education regardless of our family, home, and economic situations. The lessons I learned by watching her daily actions have helped me survive not just my doctoral program, but all my other journeys in life so far.

I also dedicate this dissertation to my husband, Luis Mora, who many times had to sit alone while I typed away on a computer.I thank him for his daily support during different challenges and for helping me recognizeand celebrate milestones. This doctoral process has been a tremendous learning experience for both of us as individuals and for both of us as a couple.

I also dedicate this dissertation to my little brother with whom I have never spent enough time. For over a decade we grew up in the same household with two different perspectiveson life, love, and happiness, which allowed us to learn and grow from each other. Regardless of how little or how much we interact, we are always there for each other, and we love each other (even if we hate saying those words).

Finally, I dedicate this dissertation to my father, a strong, proud man whose core quality is thathe loves his children and is willing to do anything for us. He has taught me many valuable lessons about life, humanity, compassion, and, above all, forgiveness, and these lessons help me be more successful each day. 


\section{ACKNOWLEDGMENTS}

I would have never survived this doctoral program without many special people in my life. First, I would like to thank my committee chair, Dr. Eric Dwyer for his guidance and patience throughout this process. He believed in me every step of the way, especially when I did not believe in myself. I also want to thank my fabulous committee members. Dr. Ben Baez helped me consider multiple perspectives about engagement and success in higher education. Dr. Teresa Lucas helped me think of sociolinguistic and sociocultural aspects that relate to my study and the success of Hispanic Generation 1.5 English language learners in community colleges. Dr. Joan Wynne helped me visualize various factors, including cultural aspects that could affect Hispanic Generation 1.5 students before, during, and after college.

The people in the Office of Graduate Studies in the College of Education helped me complete the necessary steps for completion of the doctoral program. Dr. Barbetta and her predecessor, Dr. Tashakkori, kept pushing me to move forward with my writing and data collection. Caprila Almeida worked with me via email and telephone to ensure that I completed all the appropriate steps within the required timeframes. Dr. Newman was never afraid to challenge me, forcing me to refine my research questions and overall methodology. Dr. Linda Bliss' research and editorial advice helped me create a clearer and more coherent dissertation for my readers.

I would like to also acknowledge my fellow FIU graduate students and colleagues who listened to me when I needed to vent, gave me ideas to enhance my study, and helped me with the challenges of doctoral work.I alsowish to thank my colleagues at FIU, MDC, and the different institutions where I have worked outside of Florida. They have 
been wonderful teachers, administrators, and supporters throughout my never-ending learning process within the higher education system.

I also want to thank my past, current, and future students. They have all inspired me to go back to school so that I could be better equipped to help students learn and succeed in higher education. My students' bravery, determination, and perseverancein school and in life have taught me many valuable lessons about survival and success.

I also wish to acknowledge CMCC for opening its doors to me. The faculty, staff, and administrators were helpful throughoutevery step of this process and were always willing to meet with me or work with me via email or telephone. I will never forgetthe kindness, generosity, and wisdom of the CMCC family.

Also, I would love to thank my wonderful study participants for sharing theirprecious time with me and providing me with valuable lessons on Hispanic Generation 1.5 student success in college. I could have never completed this project without them; therefore, this victory is theirs as well. I wish them all the best in school, work, and life.

Finally, I would like to thank all my friends and my large extensive family here in the United States and around the world for their patience and continued love throughout this process. They were always on my mind even when I rarely called or emailed them. I hope that I can be as supportive and understanding as they have all been during these five and a half years. 


\title{
ABSTRACT OF THE DISSERTATION \\ ENGAGEMENT EXPERIENCES OF HISPANIC GENERATION 1.5 ENGLISH LANGUAGE LEARNERS AT A MASSACHUSETTS COMMUNITY COLLEGE
}

\author{
by \\ Jacqueline Peña \\ Florida International University, 2010 \\ Miami, Florida \\ Professor Eric Dwyer, Major Professor
}

Hispanic Generation 1.5 students are foreign-born, U.S. high school graduates who are socialized in the English dominant K-12 school system while still maintaining the native language and culture at home (Allison, 2006; Blumenthal, 2002; Harklau, Siegal, \& Losey, 1999; Rumbault \& Ima, 1988). When transitioning from high school to college, these students sometimes assess into ESL courses based on their English language abilities, and because of this ESL placement, Hispanic Generation 1.5 students might have different engagement experiences than their mainstream peers. Engagement is a critical factor in student success and long-term retention because students' positive and negative engagement experiences affect their membership and sense of belonging at the institution. The purpose of this study was to describe the engagement and membership experiences of Hispanic Generation 1.5 students' at a Massachusetts community college.

This study employed naturalistic inquiry within an embedded descriptive case study design that included three units of analysis: the students' engagement experiences in (a) ESL courses, (b) developmental courses, and (c) mainstream courses. The main source 
of data was in-depth interviews with Hispanic Generation 1.5 students at Commonwealth of Massachusetts Community College. Criterion sampling was used to select the interview participants, ensuring that all participants were native Spanish speakers and were taking or had taken at least one ESL course at the institution.

The study findings show that these Hispanic Generation 1.5 students at the college did not perceive peer engagement as critical to academic success. Most times the participants avoided peer engagement outside of the classroom, especially with fellow Hispanic students, who they felt would deter them from their English language development and general academic work. Engagement with ESL faculty and ESL academic support staff played the most critical role in the participants' sense of belonging and success, and students who were required to engage with faculty and academic support staff outside of the classroom were the most satisfied with their educational experiences. While the participants were all disappointed with some aspect of their ESL placement, they valued the ESL engagement experiences more than the engagement experiences while completing developmental and credit coursework. 


\section{TABLE OF CONTENTS}

CHAPTER

PAGE

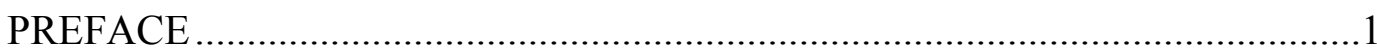

How Did I Get Here? My Journey as a Researcher ..........................................

Lessons from a Native Spanish-speaking College Student.....................................

Engagement and Retention Lessons from a Criminal Justice Student ..................12

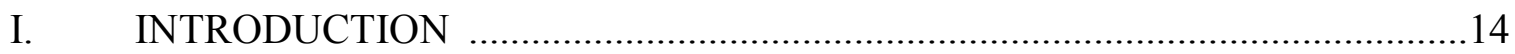

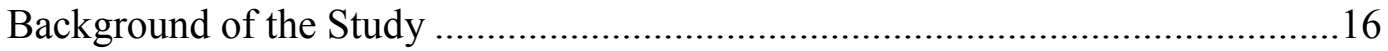

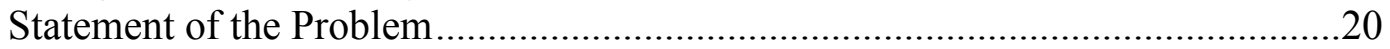

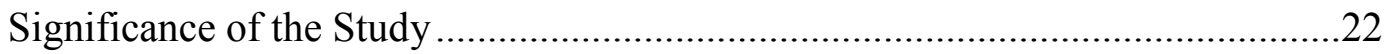

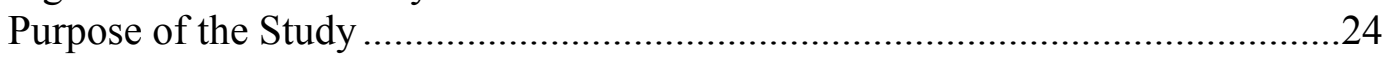

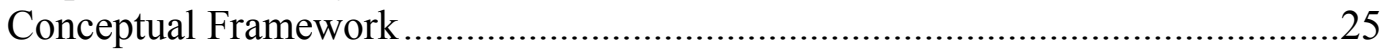

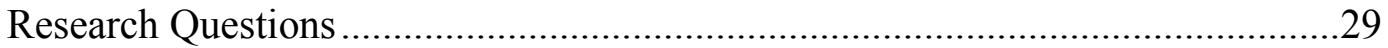

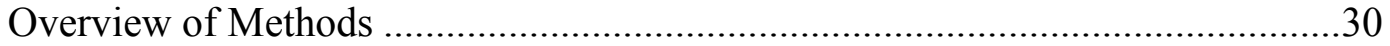

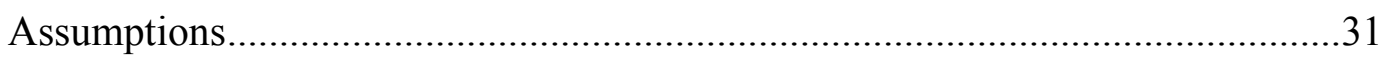

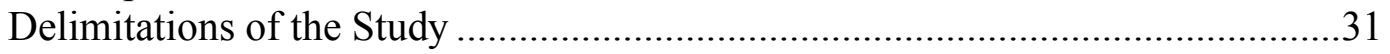

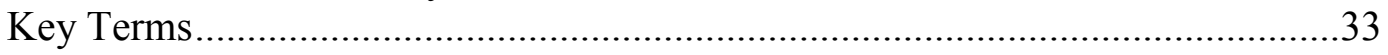

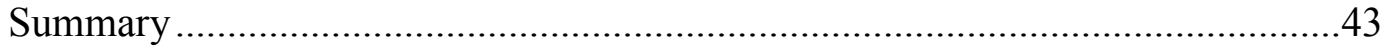

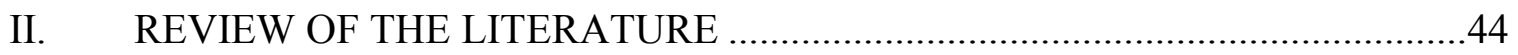

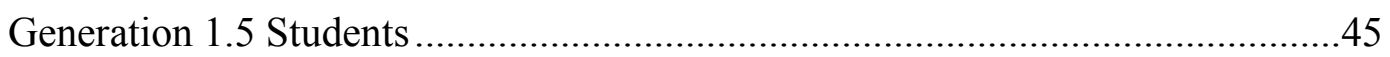

Engagement as a Key Indicator of Student Success .......................................52

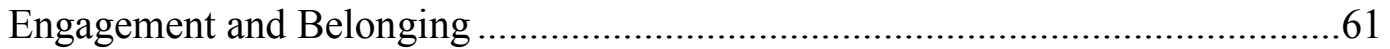

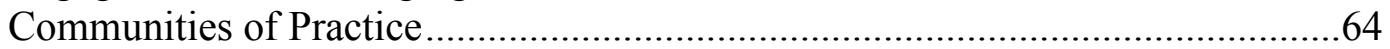

Membership in a Community of Practice ........................................................... 72

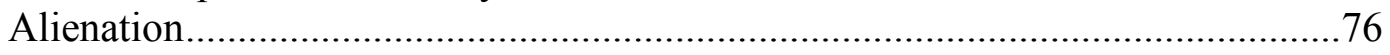

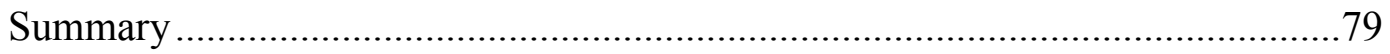

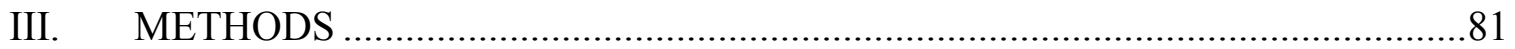

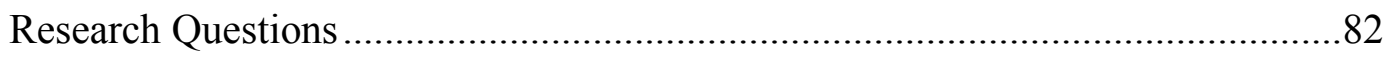

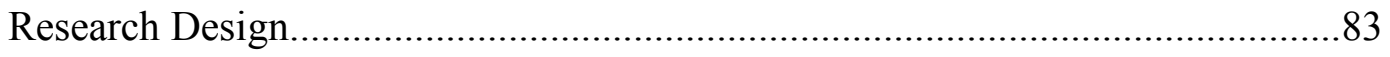

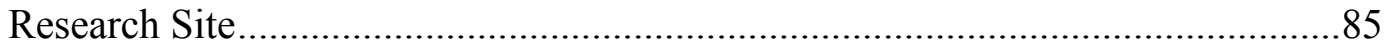

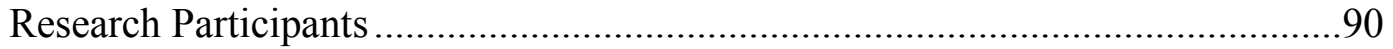

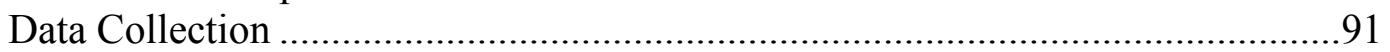

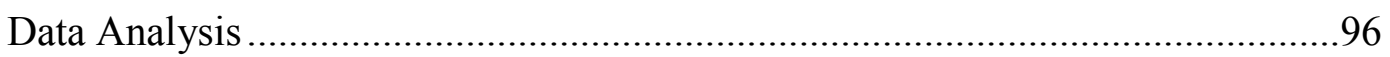

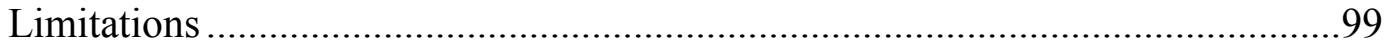

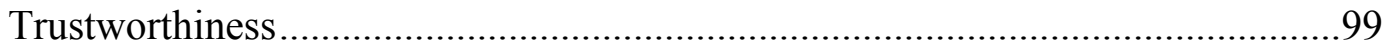

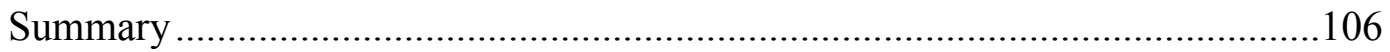

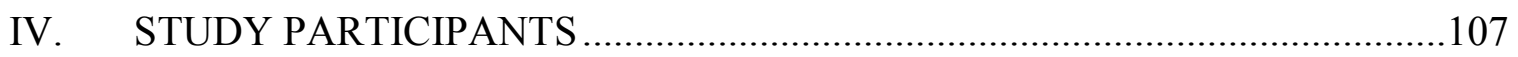

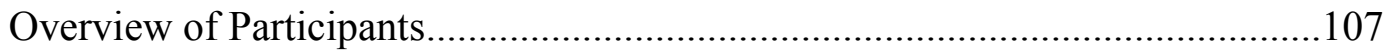

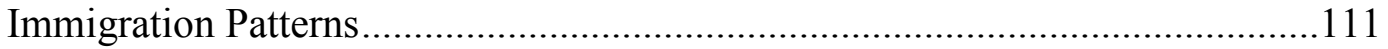




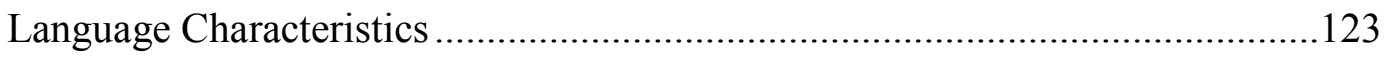

Hispanic Generation 1.5 Students at CMCC …………..................................126

Profiles of Hispanic Generation 1.5 Participants .................................................133

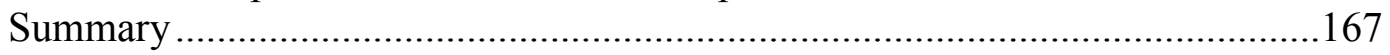

V. ENGAGEMENT EXPERIENCES WITH PEERS...........................................169

Peer Engagement inside the Classroom ..............................................................169

Peer Engagement outside of the Classroom.......................................................172

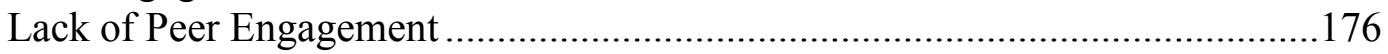

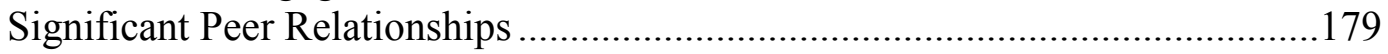

Perceptions of Engagement with Hispanic Peers at CMCC ……........................181

Peer Engagement and Belonging at the Institution.............................................185

Peer Engagement in Comparison to Other Immigrant Groups .............................186

Peer Engagement Differences among the Three Units of Analysis.....................187

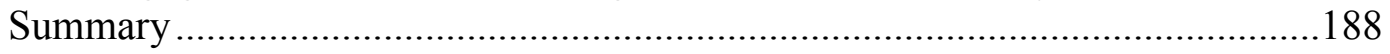

VI. ENGAGEMENT EXPERIENCES WITH FACULTY ……………………......190

Engagement with Faculty inside the Classroom.................................................190

Engagement with Faculty Outside of the Classroom..........................................203

Engagement with Faculty and Belonging at the Institution.................................210

Engagement with Faculty in Comparison to Other Immigrant Groups ...............212

Engagement Differences among the Three Units of Analysis.............................213

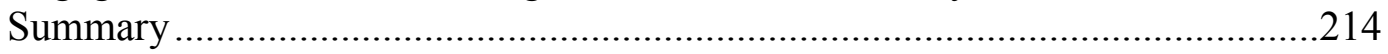

VII. ENGAGEMENT EXPERIENCES WITH STAFF ............................................216

Engagement with Student Services Staff........................................................216

Engagement with Academic Support Staff......................................................217

Structured One-on-one Support ........................................................................223

Engagement with Staff and Belonging at the Institution .....................................226

Engagement with Staff in Comparison to Other Immigrant Groups ...................227

Engagement Differences among the Three Units of Analysis............................228

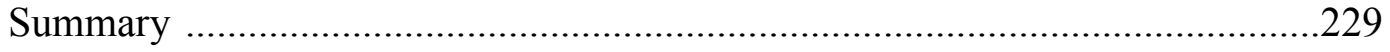

VIII. FACTORS THAT AFFECT ENGAGEMENT AND BELONGING ……..........231

K-12 U.S. Engagement Experiences..............................................................231

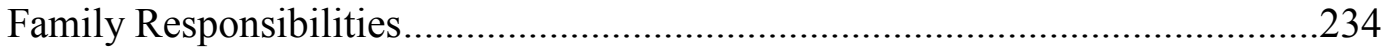

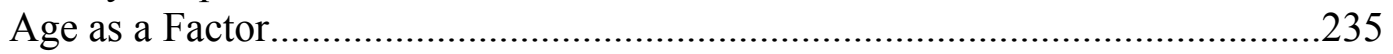

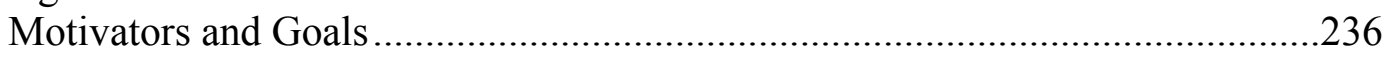

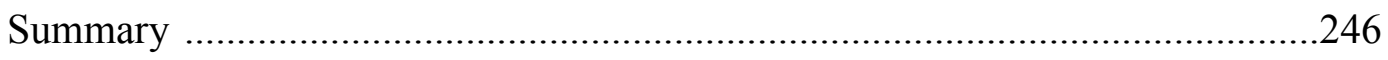

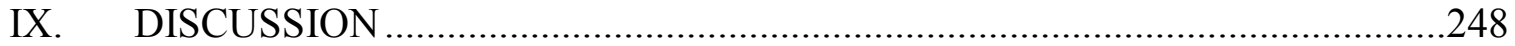

Hispanic Generation 1.5 Students at CMCC ..................................................248

Engagement Experiences of Hispanic Generation 1.5 Students ...........................250

Differences among the Three Units of Analysis ..............................................256

Developing a Sense of Belonging.................................................................259 
Looking Behind the Curtains ...................................................................261

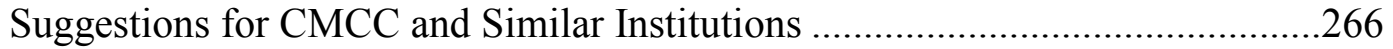

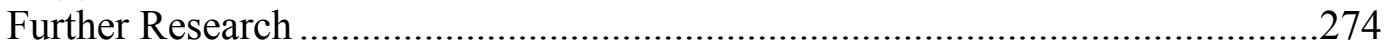

Coming Full Circle with Some Valuable Answers .........................................2276

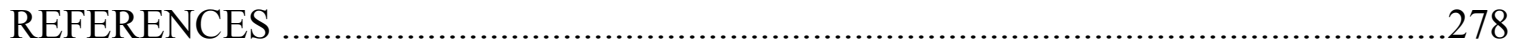

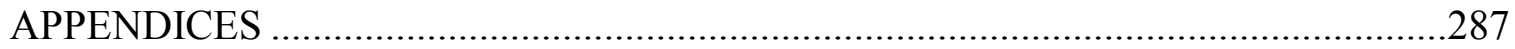

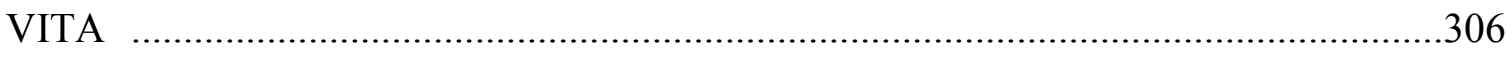




\section{LIST OF COMMONLY USED ACRONYMS}

This section contains a listing of acronyms that are used throughout the dissertation along with the full spelling of the acronym. The list is organized in alphabetical order.

ABE: Adult Basic Education

BCSSE: Beginning College Survey of Student Engagement

BICS: Basic Interpersonal Communication Skills

CALP: Cognitive Academic Language Proficiency

CNA: Certified Nursing Assistant

CoP: Communities of Practice

CCSSE: Community College Survey of Student Engagement

CMCC: Commonwealth of Massachusetts Community College

ELC: English Language Center

ELL: English Language Learner

ESL: English as a Second Language

ESOL: English as a Second or Other Language

FSSE: Faculty Survey of Student Engagement

Gen 1.5: Generation 1.5

IRB: Institutional Review Board

MOU: Memorandum of Understanding

NSSE: National Survey of Student Engagement

SEI: Structured English Immersion 


\section{PREFACE}

How Did I Get Here? My Journey as a Researcher

I did not go out seeking a career in education. The world of higher education opened up an unexpected door, and I walked into that opportunity. My entrance to this world of higher education came while I was preparing for my third year of coursework at Lehman College in the Bronx, New York. I was a straight A English major sharing an apartment with my grandmother and my aunt after moving three times that year alone. I finished a day of resolving financial aid issues at the college. After achieving my day's goal of obtaining funds for my tuition and books, I walked down the building corridor,looking for the fastest exit out of the building and to my car when a bright flyer caught my attention. The college was looking for a tutor at a time when I needed a flexible schedule to accommodate my full-time course load and my complicated home life. Soon I started my third year of college as a student and as a language and literacy tutor for students who needed help with English, Spanish, and Italian.

Shortly after starting the new job, I found myself working mostly with nativeSpanish speakers struggling to succeed academically due to challenges with reading and writing in academic English. Many of these students had "hit a brick wall": they were unable to continue studying at the institution until they passed the college's timed writing exam. From then on, my tutoring and teaching career has focused on helping students succeed in acquiring the skills necessary to pass institutional writing and reading tests and to succeed in their college coursework. 
Later, I taught English as a Second Language (ESL), developmental, and freshman composition courses in a community college, trying to help students acquire social and linguistic skills necessary for success in higher education. Many times, I was not as successful as I wanted to be. I set high goals knowing that in the new-capitalism ${ }^{1}$ of the United States, a high school diploma would not be enough for survival. My students had dreams, and I wanted to help them turn those dreams into plans and attainable goals. However, I lacked the answers to many of my own teaching, learning, and mentorship questions. Sometimes, I lacked the right questions. All I knew was that I wanted my students to succeed in whatever way theydefined success in their lives, and I was determined to identify effective ways of helping them succeed.

My quest to enhance my students' success led me to the field of education where I began doing independent research to find the right questions and the right answers for my students. My pursuit eventually led me to start a doctoral program in a college of education in Miami, Florida, where I believed I could study and do research with Hispanic students in higher education settings. 2 years later, I completed a qualitative case study on bilingual college students, which led me back to New England where for one evening I sat in front of a young woman who would guide me in finding the right questions and a path to some answers. My interactions with this study participant shaped my dissertation and opened me up to thinking about new ways of examining student success in higher education.

\footnotetext{
${ }^{1}$ While the old capitalism valued the production of products, the new capitalism values the production of ideas and information systems such as designing better ways of bringing products and services to consumers and better ways of organizing and disseminating information (Gee, 1996, 2000).
} 
Lessons from a Native Spanish-speaking College Student

I had spent semesters of my doctoral program reading about bilingual students in K-16 educational settings, and most of the literature focused on their linguistic characteristics and experiences. I wanted to learn how to support bilingual students in community colleges, and, through my cross-analysis case study in 2007 , I had the privilege of working with a young New England community college student. My study participant taught me that language experiences were only a small piece of retention and educational success. She taught me that other school-based experiences and students' perceptions of those experiences played a larger role in motivation and retention.

\section{Pre-College Experiences of a Young Immigrant Student}

Janet, my 2007 New England case study participant, invited me to her home without even knowing anything about me except that I had taught at her school and that I wanted to know about her experiences. Twelve years prior to our interview, she was forced to leave her mother behind in the Dominican Republic in order to move to the United States for an opportunity of a better life that involved education, a stable job, and a comfortable lifestyle. Janet's first educational experience was in a school where she was placed in an ungraded classroom, ${ }^{2}$ a placement that she believed occurred because she only spoke Spanish. She continued her schoolwork without knowing if she was in the sixth, seventh, or eighth grade. She took all her classes and ate lunch with the rest of

\footnotetext{
${ }^{2}$ Janet defined the ungraded classroom as a classroom for non-native Spanish-speaking students who were grouped together without any knowledge of whether they were in a particular grade (e.g. sixth grade or seventh grade). The students took all their classes together in this classroom until they were told that they were ready to move on to high school.
} 
the students in her ungraded classroom, rarely socializing with the other students in established grades at the school. The physical marginalization followed her to the playground where the students occupied opposite sides of the playground. Even though physical walls did not separate her ungraded classmates from the rest of the students, Janet explained that the two groups rarely crossed over the invisible lines.

She remained in this ungraded world until one day she was told she could move on to high school only to find herself in special education courses. She struggled to move out of the special education track where she felt she had been placed because of her language, skin color, and customs. She eventually transitioned into the mainstream courses where she remained for the rest of her high school years. Feeling like she was finally with her true peers learning a high school curriculum, Janet took all her high school classes in English while working at night in the local McDonald's fast-food restaurant to pay for her bills and everyday necessities.

Four years later, Janet graduated from high school and decided to pursue a college career. Like many students in her high school, she chose to attend the local community college because it was close to her home and workplace, was affordable, and offered an easy transition to a 4-year college should she choose to pursue a bachelor's degree in the future.

\section{Negative Engagement Experiences at a Community College}

Dressed in her McDonald's uniform, Janet went to the community college to inquire about the admission process, but she felt disdain as the person at the registration desk explained that she needed money to attend college. Having learned about financial 
aid opportunities while in high school, Janet explained that she had a full-time job and planned to fill out her financial aid (FAFSA) paperwork to qualify for federal aid. Even though her first engagement experience at the college with a staff member was negative, she was not dissuaded from completing the application process, which included the reading, writing, and math placement tests. Janet anxiously waited for her advising appointment to plan the path to her goal of obtaining a college degree.

However, Janet's image of U.S. college life shattered when she sat down with her advisor, who, after asking some background questions, informed her that she had been placed in the third level of ESL courses due to her reading and writing placement exam results. Years later, as we discussed her experiences at her dining room table, Janet still recalled her shock at the placement, whispering that she was not an ESL student and that she had never been in ESL prior to that first experience at the community college. The incident reminded her of her ungraded experience in middle school and her special education placement in high school. She felt discouraged by the new hoop she felt she had to jump through in order to obtain a college degree.

At this first advising and registration session, the advisor assured her that ESL courses would help her be more successful in her mainstream college courses, but the unexpected information shadowed the rest of her advising session as a friendly but negative and obstructive engagement experience. She left that session and registered for her classes, but that whole time, she felt "stupid," knowing that her high school peers probably did not endure this same type of placement in their 4-year colleges and universities. She explained to me that she carried that feeling of shame and stupidity through her first semester of ESL coursework. 


\section{Initial Struggles in the ESL Classroom}

Janet struggled through her initial weeks in her ESL courses. While she felt some comfort being with students who were mostly Dominican or spoke Spanish as a native language, she felt disconnected from the actual coursework and most of the teachers. She could not believe that she was sitting in ESL classrooms learning about how to order food, write checks, and even write paragraphs after 7 years of living in the United States and 4 years of high school essay writing in English.

Aside from the boring content of the reading and writing classes, Janet found the grammar classes quite challenging because she was forced to think about language in foreign ways. In ESL, she learned about sentence structure including subjects, verbs, and objects, as well as parts of speech, including adjectives and adverbs. She learned about dependent and independent clauses and types of sentences including compound, complex, and even compound-complex. She labeled sentences, took grammar tests, and even broke down her readings into types of sentences and parts of speech. She sat in communication classes, embarrassed by instructors teaching her how to pronounce words that she had been using with her friends for years and then embarrassing her communication peers whenever she spoke in class because she sounded like a native speaker. The sequential rote-teaching style and the specific language content were new and intimidating for her. She had never learned to read, write, or even speak in this manner during her middle and high school years. The simplistic content bored her. The metalinguistic approach to language learning scared her. The other students' knowledge, background, and experiences intimidated her. The challenges swayed her motivation 
throughout the semester, and upon finishing that first semester of ESL courses, she dropped out of school, feeling that she was wasting her time.

\section{Returning to College and to Her Goal of a Degree}

Over the following 2 years, Janet had a child, continued to work full-time, and was promoted to a more challenging and better paying position at McDonald's. One day, she realized that she wasn't doing anything critical or exceptional in the afternoons and became determined to graduate from college in order to be a good role model for her son. She returned to the same community college and completed her ESL coursework while still working full-time, taking care of her son, and building a home. She was determined to succeed in school and obtain an associate's degree in criminal justice.

In an attempt to find ways of being successful in college, Janet made an effort to fit in with the rest of her non-native speaking classmates and was comforted by their many shared characteristics such as their culture, native language, and experiences living in New England. Janet bonded with her peers, motivating her to attend classes and persevere with her new group of fellow ESL students. Together they helped each other inside and outside of the school with homework, tests, relationships, work, and even babysitting. She had numerous positive engagement experiences with her ESL peers. She became part of a social community within the ESL courses made up mostly of students, a few key teachers, and the ESL tutors. Within this social community or network, she received support, information, motivation, and advice.

After a few semesters and several attempts at passing the college's reading and writing placement tests, Janet said goodbye to her ESL courses and embraced the changes 
that included working with completely new faculty, advisors, students, tutors, and sometimes even staff members. She eagerly began her first non-ESL writing course, sitting in a new classroom among her new peers feeling that she had taken two steps forward in the direction of her criminal justice career. However, that first day in her new non-ESL writing classroom, Janet was disappointed when she finally realized that this course was still not a "college" course, but a developmental or basic writing class that would not count toward her degree. She felt deceived by the college and her advisors because she had celebrated in her success of finally being on the right path to her degree but then felt sidetracked in yet another non-credit course.

With all these challenges and new twists in her path to her degree, Janet was undeterred from her goal during that first non-ESL semester. She felt some comfort seeing native speakers of English in the same non-credit writing class with her, no longer feeling that she was being tracked because of her native language, skin color, or cultural background. At the end of the term, she passed the developmental writing course with at least a B and prepared herself by deciding which credit courses would be ideal for her first semester as a criminal justice student. However, when it came time to register for her courses, she sat in front of her new advisor in shock as the advisor informed her that she had to retake the developmental writing course because she had failed the college's writing test once again. While the college had a writing portfolio option that provided students with an opportunity to override the writing test results, Janet explained to me that, at that time, she was unaware of the option and was not sure if her instructor had completed the portfolio process for her. Therefore, she repeated this cycle and was 
forced to become a part-time student because she could not take any more credit courses until she assessed into the freshmen-level writing course.

\section{Finding Strength and Motivation through Personal Connections}

These negative interactions and engagement experiences challenged her desire to complete the degree, and Janet wanted to quit several times during this stage of her college education. However, she persevered because each semester in her developmental writing class, she encountered some of her former ESL peers, and they supported each other throughout the semester. She had missed the camaraderie that she learned to embrace in her ESL courses, and she welcomed these new relationships once again. Then she met a young woman who would become her best friend, her greatest fan, and a relentless motivator every time Janet needed her support. In that non-credit writing class, Janet did not feel alone until she finally passed both the course and, indeed, the writing exam.

\section{Struggling to Readjust Once Again}

Starting the new semester in mainstream courses, Janet found herself in unfamiliar territory with yet a different teaching approach from that of her ESL and developmental courses, as well as another new set of instructors and students. After adjusting to the culture of the ESL courses, and then adjusting to the culture of the developmental education courses, Janet had to adapt to yet another new environment. At the same time, she became pregnant with her second child and faced several negative engagement experiences with faculty and staff as she maneuvered through the 
mainstream education system, managing her full-time job, son, and pregnancy. After being forced to move among different groups throughout her now 10 or 11 years of education in the United States, Janet was exhausted by having to adapt physically, emotionally, linguistically, and socially to a new educational group. With each semester of ESL and developmental coursework, Janet knew that she was working her way toward her goal of at least taking criminal justice courses; however, each semester, the goal felt further away. Janet persevered at her educational goal because her close friend from the developmental writing course continued to be her greatest fan and her motivator during trying times.

\section{Finding Membership through Shared Interests and Experiences}

While completing her required credit freshmen composition courses, Janet declared her major and began taking criminal justice courses. Most of her feelings of alienation from her peers and the general college community began peeling away as she found or developed connecting points with her criminal justice faculty and peers. The first main connection that drew them all together was their interest in criminal justice and their goal of obtaining an associate's degree in that field. That interest and goal bonded her with her peers as she became a member of a new social group of criminal justice students who shared common experiences in the school as well as a common knowledge and language surrounding criminal justice.

As a student, Janet connected with her criminal justice instructors and bonded with one instructor who motivated her to attend a criminal justice club meeting or event to satisfy partially her curiosity about the field and to connect with other criminal justice 
students and professionals from the field. Prior to that interaction, Janet had no idea that the school had a criminal justice student club and her positive engagement experiences with that instructor promoted her desire and courage to attend one of the club's events. At that first club event, she discovered that she shared characteristics with the fellow attendees and presenters, the main characteristics being their love of the field and their involvement in the field as students, instructors, or professionals. She did not feel uncomfortable or alienated at the event. Instead, she felt drawn to the other people present and felt a desire to belong rather than resist this new group of college-related people.

\section{Belonging in the Institution and Enjoying Success}

A semester later, as we, the researcher and the participant, sat together at her dining room table, Janet explained how she was a full-time student once again, using financial aid to help her pay for her education. She was earning good grades in her required core courses and her criminal justice courses, which she took simultaneously. She had joined the criminal justice club, attending many of their events and extracurricular activities including a fieldtrip to a courtroom where they were able to meet a local judge. She remained focused on her academic and career goals. She continued to raise her two children on her own while working full-time, attending professional development workshops, and completing her associate's degree courses as a full-time student. 


\section{Engagement and Retention Lessons from a Criminal Justice Student}

Janet's story has several key lessons that can be applied to many community college student populations. First, Janet felt isolated from what she perceived to be a college experience by her negative engagement experiences with the first staff member she encountered at the college, her interaction with her initial advisor, and her learning experiences during the first semester of ESL courses. This alienation from the college eroded her desire to complete a college degree, and she dropped out of school after completing only one semester of full-time ESL coursework. After experiencing the visible and invisible divisions of being tracked as ungraded in middle school and as a special education student in high school, Janet did not know how to handle being labeled ESL in college. Her negative engagement experiences with different aspects of the institution led to a feeling of alienation, which contributed to her desire to drop out of school.

However, 2 years later, Janet was motivated to return to the college because she wanted to be a good role model for her son. Her motivation to obtain a degree brought her back to the classroom, and the characteristics and experiences shared among her peers helped her bond with them and develop a sense of belonging in a social group or community. Janet experienced several changes and engagement experiences in various social communities as she moved in and out of ESL and then in and out of developmental education. However, Janet did not develop a true sense of belonging to her institution until she became a part of the criminal justice program and student club. She became committed to her goal of obtaining a degree in criminal justice. She found students, 
teachers, professionals, and other key people who shared similar goals, knowledge, and activities,which helped her bond with individuals and her college social communities. She became committed to the institution through her persistence towards her degree as a full-time student, her commitment to a shared goal, and her membership in a social group or community of practice grounded in criminal justice. Janet's positive engagement experiences led her to develop a sense of belonging to a group and the institution and feelings of membership, and, at the time of our interview, this sense of belonging was motivating her to continue with her studies.

Janet's story of initial attrition, a brave return to the institution, and continued retention brings together various theories of student success in higher education literature. While in higher education, placement tests and student success are many times grounded in reading and writing skills, Janet's struggle to take credit courses and develop a sense of belonging to the institution showed that English language abilities are just a small aspect of what helps students succeed in higher education. Her story during that cold evening in November 2007 showed me that my questions and answers had been focused mostly on students' linguistic characteristics, like much of my doctoral program literature. I had overlooked how students' college experiences and their perceptions of those experiences played a key role in their long-term retention and success. Therefore, this dissertation aims to explore native Spanish speakers' experiences and their perceptions of those experiences when placed in ESL college courses after graduating from high school in the United States. 


\section{CHAPTER I}

\section{INTRODUCTION}

I realize that we've gotten research backward. The purpose of research ought to be to find out how we are different instead of how we are the same.... tests want to know how we fit in the box, not what our contributions outside the box might be. It is much cheaper to study fit than nonfit... It takes an enormous amount of knowledge to see differences. It takes much less knowledge to see similarities. (Graves, p. 147)

Obtaining some type of postsecondary education is becoming more critical for economic sustainability and the job market in this new knowledge-driven or informationbased economy that Gee labels the New Capitalism (National Commission on the Future of Higher Education, 2006). One argument for postsecondary education is that most adults need some type of postsecondary education to function productively in this changing economy, that postsecondary education provides long-term benefits (i.e., cognitive, social, and economic), and that these students pass on the benefits to other generations, therefore improving the quality of life for themselves and their family members (Kuh, Kinzie, Buckley, Bridges, \& Hayek, 2007). However, United States populations are not equally successful in accessing higher education, and, even if access were equivalent across populations, not all college student populations are successful in obtaining a postsecondary degree.

With the shift in the United States population through different immigration waves, we have seen a shift in the U.S. college population as well. One major group that is growing throughout the United States and in the college system is the Hispanic population, and this growth is evident in the increased number of colleges and universities designated as Hispanic-Serving Institutions (HSI). The HSI designation is 
appointed through the Hispanic Association of Colleges and Universities (HACU) and is provided to public or private institutions with Hispanic students making up at least $25 \%$ of the undergraduate student population (HACU, 2009; Excelencia in Education, 2009). According to HACU, there are currently 214 HSIs in the United States. However, with this increase in the Hispanic population in the U.S. and the Hispanic student population in two- and 4-yearhigher education institutions, Hispanics have been trailing behind Asians, Whites, and Blacks in terms of student success as measured by retention and degree completion (Fry, 2004; Swail, Cabrera, \& Lee, 2004).

Within the Hispanic college population, there are many different subgroups, including first, second, and third generation immigrants.An additional subgroup was labeled Generation 1.5 because of these students shared some characteristics with both first- and second-generation immigrant college students (Harklau, et al., 1999; Rumbault \& Ima, 1988). This Hispanic Generation 1.5immigrant group or population consists of Hispanic students who immigrate to the U.S.prior to high school graduation, and typically during their adolescent years. These foreign-born students are educated in the U.S. school system for several years and might desire post-secondary education after high school. In college, these students might demonstrate characteristics of first-generation immigrants in terms of reading and writing abilities while also demonstrating characteristics of second-generation students through their native-like oral abilities and familiarity with the culture and school system (Blumenthal, 2002; Harklau, et al., 1999) When transitioning from high school to college, Generation 1.5 students often assess into ESL or developmental education courses based on their English language abilities as measured by the college's writing and reading placement exams. Since 
English language characteristics are the determining factor in Generation 1.5 student placement in non-mainstream courses, college and university efforts focus on helping these students successfully move into the mainstream or credit-bearing courses with the appropriate English language proficiency to be successful throughout the rest of their coursework. Consequently, research on Generation 1.5 has focused on understanding and improving students' reading and writing abilities in ESL, developmental writing, and freshmen composition courses. However, research has not examined the long-term effects of these varying academic experiences on this population's motivation and persistence or their overall perceptions of these experiences through the different programs. Therefore, this study focused on Hispanic Generation 1.5 student persistence and success by describing their perceptions of their lived engagement experiences in academic ESL, developmental education, and mainstream courses at a Massachusetts community college.

\section{Background of the Study}

The Hispanic population is increasing rapidly throughout the United States representing approximately $15 \%$ (over 45 million) of the U.S. population (U.S. Census Bureau, 2006). Demographically, the college population similarly increases and changes proportionally in terms of race or ethnicity. According to the 2005 Current Population Survey by the U.S. Census Bureau, out of nearly 14 million undergraduate students in 2and 4-yearcolleges and universities, $12.7 \%$ were Hispanic, and this percentage continues to increase with Hispanics being the fastest growing college population (Laird, Bridges, 
Morelon-Quainoo, Williams, \& Holmes, 2007). Student success in higher education is a concern to all stakeholders involved in the different facets of an institution, and, with the increase in the Hispanic population, Hispanic student success is critical in maintaining overall institutional success. Therefore, studying different groups of Hispanic students (e.g., first generation, second generation, and Generation 1.5) is beneficial to the institutions and to individual students served by these institutions.

While the number of Hispanic students entering college is increasing, the number of Hispanic students succeeding in obtaining a degree has not been increasing at a comparable rate. Hispanics trail Asian, Black, and White students (a) in the percentage of students continuously enrolled in college without taking a semester or a year off from their studies and (b) in the percentage of students who complete a bachelor's degree in at least 8 years following high school graduation (Fry, 2004; Swail et al., 2004). In the Pew Hispanic Foundation's longitudinal study examining a cohort of eighthgrade students across the nation, only $23.2 \%$ of the Hispanic students in the sample completed a bachelor's degree within 8 years following high school graduation (Swail et al., 2004). Nationally, only $11 \%$ of Hispanics ages 25 and over have a bachelor's degree while $17 \%$ of Blacks, $28 \%$ of Whites, and $44 \%$ of Asians ages 25 and over have bachelor's degrees (Swail, Redd, \& Perna, 2003). If Hispanic students are trailing behind other major groups, our Hispanic Generation 1.5 students face even more challenges in successfully completing their degrees due to added language and social challenges throughout their K16 schooling. 


\section{Massachusetts Community Colleges and Hispanic Students}

With Hispanic students trailing behind other groups in terms of college degree completion within a 150\% completion timeframe (i.e., 3 years for an associate's degree), the state-level success rates of associate's degree-granting public institutions differs among the various states in the country. Three New England states had a lower success rate than approximately $72 \%$ of the nation's 50 states in awarding associate's degrees with success defined as obtaining the degree within a $150 \%$ completion timeframe, not including ESL and developmental coursework (NCES, 2005). According to NCES(2005) and U.S. Census Bureau data (2006), in states with large Hispanic populations such as Florida, California, and Arizona, $35.4 \%$ to $63.1 \%$ of students with associate's degrees completed their credit coursework and graduated in 3 years or less. On the other hand, with 16 public and 9 private 2-year institutions, $13.3 \%$ to $21.5 \%$ of Massachusetts' students with associate's degrees completed their credit coursework and graduated in 3 years or less (NCES, 2005; U.S. Census Bureau, 2006). Factors that could affect students' academic success as measured by associate's degree completion in 3 years include financial constraints, health problems, family issues, work schedules, academic under-preparedness, educational gaps, and English language proficiency levels. However, there are no data linking any of these specific constraints to Generation 1.5 students.

Considering its positive and nationally recognized higher education reputation in the 4-year sector where Massachusetts is more successful than approximately $76 \%$ of the nation (NCES, 2005; U.S.Census Bureau, 2006), ironically, Massachusetts is less successful at the 2-year college level. At the same time, a greater percentage of native 
and immigrant Hispanic students attend 2-year colleges unlike native and immigrant Asian and Black students who mostly attend 4-year colleges (U.S. Census Bureau, 2006; Vernez \& Abrahamse, 1996). In other words, more Hispanics attend 2-year colleges than their Asian and Black peers, and Massachusetts2-year colleges are less successful at awarding degrees within the $150 \%$ completion timeframe than 4-year colleges in Massachusetts and colleges and universities within most states.

Similar to national studies, Hispanics in Massachusetts are trailing all major groups including African Americans, Asians, and Whites in terms of successful high school completion and college degree attainment. The Massachusetts population has changed with different immigration waves over time. With a population of over 6 million residents in 2005 , the percentage of minority residents was $16.6 \%$, and included in that minority percentage are the foreign-born residents who account for $14.4 \%$ of the Massachusetts population (Achieving the Dream, 2008; U.S. Census Bureau, 2005b). The Massachusetts Hispanic population had the lowest educational attainment levels among other major groups with $42.7 \%$ of Hispanic residents ages 25 and older having less than a high school degree and only $18.6 \%$ having an associate's degree or higher (Achieving the Dream, 2008; U.S. Census Bureau, 2005b).

\section{Hispanic Generation 1.5 Students in Community Colleges}

A large number of non-native speakers of English begin their post-secondary education in community colleges, which offer more academic support services including ESL, developmental, and other academic preparatory programs (Gawienowski \& Holper, 2006; Kuo, 1999; Vernez \& Abrahamse, 1996). According to Blumenthal (2002), most 
of the nation's Generation 1.5 students attend community colleges after graduating from U.S. high schoolsbecause they need ESL and developmental coursework and might have other constraints including economic and family limitations. A designation into ESL courses adds semesters or years to their degree completion timeframe, and these course credits normally do not count towards the final associate's degree, increasing the overall amount of time and money necessary for degree obtainment. With these challenges facing Hispanic Generation 1.5 community college students, retention is a concern at the institutional level.

As a result, research needs to include more studies on Hispanic Generation 1.5 students who enter college after U.S. high school graduation yet have different social and academic college experiences than their mainstream counterparts. The gap in Generation 1.5 research makes it difficult to have a clear understanding of this student population's success within an institution, especially in New England states, such as Massachusetts, where a significant number of Generation 1.5 students are native Spanish speakers, attend community colleges, and might assess into ESL courses.

\section{Statement of the Problem}

Hispanic Generation 1.5 students who are placed in ESL courses may have different engagement experiences from other students, including their first- or secondgeneration Hispanic peers because of (a) the new ESL label and its associated perceptions and (b) the isolation of their initial college experiences with a different set of faculty and staff members during their ESL coursework. These students' K-16 engagement 
experiences could be affecting their academic success when compounded with their language and academic abilities. In order to understand Hispanic Generation 1.5 student retention and success, their community college experiences need to be analyzed within a theoretical framework of engagement, which has already been applied to other college populations. A review of literature indicates several specific gaps that should be addressed with respect to prospects of academic success for native Spanish-speaking, Generation 1.5 students:

1. There is little research with respect to Generation 1.5 students outside of studies and observations that focus on their linguistic characteristics and language development experiences in college.

2. There is little or no research on Generation 1.5 students' social and academic engagement experiences.

3. There is little research with respect to Generation 1.5 students as they work through ESL courses.

4. There is little research with respect to Generation 1.5 students as they transition between these ESL preparatory courses and their subsequent courses in college.

5. There is little research available on Generation 1.5 students past the freshmenlevel courses.

6. There is little research with respect to Generation 1.5 students that does not apply a deficit model or perspective since many studies focus on their lack of English reading and writing skills.

7. There is little research with respect to Generation 1.5 students that includes their voices and their perspectives. 
Therefore, this study focuses on the experiences of Hispanic Generation 1.5 students who first assess into ESL through a theoretical framework of engagement and membership in communities of practice, moving away from the commonly used deficit model that focuses solely on linguistic properties.

\section{Significance of the Study}

Within the fields of developmental education and composition, there has been some research on this specific group of foreign-born U.S.-educated students who struggle linguistically, academically, and socially in higher education settings, making them one of the most at-risk college student populations (Allison, 2006; Blumenthal, 2002; Harklau, et al., 1999). An increasing number of Generation 1.5 students is taking ESL and developmental writing courses, especially at 2-year colleges, even though these students have been studying in U.S. schools for over 4 years and perhaps have never been labeled ESL before college.

As Generation 1.5ers enter their ESL courses, their new peers are often older firstgeneration immigrants who might already have post-secondary degrees from other countries and/or might be learning academic English either for advancement in the current workplace or for admission into an academic program for a future career change. Therefore, when U.S. bilingual high school students assess into ESL, they find themselves in unfamiliar territory with a new set of students who might have differing goals, motivations, and expectations. While the ESL placement is based on language characteristics, many of these Hispanics might struggle in the academic settings in other 
ways outside of English language challenges. If these students are placed in ESL courses, they might struggle more than their other non-ESL Hispanic peers because of the unexpected and conflicting experiences with different facets of the institution including peers, faculty, and staff (Blumenthal, 2002; Gawienowski \& Holper, 2006). These differing experiences could affect their persistence and long-term retention in college.

While there are several articles and books written about Generation 1.5 college students, especially in the area of reading and writing abilities, there are few empirical studies concerning their overall academic success. A challenging aspect in studying this population is that little information is available on Generation 1.5 students because most colleges and universities have not been keeping track of this population (Harklau, et al., 1999). Most institutions only collect basic demographic information that would be insufficient for the identification of Hispanic Generation 1.5 students. In addition, most empirical research and theoretical papers on Generation 1.5 students have focused on this population's language struggles in the freshman-writing classroom and occasionally in the developmental or ESL writing courses using a deficit model where the focus is on the students' lack of skills. However, English language proficiencyis only a small portion of what contributes to academic success in higher education. Students' experiences, but, more importantly, their perceptions of those experiences are critical to their persistence, retention, and graduation. Positive experiences with peers, faculty, and staff are key factors in student success, and this relationship among the students, their experiences, and their perceptions of those experiences may vary between two- and 4-year institutions and student populations. 


\section{Purpose of the Study}

The literature and research on Hispanic Generation 1.5 student success as measured by degree completion needs to include more than just language characteristics as seen in much of the work coming out of the fields of developmental education and composition. Similar to the national and institutional-based research, student success for this population needs to be examined as being both academic and social processes through engagement and integration or membership in the institution. Therefore, a large number of studies on student success have been focusing on student engagement, a key indicator of student success in higher education settings, including two- and 4-year colleges (Community College Survey of Student Engagement, 2006, 2007; Kuh, et. al., 2007; National Survey of Student Engagement, 2006, 2007). Since a number of Hispanic Generation 1.5 students in Massachusetts community colleges must take college-level ESL courses before taking credit-bearing courses towards an associate's degree, these students have different engagement and membership experiences than their non-ESL Hispanic counterparts. At the same time, their engagement and membership experiences are different from even those of their ESL Hispanic peers who immigrated to the United States later in life and did not enter the college immediately after graduating from a local high school. Therefore, the purpose of this study is to describe ESL and post-ESL Hispanic Generation 1.5 students' experiences in a Massachusetts community college through a theoretical framework of engagement and membership in communities of practice. 


\section{Conceptual Framework}

Student engagement has been examined as a key indicator of student success in two- and 4-year colleges and universities. National data reveal that highly engaged students are more likely to persist and graduate (Community College Survey of Student Engagement, 2006, 2007; National Survey of Student Engagement, 2006, 2007). These engagement practices and experiences include interactions, involvement, and participation at the academic and social levels with various community college entities such as peers, faculty, and staff. Therefore, using national and institutional-based data, schools have been developing and promoting engagement-enhancing opportunities both inside and outside of the classroom such as learning communities and school clubs or organizations. However, engagement studies and a majority of the engagementenhancing opportunities have mostly focused on the general college student population. Now we see a focus on specific, well-defined groups such as women, part-time students, and Hispanics. ESL students and Generation 1.5 students have received little or no attention in the engagement literature, especially if looking specifically at Generation 1.5 students who begin college in ESL courses less than a year after high school graduation.

This engagement study is situated within the Lave and Wenger (1991) theory of communities of practice, which brings together theories of social practice (production and reproduction of engagement practices in social contexts) and theories of identity (formation or construction of the person with certain cultural and membership indicators). A community of practice $(\mathrm{CoP})$ can be a formal or informal, visible or invisible social subgroup of members with common goals engaged in common practices such as a close 
group of college students in a degree-granting program (Lave \& Wenger, 1991; Wenger, 1998; Wenger, McDermontt, \& Snyder, 2002). We become members of our first CoP during our initial years within the social context of our homes and all the social constructs associated with our home lives. From that first $\mathrm{CoP}$, individuals continue engaging with others and becoming members of other CoPs through life. In a college setting, academic and social engagement is a prerequisite and a co-requisite of membership in a CoP (Wenger, 1998). In other words, people become members of social subgroups through engagement, and they maintain their membership in these groups through continuous engagement.

A number of theoretical works, including those by Lave and Wenger (1991) and Wenger (1998), have identified that people are members of multiple CoPs, and membership within one CoP eases membership in other related CoPs. These multiple CoPs could be connected or related to each other in the form of a constellation (a group of related or connected parts). Membership in multiple CoPs within the same constellation, such as a specific community college, increases belongingness to the institution as a whole (Wenger, 1998). This increased sense of belonging to specific social groups and their associated social contexts could positively affect students' academic and social integration in the institution, which in turn positively affects students' persistence and retention (Osterman, 2000; Tinto, 1993).

Within this conceptual framework, engagement with people, tools, artifacts, symbols, or other aspects of that $\mathrm{CoP}$ is viewed as being both social and academic (Caspiet al., 2005). Without some form of engagement, there is no participation and no developed sense of belonging to a community of practice or larger institution. People's 
engagement experiences determine their membership and a sense of belonging from their perspective and their group's perspective (see Figure 1).

Positive engagement experiences that promote optimal learning and acquisition of aspects of the CoP could lead to increased membership and belongingness to specific social groups and the overall institution, which increases students' retention rates. Negative engagement experiences could lead to less participation, decreased or lack of membership, and a sense of exclusion or alienation from the CoPs and even the institution. If students do not develop a sense of membership and belonging to at least one $\mathrm{CoP}$ within the institution (i.e., a social or information network developed independently by the students or through the institution's engagement opportunities), the feelings of alienation could affect the students' attrition rate. The conceptual framework for this study was developed out of the literature on engagement, communities of practice, belonging, retention, and attrition.

Engagement has become a key indicator of academic success (Community College Survey of Student Engagement, 2006, 2007; National Survey of Student Engagement, 2006, 2007) because it promotes membership in communities of practice where social practices and identity formation come together and through which college students develop a stronger sense of belonging to the institution (the constellation of CoPs). This increased sense of belonging in the overall constellation of CoPs within the college could lead to increased persistence and retention even in the face of various academic impediments such as work, family, and health issues. However, having an increased sense of belonging to one or more groups, and not to the institution, might be sufficient in increasing persistence leading to retention. Therefore, it is crucial to 


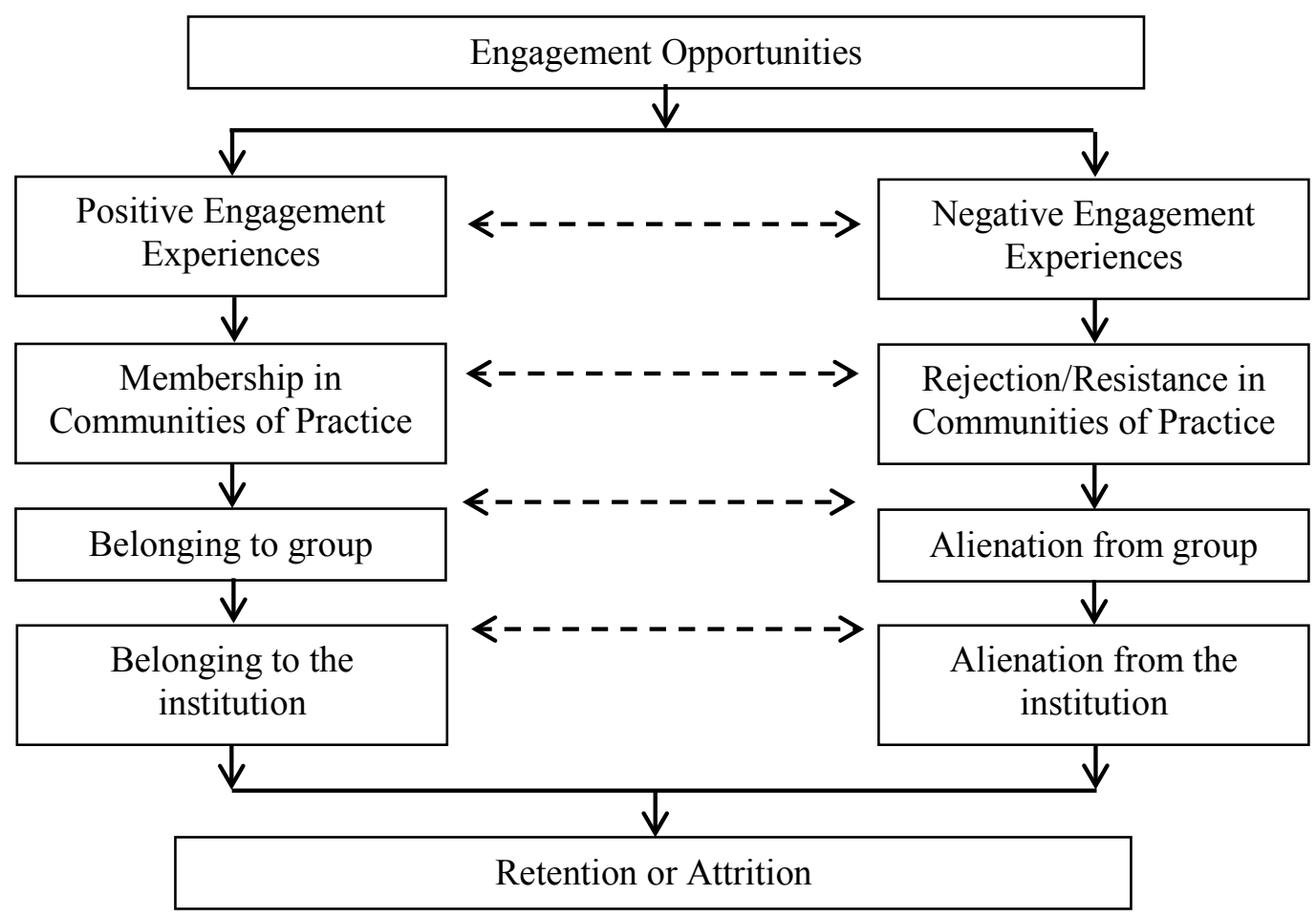

Figure 1. The conceptual framework of engagement in communities of practice.

understand students' engagement and membership experiences within community colleges through exploratory research that can paint a complex picture of membership practices. This exploratory research could open the doors to other research studies grounded in the engagement realities of these students, linking long-term academic and professional success to their engagement experiences. The purpose of this study was to paint a broad, deep, and, therefore, complex picture of ESL and post-ESL Hispanic Generation 1.5 students' engagement and membership experiences in a Massachusetts community college so that this overlooked population could be viewed outside of their English "shortcomings" and added to future engagement research. 


\section{Research Questions}

The goal of this study was to describe and analyze the phenomenon of student engagement and membership among ESL (enrolled in ESL courses) and post-ESL (completed ESL courses) Hispanic Generation 1.5 students in a 2-year community college in Massachusetts. The main research question was

- What are Hispanic Generation 1.5 students' engagement and membership experiences in a Massachusetts' community college?

The research sub-questions were

- Who are these Hispanic Generation 1.5 Students at Commonwealth of Massachusetts Community College (CMCC) $?^{3}$

- What are these Hispanic Generation 1.5 students' social and academic engagement experiences while completing their (a) ESL coursework, (b) developmental coursework, and (c) credit-bearing coursework atCommonwealth of Massachusetts Community College?

- What are the similarities and differences in the social and academic engagement experiences for these students within the three levels of coursework: (a) ESL, (b) developmental, and (c) credit-bearing atCommonwealth of Massachusetts Community College?

\footnotetext{
${ }^{3}$ Commonwealth of Massachusetts Community College (CMCC) is a pseudonym. To protect the identity of the participants and the institution, pseudonyms will be used for cities, schools, and people.
} 
- How do ESL and post-ESL Hispanic Generation 1.5 students perceive these engagement experiences in relation to their persistence, retention, and overall academic success at the college?

\section{Overview of Methods}

Coming from a sociocultural perspective, I situated this study within a constructivist paradigm in which people constantly construct new realities through their engagement experiences with members and the socially developed symbols, tools, and artifacts associated with that community of practice and the larger social context (Fosnot, 2005; Vygotsky, 1978; Wenger, 1998). Using Yin's model of descriptive single case study design (2003a; 2003b), I used naturalistic inquiry to explore and analyze Hispanic Generation 1.5 students' engagement and membership experiences in a Massachusetts community college. As a naturalistic case study, the main source of data was obtained from in-depth interviews with the participants at Commonwealth of Massachusetts Community College (CMCC), which is considered an emerging HSI with a Hispanic population of $20-21 \%$.

\section{Assumptions}

I designed this study and entered this research project with several assumptions. The first assumption was that native Spanish-speaking Generation 1.5 students enroll in higher percentages in community colleges than in 4-year institutions, and that a portion of 
these community college students assess into ESL courses when they take their college placement exams, especially in Massachusetts community colleges. Another underlying assumption was that engagement and membership experiences vary across institutions and within an institution, especially among ESL, developmental, and associate degree programs. An associated assumption is that even within the same programs, Hispanic Generation 1.5 students have varying engagement and membership experiences than their Hispanic and non-Hispanic peers.

\section{Delimitations of the Study}

Based on my research questions, conceptual framework, paradigm, and research design, this study has several delimitations. First, the study focused on a very specific group of the native Spanish-speaking population, Generation 1.5ers. Other subsets of this population were not included in this study in order to focus on characteristics and engagement experiences that are specific to Generation 1.5 students. In addition, this study limited the Hispanic Generation 1.5 population to native Spanish-speaking students who immigrated to the United States and graduated from a U.S. high school. While there is no single definition or specific boundary used across the literature for the term Generation 1.5, a more restrictive definition or boundary was desired for a more comprehensible case study. However, it was impossible to apply more restrictive criteria for the Hispanic Generation 1.5 population in Massachusetts because it was a diverse population with many unknown characteristics. Therefore, a broader definition (foreignborn U.S. high school graduates) was used in order to cast a wide enough net that would 
allow for the identification of the most common factors of Hispanic Generation 1.5 students at CMCC. Then participant identification criteria were developed using this broader definition.

In addition, only one of the Massachusetts public community colleges was chosen for this case study based on its Hispanic student enrollment. Only one community college was chosen because schools within the same region have differing characteristics and student populations. Focusing on only one school would foster a more in-depth exploration of the phenomenon at the institution. This more in-depth exploration could yield a richer descriptive case study and a more comprehensible analysis and portrayal of Hispanic Generation 1.5 students' engagement and membership experiences in this Massachusetts community college.

Another delimitation is that this study relies on the use of a descriptive single case study design, looking at engagement and membership experiences of native Spanishspeaking Generation 1.5 students who first assess into ESL within a specific institution. Such a design limits the transferability and overall generalizability of the findings and results. However, this single case study uses multiple sources of data and includes rich, thick descriptions to enhance reader or user generalizability.With the lack of research in this area and regional differences among the Hispanic Generation 1.5 population, it was critical to focus on collecting extensive data to understand engagement and membership experiences of Hispanic Generation 1.5 students at one site and allow for replicability at other sites in the future. 


\section{Key Terms}

This section contains the key terms that are used throughout the dissertation and includes definitions and explanations for some of the terminology choices. The list is organized in alphabetical order.

\section{Academic Language}

Academic language is the specialized and domain-specific language taught in school, which is used mostly after the third grade and is necessary to progress from grade to grade. Cummins (1989) names this specialized or academic language as CALP (Cognitive Academic Language Proficiency). Gee labels this term as academic Discourse or specialized language grounded in the social context and the subjects taught in school.

\section{Alienation}

Alienation is a separation from academic and social engagement activities within a course, program, or institution, which results in a disconnection from the group and therefore from the institution as well (Case, 2008; Mann, 2001, 2005). Alienation could occur through a lack of engagement, resistance to social groups or networks, rejection by members of social groups, or negative engagement experiences at the institution (see Figure 1). 


\section{American}

When using the term American, the participants were referring to individuals who had assimilated to life in the United States, which included ways of dressing, speaking, and completing day to day activities. There is no single definition of American that is applicable across the United States. For the purposes of this dissertation, the term is used in alignment with the participants' use of the term in reference to people who have made the United States their home country and have adopted the English language and cultural aspects of their relevant social groups in their daily lives.

\section{At-Risk Students}

The term "at-risk" is typically used to denote students who demonstrate qualities that might make them prone to dropping out of school. In the literature, at-risk qualities include being a first generation college student, low socio-economic status, working fulltime, having poor high school grades, and having low SAT or ACT scores. The term "atrisk" is part of a deficit model used when looking at students higher and will be used only in the second chapter when discussing the current literature on engagement and students because it is a term incorporated in that literature. Therefore, in this dissertation, the term "at-risk" refers to students who have a high risk of dropping out of college due to any of the above listed factors as well as other factors that are typically found in the drop-out population at that particular institution, and the term will be used only in the second chapter. 


\section{Basic Interpersonal Communicative Skills (BICS)}

BICS is the conversational language of the person's everyday social contexts and can be acquired at age- or peer-appropriate levels within 2 years of exposure to the language, depending on amount and type of exposure. Students enter school fully proficient in their native language at the BICS level (Cummins, 2000).

\section{Belongingness}

In Maslow's hierarchy of needs (1970), belongingness follows the physiological and safety needs of humans. He describes the need as a desire to be a part of a meaningful group, thwarting feelings of alienation or loneliness. Belongingness is the need to belong to a social group. In this study, developing a sense of belonging is seen as occurring through positive engagement experiences (see Figure 1).

\section{Cognitive Academic Language Proficiency (CALP)}

CALP is the academic and cognitively demanding language of schooling, which students must learn, acquire, and use effectively in order to successfully progress in grade-level. Students reach grade- or peer-level CALP within five to 7 years of exposure to the language depending on the exposure inside and outside of school (Cummins, 2000).

\section{Communities of Practice (CoPs)}

A CoP is a social group of people defined by the relationship among its members, their common activities, and their social contexts (Lave \& Wenger, 1991). Wenger, 
McDermott, and Snyder (2002) define CoPs as "groups of people who share a concern, a set of problems, or a passion about a topic, and who deepen their knowledge and expertise in this area by interacting on an ongoing basis" (p. 4). In a school setting, CoPs form everywhere including classrooms, cafeterias, and common areas (art studio, gym, lounge, library), and the most transformative learning experiences occur through interactions within CoPs (Wenger, 1998). Other theorists and researchers use terms such as affinity groups (Gee, 2003), social networks (Astin, 1977; Swail, Redd, \& Perna, 2003; Tinto, 1993), or information networks (Karp, Hughes, \& O'Gara, 2008)

\section{Credit-bearing Courses}

Institutions assign credits to courses in a variety of ways. For this study, the courses with college credits that apply to an associate's degree are considered mainstream or credit-bearing courses in degree-granting programs. Developmental and ESL courses are not credit-bearing courses in degree-granting programs because the credits from most of these courses cannot be applied to an associate's degree. There are some instances where one or two ESL courses can be used as electives or in lieu of the college language requirement for students wishing to transfer to a 4-year institution; however, these instances are not common or even present among many community colleges within the same state.

\section{Cyclical Immigration}

Cyclical immigration refers to the immigration pattern in which a person immigrates to the United States, returns to live in the home country, and then returns 
back to the United States. Some immigrants move back and forth between the United States and their home countries a few times before settling in one place, usually the foreign home (i.e., the U.S.). The cycle of returning to the home country and back to the United States refers to cyclical immigration.

\section{Developmental Courses}

Developmental courses are college preparatory courses assigned credit for tuition billing purposes, but the course credits do not count towards any certificate or associate's degree. The coursework is meant to help students be more successful in the college-level courses in terms of writing, reading, and math. Native and non-native speakers of English can assess into developmental courses.

\section{English Language Learners}

In this study, English language learner is a term that refers to students who assess into ESL courses when they first enroll into community college. This study focuses on Hispanic Generation 1.5 students who assess into ESL courses; therefore, these students are sometimes referred to as Hispanic Generation 1.5 English language learners to differentiate from Hispanic Generation 1.5 students who initially assess into developmental or credit courses.

$E S L$

ESL stands for English-as-a-Second Language, and the title is used to designate English language courses and students enrolled in those courses. English language 
preparatory programs take on a variety of names including ESOL (English as a second or other language) and EAP (English for academic purposes). In all these programs most or all of the English language preparatory courses for non-native speakers do not offer credits towards an associate's or bachelor's degree and focus on students' language skills to help them successfully enter and complete their desired college degree programs.

These program names have a variety of connotations that are both negative and positive for the different populations they serve. However, this study is not about the programs themselves but about the engagement experiences of these foreign-born, U.S.-educated Hispanic students who at the college-level first assess into non-credit English language courses. Therefore, for the purposes of this study, and because of the more common label used for the English language programs in Massachusetts, ESL will be used for all of these programs.

\section{ESL Hispanic Generation 1.5 Students}

This term will be used to describe native Spanish-speaking bilingual students who were educated in English-only U.S.classrooms and assess into ESL courses in college. The ESL designation demarcates those Generation 1.5 students who are enrolled in ESL.

\section{First Generation College Students}

First generation college students are students who are the first in their families to attend college, regardless of whether it is a two- or 4-year institution. 


\section{First Generation Immigrants}

This term will be used for immigrants who are the first in their families to arrive to the United States. To differentiate from Generation 1.5 college students, first generation immigrants would have arrived to the U.S. after completing their K-12 schooling.

\section{Generation 1.5}

There is little agreement on what constitutes a Generation 1.5 student. Some authors include students who start U.S.-schooling at any grade level, even if it is the $1^{\text {st }}$ grade or $12^{\text {th }}$ grade. In this study, the term "Generation 1.5 students" includes those immigrants who graduated from a U.S. high school. In college, these students are nonnative speakers of English who might need additional linguistic and academic support before taking college-level courses (Blumenthal, 2002; Gawienowski \& Holper, 2006; Harklau, et al., 1999).

\section{Hispanic Population}

Because race and ethnicity can be traced in a variety of ways, for the purposes of this dissertation, the Hispanic population includes first, second, and third generation immigrants unless otherwise noted within the text. The Hispanic population includes Spanish-speaking and non-Spanish speaking immigrants since the definition is based on geographic roots (e.g., Dominican Republic) regardless of generation (i.e., first, second or third generation immigrant). 


\section{Mainstream}

The term mainstream is used in this dissertation to identify courses and academic programs that are part of the traditional degree programs in high schools and colleges. In high school, these courses and programs are not ESL, special education, or developmental. The coursework counts toward the high school diploma. In college, mainstream courses identify those courses that are not part of the ESL or developmental courses offered at the college. The mainstream courses in college offer credits toward a certificate or either an associate's or bachelor's degree.

\section{Membership}

Membership in a Community of Practice refers to a person's participation in a social group or community. Individual participation is situated on a continuum from nonparticipation (i.e., observation of interactions and activities) to full-participation (i.e., actual interaction and completion of activities) within the social community (Lave \& Wenger, 1991). Membership status in a CoP is also on a continuum from novice or newcomer to expert or old-timer. In other words, members in a CoP have varying levels of participation and varying levels of expertise in relation to that $\mathrm{CoP}$. Other theoretical models use integration (Tinto, 1993) or involvement (Astin, 1977) to signify student membership in groups or the institution.

\section{Multimembership}

People are and must be members of multiple social communities that are tied to their home, school, work, and other lives. While membership in a Community of 
Practice means participation in a social community, multimembership implies membership in more than one social community.

\section{Post-ESL Hispanic Generation 1.5 Students}

This term will be used to describe native Spanish-speaking bilingual students who were educated in English-only U.S. classrooms and afterwards took college-level ESL courses. The post-ESL designation demarcates those Generation 1.5 students who completed at least one ESL course and have moved on to developmental or credit-bearing courses.

\section{Second Generation Immigrants}

This term will be used for the U.S.-born children of first generation immigrants.

\section{Student Engagement}

Student engagement encompasses students' interactions with peers, staff, faculty, or other college-related individuals. Student engagement includes interactions inside the classroom such as talking to a peer, speaking with the teacher, asking and answering questions, participating in class discussions, and even reading and writing, which are two forms of non-oral interaction. Student engagement also includes interactions outside of the classroom. Engagement through interaction could occur in written, oral, or other formats such as body language and signs. This study builds upon these notions of student engagement with a focus on interaction and participation, which sometimes in the literature are used interchangeably with engagement. 
Engagement also includes participation in college activities and organizations such as sporting events, clubs, organizations, and volunteer work or community/college service. Other engagement activities include working with other students on group projects, collaborating on research with instructors, working with a peer or professional tutor on an assignment, or enjoying a movie, lunch, or other activity with other collegerelated individuals. Engagement activities could be social or academic in nature, and they could involve peers, faculty, or staff.

\section{Student Success}

There are many different ways of defining and measuring student success in colleges and universities. Kuh, Kinzie, Buckley, Bridges, and Hayek (2007) discovered that student success definitions could be organized into two categories: traditional measures (exams, grades, number of credits) and desired student outcomes (acquisition of knowledge, practical competence, proficiency). However, while research studies might take many of these factors and definitions into consideration, most research focuses on the students' success as measured by degree completion within a certain timeframe. In this study, student success was measured as degree obtainment within a $150 \%$ timeframe without counting Adult Basic Education, English as a Second or Other Language or Developmental Studies courses, most of which do not count towards an associate's or bachelor's degree. Therefore, in this dissertation, student success is the obtainment of an associate's degree in 3 years after completing ABE, ESL, and developmental courses (only counting credit courses). 


\section{Summary}

ESL and post-ESL Hispanic Generation 1.5 students are rarely examined outside of their English language abilities in terms of academic success in the mainstream classrooms. Incorporating local and national research analyzing engagement as a key indicator of student success into a theory of membership in communities of practice, this study explored, described, and analyzed post-ESL Hispanic Generation 1.5 students' engagement and membership experiences in a Massachusetts community college. The following chapter explains engagement and membership in communities of practice in more detail and review the literature on ESL programs and Generation 1.5 community college students in relation to engagement and membership experiences within communities of practice. Chapter 3describes the research site and participants, the participant selection process, and the methods for data collection and analysis. Chapter 4 describes the Hispanic Generation 1.5 students at Commonwealth of Massachusetts Community College. Chapters 5 through 8 provide the study's engagement findings. Chapter 9 reviews the study's major findings and provides the study's conclusions. 


\section{CHAPTER II}

\section{REVIEW OF THE LITERATURE}

This dissertation aims to describe Hispanic Generation 1.5 students' experiences

within the framework of engagement and membership in communities of practice during and after the completion of their ESL coursework in a Massachusetts community college. The first chapter briefly described this population and the significance of examining engagement and membership in regard to native Spanish-speaking U.S. high school graduates who assess into ESL courses in community colleges. This second chapter examines the literature on Hispanic Generation 1.5 and their engagement and membership experiences in community colleges. First, Generation 1.5 students in higher education are discussed, including an inquiry into their academic, linguistic, and social characteristics. Then engagement is examined as a key indicator of student success within the theoretical framework by looking at how positive engagement opportunities lead to membership in communities of practice, which would influence long-term retention. The alternative route within the theoretical framework is proposed as well showing how negative engagement experiences ultimately lead to alienation and possible attrition. Finally, bringing Generation 1.5 and engagement research together, the chapter ends with a look at Hispanic Generation 1.5 students' possible engagement and membership experiences, focusing on students who first assess into ESL courses in a community college. 


\section{Generation 1.5 Students}

Generation 1.5 students are foreign-born, U.S. high school graduates who enter the United States during their adolescent or teenage years and are socialized in the English dominant K-12 school system while still maintaining the native language and culture at home (Allison, 2006; Blumenthal, 2002; Harklau et al., 1999; OrtmeierHooper, 2008). When these students graduate from high school and take the college placement tests, they could assess into a variety of levels, including mainstream or creditbearing, developmental, and ESL courses or programs regardless of whether they have completed part of their K-12 coursework in English-only classrooms. The label Generation 1.5 was developed for the college setting and has been used most commonly for these U.S.-educated, college-level bilingual students who demonstrate first generation language characteristics in their reading and writing (Blumenthal, 2002; Rambaut \& Ima, 1988).

Generation 1.5 students live between two worlds or cultures: the native culture, which tends to be preserved at home, and the perceived U.S. culture (often referred to as “American”), which is prevalent in school. During their schooling experiences, these students might be forced to move among ESL and mainstream communities at least twice in their academic careers: first in the K-12 system and then again in the post-secondary institution. Many times, these students are first-generation college students with parents who have not attended college and sometimes might not have attended high school either. 


\section{Generation 1.5 Language Characteristics}

Generation 1.5 students have distinct language characteristics that set them apart from native speakers as well as their first- and second- generation peers. In speech, they sound like native speakers in informal circles with minimal accents and popular expressions and slang (Blumenthal, 2002; Gawienowski \& Holper, 2006). These students could sound American with oral grammar colloquialisms like gonna or watup, which are more typical of their English-speaking social groups; however, their writing needs are different from those of native speakers and their ESL counterparts (Allison, 2006; Stasinopoulos, 2006). Having crossed over to mainstream courses during their secondary school years, these students might feel comfortable speaking with native speakers, and they might be orally fluent in both their native language (L1) and English(L2).

However, the key characteristic that sets these college students apart academically is their writing abilities, often resembling their oral language characteristics in terms of academic level, use of colloquialisms, spelling, sentence structure, and vocabulary, all of which might not match the acceptable forms of academic college writing. While in some ways, their writing abilities are similar to native-speaking developmental students, the key characteristic of their writing is that it contains fossilized second language grammatical errors, which also are present in their speech though not as easily detectable (Blumenthal, 2002; Harklau et al., 1999; Gawienowski \& Holper, 2006). According to Allison (2006), these students mostly learn English orally in school, and they do not understand the structure of the language, as they often lack the same metalinguistic capabilities that native English speakers lack. Overall, Generation 1.5 students tend to be 
semiliterate in both their first language and in English because they do not fully develop their native language before entering the U.S. school system where they have to learn the English language and the school content at the same time (Blumenthal, 2002;

Gawienowski \& Holper, 2006). In other words, as Blumenthal (2002) explains, the students' need to develop their L2 interrupts the development of their L1; thus, the effects of this interruption and poor development of both languages can carry over to their college years.

Generation 1.5 students sound like native speakers because of their constant exposure to conversational language usually upon arrival to the United States or starting with the first day of school. According to Cummins' research on language proficiency, native-like proficiency levels in conversational English are reached in approximately 2 years while native-like levels in academic English are reached within 5 to 7 years, all depending on type and amount of exposure (Cummins, 1989). In addition, Cummins explains that oral language develops faster because of the contextual clues offered in speech such as hand gestures and facial expressions, which explains why Generation 1.5 students have stronger, and most times native-like, oral language skills, while their writing demonstrates second-language characteristics. Cummins names this conversational form of a language BICS (Basic Interpersonal Communicative Skills) and the academic and cognitively demanding form of the language CALP (Cognitive Academic Language Proficiency), both of which are used in schools (Cummins, 1989; 2001). However, the ability to function with and within CALP is essential for grade or level mobility in K-12 and in college. 
Generation 1.5 students have not had enough experience with academic and cognitively demanding language during their U.S. schooling years prior to enter a community college. While they are trying to catch up to their native-speaking counterparts during their K-16 schooling, native speakers of English are progressing in language levels as well (Cummins, 1989). Therefore, Generation 1.5 students are not just trying to catch up to native speakers, but continuously are trying to keep up with the native speakers' steady progression in language proficiency, adding to their challenges of learning and acquiring both BICS and CALP for their age group. When taking college placement tests, their lower academic language skills are revealed in writing and reading activities, the results of which are used to determine college placement. As native speakers progress through their credit-bearing or mainstream courses, Generation 1.5 students might have to progress through various levels of ESL and developmental coursework before taking the freshmen level writing and introductory content courses. Therefore, it could take Generation 1.5 students two more years than their nativespeaking counterparts to graduate with the same degree if attending college full-time.

\section{Generation 1.5 Academic Characteristics}

In college, even though Generation 1.5 students might be highly knowledgeable in popular culture, they tend to lack general background knowledge, and, therefore, lack content in their writing (Gawienowski \& Holper, 2006). They might lack academic skills and have underdeveloped critical thinking skills as well, making them poorly prepared for college courses (Blumenthal, 2002; Gawienowski \& Holper, 2006). In college, these students might not know the practice or repertoire (i.e. ways of doing things, language 
use, and tools) of the academic setting, and, therefore, are unclear about the expectations others have of them (Allison, 2006). Allison (2006) explains that these students develop one set of academic behaviors while in high school that are no longer appropriate for their new educational settings. Their perceptions of teaching and learning might make them passive learners, a process which involves viewing the teacher as an authority figure and having the naïve notion that there is one correct answer for every problem and task. Gawienowski and Holper (2006) explain this mental attitude towards higher education learning as these students' unwillingness to engage in learning, perhaps because of the learned and acquired high school behaviors that do not fit the new communities of practice found in the traditional ESL courses.

\section{Generation 1.5 Students in ESL}

The mismatch of Generation 1.5 and higher education occurs mostly in the ESL courses. Many Generation 1.5 students attend community colleges because they need ESL and developmental coursework and because they might have other constraints including economic and family limitations (Blumenthal, 2002). Depending on the assessment and placement procedures of the institution, students might have to begin their academic coursework with ESL courses because of their writing and reading difficulties. In the college-level ESL courses, Generation 1.5 students take classes with more recent immigrants who have not participated in English-only U.S. K-12 classrooms.

For Generation 1.5 students who assess into ESL after completing their high school education in English-only courses, the associated labels are confusing and offensive, and could lead to anger and resentment in some cases, or disillusionment and 
doubt in other cases (Gawienowski \& Holper, 2006; Ortmeier-Hooper, 2008). In some cases, students feel insulted and might reject the newly assigned labels and perhaps even the people or groups associated with those labels (Ortmeier-Hooper, 2008). According to Gawienowski and Holper (2006), the confusion, anger, and resentment arise from the students' realization of their gap in education and inability to communicate confidently with others, and these emotions could lead Generation 1.5 students to alienate their peers, teachers, or even family members. This alienation prevents membership and a sense of belonging to the institution or at least to a community of practice within the institution.

In ESL, Generation 1.5 students, who tend to be younger than their ESL peers, have different habits and behaviors than immigrant or first generation ESL students. They might demonstrate inappropriate behaviors such as excessive giggling and chattering in the back of the room, which the students might demonstrate to cover up their inabilities and confusion (Gawienowski \& Holper, 2006). The behavior also could be explained by the students' boredom in the ESL courses, their resentment taking courses with recent immigrant students, and their frustration with the ESL form of instruction due to the difficulties they encounter considering their lack of metalinguistic knowledge (Blumenthal, 2002; Gawienowski \& Holper, 2006). Academically, these students do not seem to belong in either the ESL courses or the mainstream credit-bearing courses. In ESL, they have much stronger oral language abilities than their ESL peers, making them feel out of place during classroom instruction and group activities. However, they do not have the reading and writing capabilities to succeed with their peers in the mainstream credit-bearing courses. 
In addition, the ESL curriculum, which is designed for immigrant students, focuses on U.S. cultures and ways of interacting in the mainstream society, areas in which Generation 1.5 students are highly efficient seeing themselves many times as Americans and not as immigrants. Another conflict with the academic ESL courses in community colleges is that they are designed for immigrant students who tend to have highly sophisticated academic backgrounds including college and even doctorate degrees while Generation 1.5 students have only completed high school (Blumenthal, 2002). Finally, the ESL courses tend to address language at a metacognitive level that is unfamiliar, uncomfortable, and highly difficult for Generation 1.5 students who might have never had any type of formal language instruction in either language (Blumenthal, 2002), especially in districts where ESOL and bilingual education are not available or well-supported.

All these experiences and related emotions affect Generation 1.5 students' engagement and membership experiences in various social groups as well as their sense of belonging to communities of practice and their commitment to their institutions or academic goals. This population's characteristics make academic and social engagement especially difficult and their experiences could deteriorate their membership possibilities throughout their community college experience. One possible alternative to membership in a community of practice for this particular group could be disengagement or alienation, which hinders students' abilities to persist and succeed and is associated with attrition. Therefore, understanding engagement and membership theories and this population's engagement experiences from when they first assess into ESL or developmental courses 
could provide information on how to enhance their positive engagement experiences and long-term retention at the institution.

\section{Engagement as a Key Indicator of Student Success}

Nearly half of the undergraduate students in the United States attend community colleges, which serve a high percentage of at-risk students who are first generation college students, come from low income households, have several out-of-school responsibilities, or come from a minority group (McClenney, 2006). With so many students in community colleges and so many risk factors possibly impeding their success in graduating and/or transferring to a 4-year institution, student retention in community colleges has become a great concern for institutions and the states that fund them. Substantial research has focused on pre-college characteristics that affect goal and institutional commitment such as previous learning experiences, qualifications, individual attributes, family attributes, and family background (Tinto, 1975, 1993). While there have been studies on barriers to academic success and impediments that arise from the students' pre-college risk factors, the notion of student engagement as an indicator of student success has taken the limelight in much of the retention and persistence research in post-secondary institutions. This engagement research study focuses on the other half of Tinto's retention model where academic and social integration or membership, achieved through engagement, has a reciprocal relationship with goal and institutional commitment, which affects dropout decisions (Tinto, 1975, 1993). The current research trend on engagement relies on the assumption that increased student engagement leads to 
increased student persistence, retention, and overall success as measured by degree completion.

Engagement is a broad term that incorporates different aspects of student involvement and interactions on and off campus with faculty, staff, and peers, all of which have been tied to short and long-term retention. In light of the growing concern with college student retention, persistence, and ultimate success through graduation, many post-secondary institutions have pointed to student engagement as the key indicator of success, and, therefore, an area worth cultivating (Community College Survey of Student Engagement, 2006, 2007; McClenney, 2006, 2007; National Survey of Student Engagement, 2006, 2007). Within this framework, engagement is often defined using Chickering's definition, which divides engagement into categories that focus on student interaction and involvement with faculty, staff, peers, and the institution as a whole both academically and socially (Chickering \& Gamson, 1987, 1991; Chickering \& Reisser, 1993; Kuh et al, 2007).

In fact, engagement has been defined or classified in a variety of ways. Handelsman, Briggs, Sullivan, and Towler (2005) used exploratory factor analysis on the Student Course Engagement Questionnaire to uncover four dimensions of student engagement: skills engagement, participation or interaction engagement, emotional engagement, and performance engagement. In addition, Bryson and Hand (2007) found that student engagement was on a continuum from more engaged to less engaged on four levels: “(a) within/to a classroom or in undertaking a particular task or assignment; (b) within/to a particular module; (c) within/to and across the course/programme of study; (d) within/to the university" (p. 353). Other definitions are designed more in line with 
Tinto's integration theory (1975), viewing engagement as being twofold: academic engagement, which is associated with the learning process, and social engagement, which is related to interactions with instructors and peers (Caspi et al., 2005). These two forms of engagement would increase students' integration or sense of belonging in a college leading to higher retention rates in the end. Therefore, student engagement is composed of a variety of factors such as social and academic interactions with faculty, staff, and peers.

\section{The Relationship between Engagement and Student Success}

Increased time on campus is a key component of student engagement. Some studies and reports focus on the increased time on campus as an increase in student involvement through extra-curricular activities (Benjamin, Earnest, Gruenewalk, \& Arthur, 2007; Keup, 2006). One major factor in several engagement studies is commitment to the institution or program and to the academic major (Graunke \& Woosley, 2005; Kuh et al., 2007; Laird et al., 2007). Graunke and Woosley (2005) found that commitment to an academic major correlated with higher grades, suggesting that students had increased motivation from this commitment. Amount of time on campus, like commitment, is part of student engagement and has had a positive relationship with student success (Benjamin et al., 2007; Keup, 2006; Kulm \& Cramer, 2006). In their correlational study, Kulm and Cramer (2006) found that increased time on campus positively related to academic success as measured by persistence and academic performance because of students' social interactions with peers and faculty through activities, coursework, and on-campus jobs. 
Several studies have shown that there is a positive relationship between engagement and academic outcomes as well as between engagement and persistence. Most data used for these engagement studies come from two national engagement surveys: the National Survey of Student Engagement (NSSE) for 4-year institutions and the Community College Survey of Student Engagement (CCSSE) for community colleges. These surveys are designed and used to measure student engagement providing data used for national student engagement benchmarks and for individual institutional insight into current student engagement practices (Community College Survey of Student Engagement, 2006, 2007; Kuh, et al., 2007; National Survey of Student Engagement, 2006, 2007).

National Survey of Student Engagement (NSSE). Specifically, the findings from the National Survey of Student Engagement research show that there is a positive relationship between engagement and student grades, as well as a positive relationship between student engagement and persistence from first to second year of college (NSSE, 2006). One NSSE finding (2007) was that first-generation college students were less likely to partake in high impact engagement activities such as learning communities and research projects with faculty, which have shown to positively affect retention. While these findings were not tied directly to the sample's future academic success, the conclusions are relevant to Generation 1.5 students' current engagement practices since many Generation 1.5 students might be first generation college students as well. 
Community College Survey of Student Engagement (CCSSE). The sister of the NSSE, the Community College Survey of Student Engagement, was established in 2001 because of a need to make decisions in community colleges based on systematically collected data (McClenney, 2007). The survey is administered each year by the Community College Leadership Program at the University of Texas. McClenney, the director of CCSSE, reported on several key findings from the surveys based on nearly 600,000 responses. First, approximately two-thirds of the community college population attends school part-time, an alarming rate since the survey results also revealed that parttime students work less with their peers outside of class and interact less with faculty. In terms of academic engagement, part-time students are less engaged in classroom experiences than full-time students.

A contradiction among student and faculty perceptions was revealed when the study results showed that instructors believe their students are more engaged than what the students actually reported in the survey. Unlike 4-year institutions, especially those with residential programs, community college students are much more academically and socially engaged in the classroom than outside the classroom. Another interesting finding from the CCSSE research so far is that high risk students (i.e., most likely to dropout) who are highly engaged are most likely to persist in the institution, supporting high impact engagement initiatives that increase social and academic engagement opportunities such as mentoring programs, learning communities, and service-learning (McClenney, 2007). 


\section{Interaction: A Key Component of Student Engagement}

One crucial aspect of student engagement is faculty and student interactions both inside and outside of the classroom. Umbach and Wawrzynski (2005) compared two national data sets: the 2003 NSSE data set and the data set from an unnamed faculty survey, which might be the first version of the Faculty Survey of Student Engagement (FSSE). They found that students valued out-of-class faculty-student interactions more than in-class interactions. There was a positive correlation between faculty self-reported use of student-centered approaches (collaborative and active learning strategies) and students' self-reported engagement levels. Therefore, according to the results of their study with the two data sets increased student-centered teaching strategies in the classroom positively affected student engagement more than out-of-class interactions, and students valued in-class interactions the most (Umbach \& Wawrzynski, 2005).

Peer to peer interaction both inside and outside of class are important engagement practices. In their study on out-of-class peer engagement, Krause, McInnis, and Welle (2003) found a positive relationship between the frequency of students' interactions and student satisfaction with the college experience including their courses. The students who reported the highest frequency of peer interactions inside and outside of the class on academic and social matters were the ones who reported the highest levels of satisfaction with the institution and courses. Krause et al (2003) also found a relationship between the frequency of students' interactions with each other and their perceptions of how well they were doing academically. The students who reported feeling negative pressure in the course or institution were the ones who interacted with their peers less frequently and 
their interactions focused mostly on very specific aspects of the course such as assignments or tests.

Many community college students have part-time or full-time employment outside of school; however, in their same study of undergraduate students, Krause et al (2003) found that employment did not impede students' interactions. Having a job did not negatively affect students' interactions and levels of satisfaction with the institution

and course. In fact, those students who had a part-time job (16 to 20 hours per week) had higher academic engagement levels — i.e., interactions about the course, assignments, or tests and borrowing of materials - with their peers than the other students in the sample including those who did not have jobs.However, the students with jobs did not meet as much socially with their class peers as their non-working peers. The study did not make connections between students' interactions (part of engagement) and overall retention and academic success, and it did not explain whether the working students had jobs on campus or off campus.

\section{Engagement and First Generation College Students}

Generation 1.5 students share many characteristics with first generation college students because both groups tend to be the first in their families to attend college. Because of the lack of research on Generation 1.5 student engagement, research on first generation college students will be used to partially inform this aspect of the literature. Like Generation 1.5 students, first generation college students are at a higher risk of being less-engaged and dropping out of school than their peers (Harklau, et al., 1999). It 
is not uncommon to find that many first generation college students come from lowincome backgrounds and perhaps are U.S. immigrants or children of U.S. immigrants.

There are considerable engagement differences between first- and secondgeneration college students. In their study on academic and social engagement using the College Student Experiences Questionnaire, Pike and Kuh (2005) found that firstgeneration students were significantly less engaged academically and socially than their second-generation peers. They also perceived the college environment to be less favorable and supportive. Pike and Kuh (2005) found that first generation students were less engaged overall than second-generation students and concluded that even if colleges offer the academic and social engagement opportunities associated with college success, first generation students do not take part in these activities. This finding is similar to that of the CCSSE 2007 findings that first generation students participated much less than their peers in high-impact activities such as learning communities, research with faculty members, and study abroad programs (Community College Survey of Student Engagement, 2006, 2007).

Because first generation college students are at a high risk of not successfully completing their degrees within the $150 \%$ timeframe, Filkins and Doyle (2002) used NSSE data to examine engagement with low-income and first generation students in 4year institutions. They used the data from six urban institutions within the same area, providing nearly 2,000 study participants. Their findings suggested that low-income, first generation students benefited most from in-class participation through activities, class discussions, or student presentations that engage them in collaborative settings (Filkins \& Doyle, 2002). In addition, they concluded that there was a positive relationship between 
student engagement and cognitive and affective growth. Positive engagement experiences inside and outside of the classroom could positively affect students' perceptions of the school or campus environment. Filkins and Doyle found that students who perceived their school's environment to be supportive of both their academic and social development would be more likely to demonstrate gains in appropriate academic areas.

\section{Engagement and Generation 1.5 Students}

These surveys and studies on student engagement show how increased time on campus, commitment, interactions, and involvement affect learning, persistence, and graduation rates regardless of racial or ethnic background (Community College Survey of Student Engagement, 2006, 2007; Kuh et al. 2007; National Survey of Student Engagement, 2006, 2007). Both the NSSE and the CCSSE are focusing more on first generation college students with a third of the 2007 CCSSE sample being first generation college students. However, both national research initiatives do not differentiate Generation 1.5 students whose added language, academic, and social characteristics could affect their overall social and academic engagement opportunities and abilities. With this sometimes-unidentified population growing in community colleges across the states, engagement studies need to be more inclusive and differentiate more among the different college populations so that we can understand the fuller picture of student engagement and membership in community colleges. 


\section{Engagement and Belonging}

A critical flaw in much of engagement research is that the focus has remained at the level of student engagement without further exploring and understanding how engagement leads to persistence and success. Schuetz (2008) attempted to understand to what degree engagement accounts for retention and student success. She found that engagement accounted for 50 to $60 \%$ of the variance in belonging, competence, and autonomy connecting engagement to notions of belonging and identifying belongingness as a critical need affecting student retention. Belongingness is a human need that comes right after the fulfillment of one's basic and safety needs, and as humans, we desire to belong to some social network (Maslow, 1970). Community colleges are social organizations, and, according to Osterman (2000), schools should address the students' need to belong to these social organizations by actively enhancing students' membership in the community or organization. Engagement can meet the need to belong to a social network, and if students' belonging needs are met, they could be more committed to their social contexts and the goals associated with that social context, leading to increased retention and graduation rates (Kuh, Kinzie, Schuh, \& Whitt, 2005).

In her review of current research, Osterman (2000) sought to understand whether belongingness was important in an educational institution, whether students see schools as communities while seeing themselves as members of those communities, and how schools affect these students' sense of community. She defined a "sense of community" as the feeling of belonging to a group. From her qualitative literature review, Osterman concluded that students who feel accepted in their school community are highly 
motivated, engaged, and committed to their institution (2000). Feelings of acceptance or membership positively affect the quality of students' relationships and interactions with others within the institution as well as students' perceptions or feelings of themselves (Osterman, 2000). While belongingness as part of membership in an institution has been studied within the fields of psychology, sociology, and even business, the application of this concept to students' educational experiences could help explain their retention or attrition in relation to engagement and membership experiences.

Karp, Hughes, and O'Gara (2008) looked at students' engagement practices as part of their integration to the institution at both the social and academic levels. The study was designed using the social and academic integration sector of Tinto's 1975 retention model. The researchers used multiple in-depth interviews with a random sample of first year community college students. The interview data were coded for students' sense of belonging and their different types of social networks within the college. Seventy percent of the students in the sample reported that they felt a sense of belonging to the institution in some form, and, therefore, were integrated in some form. Ninety percent of those integrated students completed their first year at the institution and continued to the second year.

However, the second phase of data analysis for the belonging aspect revealed how students went from engagement to a sense of belonging or integration in the institution. Karp et al. (2008) found that students who developed a sense of belonging and persisted to the second year were those who were part of information networks, which they defined as "social ties that facilitate the transfer of institutional knowledge and procedures" such as how to register for courses, instructors' preferences, and key people who can provide 
the best assistance (p. 8). Participation or membership in an information network occurred mostly through academic engagement with peers or faculty. These information networks are specific forms of communities of practice where members have formal and informal ways of sharing information through formal and informal conversations, text messages, emails, or phone calls. The information networks or communities of practice in their study were created and maintained through engagement (Karp et al., 2008).

This notion of belonging and commitment through engagement is a key formula within communities of practice since engagement is crucial for the creation and maintenance of CoPs (Wenger, 1998; Wenger et al., 2002). According to Wenger (1998):

The work of engagement is basically the work of forming communities of practice. As such, it requires the ability to take part in meaningful activities and interactions, in the production of sharable artifacts, in community-building conversations, and in the negotiation of new situations. (p. 184).

These CoPs and the people who become members of these CoPs through engagement have a common goal or enterprise that they are pursuing such as an associate's degree. They engage in common or shared activities, share experiences, and develop relationships (Wenger, 1998). Academic and social engagement opportunities in the classroom, outside the classroom, and sometimes outside the institution provide the mechanism through which CoPs are formed and through which students develop a sense of belonging.

Student engagement has a positive relationship with academic outcomes including grades and persistence. Students develop ties and become committed to other people and to their academic goals, forming networks or social groups through positive interactions 
with faculty, staff, and peers in combination with other engagement experiences at the college. Both the development of networks or groups and the participation in these networks or groups increasethe students' membership and sense of belonging to the group and possibly to the institution. Furthermore, this feeling of membership and belonging facilitates students' commitment to their academic goals, their institutions or both, which increases their success rates. However, if engagement and membership experiences are negative, such as those through undesired placements, then students will feel isolated from others or wish to withdraw from others and possibly even the institution. Therefore, the key to academic success lies in positive engagement experiences that lead to membership in these networks or communities of practice, and to an increased sense of belonging through this membership.

\section{Communities of Practice}

While many studies concerning student persistence and retention at the two- and 4-year college levels focus on increased academic and social engagement in relation to student success, this study addresses engagement within a larger framework of membership and belonging in communities of practice. As other studies have shown, increased engagement is tied to increased institutional commitment because it enhances a person's sense of belonging in the social context (Graunke \& Woosley, 2005; Karp, et. al, 2008; Kuh et al., 2007; Laird et al., 2007; Osterman, 2000). The sense of belonging comes out of the students' membership in communities of practice within the institution, which are created, developed, and maintained through social and academic engagement. 
This section will demonstrate how engagement leads to and is a part of membership in communities of practice within the college, explain membership processes, and show how these processes could lead to retention and success.

\section{Defining Communities of Practice}

The theory of communities of practice (CoPs) was proposed by Lave and Wenger in 1991, and they first defined CoPs as "a set of relations among persons, activity, and world, over time and in relation with other tangential and overlapping communities of practice" (p. 98). A CoP could be a gang in the South Bronx, a family in your neighborhood, a group of workers such as a sales team at a department store, or a group of creative writing students in an undergraduate English program at a university. CoPs are everywhere. CoPs could be visible or invisible, as they exist within the physical bounds of schools, homes, communities, and other arenas in our lives (Wenger et al., 2002). Some have names; others are nameless. While some are easily identifiable, most are rather invisible. Therefore, a community college could have countless communities of practice in different programs and departments.

Communities of practice share an affinity space, a purpose, and a common goal or vision. For example, Hung, Chen, and Koh (2006) define CoPs as:

Communities of people practicing such professions as science, law or accountancy, that are oriented towards a code of conduct, ethics, history and peculiar culture. These communities of people would share similar concerns and passions, allowing them to collectively evolve the necessary structures and processes to deepen their expertise and knowledge through engaging one another on an ongoing basis (Barab \& Duffy, 2000)" (p. 300). 
In their definition of communities of practice, the authors focus on meaning making and negotiation of meaning among members of the community of practice. For example, a group of students in a degree program would make sense of degree and field requirements and negotiate meaning of content among themselves and with others in their network or group such as tutors and instructors. Members of a CoP would therefore learn by interacting with each other, teaching one another, and making meaning together. Through these interactions or engagement experiences, members develop connections, comfort, and a sense of belonging to the group and other areas associated with the group such as the actual school.

Other researchers have created their own criteria or attributes for the determination of what is and what is not a community of practice. Swales' (1990) sees CoPs as discourse communities, and he has six criteria for defining a discourse community: “(a) common goals, (b) participatory mechanisms, (c) information exchange, (d) community-specific genres, (e) a highly specialized terminology, and (f) a high general level of expertise" (as cited in Flowerdew, 2000, p. 129). Swales's criteria focus on the language and information creation and exchange within the CoP. Hara and Schwen (2006) assigned five attributes to CoPs on a broader scale than Swales. They include "(1) a group of professional practitioners, (2) development of shared meaning, (3) informal social networks, (4) a supportive culture (i.e., trust), and (5) engagement in knowledge building" (Hara \& Schwen, 2006, p. 96). They focus on the social aspect of the CoP and how the relationships of these members work within this theoretical framework. All these attributes occur because of members who help shape the CoP through meaningful or purposeful interactions. 
Some definitions of CoPs focus on the members as the defining factor. Wenger, McDermott, and Snyder (2002) proposed that CoPs are "groups of people who share a concern, a set of problems, or a passion about a topic, and who deepen their knowledge and expertise in this area by interacting on an ongoing basis" (p. 4). There is a commonality that brings together or binds a $\mathrm{CoP}$, and it is usually a common goal or belief that is inherent in the CoP and in its members such as successfully completing a course or a degree program. They continue to explain that a $\mathrm{CoP}$ "is a group of people who interact, learn together, build relationships, and in the process develop a sense of belonging and mutual commitment" (p. 34). These people come together as members of a socially meaningful group, and they are able to identify each other as members based on how they act, speak, walk, and use the tools and artifacts of that CoP.

\section{Aspects of a Community of Practice}

Community is key in the creation and maintenance of a community of practice, and, in this community, there are multiple types and levels of mutual engagement. Mutual engagement refers to the involvement of people who are engaged in activities and interactions, and the negotiation of these meanings by the same people. For example, purposeful mutual engagement occurs through the completion of a group project for a specific course. Through meaningful and purposeful interactions, people in a CoP negotiate and renegotiate meaning on an ongoing basis as the social aspects change and members of the CoP change, leave, return, or join for the first time. Differences and similarities among members come out through this engagement and relationships are created through these interactions. 
The definition of a CoP also includes the domain. A domain can range from learning English to passing a battery of assessments. In other CoPs, a domain could be situated within a profession such as teaching or nursing. "The domain creates common ground and a sense of common identity" (Wenger et al., 2002, p. 27). There is usually a common goal or idea that binds the group and defines certain aspects of that group. The domain involves joint enterprise, which refers to the communal negotiation of an enterprise by the members and through which members of a $\mathrm{CoP}$ become mutually accountable for an end goal. For example, Generation 1.5 students in an academic ESL program have an end goal of passing the assessment exams and taking credit-bearing courses towards a certificate or associate's degree, and they might work together with their instructors to accomplish this goal.

A CoP also has its tools and artifacts, as well as its own ways of being, thinking, and knowing. These aspects of the CoP tend to be the ones most easily identifiable and nameable. Wenger named this aspect of a $\mathrm{CoP}$ the repertoire, which refers to the sources developed in the $\mathrm{CoP}$ by members over time in order to negotiate meaning and complete actions. As Wenger (1998) explains:

The repertoire of a community of practice includes routines, words, tools, ways of doing things, stories, gestures, symbols, genres, actions, or concepts that the community has produced or adopted in the course of its existence, and which have become part of its practice...[The repertoire] includes the discourse by which members create meaningful statements about the world, as well as the styles by which they express their forms of membership and their identities as members. (p.83)

Gee sees the repertoire as parts of the identity kit of the members including how we use language. Instructors and students model and teach new students the repertoire of the CoP through their daily interactions. 
Gee isolates part of the repertoire of a community of practice as an identity kit that is equipped with everything needed for association with that CoP, which he names a Discourse (with a capital D) to differentiate between discourse as speech (Gee, 1989a, 1989b, 1996). As Gee explained:

A Discourse, then, is composed of ways of talking, listening, (often, too, reading and writing), acting, interacting, believing, valuing, and using tools and objects, in particular settings at specific times, so as to display and recognize a particular social identity. Discourses create 'social positions' (perspectives) from which people are 'invited' ('summoned') to speak, listen, act, read and write, think, feel, believe and value in certain characteristic, historically recognizable ways, combined with their own individual styles and creativity (Bourdieu 1979/84 1990, 1991; Foucault 1966, 1969, 1973, 1977, 1978, 1980, 1985). (1996, p. 128)

This identity kit signals the person's membership in a particular CoP and identifies that person to others as a member of that CoP. In Gee's words, "Discourses are ways of being in the world, or forms of life which integrate words, acts, values, beliefs, attitudes, and social identities, as well as gestures, glances, body positions, and clothes" (Gee, 1996, p.127). People develop these identity kits for their different social groups or CoPs through engagement with others and the artifacts of those CoPs.

In a later publication, Wenger et al (2002) further developed the notion of a repertoire and renamed this aspect of CoP membership, the practice, which they define as

a set of socially defined ways of doing things in a specific domain: a set of common approaches and shared standards that create a basis for action, communication, problem solving, performance and accountability. These communal resources include a variety of knowledge types: cases and stories, theories, rules, frameworks, models, principles, tools, experts, articles, lessons learned, best practices, and heuristics. They include both the tacit and the explicit aspects of the community's knowledge. They range from concrete objects, such as a specialized tool or a manual, to less tangible displays of competence, such as an ability to interpret a slight change in the sound of a machine as indicating a specific problem. The practice includes the books, articles, knowledge bases, Web sites, and other repositories that members share. It also embodies a certain way of behaving, a perspective on problems and idea, a thinking style, not even in 
many cases an ethical stance. In this sense, a practice is a sort of mini-culture that binds the community together. (p. 38-39)

A college as a whole has a general practice that binds the different CoPs within it. There are some similar goals, members, and activities across the institution. However, each area of the college, each program, and each campus could have multiple communities of practice with slight differences in the practice or repertoire of the group. The nursing students are easily identifiable from the computer graphics students at multiple levels. The key is that within the institution there are multiple communities of practice that overlap in some ways and differ in others.

\section{Community Colleges as Constellations of Communities of Practice}

Institutions of higher education are actually large social contexts that are made up of many CoPs. These CoPs overlap, connect, and relate to each other through common characteristics and members, and, therefore, these large social contexts with their overlapping CoPs are actually constellations (Wenger, 1998). Wenger explains constellations as multiple communities of practice related or connected through overlapping features such as the historical roots, related enterprises, shared members, geographical proximity, overlapping language variations or discourses, and shared tools or artifacts. A significant indicator of a constellation is whether or not the multiple communities of practice are all together serving the same cause (such as the education of undergraduate and graduate students), or are together within the same institution (such as a college or university). As a result, within this framework of communities of practice, a 
higher education institution might be viewed as a constellation of CoPs with some shared characteristics and members.

If 2-year colleges and universities consist of constellations of communities of practice that overlap because of shared characteristics and members, then membership in one CoP assists with membership in other CoPs and eventual socialization within the constellation of the higher education institution. Within this theory, it would be crucial for a college student to have positive engagement experiences and CoP membership during the first semester or year, which supports the initiative of providing most engagement-enhancing opportunities during the first year of college. For example, learning communities are highly effective and widely used during the first or second year of college because they provide effective engagement opportunities that lead to relationships through which students enter at least one CoP. This membership helps students socialize into higher education by learning and acquiring the necessary repertoire for those CoPs in the constellation. The socialization experience through $\mathrm{CoP}$ membership in the learning community leads to other CoP membership opportunities and further socialization into the higher education setting.

For students, especially ESL and post-ESL Hispanic Generation 1.5 students who come with more language and cultural challenges than their counterparts, engagement and membership in one CoP would ease the learning and acquisition process in other CoPs within the same constellation. However, the relation of ESL-based CoPs to other institutional CoPs might be weak due to physical or other forms of organizational separation. While completing ESL coursework, Hispanic Generation 1.5 students become members of an initial community of practice developed within the realm of ESL 
where they interact or engage regularly with other members and where they have a common goal with their peers to successfully complete ESL coursework. Many times, the ESL-based communities of practice are isolated from other communities of practice, such as those focused on specific academic disciplines, and forget to bridge with some institutional engagement enhancing opportunities such as learning communities, student clubs, and team sports.

Upon assessing into developmental and/or mainstream courses, former or postESL students are forced to engage with a new set of people who are part of other communities of practice within the university but are not necessarily tied to ESL-based CoPs. These students could be affected by having a sudden change in engagement and communities of practice rather than a gradual transition. To understand the possible relationship between sudden changes in communities of practice and students' engagement and membership experiences in a college, the concept of membership must be explored in relation to engagement and belonging for this population of students.

\section{Membership in a Community of Practice}

If communities of practice are defined and developed by their members and they each include mutual engagement, joint enterprise and a shared repertoire or practice, then how can a person coming from a completely different larger social context succeed? Membership and an increased sense of belonging are not automatic, in spite of the institutional efforts and the four walls that enclose students within a classroom. New students to a college or university must find people with whom they may have 
meaningful interactions, thus partaking in meaningful academic and social engagement opportunities with other people who are members of CoPs. Engagement, therefore, becomes a process through which (a) CoPs are formed, (b) people become members of these CoPs, and (c) CoPs are maintained or developed.

The members and their commonalities, such as the work performed (e.g. papers, coursework) and the existence within a space or place (e.g. virtual or actual classroom), best define the community of practice. However, a CoP is not synonymous with a group of people; furthermore, association with a group by applying for membership, having a particular title, or knowing someone in the CoP does not make a person a member of a CoP (Wenger, 1998). A group of people in the same physical space, such as a group of students in an ESL grammar class, is not a CoP. People cannot assume membership in CoPs through a list or set of rules that outline the dos and don'ts of the group and the shared characteristics of group members. Membership becomes a part of who people are as they approach not just that one particular community of practice but other ones as well, and membership occurs through meaningful academic and social engagement and practices. Therefore, simply being classified as an ESL, development, or mainstream student does not make students members of CoPs within those arenas.

Becoming a member of a new community of practice, such as the ones found in higher education settings, does not mean that students must abandon or reject their memberships in other CoPs and their associated identity kits. People are members of multiple CoPs, and, therefore, multimembership is not only possible but also necessary in order to function within our multifaceted social contexts (Gee, 1996; Wenger, 1998). Membership in one CoP opens doors to other CoPs in the constellation and beyond. 
While Wenger (1998) simply uses the term multimembership to signal our roles in various $\mathrm{CoPs}$, Gee uses the notion of primary and secondary Discourses to make distinctions between our different memberships. According to Gee (1989a, 1989b, 1996), our primary Discourse is the one tied to our home lives, the first CoP into which we are born and which helps shape our initial identities. "They form our initial taken-forgranted understandings of who we are and who people 'like us' are, as well as what sorts of things we ('people like us') do, value, and believe when we are not 'in public'" (Gee,1996, p. 137). It is through our primary Discourse that we are able to learn and acquire other Discourses for other social settings. The primary Discourse is like the base of our future identity construction or the learning and acquisition of multiple secondary Discourses through engagement and multiple memberships in CoPs. In the community college, students develop additional secondary Discourses as part of their membership in CoPs through engagement.

\section{Generation 1.5 Students and CoPs}

Generation 1.5 students are partially educated in the U.S. school system, and take most if not all of their courses in English-only environments during their high school years. When they enroll in a community college, they tend to see themselves as American and might want others to see them as Americans rather than as immigrants (Gawienowski \& Holper, 2006). However, because of their language abilities, they might assess into ESL courses with immigrant students. Immediately, there is a conflict of interest as the goals of the two student populations might be different. Many adult first-generation immigrants in ESL courses want to learn English either to get a better job 
or position, maintain a job, take a national exam, or obtain a graduate degree. These older ESL students might have full-time work and family commitments outside of school that Generation 1.5 students might not fully understand, and these commitments impact participation in classes and the general school.

Another difference between the two populations stems from their varying educational backgrounds and abilities, their self-identifications, and their L1 (native language) and L2 (second language or English) knowledge and abilities. Many of the adult ESL students already have college or graduate degrees from their native countries or have years of professional and life experience to guide them in their thinking. Therefore, the needs and wants of the general ESL population are very different from other college populations, and ESL programs are structured to meet the needs and desires of these older and more mature ESL students enrolled in the courses.

If Generation 1.5 students make an effort and become academically and socially engaged in the ESL programs and develop a sense of belonging within its communities of practice, then they meet another challenge when they assess out of ESL and into developmental or mainstream credit-bearing courses. These students now might have a new set of teachers, a new set of peers, and a new set of tutors and staff who will work with them on their new academic endeavors. Differences in location, instructional practices, types of assignments, and even daily academic and social interactions could affect Generation 1.5 students' social and academic engagement as they learn to maneuver in new territory and new CoPs within the same institution. 


\begin{abstract}
Alienation
Negative engagement experiences affect students' sense of belonging at an institution and could lead to a sense of alienation rather than membership. While engagement implies a connection to the group and institution, alienation is a disconnection from both (Case, 2008). Mann $(2001,2005)$ defines alienation as an estrangement from the engagement activities in which the learner should be partaking. According to Case (2008), alienation can occur at three different phases of the higher education experience: (1) when a student enters the community college, (2) when a student is trying to fit into the college or community, and (3) when the student is trying to stay in the college or community. Generation 1.5 students who assess into ESL courses might feel alienation rather than membership from the moment that they are faced with their assessment results and unexpected placement into ESL courses. Students who "feel more American" might feel alienated if they are placed in ESL courses designed for immigrant ESL students. Finally, a driving desire to get out of the ESL program, where they feel they do not belong, could lead to increased feelings of alienation rather than membership with the ESL group or the groupsin the mainstream credit-bearing courses. This alienation from communities of practice could lead to an overall alienation from the institution as a whole.
\end{abstract}

Student alienation could have many serious consequences in students' perceptions of themselves and their institutions. Tarquin and Cook-Cottone (2008) investigated 351undergraduate students to see how their alienation experiences in school affected selfconcept. The students were asked to report on their worst experience in school and then 
to fill out an alienation and trauma survey and a self-concept survey. The results indicated that there was a negative correlation between alienation and self-concept so that the higher or greater the alienation experiences, the lower the self-concept, and selfconcept was tied to feelings of belonging (Tarquin \& Cook-Cottone, 2008). The results of their study support Osterman's findings that students who did not have feelings of belonging to their institution also have lower levels of identity integration in the institution (Osterman, 2000).

Alienation results from a lack of engagement or from negative engagement experiences. However, countless acts could fall under either one of these two categories. In her study on online communities, Mann (2005) found that a failure of communication during interaction is one cause of alienation. Misunderstandings due to cultural and language differences affected communication among the students and the teacher. She concluded that for successful learning communities, communication must be open and clear among the learners and between the instructor and learners (Mann, 2005).

Therefore, engagement and membership could be promoted while alienation is prevented through supportive, meaningful, and contextualized interactions among students and the different people within the individual communities of practice and the constellation or college as a whole.

Mann's (2005) findings on communication as a critical aspect of positive engagement and membership experiences relate to Ybarra's (2004) findings in his qualitative study of Latino developmental students in a basic writing class. Ybarra found that the interactions between the Latino students and their peers and between the Latino students and their teacher unintentionally kept these students outside of the CoP even 
though they were in the same classroom (2004). The teacher tried to integrate the students into the classroom environment with conversations and both written and spoken comments, but these efforts would alienate the developmental writing students even more. The more the teacher tried to help these Hispanic developmental students, the more alienated they felt because there was a lack of comprehension in the communication patterns used by the teacher and the students. In the same way, Ybarra, himself, had faced similar rejection and dissatisfaction in trying to become a member of a community of practice within the constellation of higher education when he was a college student. He struggled to engage with other members and actually dropped out of school several times between his first year as an undergraduate and his final year as a doctoral student.

The resulting alienation from poor communication occurs because of people's differing primary Discourses or primary identity kits from their first communities of practice as established through socialization in the home. Teachers and students enter community colleges with different identity kits that might not fit the new communities of practice within the college and might not work with each other. The Discourses or CoPs found in the college have certain values and beliefs tied to those CoPs and its members, which might be different from new students' values, beliefs and previous experiences, leading to challenges and possible alienation within the institution (Bryson \& Hand, 2007). Generation 1.5 students experience these challenges when they first assess into ESL courses, when they assess into developmental courses, and when they finally assess into mainstream credit-bearing courses in degree-granting programs. They are forced to enter and exit various CoPs through their community college years, and this constant movement among programs and CoPs could affect students' engagement and 
membership experiences, especially if the institution does not intentionally bridge these CoPs.

As noted in this literature review, engagement plays a critical role in persistence and long-term retention of students in higher education institutions. Positive engagement experiences support membership in multiple communities of practice within an institution, which develops a sense of belonging within key communities of practice and the institution as a whole. This sense of belonging contributes to students' desire to persist and graduate. However, negative engagement experiences could prompt resistance or rejection to communities of practice and/or its members, leading to a sense of alienation from these social communities and perhaps to the institution as well. This sense of alienation is a contributing factor to student attrition. Applying an engagement theoretical framework to Hispanic Generation 1.5 students by exploring their engagement and membership experiences in a specific community college would yield information on their positive and negative engagement and membership experiences and how they perceive that these experiences affect their persistence, retention, and general academic success.

Summary

Amidst the challenging and changing landscape of students and colleges across the United States, Hispanic Generation 1.5 students come to our institutions with a new set of engagement and membership experiences and practices. Engagement has been found to be a key indicator of student success as measured by associate's degree 
completion in 3 years with alienation as a possible indicator of student attrition.

Engagement contributes to students' sense of belonging in the institution, which positively affects students' commitment to their institution, program, and educational goals. This sense of belonging comes from membership in communities of practice and a community college is a constellation of related communities with shared characteristics.

While engagement, belonging, membership, and alienation have been studied and reviewed in relation to certain student groups, Generation 1.5 students have been ignored in almost all of this research. With a growing Generation 1.5 population and the rapid increase in the Hispanic population as well, Hispanic Generation 1.5 students' engagement and membership experiences should be explored in order to enhance current and future Generation 1.5 engagement and membership research. This research is also necessary for the development of appropriate engagement-enhancing opportunities and transitional activities that will help this population of students become members of various communities of practice and find more ease in moving among different CoPs. Because a significant number of Hispanic Generation 1.5 students assess into ESL in community colleges, this study focused on ESL and post-ESL Hispanic Generation 1.5 students' engagement and membership experiences in a Massachusetts community college. The following chapter describes the study participants and explains the data collection and analysis methods for this study at Commonwealth of Massachusetts Community College. 


\section{CHAPTER III}

\section{METHODS}

I developed this project out of my concern for the academic success of Hispanic Generation 1.5 students in higher education settings, and I was most concerned about those Generation 1.5 students who began their college experience in ESL courses. As a teacher in New York and Massachusetts, I observed the engagement opportunities and challenges that this population faced first in the ESL courses, then in the developmental program, and finally in the mainstream degree-granting programs. The challenges were perplexing because many of these students had attended middle school and high school in the local area.

I completed this dissertation because I wanted to understand Hispanic Generation 1.5 English language learners' engagement and membership struggles and successes as they maneuvered their way through the different facets of their higher education journeys. I completed this study in hopes of identifying those struggles and successes among the Hispanic Generation 1.5 English language learners, clarifying the common characteristics of this group, and identifying some success strategies for the institution. With limited resources and research, I looked to theories of engagement and belongingness to help me start forming questions and searching for answers. Since retention and graduation are common key measures of student success, I wanted to explore these students' engagement and membership experiences and how they perceived that these experiences related to their retention and academic success. 


\section{Research Questions}

This study was designed with one principle research question based on the conceptual framework, which was broken down into various sub-questions that could address the various components of Hispanic Generation 1.5 English language learners' engagement and membership experiences at a Massachusetts community college. The main research question guiding the study was

- What are Hispanic Generation 1.5 students' engagement and membership experiences in a Massachusetts' community college?

The research sub-questions were

- Who are the Hispanic Generation 1.5 Students at Commonwealth of Massachusetts Community College (CMCC)?

- What are these Hispanic Generation 1.5 students' social and academic engagement experiences while completing their (a) ESL coursework, (b) developmental coursework, and (c) credit-bearing coursework at Commonwealth of Massachusetts Community College?

- What are the similarities and differences in the social and academic engagement experiences for these students within the three levels of coursework: (a) ESL, (b)developmental, and (c) credit-bearing in Commonwealth of Massachusetts Community College?

- How do ESL and post-ESL Hispanic Generation 1.5 students perceive these engagement experiences in relation to their persistence, retention, and overall academic success at the college? 


\section{Research Design}

This study sought to explore and describe Hispanic Generation 1.5 students' engagement and membership experiences in a Massachusetts community college. The scope of the study was limited purposely by using the conceptual framework of engagement and membership in communities of practice in order to establish case study boundaries. With description of this population's lived experiences as the goal of this study, I used naturalistic inquiry within a descriptive embedded single case study approach with theory guiding the extensiveness and intensiveness of the case being described (Yin, 2003a, 2003b). The case was Hispanic Generation 1.5 students' at Commonwealth of Massachusetts Community College.

Case studies can approach the overall research agenda differently based on the foundational definition of case studies employed by the researcher. According to Creswell (1998), “a case study is an exploration of a 'bounded system' or a case (or multiple cases) over time through detailed, in-depth data collection involving multiple sources of information rich in context" (p. 61). The case or system can be bounded by time, place, theory, event, or common lived experience (Creswell, 1998; Yin, 2003a; 2003b). Binding a case study is a necessary procedure that sets up boundaries so that the data collection and analysis processes do not become cumbersome and possibly infinite.

Yin defines the case study as:

An empirical inquiry that investigates a contemporary phenomenon within its real-life context, especially when the boundaries between phenomenon and context are not clearly evident.... The case study inquiry copes with the technically distinctive situation in which there will be many more variables of interest than data points, and as one result relies on multiple sources of evidence, 
with data needing to converge in a triangulating fashion, and as another result benefits from the prior development of theoretical propositions to guide data collection and analysis. (2003a, pp. 13-14).

His definition of a case study can incorporate quantitative, qualitative, or mixed methods research. This study employed a naturalistic qualitative approach with an embedded case study research design bound by theory and population.

Embedded case studies utilize multiple units of analysis (Yin 2003a; 2003b). An embedded case study approach was employed because of the complexity and variations in engagement and membership opportunities and experiences at the different levels and programs of an institution. In other words, the engagement and membership opportunities might be different in ESL courses than they are in developmental or in credit-bearing/mainstream courses. The three units of analysis for this descriptive single case study were the engagement and membership experiences of Hispanic Generation 1.5 students:

1. In ESL courses,

2. In developmental courses after having completed ESL courses,

3. In credit-bearing courses after having completed ESL and developmental courses. Qualitative research is an appropriate approach for exploratory research, and naturalism offers the opportunity to explore and describe participants' lived experiences within their environments. The naturalistic approach assumes that "The meaningful features of everyday life consist of participants' orientations to, and actions within, this world as they purposefully manage their realities" (Gubrium \& Holstein, 1997, p. 19).Therefore, this descriptive embedded case study was guided by naturalistic inquiry, which can help with the discovery and description of the essence or meaning of the 
engagement and membership experiences of the Hispanic Generation 1.5 students in Commonwealth of Massachusetts Community College. To protect the identity of the students and the institutions, pseudonyms are used throughout this dissertation for the names of people, cities, and colleges.

\section{Research Site}

Commonwealth of Massachusetts Community College (CMCC) is an emerging Hispanic-serving Institution (HSI) in the Massachusetts community college system. The college serves over 8,000 students a year, with nearly 4,000 full-time students. In the fall 2006 semester, CMCC had a headcount of 6361, a Fall 2006 FTE of 3600, and a minority enrollment percentage of $28.1 \%$, which was higher than the minority population enrollment in the primary student population region (Massachusetts Performance Report, 2007). Part-time students account for $64 \%$ of the student population, and $65 \%$ of the students are female. The largest minority group at CMCC is the Hispanic population, which accounted for $20 \%$ of the students in 2007 . $66 \%$ of the students were White, $2 \%$ Black or African-American, 2\% Asian, and 9\% other (CCSSE, 2009).

The college has two campuses in Massachusetts: the main campus in Hawthorne, and the Lincoln campus in Lincoln. The college offers over 70 programs with a range of offerings among the various campuses. The developmental studies department houses Adult literacy or Adult Basic Education (ABE), ESL, developmental writing, developmental reading, and developmental math as well as a variety of learning centers and labs including the Writing Center, the Reading Center, Math Center, and English 
Language Center, all of which are on the main campus in Hawthorne and Lincoln campus in Lincoln.

The ESL curriculum at CMCC ranges from level one to level four with a fifth advanced level, all of which equal 18 courses and 87 credits, 72 of which do not count towards a certificate or associates degree. The fifth level courses (i.e., Advanced Integrated Writing Skills for 6 credits and Advanced Integrated Reading Skills for 9 credits) are the only courses in the program that offer degree credits to be used in lieu of electives or language course requirements. The developmental reading program has two courses: Basic Reading and College Reading, and the developmental writing program has two courses: Introduction to Basic Writing and Basic Writing. None of the credits offered in the developmental programs may be used towards a certificate or associates degree. Figure 2 demonstrates the relationship and order among the ESL, developmental reading and writing courses, and the credit-bearing writing course.

At the time of the study, a new course had been developed and implemented by the ESL faculty under the developmental writing criteria. Since the course was developed by the ESL faculty for Generation 1.5 students who would otherwise assess into ESL Writing 4, this course was included as part of the ESL courses when looking at ESL student placement at CMCC. However, in terms of student course progression, the new course is listed before Introduction to Basic Writing as an ESL course within the developmental coursework designation because students take English Writing Skills prior to developmental writing or freshmen composition courses. 


\begin{tabular}{|c|c|c|c|}
\hline \multicolumn{2}{|c|}{$\begin{array}{c}\text { Grammar and Writing } \\
\text { Coursework }\end{array}$} & \multicolumn{2}{|c|}{$\begin{array}{l}\text { Reading and Oral Communication } \\
\text { Coursework }\end{array}$} \\
\hline $\begin{array}{l}\text { ESL Grammar } 1 \\
\text { (ESL) }\end{array}$ & $\begin{array}{l}\text { Writing } 1 \\
\text { (ESL) }\end{array}$ & $\begin{array}{l}\text { Reading } 1 \\
\text { (ESL) }\end{array}$ & $\begin{array}{l}\text { Listening/Speaking } 1 \\
\text { (ESL) }\end{array}$ \\
\hline $\begin{array}{l}\text { ESL Grammar } 2 \\
\text { (ESL) }\end{array}$ & $\begin{array}{l}\text { Writing } 2 \\
\text { (ESL) }\end{array}$ & $\begin{array}{l}\text { Reading } 2 \\
\text { (ESL) }\end{array}$ & $\begin{array}{c}\text { Listening/Speaking } 2 \\
\text { (ESL) }\end{array}$ \\
\hline $\begin{array}{l}\text { ESL Grammar } 3 \\
\text { (ESL) }\end{array}$ & $\begin{array}{l}\text { Writing } 3 \\
\text { (ESL) }\end{array}$ & $\begin{array}{c}\text { Reading } 3 \\
\text { (ESL) }\end{array}$ & $\begin{array}{l}\text { Listening/Speaking } 3 \\
\text { (ESL) }\end{array}$ \\
\hline $\begin{array}{l}\text { ESL Grammar } 4 \\
\text { (ESL) }\end{array}$ & $\begin{array}{l}\text { Writing } 4 \\
\text { (ESL) }\end{array}$ & $\begin{array}{l}\text { Reading } 4 \\
\text { (ESL) }\end{array}$ & $\begin{array}{c}\text { Listening/Speaking } 4 \\
\text { (ESL) }\end{array}$ \\
\hline $\begin{array}{l}\text { Advanced Integ } \\
(\mathrm{ESL} / \mathrm{cr}\end{array}$ & $\begin{array}{l}\text { riting Skills } \\
\text { ing) }\end{array}$ & $\begin{array}{r}\text { Advanced I } \\
\text { (ES }\end{array}$ & $\begin{array}{l}\text { ted Reading Skills } \\
\text { lit-bearing) }\end{array}$ \\
\hline \multicolumn{4}{|c|}{$\begin{array}{l}\text { English Writing Skills } \\
\text { (ESL/developmental) }\end{array}$} \\
\hline $\begin{array}{r}\text { Introduction } \\
\text { (deve }\end{array}$ & $\begin{array}{l}\text { Writing } \\
\text { l) }\end{array}$ & \multicolumn{2}{|c|}{$\begin{array}{l}\text { Basic Reading } \\
\text { (developmental) }\end{array}$} \\
\hline $\begin{aligned} \text { Basi } \\
(\text { devel }\end{aligned}$ & & \multirow{2}{*}{\multicolumn{2}{|c|}{$\begin{array}{l}\text { College Reading } \\
\text { (developmental) }\end{array}$}} \\
\hline $\begin{array}{l}\text { Freshmen } \\
\text { (credi }\end{array}$ & $\begin{array}{l}\text { ition I } \\
\text { g) }\end{array}$ & & \\
\hline $\begin{array}{l}\text { Freshmen } \\
\quad \text { (credi }\end{array}$ & $\begin{array}{l}\text { ition II } \\
g)\end{array}$ & & \\
\hline
\end{tabular}

Figure 2. ESL, developmental and freshmen writing course progression at Commonwealth of Massachusetts Community College.

According to the Massachusetts Performance Report (2007), the mission of the college is to:

serve the people of the greater Monroe Valley as a caring and comprehensive center of educational excellence that offers high-quality, affordable adult and post-secondary education through the associate's degree level, as well as a broad 
range of occupational programs and community services which enhance the social, cultural and economic life of the region.

As part of its core values, CMCC supports student engagement, collaboration, personal and professional growth, respect, diversity, access and opportunity, and excellence. Engagement is listed as the first Core Value of the institution, which states, "We are committed to fully engaging our students as active learners by providing a diverse range of educational experiences" (Commonwealth of Massachusetts Community College, 2009). With this framework and core value of engagement, CMCC has continuously developed engagement-enhancing opportunities including learning communities and community service projects.Individual faculty members and staff have developed engagement opportunities in order to get specific student populations engaged at the college such as a Hispanic book club on the Lincoln campus.

Commonwealth of Massachusetts Community College participated in the 2007 CCSSE study. They participated in 2009 and are scheduled to participate again in 2011. However, out of the 2007 results, the college has already begun modifying engagementenhancing opportunities to increase overall student engagement. Some changes based on the 2007 results include partnering with high schools to help high school graduates be better prepared for college work, improving student advising, and using or increasing the use of theme-based learning, service-learning, and learning communities (Greenslade, 2008). The college also developed the Student Engagement Center in order to provide students with well-rounded civic, social, and academic engagement experiences (Student Engagement Center brochure, n.d.). The center houses the student clubs and 
organizations and the leadership programs, and it implements various student activities on both campuses throughout the year.

The associate dean of developmental studies was approached upon approval of the proposal to serve as the initial gatekeeper for this institution. She helped me obtain the necessary permissions at the college so that I could complete the study, and she pointed me to the appropriate people for various aspects of the study including the college's Institutional Research Board (IRB) process and individuals who could provide valuable information on the Hispanic Generation 1.5 population during my time at the research site. I completed the IRB approval process in the summer of 2009 and the Memorandum of Understanding (MOU) development and approval process in September 2009.

Once the IRB and MOU were approved, I developed selection criteria for the dean of research and planning to conduct data queries and identify potential participants. The dean of research and planning provided a list of possible participants based on the dissertation selection criteria. Using that institutional research list, the interim ESL coordinator and the English Language Center coordinator assisted in reaching the participants. They also served as onsite gatekeepers, identifying faculty and staff for the informal interviews and providing valuable information about the college, the ESL curriculum, and the Hispanic Generation 1.5 population.ESL faculty, staff, and administrators haveextensive knowledge of the Hispanic Generation 1.5 student population, and, therefore, werecontacted throughout this study. For compensation, the college and the program were given an extensive report of the results for its institution 
based on all data collection methods. At the end of the entire study, the college gatekeeper received copies of the finished dissertation.

\section{Research Participants}

All research participants were current or past students of the college who permanently immigrated to the United States during their adolescent or teenage years, and theygraduated from high school in the United States.All students recruited for the study took or were enrolled in at least one ESL course.The participants were students who were either enrolled at the college at the time of the study or had graduated from the college in the last few years.

The student-participants for the interviews were recruited with the help of the Associate Dean of Developmental Studies who assisted with the initiation of the study at the research site and coordinated the student recruitment efforts at the community college. The college's institutional research office provided a list of students who fit the participant criteria to the English Language Center coordinator and the ESL curriculum coordinator, who called the students to see if they were interested in participating in the study. The English Language Center coordinator then emailed me the list of interested students with their phone numbers so that I could talk with them about the study and schedule an interview time. Because of the nature of this population and the number of challenges in taking time out from school, work and family responsibilities, participants were compensated in two different ways. First, at the start of the interview session, they were provided with food options based on the time of day (e.g., sandwiches, snack 
plates,or pizza). Second, participants were provided with a $\$ 10$ gift card. Currently enrolled students were given a gift card to the college's bookstore, which they could apply to the purchase of books, supplies, or even snacks. Program completers were given a gift card to a large department store, which was near the school and offered a greater selection of products.

\section{Data Collection}

For this descriptive case study, interviewswith Hispanic Generation 1.5 students werethe main source of data. This source of data came from naturalistic inquiry techniques in order to paint a picture of engagement and membership experiences from the students' perceptions of their lived engagement experiences. Since descriptive case study research incorporates multiple sources of data (Yin,2003a, 2003b), other sources of data included (a) documents from the college such as, newspaper clippings, and official institutional reports; (b)unstructured interviews with ESL and non-ESL faculty and staff; (c) archival records such as those found on the college's web site; and (d)observations of students' engagement and membership practices outside of classes in gathering areas such as tutoring centers, lounges, and cafeterias. These additional sources of data assisted in the analysis of the student interview data and provided more information about the Hispanic Generation 1.5 students' daily engagement experiences at the community college. 


\section{Unstructured Interviews with Key Employees}

Throughout the study, especially during the preliminary stages of data collection, key staff, faculty, and administratorsin ESL, developmental, and degree-granting programs were identified and approached at the research site for informal unstructured interviews about theirHispanic Generation 1.5 students and the engagement opportunities at the community college.These interview questions varied, depending on the position of the participant, the area of work or instruction, and the role that the participant played in student engagement and membership at the college.These unstructured interviews were conducted in person and supplemented with telephone and email conversations when necessary. Data were documented on a contact summary sheet (see Appendix G). I attempted to use the data from these informal interviews to paint an initial picture of the school culture and the institution's perceptions and approach to admitting, assessing, and educating Hispanic Generation 1.5 students. These interviews assisted with developing and structuring the interviews for the special population of Hispanic Generation 1.5 students found in that particular institution.

\section{Documents and Archival Records}

School documents, such as graduation rates and retention reports were collected and analyzed for this specific population of students. Some archival records included in the data collection were survey data, institutional reports, and publications about the institution, most of which are available on the college's website. All the preliminary data gathered through the document analysis helped me, as the researcher, become better acquainted with the institution prior to the interview data collection. 
Unstructured Interviews with CMCC Students

I spent at least 8-11 hours a day Monday through Thursday and at least 6-8 hours on Fridays at CMCC during the data collection phase. During that time, I interacted with the students in the academic support centers, cafeterias, lounges, and student services areas. Field notes were maintained throughout each day and these interactions were noted. Whenever possible, I completed unstructured interviews with Hispanic students at CMCC. The interview questions varied, depending on the students and their experiences at the college. For example, some students were completing their first semester at the college and were only taking ESL courses, so their unstructured interview questions focused on their engagement experiences in their current ESL courses with their teachers and peers as well as their perceptions of those experiences. Some participants had been at the college for a couple of years and might have worked at the college as well. Their questions focused more on their overall engagement experiences at the different levels and areas of the school as well as their perceptions of Hispanic Generation 1.5 students at the college.

Interviews with Current and Former ESL Students

The main source of data for this case study was interviews with current and former CMCC students who were Hispanic Generation 1.5 English language learners. I interviewed 16 participants who were enrolled in ESL courses or had completed the required ESL courses. During the data collection phase, the participants who had completed their ESL coursework were enrolled in non-ESL courses (developmental or credit-bearing) or had graduated from CMCC with an associate's degree. The interview 
participants had to have graduated from a U.S. high school, assessed into ESL at CMCC, and completed at least one ESL course by the end of the Fall 2009 semester.A student information checklist (see Appendix B) was filled out for all the student participants in order to make sure that they fit the research criteria at the beginning of each interview.

The original participant criteria stated that potential participants must have been born in a foreign country. However, with this study, I had to expand that definition because many of the potential participants and three of the study participants were born in the United States, providing them with American citizenship. These participants were raised and educated in the Dominican Republic, which they perceived as their home country, and they did not have any memories of life in the U.S. until they immigrated as adolescents or teenagers.

I used a semi-structured responsive interviewing technique with an interview guide composed of main questions, and I supplemented those questions as needed using probing questions (Bogdan \& Biklen, 2003; Rubin \& Rubin, 2005). Some types of probing questions included continuation probes (e.g., “And then?”) and elaboration probes (e.g., “Could you give me an example?”) as described by Rubin and Rubin (2005). The interview guide focused the interview discussions on the lived engagement and membership experiences of Hispanic Generation 1.5 students who first began their college coursework in the ESL courses. The purpose of this semi-structured technique was to allow the interviewer and interviewee to go off on related tangents or in a more natural discussion pattern that could help paint a whole picture of the experience and overall phenomenon. Having interview guides with common main interview questions (see Appendix C, D, E, and F) allowed me to collect comparable data across the participants 
regardless of their academic status at the time of the interview. The interview guide was designed within the conceptual framework of engagement as part of membership in communities of practice since the framework is being used to determine the extensiveness, intensiveness and general boundaries of the case study (Yin, 2003b). Binding this case study with theoretical and population boundaries helped prevent data collection and analysis processes from becoming too cumbersome and possibly too vast for completion. The boundaries kept me on task and focused on the research questions.

Using a responsive interviewing approach, I formed a conversational partnership with the participants, emphasizing the cooperative nature of our relationship as we worked together to find a shared meaning of the engagement and membership experiences of this population (Rubin \& Rubin, 2005). I held most interviews on campus in small conference rooms, student gathering areas such as the Lincoln student lobby, or in the main academic support area. Some of the participants had time and transportation constraints; therefore, one interview was held at the participant's home and another one was conducted over the phone. All the interviews were audio-taped with two digital recorders for accuracy and the interviews lasted60-120 minutes. The interview length variance was based mostly on the language of the interview (i.e., Spanish or English), and the participants' listening and speaking skills for the language used throughout the interview.

I personally transcribed all the English and Spanish interviews in Microsoft Word because, as a researcher and active learner, I find the transcription process to be an initial and critical avenue for me to enter the lived world of my participants. I maintained journal notes throughout the transcription process, taking time to reflect and acknowledge 
my subjectivity and possible emerging themes or codes. The Spanish interviews were not translated. I worked with the English and Spanish interviews in their original language and form throughout the data coding, data analysis, and drafting of the dissertation as a measure of data integrity. The quotes within the dissertation chapters were then translated with the assistance of local professionals who completed their K-12 schooling in the Dominican Republic and attended college in the Dominican Republic as well.

\section{Data Analysis}

All interview data were analyzed first through an open coding approach within the conceptual framework of engagement and membership in communities of practice. Coding helps a researcher organize the data, break it down into manageable units, and search for themes and patterns (Bogdan \& Biklen, 2003; Rubin \& Rubin, 2005).Through open coding, the researcher constructs categories or themes of the phenomenon being studied, and through continuous and sometimes several rounds of coding, the researcher forms subcategories or sub-themes for each of the larger themes in the data (Creswell, 1998). An inductive content analysis approach was used to develop the coding map of broad concepts, themes within those concepts, and codes within those themes. According to Patton (2002), "content analysis is used to refer to any qualitative data reduction and sense-making effort that takes a volume of qualitative material and attempts to identify core consistencies and meanings" (p. 453). The emerging themes in the data were the core consistencies, and these themes were organized into broader concepts for easier data management and analysis. 
Coding is not a linear process, but from the open coding, I was able develop a flexible coding map to be used for the final coding and analysis of all the transcript data. I also usedthis coding process for archival records, documents, reports, and contact summary sheets. All coding, except for interview coding, was done by hand using a pencil to write the codes along the document margins. Interview coding wasaccomplished in the computer, using Microsoft Excel to make the data more manageable and to make relevant themes, codes, and data more easily accessible later on in the analysis and interpretation processes by using the filter function within Excel (see Appendix I).In order to code in Excel, the Microsoft Word transcripts were divided up within a table by lines or complete utterances. One table row was devoted to each complete utterance for one speaker. Dividing up the transcript by complete sentence or utterance made the coding process simpler and more flexible, allowing me to code for the multiple units of analysis with double and triple coding of individual utterances if necessary.

For the first round of coding, I typed emerging themes and researcher notes in cells adjacent to the actual transcript lines following the conceptual framework of engagement and membership in communities of practice and focusing on engagement experiences at CMCC. For the second round or level of coding, I pulled out some codes and emerging themes and assigned the codes and themes to the transcript lines within new columns in the Excel spreadsheet. Using this initial coding process, a coding map was developed with themes and codes organized under specific concepts, including engagement with peers, engagement with faculty, and engagement with staff (see Appendix H). 
Using this final coding map, each participant's sentence or utterance was coded for a third time for concept, theme, and code. As an embedded descriptive case study, the interview data had to include additional coding to allow for the analysis of data by unit of analysis. A unit of analysis column was added to the Excel spreadsheet and each participant interview line was coded as being: (a) $\boldsymbol{E} \boldsymbol{S} \boldsymbol{L}$ for engagement experiences during ESL coursework, (b) developmental for engagement experiences during developmental coursework, (c) credit for engagement experiences during credit coursework, (d) all for engagement experiences throughout the general CMCC experience, (e) $\boldsymbol{H} \boldsymbol{S}$ for high school engagement experiences that could affect college engagement, and (f) $\boldsymbol{K}-\boldsymbol{8}$ for pre-high school engagement experiences that could affect college engagement. The data were analyzed for individual concepts, themes, codes, and units of analysis using the filter options in Excel. All data were coded and analyzed in the original language used by the participants (i.e., English or Spanish).

The interview data were translated only after the interview quotes were integrated with the text of this dissertation. The inserted quotes were then edited to allow for readers to understand the spoken text with more ease. First, speech disfluencies (e.g., repeated syllables, repeated phrases) and filled pauses (e.g., um, like) were eliminated from the text if they potentially interrupted the reader's ability to understand the interviewee's meaning. In the interview quotes, an ellipsis represents text that was cut out from the quote for consistency and clarity. Abandoned utterances (i.e., incomplete thoughts) have a dash after the last word of that abandoned utterance. 


\section{Limitations}

There were several limitations to this study. First, I attempted to recruit Hispanic Generation 1.5 English language learners who started their coursework in ESL but had withdrawn from the institution. However, I was unable to obtain the necessary data for the ELC and ESL coordinators to identify and contact these former students. Another

limitation is that only 10 Hispanic Generation 1.5 participants were interviewed. A larger sample would have been ideal for a higher level of trustworthiness of the data as well as for additional examples and explanations of certain themes that emerged from the data.

\section{Trustworthiness}

Some researchers use quantitative or post-positivist terms such as reliability and validity to discuss trustworthiness in qualitative research. Yin (2003a) proposes case study tactics for construct, internal, and external validity as well as reliability. Others propose four criteria for trustworthiness: credibility, transferability, dependability, and confirmability (Erlandson, Harris, Skipper, \& Allen, 1993; Lincoln \& Guba, 1985; Schwandt, 2001). Newman and Benz (1998) use validity and legitimation as the way to get to truth value. My trustworthiness measures took all of these terms and definitions into account.

\section{Credibility}

In this study, credibility was addressed as being similar to internal validity or "truth value" (Newman \& Benz, 1998). Since qualitative research within the paradigm of 
constructivism does not assume that there is an objective truth, the relationship between the data collected and the phenomenon that the data represent is established through credibility methods (Erlandson et al., 1993). I attempted to establish credibility through prolonged engagement at the site, member checking through the sharing of transcripts and findings with participants and gatekeepers and triangulation.

Prolonged engagement. During the data collection period, I observed student activities in the advising and career services centers, tutoring centers, and general gathering areas such as cafeterias and building lobbies on both the main campus and the Lincoln campus. Whenever possible, I interacted with students and asked them about their engagement experiences at the college. Using a research journal, field notes, and contact summary sheets (see Appendix G), I documented data from these observations and interactions to assist with data analysis. This process showed me the extent of Hispanic Generation 1.5 student involvement and engagement with faculty, staff, and peers in various areas of the institution. The information obtained from the prolonged engagement and field notes helped me develop questionsfor the faculty and staff at the college concerning the students' engagement experiences and led to follow-up questions to augment the main questions in my interview guides for the study participants.

Peer review. To step out of the research context and reflect on the data and overall study, I worked with my dissertation writing group, composed of fellow doctoral students, as well as my research site gatekeepers, all of whom have been working in the field for many years as faculty, staff, and administrators. I documented all peer review 
conversations, meetings, and relevant interactions in the researcher journal so that I could review the information when necessary. In the peer review process, my writing group provided feedback on my data collection and analysis techniques. For example, my peers offered suggestions on how to code and analyze for multiple units of analysis in a more efficient manner, and they introduced the use of Excel and Access for such a task.

After some discussions and lessons on how to use both programs, I chose to use Excel for my data coding and analysis because it allowed for the coding features that I needed including double and triple coding and proved easier to use for data management and organization, including the ability to filter down to individual categories, themes, and codes. Afterwards, some of my doctoral peers provided suggestions on how to organize my transcript data for optimal analysis of coded data within Excel. They provided suggestions on how to organize my columns for the best use of the filtering function so that I could manage the data in manner that allowed me to answer my research questions.

Member checking. As part of the member-checking process, the transcribed interviews were emailed to the participants, and I asked the interview participants to check the manuscripts for accuracy and to reflect upon their responses. Even though I removed identifiers from the manuscripts, there might have been some parts that the participants viewed as too distinguishable, and they had an opportunity to ask for those additional identifiers to be removed. Only one participant responded to my emails or phone calls after the data collection process, and none of the participants chose to comment on the transcripts.I had hoped to share the findings with the participants in follow-up interviews or focus groups in order to see how my representations of the 
participants' realities relate to their perceived realities, but I was unable to schedule follow-up interviews. Some participants did not answer my calls or emails, and others could no longer be located with the contact information I had used for the interviewing process.

Since I was unable to successfully complete the member-checking process, I chose to incorporate expert review throughout the study. I shared the data findings and interpretations with the faculty and staff who were part of the case study and who workedwith this student population on a daily basis. The faculty and staff shared their opinions about the data and their experiences working with Hispanic Generation 1.5 students. They compared their engagement experiences with the students to some of the findings, and they shared the various ways in which they engaged their students inside and outside of the classroom. The faculty and staff described the different types of engagement opportunities that they saw their students experience. Their feedback helped me see the data from different angles and perspectives and provided connections between the students' descriptions of their engagement experiences and the intended engagement opportunities offered by the faculty and staff mentioned in the interviews. The additional data informed my final analysis and interpretation while ensuring credibility.

Triangulation. While data was primarily collected through interviews with Hispanic Generation 1.5 students, other data collection methods were employed such as document analysis, observations at the research site, and unstructured interviews with key staff and faculty who had been involved with this population's engagement at the college. These data collection activities and the actual data were documented on the contact 
summary sheet (see Appendix H). The additional types of data helped me fill in some of the gaps from the participant interviews. For example, in order to understand the participants' described experiences with a faculty member, I would turn to the notes from my unstructured interview with that faculty to understand the engagement opportunities presented to the students by that instructor. Making these connections across the different types of data helped me fill in many information gaps and paint a fuller picture of the Hispanic Generation 1.5 students' engagement experiences at the college.

In addition, six other current and former students were interviewed using the same interview questions that were used with the Hispanic Generation 1.5 participants. The six interviewees were organized into three groups: two first Generation Dominicans, two second Generation students (one Dominican student and one Cambodian student), and two Haitian Generation 1.5 students. The data from these six interviews were used for data triangulation purposes and helped with the examination of the Hispanic Generation 1.5 participant data from different perspectives.

\section{Transferability}

While generalizability to larger samples or populations was not the ultimate goal of this study, applicability to other similar situations is possible especially with descriptive case study design, which aims to paint a full picture of the phenomenon. According to Erlandson et al.(1993), naturalistic research does not assume that the information obtained from one case or qualitative study will have no relevance for other situations. There might be shared characteristics among cases or situations, which allow for transferability, a term that is parallel to external validity (Yin, 2003a). To enhance 
transferability, I tried to use rich, thick descriptions of the data, including many interview quotes, to paint as full a picture of the phenomenon as possible.

With a fuller picture of the phenomenon, readers may find applicability of the case study findings for situations that they experience, which is known as reader or user generalizability. Corbin and Strauss (1990) explain that with this form of generalizability readers must decide what aspects of the findings apply to their situations or contexts and what aspects of the study should guide the reader in practice or research. Stake (2000) signifies this type of generalization as naturalistic generalization which is "arrived at by recognizing the similarities of objects and issues in and out of context and by sensing the natural covariations of happenings" (p. 22). Readers can take the findings and conclusions within the framework of the research study and make comparisons with situations within their own lives, which is the process of making naturalistic generalizations (Stake, 2000).

\section{Dependability}

Dependability is similar to the notions of reliability and replicability where the researcher completes and writes-up the study in a form that allows other researchers to replicate it (Yin, 2003a). To enhance dependability, I kept a researcher's calendar and journal in which daily work on the study was documented, including reflections during the transcription, coding, and analysis processes. In addition, I created an audit trail, which isan organized and well-documented collection of materials (Schwandt, 2001) using the contact summary sheets. The dissertation includes all data collection procedures, sample coding, coding maps, sample transcripts, and all documents used for 
data collection including agreement letters, observation and field note documentation protocols (i.e., contact summary sheets), and interview guides.

\section{Confirmability}

Qualitative research cannot be completely free of subjectivity since the researcher is the main instrument for data collection and analysis (Bogdan \& Biklen, 2003;

Erlandson et al., 1993). Therefore, confirmability is necessary to help verify that the data findings and analysis are not just the researcher's perceptions of the event, but an actual description and/or explanation of the phenomenon from the perception of the people (participants) involved. The audit trail used for dependability was used for confirmability purposes as well. Through the documentation process that took place in my researcher journal and contact summary sheets, I had the opportunity to check my own subjectivity and make sure that I was focused on the actual data that were collected rather than on my own memories or perceptions of that data.

I used the documentation process to manage my own subjectivity not only during the data collection process, but during the data analysis process as well. I took time to acknowledge my role in the study and my personal opinions, experiences, and assumptions with various aspects of the study including the school, population, region, and curriculum. I wanted to acknowledge my opinions, experiences, and assumptions early in the study so that they would not cloud my judgment while collecting, managing, coding, and analyzing my data. For example, I have always valued peer engagement because it was the most critical factor in my own retention during my first year in college. During my first semester in college, I was part of a learning community in 
which all students took all courses together with the same instructors, and the peer engagement through this learning community experience supported my academic success. For this study, I acknowledged my experience and perspective on peer engagement in order to focus on what the study data revealed. Recognizing my own subjectivity during each part of the research process helped me explore my participants' perceptions of the phenomenon of Hispanic Generation 1.5 student engagement at the college rather than my own perceptions of that phenomenon.

\section{Summary}

This chapter explained the research methods for this study on Hispanic Generation 1.5 English language learners' engagement and membership experiences in a Massachusetts community college. The research design was a descriptive embedded case study with three unit of analysis, which incorporated a naturalistic inquiry approach with interviews as the main source of data. The research site and participants were described. Finally, all data collection methods, data analysis techniques, and trustworthiness measures were explained in detail. The next five chapters present the findings of the study, followed by a discussion of the findings. 


\section{CHAPTER IV}

\section{STUDY PARTICIPANTS}

This study focused on the engagement and membership experiences of Hispanic Generation 1.5 students at a Massachusetts community college. The dissertation findings are divided up into five chapters. The purpose of this chapter is to describe the Hispanic Generation 1.5 population at Commonwealth of Massachusetts Community College (CMCC). First, an overview of the participants is provided along with a description of their immigration patterns and language characteristics. Then, the participants' initial experiences at $\mathrm{CMCC}$ are described, including their reasons for attending $\mathrm{CMCC}$, their assessment experiences and their perceptions of the ESL placement at the college. The chapter ends with a detailed profile of each of the 10 Hispanic Generation 1.5 participants who participated in the semi-structured interviews during the study.

\section{Overview of Participants}

Hispanic generation 1.5 students were identified by the Office of Institutional Research and contacted by the Developmental Studies Department for participation in the study.Of those potential participants, I interviewed 10 individuals (see Table 1) who fit the profile of Hispanic Generation 1.5 because:

- Their first language is Spanish.;

- They attended school in their home country (the Dominican Republic); 
- They immigrated to the United States during their middle school or high school years; and

- They graduated from a U.S. high school.

To protect the identity of the interviewee participants, the participants' names were not used during the audiotaping of the interviews. Participants were asked to create a pseudonym at the beginning of the interview. If they could not come up with a pseudonym, the researcher created one and presented that pseudonym to the participant for approval before continuing with the interview.

I interviewed other participants during this study whose first language was not English:one Hispanic second generation student, one Asian second generation student, two Hispanic first generation graduates, and two Haitian Generation 1.5 students (see Table 2).These additional participants provide valuable contrast data from multiple angles for this study.However, since the purpose of this dissertation was to describe Hispanic Generation 1.5 students' engagement and membership experiences at a Massachusetts community college, this chapter will focus only on the 10 participants who fit the Hispanic Generation 1.5 profile and use other findings only for contrasting or comparison purposes.

Generation 1.5 students do not go unnoticed at CMCC. Many faculty and staff members refer to this group of students as "the bilinguals" and realize that these students have different needs than first generation and second generation immigrants, especially in terms of writing and sometimes reading comprehension. The key concern for Hispanic Generation 1.5 students is grammar or the ability to express ideas in a written format 
Table 1.

Summary of 10 Study Participants Who Fit the Original Criteria

\begin{tabular}{|c|c|c|c|c|c|c|c|}
\hline Participant & $\begin{array}{c}\text { Immigration } \\
\text { Age }\end{array}$ & $\begin{array}{c}\text { Interview } \\
\text { Age }\end{array}$ & $\begin{array}{l}\text { Grade } \\
\text { started } \\
\text { in U.S. }\end{array}$ & $\begin{array}{c}\text { Years } \\
\text { in U.S. } \\
\text { Schools }\end{array}$ & $\begin{array}{c}\text { Home } \\
\text { Language }\end{array}$ & $\begin{array}{l}\text { PublicLan } \\
\text { guage }\end{array}$ & $\begin{array}{l}\text { College } \\
\text { Level }\end{array}$ \\
\hline Anthony & 13 & 19 & $7^{\text {th }}$ & $4 \frac{1}{2}$ & $\begin{array}{l}\text { Spanish } \\
\text { and } \\
\text { English }\end{array}$ & English & $\begin{array}{l}\text { Graduated } \\
\text { Completer }\end{array}$ \\
\hline Aracelis & 17 & 32 & $11^{\text {th }}$ & 2 & Spanish & $\begin{array}{l}\text { Spanish } \\
\text { and } \\
\text { English }\end{array}$ & ESL \\
\hline Awilda & 17 & 22 & $12^{\text {th }}$ & $1 \frac{1 / 2}{2}$ & Spanish & $\begin{array}{l}\text { Spanish } \\
\text { and } \\
\text { English }\end{array}$ & ESL \\
\hline Carlos & 15 & 21 & $11^{\text {th }}$ & 2 & Spanish & Spanish & ESL \\
\hline G & 9 & 22 & $3^{\text {rd }}$ & 10 & $\begin{array}{l}\text { English } \\
\text { and } \\
\text { Spanish }\end{array}$ & $\begin{array}{l}\text { English } \\
\text { and } \\
\text { Spanish }\end{array}$ & $\begin{array}{l}\text { ESL, DR, } \\
\text { DM, Credit }\end{array}$ \\
\hline Ingrid & 5 & 19 & $8^{\text {th }}$ & 5 & Spanish & Spanish & ESL \\
\hline Juan & 15 & 35 & $8^{\text {th }}$ & 5 & $\begin{array}{l}\text { English } \\
\text { and } \\
\text { Spanish }\end{array}$ & $\begin{array}{l}\text { Spanish } \\
\text { and } \\
\text { English }\end{array}$ & Credit \\
\hline Sara & 14 & 22 & $9^{\text {th }}$ & $31 / 2$ & $\begin{array}{l}\text { Spanish } \\
\text { and } \\
\text { English }\end{array}$ & $\begin{array}{l}\text { Spanish } \\
\text { and } \\
\text { English }\end{array}$ & Credit \\
\hline Stephanie & 14 & 21 & $9^{\text {th }}$ & 4 & Spanish & Spanish & ESL \\
\hline Tomas & 17 & 24 & $12^{\text {th }}$ & 1 & Spanish & $\begin{array}{c}\text { Spanish, } \\
\text { now } \\
\text { English }\end{array}$ & $\begin{array}{l}\text { Graduated } \\
\text { Completer }\end{array}$ \\
\hline
\end{tabular}

Note. ESL refers to all courses developed and taught by the ESL faculty. DR refers to developmental reading courses. DM refers to developmental math courses. Public language refers to the language(s) used in the community and the workplace. College level refers to the interviewee college coursework level or status at the time of the interview. 
Table 2.

Summary of Six Other Interviewees.

\begin{tabular}{cccccccc}
\hline \multirow{2}{*}{ Participant } & $\begin{array}{c}\text { Immigration } \\
\text { Age }\end{array}$ & $\begin{array}{c}\text { Interview } \\
\text { Age }\end{array}$ & $\begin{array}{c}\text { Grade } \\
\text { started } \\
\text { in U.S. }\end{array}$ & $\begin{array}{c}\text { Years } \\
\text { in U.S. } \\
\text { Schools }\end{array}$ & $\begin{array}{c}\text { Home } \\
\text { Language }\end{array}$ & $\begin{array}{c}\text { PublicLan } \\
\text { guage }\end{array}$ & $\begin{array}{c}\text { CollegeLev } \\
\text { el }\end{array}$ \\
\hline
\end{tabular}

Haitian Generation 1.5 Students

$\begin{array}{cccccccc}\text { MJ } & 17 & 18 & \begin{array}{c}11^{\text {th }} \\ \text { grade }\end{array} & 2 & \begin{array}{c}\text { Creole } \\ \text { and } \\ \text { English }\end{array} & \begin{array}{c}\text { Creole } \\ \text { and } \\ \text { English }\end{array} & \text { CR, Credit } \\ \text { Bella } & 16 & 19 & 10^{\text {th }} & 3 & \begin{array}{c}\text { Creole } \\ \text { and } \\ \text { English }\end{array} & \begin{array}{c}\text { Creole } \\ \text { and } \\ \text { English }\end{array} & \begin{array}{c}\text { ESL, DM, } \\ \text { Credit }\end{array}\end{array}$

First Generation Students Placed in ESL

$\begin{array}{cccccccc}\text { Laura } & 22 & 31 & \text { NA } & \text { NA } & \begin{array}{c}\text { Spanish } \\ \text { and } \\ \text { English }\end{array} & \begin{array}{c}\text { Spanish } \\ \text { and } \\ \text { English }\end{array} & \begin{array}{c}\text { Graduated } \\ \text { Completer }\end{array} \\ \text { Yesenia } & 17 & \begin{array}{c}\text { Not } \\ \text { disclosed }\end{array} & \text { NA } & \text { NA } & \begin{array}{c}\text { Spanish } \\ \text { and } \\ \text { English }\end{array} & \begin{array}{c}\text { Spanish } \\ \text { and } \\ \text { English }\end{array} & \begin{array}{c}\text { Graduated } \\ \text { Completer }\end{array}\end{array}$

Second Generation Students Placed in Writing for Generation 1.5 Students (ESL/DEV)

$\begin{array}{cccccccc}\text { Kevin } & \text { Born in U.S. } & 19 & \text { Pre-K } & 14 & \text { English } & \text { English } & \begin{array}{c}\text { ESL, DM, } \\ \text { Credit }\end{array} \\ \text { Jerry } & \text { Born in U.S. } & 18 & \text { Pre-K } & 14 & \begin{array}{c}\text { English } \\ \text { and } \\ \text { Khmer }\end{array} & \begin{array}{c}\text { English } \\ \text { and } \\ \text { Khmer }\end{array} & \begin{array}{c}\text { ESL, DM, } \\ \text { Credit }\end{array}\end{array}$

Note. ESL refers to all courses developed and taught by the ESL faculty. DR refers to developmental reading courses. DM refers to developmental math courses. Public language refers to the language(s) used in the community and the workplace. College level refers to the interviewee college coursework level or placement at the time of the interview. 
using correct sentence structure and grammatical configurations. Therefore, "the bilinguals" are taken into consideration when developing curricula and course lessons mostly in the ESL, Basic Writing, and two composition courses.

The purpose of this study was to describe Generation 1.5 students' engagement and membership experiences at CMCC. A critical part of that process is identifying and defining the Hispanic Generation 1.5 population at CMCC and one of the research questions focuses on this area. The main sources of data used to define this population at CMCC were the Student Information Survey and the interviews which included questions on the participants' U.S. schooling experiences, high school engagement, and daily activities. This chapter describes the Generation 1.5 population at CMCC including background information on the study participants with a focus on immigration patterns and non-scholastic characteristics such as language use and daily activities. When appropriate, the participants are compared to the other groups of students interviewed in order to define Hispanic Generation 1.5 students at CMCC in contrast to these other groups. Finally, this chapter ends with in-depth profiles on each of the student participants who fall within the Hispanic Generation 1.5 criteria used for this study.

\section{Immigration Patterns}

The Student Information Survey and the interviews provided data on the participants' immigration activities, which were used to decide on the profile of the participants. More importantly, the data showed that Hispanic Generation 1.5 students at 
$\mathrm{CMCC}$ have different immigration patterns and different reasons for immigrating to the United States as shown in Table 3.

\section{Table 3.}

Participant Immigration Summary

\begin{tabular}{|c|c|c|c|}
\hline Participant & Birth City & Birth Country & Reason for U.S. Immigration \\
\hline Ingrid & Santo Domingo & Dominican Republic & $\begin{array}{l}\text { To live with dad and study in } \\
\text { the U.S. }\end{array}$ \\
\hline Stephanie & Bonao & Dominican Republic & Immigrated with family \\
\hline Aracelis & Tenares & Dominican Republic & Immigrated with family \\
\hline Awilda & Bonao & Dominican Republic & $\begin{array}{l}\text { To live with mother and study } \\
\text { in the U.S. }\end{array}$ \\
\hline Juan & Samana & Dominican Republic & Immigrated with family \\
\hline G & New York City & United States & To live with mother \\
\hline Carlos & $\begin{array}{c}\text { San Francisco de } \\
\text { Macoris }\end{array}$ & Dominican Republic & Immigrated with family \\
\hline Sara & Boston & United States & To study in the U.S. \\
\hline Anthony & $\begin{array}{l}\text { San Pedro de } \\
\text { Macoris }\end{array}$ & Dominican Republic & To live with father \\
\hline Tomas & *Massachusetts & United States & $\begin{array}{l}\text { To graduate from a U.S. high } \\
\text { school and go to a U.S. college }\end{array}$ \\
\hline
\end{tabular}

Note: Tomas did not disclose his exact city of birth. 
Not all participants were born in their home countries. All participants could be identified as Dominican-American based on what they perceive to be their native home country, language, and current immigration status.

\section{Hispanic Generation 1.5 Participants as Dominican-Americans}

This study focused on Hispanic Generation 1.5 students' engagement and membership experiences, and the term "Hispanic" encompasses many different geographical and cultural roots. As discussed in the Key Terms section within Chapter 1, the Hispanic population definition for this study is based on geographical roots (e.g., Dominican Republic, Puerto Rico, and Cuba). During the recruitment phase of this study, no parameters were used for geographical roots so that all Hispanic Generation 1.5 current and former students could be included within this study. However, all Hispanic Generation 1.5 participants were Dominican. They saw their home country as the Dominican Republic and their new home as the United States, therefore, having a hyphenated identity as Dominican-Americans.

The obtainment of a Dominican sample was not an accidental occurrence. Instead, it revealed the results of the New England population shifts that occurred mostly during the last two decades. Most of the participants lived in Lincoln, Massachusetts, a small city with the highest percentage of both Hispanics and Dominicans in the area. Anthony lived in Madison, Massachusetts, which had a higher percentage of Hispanics than the state of Massachusetts. Hawthorne, the location of the CMCC main campus, also had a high percentage of Hispanic residents than the rest of the state. Table 4 presents relevant demographic information for these three neighboring cities. 
Table 4.

Demographic Information for Three Neighboring Cities

\begin{tabular}{ccccccc}
\hline City & $\begin{array}{c}\text { Total } \\
\text { Population }\end{array}$ & $\begin{array}{c}\text { Speakers of } \\
\text { a Language } \\
\text { Other than } \\
\text { English }\end{array}$ & $\begin{array}{c}\text { Percentage } \\
\text { of } \\
\text { Hispanic } \\
\text { Residents }\end{array}$ & $\begin{array}{c}\text { Percentage } \\
\text { of Foreign } \\
\text { Born } \\
\text { Residents }\end{array}$ & $\begin{array}{c}\text { Bachelor's } \\
\text { Degree or } \\
\text { Higher }\end{array}$ & $\begin{array}{c}\text { Per Capita } \\
\text { Income }\end{array}$ \\
\hline Hawthorne & 58,753 & $17.9 \%$ & $11.8 \%$ & $9.1 \%$ & $30.2 \%$ & $\$ 29,755$ \\
Lincoln & 71,234 & $74.1 \%$ & $70.8 \%$ & $34.7 \%$ & $11.1 \%$ & $\$ 16,080$ \\
Madison & 46,179 & $28.0 \%$ & $20.0 \%$ & $15.0 \%$ & $23.1 \%$ & $\$ 27,333$ \\
\hline
\end{tabular}

Note. Created using demographic data from the 2006-2008 American Community through the U.S. Census Bureau (http://www.factfinder.census.gov).

This area in Massachusetts has attracted a large number of Hispanics over the last few decades, especially Dominicans who immigrated mostly from New York or directly from their home country, the Dominican Republic. Mostly immigrating to this area in the 1990s, Dominicans made up 38\% of the Hispanic population in Lincoln, Massachusetts by 2000 (Borges-Méndez, 2007). In the 1990s, New England experienced a boom in its knowledge-based economy that included bio-technology and computer technology, and this boom freed up many lower level positions in other areas for Hispanics (BorgesMéndez, 2007). Many immigrants were attracted to areas with a lower cost of living and many low-level positions that did not require a college degree and many times did not require more than very basic English skills.

Borges-Méndez (2007) explains how Dominicans moved into this New England area and were followed by friends and family members during the late $20^{\text {th }}$ century. They formed enclaves throughout Massachusetts, with Lincoln being an example of a city with a large Dominican enclave and evidence of the language and culture in everyday living. 
However, Dominicans still struggled at the end of the $20^{\text {th }}$ century with social and economic integration in many of these Massachusetts cities, and most timeshave suffered exclusion from many social and political circles, especially in the mostly Hispanic city of Lincoln, Massachusetts, (Borges-Méndez, 2007).

Evidence of this history was present in the participants' anecdotes and responses to questions about their experiences outside of the college. Most participants lived in Lincoln, Massachusetts, worked or had parents who have worked in factories and in lowlevel positions, and had to work while going to school to cover their daily expenses. They identified closely with the Dominican culture and lived within the Dominican culture in their everyday lives while also identifying with the American culture and some of the beliefs and value systems associated with that culture. Therefore, the Hispanic Generation 1.5 participants represent a bilingual, bicultural hyphenated population of Dominican-Americans in Massachusetts.

\section{Hispanic Generation 1.5 Students’ Immigration Patterns}

As mentioned earlier, all the Hispanic Generation 1.5participants assessed into ESL after high school graduation. They were all Dominican and had completed some of their K-12 schooling in the Dominican Republic. The participants in this study had various immigration patterns and fall into three categories based on where they were born and age of permanent immigration to the United States. Some participants are part of more than one category.

The first category was composed of participants who immigrated to the United States before or during their middle schools years. Anthony, G, Ingrid, and Juan 
werepart of this this first category. These participants had the longest exposure to academic English via their U.S. schooling since they spent 5 to 6 years in English classrooms. The lengthier exposure to academic English meant that they had welldeveloped Basic Interpersonal Communication Skills (BICS), communicating orally almost like native speakers. These participants also had highly developed Cognitive Academic Language Proficiency (CALP) in comparison to other Generation 1.5 groups. However, the participants in this group still needed further CALP development, which led to an ESL writing placement at CMCC.

The second category was composed of participants who immigrated to the United States during their high school years. Aracelis, Awilda, Carlos, Sara, Stephanie, and Tomas were part of this second category. These students had four or feweryears of exposure to academic English in their U.S. high schools. The development level of their BICS differeddependingon the city of U.S. residency. Some cities had a very high usage of Spanish for everyday work and living situations such as Lincoln, Massachusetts. High school students living in these Spanish-speaking areas were more likely to use English only in their classrooms, so they did not fully develop their BICS prior to college entry and sometimes also assessed into Listening and Speaking ESL courses at CMCC. Some of these Generation 1.5 participants who immigrated during their high school years spent one or 2 years in ESL or bilingual transitional programs in their U.S. high schools, and in some high schools those transitional years did not count towards high school graduation, depending on year of entry.

The third category was composed of participants who were born in the United States, granting them automatic dual citizenship (United States and Dominican Republic). 
After 1 to 5 yearsof living in the United States, the participants in this third group were taken by their parents to live in the Dominican Republic where they completed most of their K-12 schooling. During my years teaching and living within this community in Massachusetts, I observed many parents who gave birth to their children in the U.S. and raised them in the Dominican Republic. Parents who had the ability and the resources to travel for limited time periods out of the Dominican Republic took advantage of the dual citizenship laws. They had their children in the United States but raised their families back home in the Dominican Republic.

This third group did not fit the original definition of Generation 1.5ers presented by Rumbault \& Ima (1988), who define the group as being neither first generation immigrants who make the decision to immigrate with the family to the U.S. nor second generation immigrants who are born and stay in the U.S. However, for this study, these individuals were included as Hispanic Generation 1.5 participants because they view the Dominican Republic as their home country, speak Spanish as their first language, and have limited or no memories of living in the United States during their childhood. Therefore, participants who fall within the first category (immigrated before or during middle school years) and second category (immigrated during high school years) were also coded for this third category. This third group included G, Sara, and Tomas.

\section{Reasons for U.S. Immigration}

The study participants who fit the Hispanic Generation 1.5 profile immigrated to the United States for different reasons with higher education in the U.S. being involved in the immigration decision. Most participants immigrated to the United States because 
they were asked to come over by family members or they immigrated with their own family members. Most of the participants who immigrated with or for family rarely questioned the immigration request and saw the immigration process as a natural progression in their lives. Both the oldest male participant and the oldest female participant were part of this first group because they immigrated with their parents and other family members and stayed in the United States where they got married and havebeen raising their children.

However, there were a few participants who did not want to leave the Dominican Republic but felt they had no choice because their parents had requested their immigration to the U.S. These participants entered the U.S. and their schools with negative attitudes and nostalgia for the home country. When describing their schooling experiences, they mostly focused on the challenges they faced and negative incidents or situations, which they believe contributed to their college placement. These nostalgic and regretful students were the participants who were still taking ESL courses at CMCC and wanted to move on to their credit coursework. For example, Awilda only looked at her high school experience negatively, not noting a single positive outcome of attending high school in the U.S. At the time of the interview, she was taking ESL courses, and she was frustrated with her inability to move into her credit coursework.

Within this category of immigration patterns, the third group of participants willingly immigrated to the United States in order to go to college and obtain a degree from a U.S. college or university. Sometimes, these participants lefttheir immediate family behind in order to achieve their U.S. educational goals. For example, at the age of 11, Tomas realized that his career goal was to become a reconstructive surgeon. When in 
high school, he decided that he would be more successful in attaining his career goal by graduating from a U.S. university and then moving on to medical school. The easiest way for him to enter a U.S. college or university was by graduating from a U.S. high school. Therefore, after completing his junior year of high school, Tomas left his parents behind in the Dominican Republic and moved to Massachusetts to complete his senior year of high school and then enroll at CMCC.

The reasons for the participants to immigrate to the U.S. are similar to the immigration reasons of other groups interviewed during data collection. The Hispanic first generation immigrants willingly came to the United States to obtain a college degree just like Tomas. Laura immigrated to Massachusetts in search of a college education and a better life after having a child with her boyfriend. Yesenia immigrated to the U.S. before completing her high school degree in the Dominican Republic, but she chose to obtain her GED and then enroll at CMCC rather than complete high school in the U.S. because it was a straighter path towards her goal of obtaining a college degree. Both of these female participants had graduated from CMCC with an associate's degree and were working in their field of study.

These immigration reasons are also similar to those of the Haitian Generation 1.5 students, one of whom left his family behind in order to graduate from a U.S. high school and then a U.S. college. The female Haitian Generation 1.5 students immigrated with her family when she was in high school, but like the first group of Hispanic Generation 1.5 students, she did not question the immigration decision and saw the process as being a natural progression in her educational life. 


\section{Cyclical Immigration}

Immigration to the United States was not permanent and stable for some of the Hispanic Generation 1.5 students in the sample. Some of the study participants immigrated to the United States during middle school or high school, but had to temporarily return to their home country, the Dominican Republic, where they completed up to one year of schooling outside of the United States. The move back and forth between the Dominican Republic and the United States meant changing school curriculum, friends, community and school language, school habits, and even culture and perceptions of everyday life. The changes were not effortless for any participant who moved back and forth during the high school years.

Moving from one country to another had multiple implications for these participants. First, participants felt a loss of academic abilities with the transferring between schools in two different countries. Anthony attended middle school and 2 years of high school in the U.S. before returning to the Dominican Republic where he completed his junior year. Upon his return to Hawthorne High School in Massachusetts for the completion of his senior year, he felt he was starting from scratch, and he stated "And everything, everything was hard. Everything was hard." One challenge was language. He felt that "English was going away" because "it's only Spanish over there [Dominican Republic].” After a 1-year absence from a U.S. school, Anthony felt he had to reacquire some written and spoken English language skills while catching up to his native-English speaking peers who had continued learning academic English throughout the year he was away. 
Aside from language, the school curriculum posed several challenges during that senior year, and Anthonyneeded to take many courses he would not be scheduled to take if he stayed in the United States for his entire high school experience. Anthony explained,

They didn't really want to give me some of the credits that I had from the high school that I went in DR for that year. So school was hard too cuz I had to pick up everything. So I was like "All right. I'll take AP Spanish. I'll take AP Math." I was really good at Math. So I was like "I'll take the math. I'll take the chemistry. I'll take everything." Like if I would have stayed, I only had to take one class my senior. It was just...I think it was two gym and one English. Done. Instead I had to take all of them. I think I had to take extra classes and I was like "Oh man."

His academic plans were changed by his cyclical immigration to the Dominican Republic and back to the United States.

Anthony was a promising athlete in high school with scholarship opportunities prior to his immigration back to the Dominican Republic. However, he felt that he lost many of his athletic opportunities and abilities by going to the Dominican Republic for a year. When he returned to the U.S., he explained:

I was trying to pick up my running. It was horrible. It was horrible. No I wasn't in the shape that I was when I was in sophomore year. Because it was like freshmen year, good, good, all right. Sophomore year it was like excellent. Sophomore year was good. And then when I lost that year, I started from scratch like nothing. I had nothing. It was just school. School was everything.

Anthony felt that cyclical immigration led to a stripping of his academic and athletic achievements. Upon his return, he had to put all his efforts into only one aspect of his high school life, and he chose academics.

Ingrid's academic experience was similar to Anthony's experience. After a difficult year living in Massachusetts with her father and attending $8^{\text {th }}$ grade at the 
Addison School, Ingrid returned to the Dominican Republic to live with her mother for nine months. She completed freshmen year in the Dominican Republic, and then returned to the United States to complete the rest of her high school degree. When looking at the effects of those nine months outside the U.S. school system, Ingrid explained that she forgot all the English that she had learned. For Ingrid, cyclical immigration meant learning, unlearning, and relearning English, which was critical for her academic success in the U.S.

For the participants who had cyclical immigration patterns, the loss of English language abilities was the most critical effect of transitioning to Dominican schooling and back to U.S. schooling. They viewed language as being the most critical aspect of successful residency in the United States and overall academic success. Therefore, they focused the effects of their cyclical immigration mainly on language acquisition and loss. They rarely worried about specific on curricular or extra-curricular activities with the exception of Anthony.

For example, Sara was supposed to complete her high school education in the United States, and she immigrated to the U.S. at the start of freshmen year. She did poorly in school during the freshmen year due to her English language abilities, so she returned to the Dominican Republic to complete sophomore year. However, her goal was to graduate from a U.S. high school and attend a U.S. college. Therefore, while Sara understood her mother's decision to raise her children in the Dominican Republic, she did not see the educational benefits since her mother always planned to and eventually did immigrate to the United States so that her children could go to U.S. colleges. English is a critical part of a U.S. college education, and Sara felt that she was not prepared. 


\section{Language Characteristics}

Language characteristics are a critical defining factor for Generation 1.5 students in college classrooms. Therefore, an examination of the study participants' language use could provide information that relates to assessment, enrollment, and engagement at the community college. This section explores various language characteristics and patterns of the 10 Hispanic Generation 1.5 participants. Since language is part of our everyday lives, this section includes findings on the participants' language use as well as language characteristics inside school and outside in the community, home, and workplace.

\section{English as a Secondary Language}

One key language characteristic of this particular group of Hispanic Generation 1.5 students is that the language most used is Spanish. This finding is different than what the literature presents on Generation 1.5 students and daily language use, with English typically being the most used language in the school and the community. Most of the study participants used Spanish as the primary language inside and outside of school similar to their older first generation ESL peers, and five participants completed the study interviews mostly or completely in Spanish. However, all participants used English inside their classrooms when speaking with instructors. English then became a secondary language for these participants who explained that English was not critical for their daily lives outside of the classroom including the workplace, the community, and the home.

In school, most of the study participants used Spanish when communicating with peers outside of the classroom and sometimes even inside the classroom. Since a large 
percentage of the ESL students were Hispanic and one campus is situated in a Spanishspeaking community, the participants were always in contact with peers who spoke Spanish as a first language, and they naturally conversed in Spanish without hesitation. These participants used English when communicating with instructors and staff at the college.

In the community, the participants found that the main language was Spanish, especially in Lincoln, Massachusetts. Most businesses operated in Spanish including supermarkets, restaurants, grocery stores, and clothing shops. Whether walking, driving, or relaxing outside, people in Lincoln mostly communicate in Spanish with each other. Therefore, the participants mainly used Spanish when out in the community unless they lived in areas that were not highly populated with Hispanics such as Madison and parts of Hawthorne, Massachusetts.

At home, most participants used Spanish usually because it was the main or only language spoken by their family members, especially their parents. Awilda, Ingrid, Stephanie, Aracelis, and Carlos mostly used Spanish at home, and they all completed the study interviews in Spanish. Juan and Anthony used both Spanish and English at home, but Anthony forced himself to use English with his brothers at home. G and Tomas mostly used English at home and some Spanish with family members. These last four participants completed the interviews in English. Sara was speaking more English at home since her mother was proficient in English as well. However, Sara moved in with her boyfriend shortly before our interview, and he spoke Spanish as a first language; therefore, she used mostly Spanish at home now. 


\section{English Speaking Skills}

As explained in the second chapter, the Generation 1.5 literature continuously explains that Generation 1.5 students have strong oral language skills in English and sound like native speakers when using English in everyday conversation (Blumenthal, 2002; Gawienowski \& Holper, 2006). The findings from this study contradict this aspect of the Generation 1.5 literature and demonstrate a need for a more complex analysis of Generation 1.5 students English language abilities in relation to other characteristics. As mentioned previously, five of the study participants completed the interview mostly or entirely in Spanish, and some clearly expressed their desire to participate in Spanish. Ingrid started the interview by asking me not to laugh at her when she spoke English, and when she realized that I was also a native Spanish-speaker, she asked if she could speak in Spanish throughout the interview.

Some of the study participants hadthe appropriate English oral language skills to complete the interview using mostly English; however, they feltmore comfortable using their native language, Spanish. Other participants showedlower English speaking and listening skill levels and were unable to express many of their ideas in an English-only interview setting. The language preference and English language skill levels might be attributed to the language use in the cities and communities where these participants reside. Some of these participants lived in a mostly Spanish-speaking community and used English mostly inside of the classroom; therefore, they were not provided with enough opportunities to develop their BICS. 


\section{Hispanic Generation 1.5 Students at CMCC}

Generation 1.5 students are unique across colleges, states, and regions. Understanding the students' backgrounds helps readers better visualize the students within the study's setting. One critical aspect of the student experience is the initial exposure to the institution. However, the experience that leaves the greatest impact on the students is their assessment placement experiences, especially for Generation 1.5 students who assess into ESL. This section focuses on why the students selected CMCC, their initial experiences with the assessment and placement process, and their perceptions of their ESL placement.

\section{Selecting CMCC}

The Hispanic Generation 1.5 study participants chose to attend CMCC for a variety of reasons. The most common reason was the convenience that the institution offered in terms of its location and scheduling. The school has a main campus in Hawthorne, Massachusetts, and an Lincoln campus in Lincoln, Massachusetts, and the college provides free shuttle transportation between campuses. In terms of scheduling, the college offers morning, early afternoon, and evening ESL courses, and students can take any combination of course times as long as they follow curricular requirements. Another reason for selecting CMCC was the low tuition, especially when compared with private 2-year and 4-year institutions. Participants expressed that overall CMCC costs were lower than even public 4-year institutions in Massachusetts and nearby New Hampshire cities. 
Some students purposely chose CMCC as a stepping stone to another institution. Tomas wanted to attend a 4-year university and then medical school. He attended CMCC as a step toward a 4-year university believing that a community college could offer more time with instructors, more language preparation, and more academic support including tutoring and advising. After graduating from UMass Amherst with his bachelor's degree, Tomas enrolled at CMCC again, using the school's EMT certification program as a step towards medical school.

Anthony enrolled in CMCC in order to complete his associate's degree and transfer to a 4-year institution where he could get a bachelor's degree in mechanical engineering. He specifically chose CMCC as a step towards a bachelor's degree because of the college's location and low tuition costs in comparison to 4-year institutions. On the other hand, Carlos chose to attend CMCC to improve his English language skills so that he could enroll in a technical college. The college's ESL program was the critical decision factor for Carlos rather than location or price.

The male students focused more on the selection of CMCC as a step in their educational journey, not the final destination. The women, however, spoke of their decision to attend $\mathrm{CMCC}$ as a final step in an education journey that should end with a degree and a career. For example, Aracelis, the oldest female participant, chose to attend CMCC primarily because she wanted a short educational journey that ended with a certificate or an associate's degree. She wanted to be better in her current position and advance in the workplace or obtain a better position when she was older. That primary goal led her to CMCC when considering the school's location and cost. 
Some students were already a part of the CMCC community through their participation in one of the high school bridge programs for students who could not pass the Massachusetts Comprehensive Assessment System (MCAS) exams. The MCAS is the state's $10^{\text {th }}$ grade English Language Arts and Mathematics tests, which all public school students in Massachusetts must pass in order to graduate with a high school diploma regardless of disabilities or English language proficiency levels (http://www.doe.mass.edu/mcas/overview.html). This particular program (known as the bridge program) functions within the Hawthorne campus. Participation in this specific bridge program requires that the high school students complete the assessment and placement process at $\mathrm{CMCC}$ since they are taking courses at the college while completing final high school requirements and taking MCAS preparation classes. Through various program activities, the studentscompleted all financial aid and enrollment paperwork at the college before graduating from high school. Awilda began her educational journey at $\mathrm{CMCC}$ through the bridge program in Hawthorne. She wanted to be a medical assistant, and having everything ready for her at the institution made it very easy for her to transition into college life. Staying at CMCC for college was the easiest and most convenient next step in their educational journeys since they were already enrolled, had been placed in appropriate levels, and had experienced college life by taking college courses and engaging with faculty, staff, and students.

\section{Assessment Experiences}

The assessment experience was not very eventful for most of the study participants. Some participants took the college's entry assessment as part of their initial 
work for the ARC program on the main campus. Awilda and Sara had to take the assessment on the Hawthorne campus in order to take ESL courses at CMCC as a high school senior. Ingrid and Stephanie did not even mention their assessment experience at CMCC. Aracelis was fine with taking the test and figured that it did not matter if she did well or not because starting college again was the most important thing to her.

Carlos was very nervous about the assessment until he took the test on the Lincoln campus. He explained that he thought it was a bigger deal than it really was. Tomas expected to be in an uncomfortable and stressful situation while taking the test during the summer of 2003. However, once he was on the Lincoln campus, he calmed down. He explained:

But somehow, the people that were working on the assessment, they didn't put pressure on me. Even though they were strict with the time while I was taking all the different sections of the assessment test, they also tell me "Take your time. Don't worry." That was kind of good because I was not feeling bad. I was going to start in September no matter what level, but I was going to start in September, and that I already had some confidence in me.

The assessment process actually helped Tomas develop his own confidence and develop a positive connection to the institution. However, one difference between Tomas and the other Hispanic Generation 1.5 students is that Tomas not only expected but desired to be placed in ESL courses so that he could improve his academic English skills. While there was pressure to do well on the assessment, he did not feel pressure to assess into credit courses.

Unlike Tomas who found the experience to be empowering, some participants were uncomfortable during the assessment process. Juan did not like the test, as he stated: 
When I came in to take the test, I didn't like it. It was, the experience was good and everything but then it was like you had to take it, and I didn't feel comfortable especially with the writing and all that stuff. But I...they didn't treat me bad or anything like that, but I was nervous about taking that test being that I hadn't been in school for a while so it was kind of nerve-racking. (113-116)

Juan had difficulty with writing and having to complete an essay as part of the assessment process was very uncomfortable for him.

Anthony also had an uncomfortable experience taking the assessment at $\mathrm{CMCC}$, but his discomfort was based on the length of the exam and his lack of knowledge about the assessment process. He explained:

Yeah. I came here. I applied. I had to take a test. All right. I didn't care about it. "What is this for?"

"We just want to see how you are doing and what you can do."

Middle of the summer, I just want to be out of here. I took the test. More questions. "Oh this. I have to type this." I was like "All right. I just want to get like over this." I want to go out. I want to do something. You know what I mean? It was summer. And I didn't really think. And I was like "All right."

Anthony did not understand why he had to take the assessment. He had not prepared for such a lengthy assessment, and he had not considered studying or preparing for the test because it was a low stakes test to him. Overall, Anthony was unaware of the types of tests to be included in the overall assessment, and he was unaware of the consequences of the reading, writing, and math tests.

Not having assessed into developmental or credit courses, Anthony was asked to take the ESL assessment as well. He described that experience in the interview.

So like they called me again. "You have to take the test again."

"We just want to see something." So it was written. I had to write an essay...with a pen. So then they were like "Okay. You did really good in the one that you wrote. You did really bad in this one." Then I had to talk to one of the ESL persons. I was like "Why? I think my English is very good, but I might be mistaken." 
Anthony did not experience discomfort over the assessment activities. He felt frustration over the length and the lack of information about the process, especially after being called back for the ESL assessment.

\section{Perceptions of ESL Placement}

After completing the institutional assessment process, the $\mathrm{CMCC}$ students who are labeled as ESL must take the ESL assessment in order to determine writing, grammar, listening, speaking, and reading levels. After completing the entire assessment process, students meet with an advisor and complete the registration process either in a scheduled one-on-one session or in an ESL one-stop registration. Students are told their placement at these scheduled sessions. This section of the chapter focuses on the students' perceptions of their placement in ESL.

Contrary to the Generation 1.5 literature, not all the participants were upset or surprised by their ESL placement. Tomas, Aracelis, and Carlos were comfortable with their placement in the ESL courses because they knew they needed to learn more academic English. Carlos purposely chose to attend $\mathrm{CMCC}$ in order to acquire more academic English writing skills so that he could enroll in a technical college. Aracelis knew she needed to learn more academic English based on her experiences using the language in the workplace. Tomas desired to learn academic English as best as possible so that he could be successful as he advanced towards medical school. Awilda was assessed and placed through her high school transitional program and she did not have any issues with her original placement in ESL courses because she believed high school had not provided her with enough English skills to be successful in college. 
Some of the participants were unhappy with their ESL placement because they felt that they were not going to have enough exposure to academic English. For example, Ingrid was disappointed that she could only take ESL courses and that they were mostly with fellow Spanish-speaking students. She explained:

I would have liked to enter directly into regular classes because ESL is like wasting time for me. First, I mean, in part good because it is helping me improve my English. But I would have liked to enter directly into regular classes because it would have helped me more being around people who do not speak Spanish.

Ingrid felt that the ESL placement meant that she would be isolated from non-Spanish speaking peers and that she would have fewer opportunities to practice and learn academic English.

Anthony was upset with his ESL placement once he learned that being in ESL restricted him from taking many developmental and credit courses. His frustration came more from the course-taking restrictions that come with the ESL placement. Stephanie experienced the same type of frustration because she could not take any courses outside of the ESL curriculum. However, the enrollment officers in the front desk on the first floor of the Lincoln campus helped her understand the benefits of taking the ESL courses and then the credit courses. She explained:

I would like to be able to take another class but the person down there tell me that no, like I am not prepared. It will be too hard for me. And I instead will wait a little bit because I do not want to get a bad grade. I don't want to waste time like I did in Lincoln High that I graduated with low grades, which I didn't want.But instead I wait a little bit more to finish English because then I will go to the basic. And when I am in the basic, I will start to take the other classes.

Stephanie felt that she had a clear plan for advancing in her academic career but only after understanding the value of taking ESL courses before enrolling in a degree or certificate program. 
G was also disappointed with his ESL placement believing that he had gotten through the ESL obstacle in his New York community college. He thought that he would not need to take any more non-credit ESL or developmental courses after having completed many of these courses in New York. Then he learned that his ESL and developmental credits did not transfer since the credits do not count towards the associate's degree. However, once in the writing course with Ralph, G understood that he had some weak writing areas, and both the classroom instruction and the one-on-one instruction with Ralph focused on his writing weaknesses. He felt he was learning in the writing course, and he was impressed by the instructor's attention to his writing.

Some participants did not mind the ESL placement, but were upset about their assigned levels. Stephanie felt that she was placed in ESL levels that were too low for her abilities and years in the U.S. school system. Juan was upset once he learned of his placement in the ESL levels, but not with his writing placement. He expected to be placed in low ESL levels for writing because he felt he had not gotten adequate academic English instruction in his vocational high school, and he knew that his writing was weak. He was surprised by his ESL reading placement, and even though he had completed all his reading requirements, he was still bitter about the reading requirement during the interview.

\section{Profiles of Hispanic Generation 1.5 Participants}

Since this dissertation study focused on the engagement and membership of Hispanic Generation 1.5 students at a Massachusetts community college, the main 
sources of data were the participant interviews conducted from November 2009 to February 2010. The interviews and the Student Information Survey data provided information to define the Hispanic Generation 1.5 students at CMCC. This chapter has described this particular student population at the community college as a collective group using data from these two sources. This final section of the chapter provides a profile for each of the 10participants who fit the Hispanic Generation 1.5 criteria.

Anthony

In everything I do, I don't just give it a little bit. I'm not just "Oh I'm going to do it. Okay." I give it all...everything that I do, I do my best.... So I'm going to give my all in everything that I do. So it's not just a little bit. Like "Ah. I'll do it." No. If I'm going to do it. I'm going to do it. So I give it all in everything I do. So that's the thing.

Anthony always described himself as a survivor who worked hard to do well. His story is one of cyclical immigration with a number of membership and alienation experiences throughout his high school years. Anthony was born in San Pedro de Macoris in the Dominican Republic where he completed all of his elementary schooling. When he was 13, he immigrated to the United States with his brothers, leaving his mother and youngest brother behind in the Dominican Republic. He and his brothers moved to Madison, Massachusetts with their father, and they entered Mackenzie Grammar School.

Middle school experiences. Anthony entered the seventh grade and found his first year in the U.S. very difficult because of his poor English skills and lack of knowledge of U.S. customs. He had no understanding of English prior to entering the U.S. school system where he heard English all around him, but felt like he was hearing "noise." The 
school customs seemed very different and confusing including the daily process of students changing classrooms for each subject, the morning rituals such as pledging allegiance to the U.S. flag, and the practice of taking buses home after school. This confusion during the seventh grade made it difficult for him to enjoy positive engagement experiences.

In this first U.S. school, he went to mainstream classes and attended ESL classes with 4 to 6 other people, most of whom were his brothers. He felt that while the teachers were kind to him, they helped him too much with his academic work and did not allow him to be more independent in his learning. He did not want so much help with daily activities because he wanted to learn both the academic and language skills as best as possible. He wanted the teachers to support him in the learning experience rather than always accommodating him as if he had a language handicap. He said that too much of that "oh but he's not from here" help from his mainstream teachers hurt him in terms of engagement and belonging in junior high school because he got special treatment that differed greatly from the treatment that the other students were receiving from their teachers.

High school experiences. Eventually, Anthony grasped enough English to navigate through daily life and his mind turned into a sponge soaking up the English used around him, especially in television and music. Soon he was prospering at home and at school, and he successfully transitioned to the local high school (Madison High School). In high school, he was very engaged with his peers because he was very social and friendly with the students, teachers, and staff at the school. He did well academically, 
earning As and Bs in high school. He was gaining a positive reputation as a track star and was offered the opportunity to race in national meets and to become team captain before his senior year.

Cyclical immigration: Disruption in U.S. schooling. Unfortunately, Anthony's father was unable to care for his children while working full time, moving to a new place, and completing the citizenship process for himself and his children, so Anthony and his siblings were sent back to the Dominican Republic for a year. In the Dominican Republic, Anthony attended a Spanish only school, as is typical in his country, but shortly after the year started, he was faced with a teacher protest that left him out of school for several months. Upon his return to school, the teachers and students had to rush to complete the required curriculum in one third of the time. At the end of that year in the Dominican Republic, Anthony and his brothers were able to return to the U.S. and continue school in the Madison public school system. However, Anthony felt that during that year in the Dominican Republic, he lost a great deal of his English language abilities, academic skills, and athletic skills. .

Cyclical immigration: Return to U.S. schooling. After some initial struggles, Anthony caught up to the school curriculum and continued developing his English language skills. He returned to the track team at his high school and was team captain during his senior year. He felt ready for college life, so he applied to CMCC because it was close to home, was affordable, and had a track team. After admission into the college, he completed the assessment and placement process unaware of the importance 
of the assessment and how the placement process worked at a community college. He assessed into ESL reading and writing courses as well developmental math. Feeling out of place in his courses, he argued for a reassessment and was placed in College Reading and high level math courses such as Calculus and Business Calculus. However, his ESL writing placement restricted him from taking most credit courses.

Experiences at CMCC. Contrary to his original beliefs, Anthony found his ESL course to be the most difficult writing course at the college. He found the English Language Center and his ESL writing instructor effective in helping with various skill areas. However, he found that the other academic support labs were not critical to his success especially the College Reading lab, which he saw as a game or contest in which you get through your reading cards as fast as possible. He also disregarded the importance of the Writing Center, which was required for all Basic Writing (developmental) students because he felt the teacher had the actual knowledge and authority while the tutors were just trying to earn a paycheck rather than helping him develop his writing skills. He explained:

Because what you do you guys do? You guys correct it, change some things, and-... For the Basic Writing, it was just putting, it was helping you things...I don't know. I think they just want to have something to do. I don't know. They just want a job. Like you know what I mean? So you have to combine this with this. I think they should have more like...I think if you need help, you go there. Instead of just one of the requirements.

Anthony felt that the writing lab was required for each Basic Writing assignment so that the tutors could have enough work and be paid for their time on campus. He felt that the teacher's feedback was more critical and that the writing lab should be optional. 
Unlike most of the Hispanic Generation 1.5 study participants, Anthony was highly engaged with his instructors, tutors, and peers. He talked with all groups both inside and outside of the classroom or lab setting, and he developed close bonds with critical college members including the ELC staff and his ESL writing instructor. He was on the college's track team and recruited dozens of students to join the team. He had continued with track and his full-time studies while working three part-time jobs. Academically, he was doing well, and he made it on the dean's list his first year. His goal was to graduate from CMCC and go to a four year institution to study mechanical engineering. He hoped to eventually obtain a position that would allow him to live comfortably and bring his mother and youngest brother from the Dominican Republic to the United States.

Aracelis

My greatest motivation is that I can speak and understand when a person speaks to me only in English, that he/she speaks to me well, that I can answer that person. Something that, a title, something that I can say, I am this. That's it. And that my sons at least say "Look, my mom did this. My mom graduated." That is the only thing.

Aracelis was a Hispanic Generation 1.5 student who dropped out of CMCC nearly 10 years ago because the combination of several negative experiences along with some added challenges drove her to leave school for a few months after she got pregnant with her first child. When she tried to return a year later, a negative engagement experience with a faculty member still clouded her paperwork and resulted in a need to retake the course, which was only taught by that particular instructor. Faced with several challenges, including the need to retake that particular course, she chose not to return to 
$\mathrm{CMCC}$ for another 9 years. However, her children, her desire to learn academic English, and her goal of getting a degree motivated her to return to school and persevere at the school regardless of her engagement experiences at the college.

Immigrating to the United States. Aracelis was born in Tenares, Dominican Republic, but she was raised in Santo Domingo, the country's capital. As a teenager, Aracelis immigrated to New York with her family without even questioning the change as if the move was a natural progression in their lives as Dominicans. Living in Manhattan (New York City) for her first year and a half in the U.S., she attended a public high school near her home. Her first year in the United States was difficult because she was living in a large, loud city and attending a school where students used drugs, had sex, got into fights, and sometimes even shot each other.

Negative engagement experiences in high school. Aracelis's main concern during that first year in high school was not her English language abilities, but her survival in a new, unfamiliar, and scary school environment. When asked about her first days in high school, she described them as frustrating. With very limited English abilities, she could not interact with her peers who made her feel like an outcast. She explained:

Because the peers, the majority of them spoke English. They looked at you, the ones who were Latino from over there, they looked at you really ugly. The same week that I started there, I had a problem, well, not a problem. I came out of the cafeteria. I tripped with a tall, American girl and she told me- And I was looking back and collided with her. And she says a lot of bad words that I am not going to say. But she told me a lot of bad words and I did not understand her so I could not tell her anything. And she tells me to tell her "Sorry," and I told her "Sorry." And she tells me like to sit or something like that and I told her no. Then she told me like this like lifting up her face and I lifted my face. And when 
she said she wanted to fight with me, behind were coming, arrived a bunch of girls. So what did I do? I left because I did not understand what they were saying.

As she walked away, the girls began to fight. With such experiences, engagement at her new U.S. high school was tricky and dangerous for Aracelis, so she kept her head down, went to class, and went home at the end of the day. She avoided unnecessary interactions with many of her peers.

After that first year, her family moved to Lincoln, Massachusetts, a city with a population of less than 100,000 residents. In Lincoln High School, Aracelis still encountered a few difficult situations with her peers because there were a few small gangs in the school, and she occasionally caught students smoking pot or doing other drugs. However, she did not witness any violence like in her New York school, and she met many fellow students who were good to her. She also had a much more fulfilling classroom experience with her coursework and teachers in Lincoln High School.

Initial experiences at CMCC. Aracelis completed high school and then moved on to Commonwealth of Massachusetts Community College, where she assessed into ESL courses. Aracelis was satisfied with her initial placement at the college because she had only been in the United States for a few years, and she was aware of her poor academic English language skills. While completing her ESL courses, Aracelis spent a significant amount of time with her ESL peers. They did their homework together, formed study groups, and gathered in open areas to spend time together. Aracelis valued her social and academic engagement opportunities with her peers. 
A 10-year hiatus. While still enrolled in ESL courses, Aracelis got pregnant. At the same time, her school schedule changed because she moved to upper level ESL courses, which were only offered at the main campus in Hawthorne, Massachusetts. Aracelis had to drive in the snow with morning sickness to the main campus in order to take her courses. The difficult pregnancy and the tough winter took a toll on her. She stayed away from school the following semester in order to have her child. When she tried to register for courses about a year after giving birth, Aracelis discovered that she had to retake one of her courses because she had received a grade lower than the required minimum of $\mathrm{C}+$. She had not expected to get an $\mathrm{A}$ in that particular course, but she had not been made of aware of potentially obtaining such a low grade. She felt that her teacher had failed to communicate her actual status in the course and her need to do something different in order to pass. After this incident, Aracelis stayed away from the college for nine more years during which time she had more children and raised them with her husband.

A return to $C M C C$. Ten years later, Aracelis' oldest son convinced her that she needed to go back to school and learn academic English. She realized that she needed to strengthen her language skills and complete a degree in order to have the tools necessary to help her children with their schoolwork and to be a positive role model in their lives as well. Having been promoted to a position in a mostly English work environment, Aracelis also knew that she needed to enhance her English language skills in order to maintain her job. She completed the admissions process at the college and took the reading, writing, and math assessments once again. At her advising session, she was 
informed that she needed to go back down a level or two for each of the language courses (i.e., writing, reading, grammar, and listening/speaking) based on her assessment results. Aracelis was upset at first, but she was determined to do what she needed to do in order to succeed even if it meant retaking some courses.

At the time of the interview, Aracelis was still taking ESL courses as a night student on the Lincoln campus. She kept herself motivated with her goals of learning academic English and graduating from a college program so that her children could be proud of their mother. While she had always wanted to get a degree in business, she knew that she could not devote the weekly hours and the necessary number of years to pursue the bachelor's in business while sacrificing time with her family. Therefore, she chose to complete a short certificate program after completing her ESL and other required coursework.

Awilda

I want it. I want to stay here [at CMCC], but I don't want it. I want it and I want it. I'm the middle because... maybe if I pass the test, oh my God, I think so I would stay here because it's close to me. You know of my house? So right now I know most, many people so I've got many friends so I know a lot of teachers. So now I am familiarized with this university....I don't want to continue taking more ESL classes. Now, too many ESL classes that we have to take, when we are here in CMCC so I don't want to waste more time.

Awilda was born in Bonao, Dominican Republic where she completed most of her K-12 schooling. While Awilda was in high school, her mother immigrated to the United States and spent one year living and working in Lincoln, Massachusetts. During that time, Awilda stayed in the Dominican Republic with her father, brother, and two 
sisters. However, after one year of living in the United States, Awilda's mother requested that her daughter, Awilda, live with her in the United States and finish school in Massachusetts. In the middle of her senior year, Awilda left her home in the Dominican Republic and arrived in Massachusetts on Thanksgiving Day (November 25, 2005).

U.S. high school experiences: The transitional program. After the Thanksgiving holiday, Awilda became a student at the local high school (Lincoln High) but had to complete that first year isolated from the mainstream population while completing a transitional language program with other Spanish-speaking students. She took all her classes with the same group of students and had five different instructors, many of whom used Spanish in the classroom. She believed the transitional program was meant to help her acquire academic English, but she was frustrated by her teachers and classmates mostly using Spanish inside and outside of the classroom. She felt the high level of Spanish use thwarted her English language acquisition process.

Also, Awilda was dissatisfied with her high school education because of the curricular mismatch while in the transitional program. For example, during that first year in Lincoln High, she was assigned readings that did not correspond with her English language abilities. One required text was Romeo and Juliet. Awilda explained:

I didn't speak English. Right? She [My English teacher] made me read a book, Romeo and Juliet. The teacher. My English teacher. Romeo and Juliet and I, how am I going to understand this if I never in my life have taken English classes? Then she would give me many projects, projects, projects, projects, projects. Then she didn't teach me because for you to teach a person at a low level, you have to start from the basics. You as a professor have to know that with the basics. She didn't. When I went to her, [she had] a mess of papers. You 
had to do this and do this. A binder. Romeo and Juliet and me "Ah no." I would only say, "Oh my god." I was frustrated. I was really frustrated.

Awilda did not understand the required reading texts due to her English language skills; however, she was expected to learn English while completing the mainstream curriculum in an isolated environment.

Another required text was Anne Frank, which was more accessible than Romeo Juliet since it used English structures that were more aligned with the English structures she was learning in her ESL class. However, the book's English level was still too high for her own English language abilities at that time. Awilda explained:

Yeah I had to read Frank, Anne Frank. I cannot tell you anything about that book because I did not understand anything. I did a project about it, but in reality I don't know what I did because I, at that time, I.... You give it to me now, and okay. I can do for you a project but before no. We also did, what thing? Because there was another professor who also would give us something basic. But it was not enough.

While struggling to read Anne Frank, Awilda was getting basic English classes in her transitional program. Most of her learning assessments were based on projects rather than tests or essays, which allowed her to maneuver successfully through the system, pass her first year, and transition into the mainstream population and high school curriculum. However, in this transitional program, she felt she did not learn anything.

High school experiences while in mainstream courses. The following academic year, Awilda entered the mainstream curriculum at Lincoln High School. There she participated in the standard senior year courses including English, and she performed at an acceptable level earning As and Bs in her courses with the assistance of teachers and personal tools such as her digital bilingual dictionary. During senior year, she had to take 
the MCAS, which tested her math and English language skills. She felt that the statemandated test was much easier than the mandated tests in the Dominican Republic, which covered more subject areas. As a math lover, she passed the math portion of the MCAS on her first attempt. However, she was two points away from passing the English language portion of the MCAS. Therefore, she could not graduate from high school after being a senior at the school for one and a half years.

A high school to college bridge program. The following year, she entered a high school bridge program for students who had completed most or all of high school but could not pass the MCAS. In this bridge program, Awilda spent a year taking ESL courses at $\mathrm{CMCC}$ while completing final high school curricular requirements in a selfpaced setting. The key component of this particular bridge program is its emphasis on the MCAS, and as a student in the program, Awilda spent most of her academic time on MCAS test preparation activities and extensive essay writing. With the help of the bridge program, Awilda passed the MCAS writing test and could finally go to college.

CMCC experiences. By the time Awilda passed the MCAS, she was already taking ESL classes at CMCC.Because of the process built into the bridge program, she had already taken the college's placement test and completed all necessary paperwork. Therefore, she chose to continue her undergraduate studies at CMCC because it was the most convenient option and because the school was ideally located near her home.

At the time of the interview, Awilda was taking Advanced Integrated Writing Skills for the second time because even though she had passed the course the previous 
semester, she failed the college's writing test. In order to continue into developmental and/or mainstream credit courses, students must pass the college's writing test at the end of the semester. A portfolio option was presented to her, but no one followed up with her. Therefore, she did not know if her portfolio had been reviewed or the outcome of the review. She was frustrated with the assessment system and the ESL placement process because she had been standing right in front of the gates for two semesters waiting for a chance to cross over to the mainstream curriculum. She had obstacles in high school and now she was facing similar obstacles in college.

Regardless of her struggles, she recognized the critical role that the ESL program and its faculty played in her academic life. She explained:

Well um well the truth, the truth, the truth. Practically, the little English that I know, I learned it here. So the professors here are very good. So I cannot complain about that. At least the ones that I have ended up with for my English class and all that. They understand anything.

Aside from academic frustrations, Awilda had developed several friendships with her ESL peers, and she developed an intimate relationship with a former ESL student who was her boyfriend at the time of the study. While in college, Awilda had been working full-time at a local fast food restaurant, so her weekdays were full. She worked in the daytime, went home to shower and eat, took evening courses, and then went home to complete her homework. Her immediate goals were to get out of ESL and to start taking credit-bearing courses towards her future career as a medical assistant.

\section{Carlos}

My mother motivates me...because my mom tells me that she is here for us. If not, she would not be here. So she does not want to like leave us 
like that without studying because she wants to leave us on a good path.

That makes me, that was what made me start again.

Carlos was born in San Francisco de Macoris, Dominican Republic, where he studied in public schools and played baseball until his immigration to the United States at the end of his junior year of high school. He and his mother immigrated together when he was 15 years old, and they reunited with his father who had been living and working in Massachusetts. As a high school student, he enrolled in Hawthorne High School and was placed as a senior based on his academic history. However, Carlos pushed the school advisors to place him as a junior so that he may be better prepared to enter a U.S. college after high school graduation.

High school experiences. In high school, Carlos felt that most of the classroom activities were based on worksheets, and that the curriculum did not demand enough writing instruction or practice. He explained, "Yes the classes are good. [But] they don't put you to write a lot...They show you how to read and speak a little. But writing... Because they always take out a copy [handout]. One only does is fill out sheets." The curriculum activities included reading and speaking development, but he rarely wrote essays and occasionally wrote short paragraphs. For writing practice, he mostly wrote sentences, which were usually for the worksheet activities.

In high school, Carlos was required to take the MCAS. Carlos recalled his test taking experience as being awkward because he was Hispanic.

Because when one takes the MCAS, the Americans, they put them two or three they are put at one table like you and I are now. But the Hispanics no. I don't know if it was the professor who like works with the Hispanics because he was the one who divided up, but then the Americans, they don't put them like that. If there are two, they put them as two and three I believe that there were some. But the Hispanics no because they say that we copy from each other. Like if you are 
there next to me, and I am taking, or if I don't know something, for curiosity perhaps I look at you. That has nothing to do thatyou are American or Hispanic. That has nothing to do with race.... But to us, they put us one per table.

Carlos felt uncomfortable taking the English portion of the MCAS during which the Hispanic students were segregated and placed individually at tables spread throughout the room. Under these circumstances and with his limited English language abilities, Carlos did not pass the English portion of the MCAS, so he completed tutoring sessions during his study hall time and after school while earning mostly As in his content courses. His participation in the tutoring program and his high grades helped him get an exemption on the MCAS English test so that he could graduate from high school at the completion of his senior year.

For extra-curricular activities, Carlos discovered too many obstacles that were not present in the Dominican school structure including the scheduling of curricular and extra-curricular activities and the various requirements for involvement in sports. $\mathrm{He}$ explained:

When I entered the high school, I took the steps to enter the high school team, but they....If you do not pass the history class, you do not play. If you are not a sophomore, you have to pay.... So then they use a strange method here for the game. Because they when we wentto play, after one gets out of school, one take a bus and goes directly to the stadium. But you don't eat, you don't go home. You go from the school to the stadium to play. So then one has to be tired, you understand, without eating. Then, besides that, one has to pay.

The U.S. school and extra-curricular structure were exhausting and daunting to him, and the structure was different from the Dominican Republic where students went home after school and then returned to school in the late afternoon for extra-curricular activities.

Carlos also had language difficulties that affected his involvement in sports. First, he had difficulty passing certain classes during his first year in the United States because 
his first language was Spanish and all his courses were in English. He was failing History, which students were required to pass in order to play on a sports team. Carlos also had language misunderstandings that affected his involvement in the high school baseball team. He explained:

One day we were going to practice. Then they announced, but I did not understand. I understood that they weren't going to play, but it was the sophomores, the ones in sophomore year. But I was a junior. So I thought that none of us were going to play. And I did not go to practice.

That team meeting was critical for team selection for the academic year, and Carlos missed the meeting and an opportunity for team selection because of this misunderstanding. Unable to play baseball in high school, Carlos studied for 2 years while working 30 to 40 hours per week at a local fast food restaurant.

Taking time off before college. After high school graduation, he went to work full-time at a radiator company where his father worked as well. He hoped to attend ITT Technical Institute or Universal Technical Institute (UTI) in New England so that he could work as a mechanic at a car dealership or as a designer like the radiator designer at his company of employment. However, his writing was not at an appropriate level for enrollment in either of these institutions, and he spent a year working at the radiator company hearing advice from coworkers and family members who insisted he attend college. Finally, his sister took him to CMCC to apply, and he discussed tuition reimbursement options with his boss. The company offered to pay for his courses since he wanted to study a major that related to his current company of employment and since he was going to learn academic English, which he could use on the job. 
Experiences at CMCC. At CMCC, he assessed into ESL, and he enrolled for these courses in order to improve his academic writing abilities and reapply for ITT or UTI in the future. At the time of the interview, Carlos was 21 years old. He had been studying at CMCC for 1 year taking low-level ESL courses including Grammar 1, Writing 1, and Listening/Speaking 2. While his speaking skills were above level 2, he could not take his appropriate level in that language area or in reading because ESL students could not enroll in courses that are more than one level apart.

He had not missed a single day of class during that first year at CMCC even though he worked full-time at his company and part-time on Sundays making deliveries for his sister's company. He did not see employment as an obstacle for his academic success, but he did see employment as an obstacle in his ability to be more involved at the institution. For example, he would love to play baseball on the college's team, but all meetings and practice sessions were in the daytime when he was working. Overall, Carlos was very shy and quiet with people who he barely knew, but he had some male and female friends in his ESL courses. He spent his free time with his friends watching movies, shopping at the mall, or going to nightclubs.

G

I chose because I plan to finish. I want to get my 60 credits and be done. My goal is to get my 60 credits. I already took the police test for Lincoln. I passed it. Once I get my 60 credits, I go to the academy. Then I'll be kicking doors down.... I'm not sure. Like I want to start my career as a police officer. But my main goal is to become a detective. I have to spend a year or two in the force. When I reach that level to detective, I want to transfer to New York. 
G was born in the Bronx, New York and was taken to the Dominican Republic where he began his schooling experience. After a few years of living and going to school in the Dominican Republic, G immigrated to the United States with his family. He completed a few years of elementary schooling in the Bronx, and then his family temporarily sent him back to the Dominican Republic where they thought he would be better behaved and more successful in school. Eventually, he permanently immigrated to the United States, where he completed high school.

High school experiences. In high school, G struggled to be successful because he felt that there were too many students in the classroom and that the instructors were not interested in the students or their success. When describing his high school classroom, he discussed how students were allowed to walk in and out of class at any time and how teachers at the end of the semester would automatically pass the students without taking grades and coursework into sufficient consideration. G was left with notions of teachers generally not caring about students because they were only in front of the classroom in order to get a paycheck. G felt that his high school educational experiences did not support his academic transition into college and his disappointment in the public school system was evident in his tone of voice and his chosen examples during the interview.

College experiences in New York City. After high school, G enrolled at the local community college where he was placed in ESL and developmental courses, while many of his friends went to 4-year institutions and did not have the ESL or developmental hurdles as G. This discrepancy did not discourage G, who continued to attend the 
community college with the hopes of eventually obtaining enough credits to begin the process of becoming a police officer. However, while in college, he felt that many of his instructors were not invested in the students' academic success and might only be in front of the classroom for a paycheck similar to his high school teachers. He explained that the lack of significant positive engagement experiences with his New York faculty members made him feel as if he did not belong at that school because the school did not care about him. His feelings of alienation resulted in his attrition from the college.

A new opportunity in a new place. Regardless of his educational struggles, G still had a goal. He wanted to do something with his life. Then he met his father, who had been living in Lincoln, Massachusetts. This new relationship in a new city opened up another door of opportunity towards his goal of doing something positive with his life through a college education. Therefore, G moved to Lincoln, Massachusetts, obtained a job at a local car dealership, and enrolled at CMCC with the goal of completing 60 college credits in order to enroll in the police academy for Lincoln, Massachusetts.

Enrolling at CMCC. Upon enrolling in the college and completing the institution's reading, writing, and math assessments, G was informed that he placed into ESL and developmental level courses again. The placement frustrated $\mathrm{G}$ who had completed all the required ESL and developmental education coursework at the community college in the Bronx. At CMCC he learned that those credits did not count towards a degree and did not transfer to CMCC. Upset with the process, G pushed himself to register for the advised ESL and developmental math courses along with 
Introduction to Law because he had already made many sacrifices for his education, including moving to Massachusetts.

Not engaging with peers at CMCC. With his educational past, G wanted to focus on his studies while attending CMCC; therefore, he did want to partake in peer engagement opportunities inside or outside of the classroom unless required by the course instructor. He also did not want to take classes on the Lincoln campus where he might see many of his Hispanic community members. He felt that having too many Hispanic peers would distract him from his studies because he would want to engage with them during class time and outside of school. Knowing his weaknesses as a student, G chose to take classes on the Hawthorne campus, which felt more like a learning community than the campus with a lower percentage of Hispanic students than the Lincoln campus. At the time of the interview, he was still enrolled in ESL and developmental courses as well as Introduction to Law, and he was working towards his 60 credits in order to enter the Lincoln police academy.

Ingrid

[I am here in college] because I want to become a child psychologist. It is like a goal that one has of doing something in life. For myself and to help my family. There it is.

Ingrid was born in Santo Domingo, Dominican Republic, where she lived with her mother until the eighth grade. She always dreamed of a better life that involved getting a college degree and a career in an area that she liked. Her dream also included helping out her mother who raised her in the Dominican Republic. With those dreams, 
Ingrid and her brother left their mother and moved to Lincoln, Massachusetts tolive with their father and study in the local public schools.

Negative high school experiences. Ingrid completed the eighth grade in Addison MiddleSchool. She never felt comfortable at her middle school because many of her Hispanic peers made fun of her English speaking skills and accent. After completing one year of school in the U.S., Ingrid decided to go back to the Dominican Republic for high school. However, while studying in the Dominican Republic once again, she realized that she needed to complete her education in the U.S. if she wished to move forward with her goals of becoming a child psychologist and bringing her mother to the U.S.

Therefore, she moved to Connecticut where she lived with her aunt and uncle and studied in a public high school for the next 3 years.

In her new high school, Ingrid felt very comfortable. She did not have any conflicts with students and no one teased her about her English language skills or her accent. She explained:

There it great like because as soon as I had entered there, like I was capturing again everything I had learned here in Addison, the English. And it was a bit easy. There I did not have problems with anyone. No one bothered. They did not laugh. There everyone was learning. I liked it. It was good.

The most difficult aspect of her high school experience was peer engagement because of the negative peer engagement experiences at Addison middle school. However, while attending high school in Connecticut, she was able to move beyond her past negative experiences and have a positive relationship with the general student population at the high school. 
Enrolling at CMCC. After high school, Ingrid desired to continue her education in a U.S. college, but she had some financial aid complications and was unable to enroll in a Connecticut college. Therefore, she moved back to her father's home in Lincoln, Massachusetts where she was able to obtain financial aid and enroll in CMCC. Upon her arrival at CMCC, Ingrid lacked confidence to speak in English, especially in a new school, so she searched for staff members who spoke Spanish during her enrollment period. Then she took the college's assessments and placed into the upper level ESL grammar, writing, and reading courses. While she accepted her placement in ESL courses, she desired to take at least one credit course where she would not be studying the English language with other Hispanic students. Taking courses with her mostly Hispanic peers encouraged Ingrid to use Spanish rather than English with her peers inside and outside of the classroom, especially with her fear of using English during oral communication.

Engagement at $C M C C$. While taking ESL courses, Ingrid met many Arab students who she viewed as her school friends. She enjoyed spending time with her Arab friends because she learned new things about the English language from her daily interactions with them and because she was forced to use English with these non-Spanish speakers. In addition, she developed one significant relationship with another Hispanic peer taking ESL courses. They studied together and completed the online portion of their hybrid ESL course together in the Lincoln campus computer lab.

Unlike many of her Hispanic Generation 1.5 peers, Ingrid did not work. She lived with her father and took public transportation or got a ride to school since she did not 
own a car. Because she did not have a car, she chose to take all her classes at the Lincoln campus, which was not too far from her home in the same city. Even though Ingrid did not have any home and work responsibilities that demanded much of her time, she did not participate in institutional engagement activities hosted by the Student Engagement Center or other areas of the college. However, Ingrid confessed to desiring more engagement. She wanted to be more involved at the college and partake in some student activities. She explained that she wanted to join a sorority, but she was unaware that CMCC, and most community colleges, do not have sororities. Even though she desired more involvement opportunities and to be overall more engaged, she never took a step towards participating in any engagement opportunities outside of the classroom. It was unclear as to whether her fear of English-only oral communication kept her away from many positive engagement opportunities at the institution.

Juan

[I came to CMCC] because of my son. It took me a while to come. I was married. And my wife, she always tell my son, "You need to get good grades so that you can go to a college."

So one day he asked, "So why didn't you go to college?"

I said, "Cuz I was too busy."

He was like, "Why don't you go to college now?"

So after that conversation that stayed in my mind and it took me for like a year before. He just kept going on and on. And I asked myself, "So why don't I go to college now?" So eventually I came in and registered myself.

Juan was born in Samana, Dominican Republic where he lived and studied until he immigrated from the Dominican Republic to the United States with his family at the age of 15. They moved to Lincoln, Massachusetts where he attended the local vocational 
high school. In high school, he majored in autobody and graduated with a high school diploma and the credentials to work in the field. Therefore, immediately after graduating from high school, Juan was able to find a job to support himself. However, looking back at his high school experience, he realized that his high school did an excellent job preparing students for specific jobs or careers, but that it did not provide the necessary tools for students who desired to go to college.

Life after high school. Juan worked in auto body for 3 years but he did not enjoy that line of work for a couple of reasons including the amount of dust in the workplace, which bothered him. Therefore, he moved into the medical field as a Certified Nursing Assistant (CNA), which he had been doing for approximately 12 years. However, he felt that there could be more in his life, especially in a family where all his siblings had graduated from college and were enjoying successful careers while his wife was completing her master's degree at a nearby private institution. Then one day his son reiterated the household message of going to college to his father and asked why he did not return to school. Juan's wife had always suggested that good grades were necessary in order to enjoy the privilege of going to college, and Juan's son reminded him of the critical role that college played in their family.

Enrolling at CMCC. That college conversation with his son left Juan thinking about the different career doors that a college degree could open for him. Finally, that conversation motivated him to go to the local community college and complete the necessary paperwork to become a student at CMCC. He completed the admissions and enrollment processes including the institution's reading, writing, and math assessments. 
He stated that the assessment experience was good, but he did not feel comfortable while taking the different tests, especially the writing test, because he had been out of school for over a decade.

Soon after the assessment, Juan had his advising appointment where the assessment results were reviewed by a faculty member or the ESL coordinator, and he received his ESL placement during that session. Juan was placed into ESL reading and writing courses, and that placement made him upset. Juan accepted that he was a weak writer because he always found writing to be a difficult task, and it was one of his least favorite subject areas in school. However, he never thought that he needed ESL reading assistance because he had been reading in English for over a decade, and he enjoyed reading. Regardless, Juan enrolled in the advised courses, completed his ESL coursework, and was taking credit courses at the college at the time of the study.

Engagement experiences. As an older, returning student, Juan was taking several courses a semester while working full time as a CNA at a nearby nursing home and taking care of his family. He never participated in institutional engagement opportunities hosted by the Student Engagement Center. He rarely went to the campus except to take classes, complete required lab or tutoring sessions in the academic support centers, or meet with peers to study for a midterm or final exam. While Juan did not perceive social engagement and peer engagement on campus as being critical to his success, he did meet with a classmate a couple of times in nearby bars to chat, which was the only type of offcampus interaction that he described. 
Planning for the future. Juan wanted to get into the radiology program at the college, which was a very competitive program in the region. He had almost completed all requirements for the application process with the exception of a few more courses that he needed to complete. Realizing that even if accepted, he might be placed on a waiting list, Juan was planning on ways to take some of the program courses while on the waiting list so that he could maximize his time while in the program and perhaps finish sooner than typically scheduled. His educational and career goals included entering and completing the radiology program, obtaining a job in the field, and eventually completing a relevant master's degree so that he could be successful like his wife and siblings both in the educational arena and the employment arena.

Sara

Well, I really want to do something in the future. I want to have a career and something too. And I need to support my family too. I'm not sure [what I want to do] but before I was into psychology because I just really want to do something to have something to do, to have a career, but I really don't know what I like.... I was just gonna, cuz I've been in ESL for too long. And I was just going to decide to go into nursing assistant next semester.

Sara was born in Boston, Massachusetts, and when she was about two or three years old, she was taken to the Dominican Republic where she lived and studied until the end of junior high school (eighth grade). Even though her Dominican education had only been in Spanish, Sara returned to Massachusetts in order to start high school as a freshman. She performed poorly during her first year in high school because she did not possess the necessary English skills to maneuver in the English-only school setting and 
curriculum. Therefore, she returned to the Dominican Republic at the end of her freshmen year.

Committing to a high school education in the U.S. Determined to study and live in the United States, Sara returned to Massachusetts halfway into her junior year, and she enrolled at the same high school she attended as a freshman (Lincoln High School). She explained that in high school, instructors did not teach her English. She was placed in English-only mainstream courses, and she had to progress alongside native English speakers and fellow Hispanic students who had been raised in the United States. In her senior year, she faced the challenge of taking the MCAS, which she needed to pass in order to graduate from high school. She failed the MCAS; therefore, she had to repeat her senior year in high school and retake the test.

Participation in a high school to college bridge program. Having failed the MCAS as a senior, Sara went to a bridge program, where she received MCAS-based instruction, including test-taking and essay writing skills. While in the bridge program, she took ESL courses at CMCC, and she spent most of her time with her bridge program peers and with her bridge program instructor, Max Lansing, mostly within a designated $\mathrm{ARC}$ area. Therefore, she felt comfortable in the bridge program because she was learning the skills necessary to pass the MCAS and she was having positive engagement experiences with her peers in an area that felt safe. 
Taking ESL courses at CMCC. At the end of the academic year, she passed the MCAS and continued her studies at CMCC. During and after her ARC experience, Sara found an ESL instructor, Jennifer Tennison, who she still adored at the time of the interview. Sara had made a positive connection with this instructor who demonstrated a true concern for her students and provided them with the resources and support inside and outside of the classroom. Sara took multiple courses with Jennifer Tennison, including grammar and reading. When discussing her ESL experiences, she talked fondly of this instructor and tied all her positive engagement experiences during ESL to her experiences with this ESL instructor.

At the time of the interview, Sara was taking Composition 1, which she found more difficult than the ESL and developmental writing courses because she had to write a research paper. She was an avid reader and had recently finished reading the Twilight series. Even though she was already taking credit courses, she did not have confidence in her ability to write in credit courses. However, she felt she had spent too much time taking ESL courses, and she wanted to take more credit courses so that she could move forward with her nursing assistant career goal.

As a CMCC student, Sara did not engage in extracurricular activities. When asked if she would be interested in joining any clubs or organizations, she simply said "I guess," as if she had not given it much thought. Outside of her courses, Sara spent time on campus mostly to use the computer lab even though she had a computer and internet service at home.

At the time of the interview, Sara had just moved in with her boyfriend and was preparing for the birth of their first child. Her goals were focused on finishing school and 
getting a job, preferably in the nursing field. She did not want to work in a factory ever again after years of working in Massachusetts factories. All her siblings were in the United States with the goal of graduating from a U.S. college. Some of her siblings were currently enrolled in college, one even in CMCC's ESL courses, and one of her siblings had already graduated with a degree in criminal justice.

\section{Stephanie}

To speak and write, I did not know [English]. I did not know. I felt like if I took...how do I tell you? Do you know when you are small, you say, "I am going to do this. I am going to do the other and blah blah blah." So there are many obstacles that they put in the way for you and it's not what you expect. They told me that this was a good school to learn English and stuff. That they teach you a lot and that you put yourself in a 2-year program and in 2 years you know and things like that.

Stephanie was born in Bonao, Dominican Republic, and she immigrated to the United States with her family when she was 14. She enrolled in Lincoln High School at a time when the English curriculum and language regulations were being changed periodically in search of the right balance for the city's children. Unfortunately, Stephanie got stuck in that system, being moved back and forth from bilingual to English-only courses and even wasting a year completing "transitional" coursework that did not count towards her high school degree. After bouncing around within the school system for several years, Stephanie graduated from Lincoln High School without having the ability to communicate in oral or written English. Therefore, in 2006, she enrolled at CMCC because of its reputation for helping students learn academic English and transition into academic degree programs. 
Committing to CMCC. When she enrolled at $\mathrm{CMCC}$, Stephanie completed the assessment process and met with her advisor who informed her that she had placed into ESL courses. Stephanie was comfortable with the ESL placement but dissatisfied with her ESL level, which she felt was too low. However, having limited options, she enrolled in the courses and completed her first semester of ESL courses while working full-time. During that first year at CMCC, Stephanie got pregnant. She left the school in order to have her child and return to work. Eventually, she realized that time was flying by, and she had not even completed her ESL course requirements. She wanted to finish a degree program at CMCC, but her mother disagreed feeling that Stephanie would make better use of her time if she worked full-time rather than go to college.

Against her mother's wishes and her own fears of being away from her son for too long, Stephanie returned to CMCC and enrolled in ESL courses again. She was happy with her decision to return to the college, and after seeing her former peers taking credit courses, she wished she had returned to the college sooner. At the time of the interview, Stephanie was still enrolled in ESL courses, and she had decided to go into the medical field, ideally to become a CNA. She stayed motivated by her goal of learning academic English and graduating from a degree program in the medical field.

Engagement at $C M C C$. Stephanie rarely engaged with faculty, staff, or peers at the college unless necessary for her coursework. She had to worry about her home, her son, her job, and her studies, and all these responsibilities kept her away from campus unless it was necessary for her academic success. While she did not seek or desire significant peer engagement opportunities, she was very social and friendly on campus. 
Many of the students knew her son and the son's father, so they were very friendly with Stephanie and greeted her often. However, Stephanie did not find that engagement played an important role in her success and did not express a need to be more engaged inside or outside of the classroom.

\section{Tomas}

Since age 11, I've been having this feeling inside of me of wanting to help people and some experiences have also taught me how going to medical school and being a doctor, it is something that will give me that satisfaction of helping people.... I want to work with people who are poor or have this disfigurations so they can value life more and they can have a better self-esteem and all the reasons that I can spend days telling you about. But all I want to do is help change people's lives. It feels great and emotional because people can be healthy but they can also be like feel depressed or miserable. So my goal in being a physician, being a surgeon is to help people going through a change in their lives both physically and emotionally so that they don't feel depressed. So they feel good, as good as I feel being alive.

Tomas was born in the United States, which provided him with automatic U.S. citizenship. He was taken to his home country, the Dominican Republic, where he completed all of his K-12 schooling except for senior year. While in the $11^{\text {th }}$ grade, Tomas decided to finish high school in the UnitedStates so that he could transition into a U.S. college or university. His older sisters had chosen a similar path and had completed high school and college in the United States. Therefore, he followed in their footsteps, leaving his parents behind in the Dominican Republic. From that moment, Tomas's goals were clear. He wanted to learn English, graduate from college, and go to medical school so that he could become a reconstructive surgeon. These goals kept him focused and motivated each step of the way. 
U.S. high school experiences. Tomas immigrated to Lincoln, Massachusetts, where he lived with one of his sisters while he attended Lincoln High School. In his senior year of high school, he took ESL courses and mainstream content courses as well. While new to the country and the school system, he found his educational experience to be very positive and rewarding, unlike other participants who immigrated to the United States during their high school years. Tomas explained:

I want to say that it was a unique experience; it was also fun and challenging. It was a time when I was experiencing a new culture and hanging around people who spoke English; it was something that I want to learn. It was one of my goals before graduating. So I want to say that it was a unique experience. I'm grateful for the teachers that I had and counselors. They really put me on the road to keep going to college.

Having voluntarily immigrated to the United States with a clear goal helped Tomas see

his U.S. high school experience as a gift for preparation for a U.S. college. His

perspective is based on gratitude for the educational opportunities rather than focusing on challenges or negative aspects of his experience.

As a transitional phase to a U.S. college, Tomas took advantage of any

opportunities for academic support or advice including the encouragement to attend a community college prior to going to a university. Tomas explained:

Well my ESL 3 teacher, for instance, she would talk to me about how I should go to a community college instead of going to a 4-year college where I could learn my English... "Try to focus going to CMCC," she said, for 2 years where I can concentrate in my English skills better. Other teachers encouraged me to apply to scholarships, which I was fortunate to get one for CMCC, and my counselors would tell me how to get...she would tell me things, how to be around. How to, let's say, she would kind of like telling me how the new culture, you know how different it was from the Dominican culture.

Tomas was grateful for the academic, personal, and cultural advice and support as he planned his way to his college degree and eventually his medical degree. 
As a high school student in Massachusetts, Tomas had to take the MCAS, a graduation requirement, but he failed both the math test and the English test on his first attempt. Luckily, he discovered an afterschool and weekend program for students in his situation. He worked on his math and writing skills through the program, and he was allowed to graduate based on his original MCAS scores and his participation in the preparatory program. Tomas expressed his gratitude for the opportunity to participate in such a program and for the opportunity to graduate without retaking the test.

Experiences at CMCC. In 2003, Tomas, a high school graduate, completed the admissions process at CMCC, which provided him with a presidential scholarship. His first semester at CMCC, Tomas took level 4 ESL courses, two of which were a linked learning community, and he worked with the ELC staff on required reading lab assignments and other course activities. At the end of the semester, Tomas passed the institutional assessments and moved out of ESL and into developmental reading and writing courses. He had the opportunity to take his developmental courses with the writing and reading curriculum coordinators. The following semester, the coordinators formed a learning community for Composition 1 and College Reading, and Tomas registered for the learning community in order to continue taking courses with these faculty members.

At CMCC, Tomas flourished. He completed all of his credit coursework with As and Bs, and he accepted a work study position in which he provided office support for his former writing and reading instructors. As a work study student, Tomas was exposed to a variety of faculty members, and he interacted with the faculty and staff on a daily basis. 
A faculty member even invited him to sit on a committee for the appreciative inquiry project for the college, another experience that Tomas still values after college graduation. In 2007, Tomas graduated from CMCC with his associate's degree, and he was awarded the Outstanding Student Award.

After CMCC graduation. After graduating from CMCC, Tomas attended UMass Amherst for 2 years, and he graduated with his bachelor's degree in 2009. Feeling that he did not have sufficient voluntary medical experience for success in medical school, he enrolled at CMCC once again for the Emergency Management Technician (EMT) nondegree program. At the time of the interview, Tomas had been working as an EMT for approximately a month, and he was in the process of taking the MCAT as a preliminary step to the medical school application process. His goal of being a reconstructive surgeon was still a strong, positive driving force for him as he progressed towards medical school 7 years after his initial immigration to the United States.

\section{Summary}

The purpose of this chapter was to describe the Hispanic Generation 1.5 students at Commonwealth of Massachusetts Community College. While 16 current and former students were interviewed for this study, only 10 participants fit the criteria established for the research study. The data revealed that these students had differing immigration patterns and pre-college schooling experiences. They shared a common first language, Spanish, and they mostly spoke Spanish in their daily lives, especially if they lived and 
worked in Spanish-speaking communities, such as the ones found throughout Lincoln, Massachusetts and parts of Madison and Hawthorne. The language characteristics and immigration experiences of CMCC's Hispanic Generation 1.5 students differed from the common characteristics of Generation 1.5 students presented in the literature. Therefore, this chapter ended with a detailed profile of each participant who met the study's participation criteria in order to provide enough information to enhance the reader's overall understanding of the study findings and enhance reader generalizability. The following three chapters will present the findings on the engagement experiences of Hispanic Generation 1.5 students at CMCC. 


\section{CHAPTER V \\ ENGAGEMENT EXPERIENCES WITH PEERS}

The purpose of this fifth chapter is to present the study findings on Hispanic Generation 1.5 students' engagement experiences with their peers at Commonwealth of Massachusetts Community College (CMCC). Students were engaged with their peers both inside and outside of the classroom, and they spoke about several forms of engagement with peers. The findings on peer engagement will be presented in four sections:(a) peer engagement inside the classroom, (b) peer engagement outside the classroom, (c) perceptions of peer engagement, and (d) the development of a sense of belonging through peer engagement experiences at CMCC. The chapter ends with a comparison of Hispanic Generation 1.5 students' engagement experiences across the three levels or units of analysis as well as a comparison of their engagement experiences with the experiences of other groups at CMCC.

Peer Engagement inside of the Classroom

The most common form of peer engagement for all participants was academic engagement within the classroom. Most participants discussed engaging with peers inside the classroom for classroom activities and to ask for general help. This section focuses on various types of in-class peer engagement experiences and perceptions discussed by the Hispanic Generation 1.5 participants and their perceptions of those experiences. 
Comfort with Fellow Hispanic Peers in ESL Courses

One critical factor for in-class peer engagement was that the participants were Hispanic and so were most of their ESL peers. For the participants, this commonality meant that peer engagement was acceptable and even inevitable. Aracelis explained that they (i.e., the students in the classroom) are all Latinos, and, therefore, it was natural for them to engage in the classroom and help each other during classroom learning activities. She explained, "It's with the companions; we all help each other well. We are Latinos. We are trying to learn the same language, and if you know more than me, help me, that when you need [help], I am there. Understand?" Aracelis described these peer interactions focused on learning activities as a natural part of the classroom learning process.

Like Aracelis, Awilda and Tomas felt comfortable in their ESL courses because they were with fellow Hispanics working together towards the same goal- to learn academic English. They engaged with their peers inside of the classroom, especially during learning activities. Juan was an older returning student, and he explained that the age differencesin his non-ESL courses sometimes made him feel alienated in his courses where he sat with teenagers and young adults. However, having mostly Hispanic students in his ESL courses and working on the same goal of learning academic English helped him engage more in-class and get over his initial feelings of alienation.

Most of the students in the ESL classrooms were Hispanic like the Hispanic Generation 1.5 participants. As the participants progressed in their coursework, they noticed that there were less Hispanic peers in their developmental writing and reading courses. After completing developmental courses, they found few Hispanic students in 
their credit courses, especially the credit-bearing courses beyond the two required composition courses. Participants who had moved beyond the ESL courses commented on the decreased number of Hispanic peers as they progressed beyond ESL; however, they did not provide many explanations about how they felt in courses with few Hispanic students.

\section{Teacher Initiated Peer Engagement}

Contrary to Aracelis' viewpoint of peer engagement being inevitable, some participants admitted to only interacting with peers within the classroom when prompted by their teachers in structured activities. For example, Carlos mentioned that Hispanics stick together, and he discussed the importance of peer engagement in the classroom and the types of in-class peer engagement activities. However, in class, he engaged with his peers mostly when the teacher created opportunities for engagement such as having students share drafts. He did not discuss voluntary or spontaneous interactions or engagement activities with his peers within the classroom.

Like Carlos, G rarely engaged with his peers inside the classroom spontaneously. His peer engagement experiences within the classroom took place when the instructor created a peer engagement opportunity and literally pushed or required students to work together. When probed for an explanation for his lack of voluntary engagement, G pointed to the structure of the classroom as being a primary culprit for the lack of peer engagement. He explained that the seating arrangement did not allow for easy and comfortable classroom interactions. His anecdotes provided evidence that the teachers' creation of engagement opportunities was a critical factor for peer engagement in the 
classroom, especially with Hispanic Generation 1.5 students in ESL courses at the college.

As evidenced in the discussions with Carlos, G, and several other participants, the most common and effective form of in-class peer engagement was based on cooperative learning activities, especially when the instructor assigned the partners or group members. When discussing peer engagement, Carlos focused mostly on engagement that took place during structured cooperative activities such as peer editing. He explained:

The professor put us to do activities like write a paragraph. So we exchange with other students. I correct it for one. He correct it for me. Like that. Sometimes, if they don't know something, and I know it, I tell them the way that I think that I know.

$\mathrm{G}$ expressed that he participated in very limited voluntary or independent peer engagement within his classes, but that he had begun engaging more with his peers in his Computer Applications class because his instructor assigned partners for some of the more recent class activities. However, he never described the actual relationships with his peers and how they worked together.

Peer Engagement outside of the Classroom

The study data revealed that in-class engagement was more common and more important with peer engagement outside of the classroom. There were limited intentional peer engagement opportunities outside of the classroom. The ESL curriculum rarely if ever provided extracurricular activities or events for the students, and the faculty and staff rarely required students to work together on projects outside of class. Therefore, only a 
few participants engaged with peers outside of the classroom, and most of the out-ofclass interactions were for academic purposes.

\section{Academic Peer Engagement}

The most common type of peer engagement among the Hispanic Generation 1.5 participants was academic engagement, and the most common purpose was to catch up with class work or homework. For example, Awilda talked with some of her peers outside of class to discuss homework assignments. Aracelis mentioned that, as Latinos who support each other, she and her peers called each other to find out about missed class work and to understand homework assignments. Like Awilda and Aracelis, most participants discussed brief types of coursework-based engagement experiences when referring to peer engagement outside of the classroom.

A few participants went beyond descriptions of brief encounters outside of the classroom and discussed more meaningful academic engagement experiences with their peers. For example, Juan formed a study group with his Algebra peers, and they met at the Lincoln campus to study for their exam. Ingrid worked with a friend on her ESL assignments before and after class in the evenings. Carlos sometimes completed course assignments with his peers outside of the classroom in the building's study/lounge area.

\section{Engagement with Peers through Involvement Opportunities}

Out of all the participants, Anthony was the one most engaged with his school peers in the study because of his involvement in the college's track team, through which he engaged daily with his school peers. He introduced himself to new students and 
became the team's recruiter, helping him interact with a greater number of peers on a daily basis than any of the other participants. For track, he was the team captain and the main student recruiter because of his strengths in interacting with his peers. His work as a recruiter helped him become a role model and mentor to other CMCC students. $\mathrm{He}$ discussed how he helped specific students join the team and do something meaningful for themselves through track. Anthony was determined to improve consistently as a person through school, sports, work, and other life experiences, and he motivated his peers to join the track team and to work towards a better life as well.

As with his track-based mentorship work, Anthony served as a role model to other students at the college and in the local high schools through his involvement with a Hispanic engineering group in New England. He explained:

We go to high schools and we talk to involve Hispanic people in the engineering field, so we go to Lincoln High, Madison High, Hawthorne High. We go and talk to all the Hispanic community and be like "Oh you guys. Look where I am. You can do the same thing." And it's not hard.

Anthony's positive engagement experiences in high school and college empowered him to develop into an independent, self-motivated, goal-setting individual, and, as such, he wanted to share his knowledge and experiences with otherstudents, interacting with peers on a daily basis.

For many participants, school engagement activities conflicted with school and work schedules, which led to decreased engagement among ESL Hispanic Generation 1.5 students unless provided with well-designed opportunities by classroom instructors. Outside of class, Carlos participated in a couple of school activities with his peers. He even won a digital camera for his participation in a science event in which students sat in 
mini science lectures and completed science activities as part of an initiative to get students more interested in science. However, he was only able to participate because his evening instructor informed the class of the activity and started the class late in order to provide students with an opportunity to attend the event and walk over to the building where they normally take their evening ESL courses. The instructor's ability to modify the class schedule and encourage her students to get involved helped Carlos engage with peers through structured engagement activities at the college. However, many instructors, particularly adjuncts, might not be aware of these activities or feel uncomfortable altering class times and encouraging students to participate.

\section{Social Engagement Outside of School}

Anthony's extra-curricular activities pushed him to engage with his peers outside of the school for non-academic purposes. Other participants who engaged outside of school were not involved in extra-curricular activities. Juan engaged with at least one peer outside of the school on a few occasions. When asked about those experiences, he explained that they would go to a bar, have a few beers, and chat for a while.Even though it was a small city with limited engagement areas, Lincoln had many bars and cafes where local residents could meet up with friends and relax over food and drinks.

Carlos spent a significant amount of time engaging with his peers outside of the classroom and outside of the school as well. He chatted with peers before class, during class breaks, and after class. He was often seen with female classmates chatting about non-academic topics before the start of class and during class breaks. Carlos also engaged more with his peers outside of the school than all the other study participants. 
Sometimes he visited his friends at home. In addition, he and his peers went out to the movies, the mall and the local nightclubs. Unlike the academic peer engagement experiences of both Anthony and Juan, Carlos focused mostly on social engagement with his peers, and his engagement activities took place outside of Hawthorne and Lincoln.

\section{Peer Engagement and Satisfaction with the College Experience}

The three male participants (i.e., Anthony, Carlos, and Juan) were very satisfied with their engagement and overall experience at $\mathrm{CMCC}$, and they were the most highly engaged students out of all ten Hispanic Generation 1.5 participants. Their peer engagement experiences and their perceptions of their college experience support Krause et al.'s (2003) findings that there is a positive correlation between the frequency of students' interactions outside of the classroom and student satisfaction with the whole college experience. The Hispanic Generation 1.5 students who engaged minimally with peers outside of the classroom expressed some dissatisfaction with the institution and/or part of their educational experience. However, none of the participants regretted attending CMCC or desired to leave the institution, with the exception of Awilda who was frustrated by her inability to move beyond ESL courses because she had not passed the required writing assessment.

\section{Lack of Peer Engagement Experiences}

Even though some participants expressed that being Hispanic like their ESL peers was a positive feature for peer engagement, most participants had not had many peer 
engagement experiences outside of the classroom, and some participants had no peer engagement experiences to share during the interviews. Some of the Hispanic Generation 1.5 students chose not topursue peer engagement outside of the classroom because they wanted or needed to focus more on their family responsibilities and their school or academic responsibilities.

\section{Family Responsibilities rather than Peer Engagement}

None of the female participants discussed spending time with peers outside of school or being involved in activities or sports. For these female participants, the most significant reason for not interacting or engaging with peers was their responsibility to their loved ones. Some female participants had children, and they chose not to engage with peers outside of the classroom because they needed to devote non-classroom time to their jobs and their families.

Stephanie was a young mother to a little boy, who she brought to her interviews. She explained that family comes first for her and that when students start building a family, they cannot detract their attention to peer engagement or school activities. She had no strong relationships at the school, and most of her engagement experiences were what she called "hi and bye" conversationswith peers. Like Stephanie, Aracelis was also a mother. She had three children, and she was very conscientious of how she chose to use her time because she wanted to devote enough time to her children, especially on the weekends. Her children came first, and she already felt that she was sacrificing her children for class time three to four nights a week. Therefore, her peer engagement 
experiences were very limited outside of the classroom, and she never considered participating in any school activities.

Sara was in a similar situation as Stephanie and Aracelis because she was preparing to be a mother and chose not to engage with peers outside of the classroom. At the time of the interview, she was pregnant with her first child and had just moved in with her boyfriend. Her time out of class was focused on preparing her new home and preparing for her new child. Once the child was born, her time would go to caring for that child. Peer engagement outside of the classroom did not seem critical to her daily life even though she wished she had a peer who could help her with schoolwork. However, in-class peer engagement was important to Sara. She explained that she did not really know many people at the school, but she was positive that she would meet more people in her courses and perhaps increase her peer interaction within her courses as she continued taking classes.

\section{Academic Responsibilities rather than Peer Engagement}

Some participants chose not to participate in engagement opportunities because they wanted to focus on their schoolwork regardless of opportunities or suggestions provided by their instructors. For example, Anthony was highly engaged both inside and outside of the college; however, when he first arrived at the college, he did not even want to join the track team because he was afraid that engagement at the institution would keep him away from his studies and deter his academic success. He explained:

When I came here, school was like taking my time so I was like, "I'm not running. I'm not running for the school. I'm not." School was too much. "No running for me. I'm just gonna focus on my school and have my career. Forget 
about the running. What is running going to give me?" That's what I was thinking.

Anthony initially perceived involvement and engagement as potential hindrances to his academic success. He tried to stay away from extra-curricular activities, but he could not resist track after years of being on his high school track team.Later, Anthony realized that track was critical to his success as a student because he was a more satisfied, and engaged,and academically successful person when he had multiple responsibilities in his life.

Echoing Anthony's initial sentiment about peer engagement as an academic detractor, Tomas did not seek involvement or engagement with his peers outside of the classroom so that he could focus on his academic responsibilities and goals. Tomas was not involved with school engagement activities such as sports, clubs, and other extracurricular activities because he was focused on his studies and his goals of getting a bachelor's degree, going to medical school, and becoming a reconstructive surgeon. Peer engagement was not important to him in reaching these goals, and many times he chose to do homework assignments and get tutoring rather than spend time with his classmates.

\section{Significant Peer Relationships}

A few participants actually engaged in extensive academic peer engagement through significant relationships with particular peers, and these relationships had a positive impact on their academic success at CMCC. Ingrid developed a significant relationship 
with another female student, and the two friends counted on each other for homework assistance.

I met my friend Jenny in CMCC and she was in the same position as I with the English and all that. And we started talking. We have become good friends like good friends. But she is very intelligent. Sometimes we help each other for example with the homework. Sometimes we try to do it together. Like "I don't understand this. Help me."

Ingrid developed a relationship with a peer and through that relationship they supported each other in moving forward with their studies. They completed homework assignments together and used the computer lab together as well.

Other participants developed significant relationships with peers that evolved into romantic or intimate relationships at some point. Awilda met her boyfriend in an ESL course, and they supported each other academically inside and outside the classroom. However, her boyfriend was no longer enrolled at the college because of financial aid issues. Sara's boyfriend attended CMCC, but she explained that he was in a "low" ESL level while she was taking credit courses. This difference in academic level and English language skills meant that she spent their free time helping him with his assignments. If she needed help, he could not assist her because she was at a much higher academic level.

Like Awilda and Sara, G met someone who became his girlfriend during his first semester at CMCC. However, G's girlfriend provided him with support other than homework assistance unlike the other participants who developed significant relationships at the college,. She pushed him every day to meet his academic obligations so that he could be successful. She would call him in the morning to wake him up for class and even offer him a ride to school so that he would not be late. She reminded him of classmeetings and assignments. However, $\mathrm{G}$ and his girlfriend broke up, which meant 
that he lost that external support system that enhanced his success as a college student. Therefore, he was trying to find a support system with his course instructors.

\section{Perceptions of Peer Engagement with Hispanic Peers at CMCC}

While the literature points to peer engagement as having a positive effect on students' academic success, most study participants did not perceive peer engagement to be highly beneficial for their own academic advancement. Participants believed that peer engagement with Hispanic peers outside of the classroom negatively affected their English language learning and even their academic success. Some participants even expressed peer engagement as being a negative influence and a possible deterrent in their academic goals. This section focuses on the participants' perceptions of engagement with Hispanic peers.

\section{Language Learning and Peer Engagement}

Participants preferred spending time with non-Hispanic peers for a variety of reasons. The first and most common reason was that the participants were forced to use English with non-Hispanic peers, which helped them develop their English language skills outside of the classroom. Aracelis enjoyed working with a Chinese peer in her ESL courses not just because he was helpful during computer-based learning activities, but also because he could not speak or understand Spanish. Therefore, Aracelis was forced to communicate with her Chinese peer in English, their only common language, which helped her develop her academic English speaking skills. 
Ingrid explained that she had Arab friends at $\mathrm{CMCC}$ and preferred spending time with them because she practiced her English and even learned some new words with them. She stated:

It's good cuz I take it like a practice for my English. I feel that it helps me and like that we can learn one from the other. There are many things that I don't know in English that they know.

In relation, her main issue with being placed in ESL courses was that she had to take classes with other Hispanic students, which gave her many opportunities to use Spanish rather than English. She felt that interacting with her Hispanic peers hindered her ability to practice and improve her English speaking skills.

Carlos echoed Ingrid's concern of learning English with fellow Hispanics in the classroom. He explained:

To learn like more the language, I don't think that it's good [to be with Hispanic peers]. To learn the language no because you are always going to speak in Spanish....Like making friends and that, I wouldn't feel the same. But to learn, one learns more [without Hispanic peers] because if you do not have with whom to speak Spanish, you have to speak English.

During class breaks outside of the classroom, Carlos would engage with his peers using mainly Spanish. Inside of the classroom, all participants used English as much as possible because the instructors would not allow the use of Spanish inside the ESL classroom. However, the English-only rule did not always apply in non-ESL classrooms when engaging with peers. The non-ESL teachers did not require that students use English in the classroom when they engaged with their peers during group activities, and sometimes did not care which language the students used with each other during class time. 


\section{Academic Success and Peer Engagement}

For some participants, Hispanic peers were a bad influence and deterred them from their studies and success even though they were all in an emerging Hispanicserving institution and most of them lived in Spanish-speaking communities. G had difficulty taking non-ESL courses at the Lincoln campus of the college because most of the courses had a very high number of enrolled Hispanic students. He felt that the overly-Hispanic setting distracted him from his academic responsibilities as if the students' "bad vibes" could reach him and negatively influence him. He explained:

And like the people know me. You see the vibes. Like it travels to you. Oh you're like "Oh whatever." Let's say you have someone negative always in front of you always talking. For that class I gotmostly girls and they've got me tired with that soap opera crap. "Oh come on, man! I want to do the work but you keep talking right there?"

G did not want to be in the perceived negative Hispanic peer environment that he left in New York. He wanted to focus on his studies and aim for academic success, and he found his Hispanic peers to be a distraction at the Lincoln campus.

Like G, Anthony was open about his perceptions of his Hispanic classmates. He felt an internal conflict when speaking about his peers because he was Hispanic, and he enjoyed the company of his peers. However, he also felt that his Hispanic peers were deterrents to his success and could hold him back in school and in life. He explained:

Like I don't have a lot of Hispanics [friends] just because. Because they get me lost. Because they're friends, but I feel like most of them like don't feel like they want to move on, progress, do something better for their lives, and I want to. I want something better for my life. I want to be somebody. And Hispanic students, like most of them like because of the way they are, most of them they just want to like "Ah." 
For Anthony, the "ah" was a sound of just wanting to continue doing the same things, including working, watching television, and going to school, but not pushing themselves to the next level in order to advance academically, financially, and personally. Anthony struggled to articulate the quality of his Hispanic peers who he believed negatively impacted his ability to progress towards having something better in his life and being somebody. He struggled with both his perceptions of his Hispanic peers and his perceptions of his relationship with these peers.

Anthony did not try to group Hispanics as bad people in the academic setting, but he made a clear distinction between his Hispanic and non-Hispanic peers, seeing that his non-Hispanic peers had goals and plans for reaching those goals.

But I have really good friends like that, Hispanic. Yeah. They're my people but my other friends they have a plan. They have goals. "And look with whom you travel, and I will tell you who you are." If I'm with people that want nothing for their lives. I'll make the same mistake, maybe. So if I'm with people who know more than me, who are intelligent, which I have Spanish friends too that are mentally like that but most of them are not. So those people, those are the people that I need because they will drive me.

Anthony's description of his peers and his peer engagement choices highlighted his internal conflict with belonging to his own group (i.e., Hispanics in Massachusetts) and leaving his Hispanic peers behind for academic and life goals that are based on his education. Engagement with fellow Hispanic students mightseem logical because the cultural and linguistic commonalitiesease the academic support process. However, some of the participants found that these commonalities also enhanced the effect of negative influences within their cultural groups such as spending too much time on non-academic activities. 
Peer Engagement and Belonging at the Institution

The participants related their perceptions of their peers and peer engagement experiences to their sense of comfort and belonging in the courses, program, and institution. G sometimes struggled with belonging at the main campus because he had difficulty making friends inside and outside of the classroom. He felt his peers were not as accepting of him as his peers on the Lincoln campus or in his New York City community college. While he desired to not be distracted with Hispanic peer in the Lincoln campus, he still felt a need to fit in with his peers at the main campus.

G had several stories of not fitting in with his peers on the main campus, and the same day as the interview, he had an uncomfortable experience on his way to his writing class. He came into the building with his winter jacket and a colorful winter hat. He explained:

Like I was coming in the building and some girls just kept looking at me. "You like the hat. Take a picture." What's wrong? I feel like I'm in high school. God! But I'm the type of person who will talk and go up to you, "Hey!" but I kind of get a little intimidated here [on the Hawthorne campus].

G was a very outgoing person based on his actions and words during the interview and his personality outside of the school. However, the main campus made him feel like an outsider when trying to connect with his peers. He was struggling to speak up with peers, even the ones in his learning community, who he saw for a minimum of 8 hours a week.

Like G, Carlos experienced a sense of not belonging when he first started taking courses at CMCC. He explained that he was in a new school with new peers, taking ESL courses, which were all at night. All these aspects of being a student at CMCC were new 
to him and made him feel uncomfortable and alienated. However, because of his friendly and outgoing nature, Carlos overcame many of his fears and discomforts and began to engage classmates inside of the classroom and then outside.

For most participants, social and academic engagement outside of the classroom did not relate to their sense of belonging at the institution. If they did not feel comfortable with the social environment outside of the classroom, the participants did not mind very much and did not express feelings of disengagement or alienation except for G. However, feeling comfortable among their peers within their actual courses related to how they expressed their feelings of belonging at the institution. The participants many times connected how they felt within the classroom among their peers to how they felt being at the institution in terms of comfort and belonging.

\section{Peer Engagement in Comparison to Other Immigrant Groups}

Like the Hispanic Generation 1.5 participants, all other immigrant groups valued in-class peer engagement the most, especially while completing cooperative learning activities. The peer interaction and engagement experiences of the Hispanic Generation 1.5 students were different from those of their first generation Dominican peers, second generation peers, and Haitian Generation 1.5 peers. Many of the Hispanic Generation 1.5 students participated in some form of peer interaction outside of the classroom. The Dominican first generation students did not provide specific examples of peer engagement outside of the school, but they discussed how they constantly met with each other outside of the classroom and helped each other with assignments. Laura even 
learned about her new home city, Lincoln, through her peer interactions outside of the classroom. The second generation participants were more socially engaged with their peers than the other groups of students, and they spent time playing basketball or hanging out in the student center on the main campus. They enjoyed non-academic peer engagement and wanted more of that social engagement with their peers unlike the Hispanic Generation 1.5 participants. The Haitian Generation 1.5 students were much more engaged with their peers than their Hispanic counterparts outside of the classroom as well. They participated in school activities and even played soccer on campus with their peers on Saturdays.

Peer Engagement Differences among the Three Units of Analysis

Generation 1.5 students were most engaged with their peers inside the classroom while they were taking ESL courses in which they worked together on various learning activities. Peer engagement was more natural for the students in the ESL courses because they shared more common characteristics with their peers. Most ESL students at CMCC were Hispanic, and they were all there for the same purpose - to acquire academic English. These commonalities made the students more comfortable interacting with each other, especially during structured group learning activities. The participants also engaged with their peers outside of the classroom by providing course information mostly before the start of class. Some of the participants helped each other with ESL classroom assignments outside of the classroom, like Ingrid and her friend who got together at least once a week throughout the semester to complete homework assignments. 
The participants engaged less with their peers when they transitioned to their developmental writing courses. They engaged with their peers the least when they transitioned into credit courses. In the developmental and credit courses, Hispanic Generation 1.5 students had less in common with their classroom peers. As they moved up in their coursework from developmental to credit courses towards a degree, the percentage of Hispanic students in the classes continued to decrease depending on the major. However, according to the faculty, the developmental and credit writing courses incorporated cooperative learning activities or at least some form of group work, which helped increase the amount and type of interactions among classroom peers. For example, the Basic Writing course required that students share drafts of their papers with each other for peer editing activities. Credit courses adopted more lecture models and discussion groups and integrated the least amount of structured peer engagement opportunities.

\section{Summary}

This chapter included the findings on the Hispanic Generation 1.5 participants' engagement experiences with their peers. Overall, male participants were more engaged with their peers than female participants, and they were more likely to engage outside of the school and be involved in school activities. Most female students did not engage much with their peers outside of the classroom, especially female participants who had children, were involved in a romantic relationship, or were pregnant. Ingrid was the only participant who did not fit this profile, and she was the only female participant who 
engaged extensively on academic matters outside of the classroom with a peer. Many participants preferred to not engage with peers outside of class because they did not want to spend additional time away from their family, work, and academic responsibilities, or they felt that their Hispanic peers could deter them from their studies. The most interesting finding was the desire not to be engaged with Hispanic peers, especially for the younger participants who were attending $\mathrm{CMCC}$ with the goal of graduating and "being somebody in life" such as Tomas and Anthony.

The next three chapters will include additional engagement findings from the study. Chapter 6 presents the findings on Hispanic Generation 1.5 students' engagement experiences with faculty. Chapter 7 focuses on Hispanic Generation 1.5 students' engagement experiences with staff members at the college. Chapter 8 presents findings on factors that affect Hispanic Generation 1.5 students' engagement at CMCC. 


\section{CHAPTER VI}

\section{ENGAGEMENT EXPERIENCES WITH FACULTY}

This chapter focuses on Hispanic Generation 1.5 students' engagement experiences with faculty at CMCC. The participants engaged with the faculty both inside

and outside of the classroom. There were differences in the type, purpose, and perception of the engagement experiences. Hispanic Generation 1.5 students mostly engaged with faculty during class time. Students sometimes engaged with faculty outside of the classroom, mostly to discuss learning in the course and mostly before or after class. The findings show that the Hispanic Generation 1.5 participants at CMCC perceive that their engagement experiences with faculty outside of the classroom had the greatest impact on their sense of belonging at the institutional level. However, the most powerful type of engagement experience was structured one-on-one time with faculty members outside of class time, and the second most powerful types was participation in program or college projects. In this chapter, the faculty and student engagement findings are divided into three sections: (a) in-class engagement experiences, (b) out-of-class engagement experiences, (c) other engagement experiences with faculty, and (d) the development of a sense of belonging through faculty-student engagement experiences.

\section{Engagement with Faculty inside the Classroom}

The most common type of engagement with faculty members was in-class academic engagement focused on course activities. Many participants admitted to only 
engaging with faculty inside of the classroom and mostly during class time rather than engaging with faculty before class, after class, or during class breaks. Some participants engaged instructors during non-instructional time but still in the classroom. For example, Carlos engaged with his instructors inside of the classroom during class breaks and only on topics that related to how he was doing in the course and how he was doing in related courses as well. He rarely engaged with faculty outside of the physical classroom. These engagement experiences with faculty during instructional activities shaped the students' perceptions of their engagement experiences with the faculty and their perceptions of those faculty members, which fueled their perceptions of the school as well. Therefore, this section focuses on the students' engagement experiences with faculty members and their perceptions of the faculty at CMCC.

\section{Positive Perceptions of Classroom Engagement with ESL Faculty}

Regardless of how they perceived their ESL placement, the Hispanic Generation 1.5 participants had positive engagement experiences with ESL faculty members, and, therefore, had positive perceptions of the ESL faculty. Students who were enrolled in ESL courses at the time of the study only had those ESL faculty engagement experiences to share. However, half of the participants were taking or had taken developmental or credit courses at the time of the interviews. These participants had broader faculty engagement experiences, but they also focused on the ESL faculty when discussing positive engagement experiences with faculty members and positive perceptions of faculty at CMCC. Most of the participants did not include developmental or credit faculty when discussing positive engagement experiences with faculty at CMCC. 
In general, participants found that the instructors at $\mathrm{CMCC}$ were nice to students and helpful in class. Some participants based their positive perceptions on how well the instructors worked with students academically. Ingrid, an ESL student, expressed that she got along well with the ESL teachers. She assured me that if students need help, there were teachers who could explain things to them. Carlos also had a positive perception of his ESL instructors. He felt that his current ESL teachers were all very nice and that they were teaching much better than his high school instructors. He expressed that he was learning a lot more English at CMCC than at his high school.

Sara had positive engagement experiences with one of her first ESL instructors, with whom she continued to take more ESL courses. When discussing the CMCC faculty, Sara always remembered that ESL teacher fondly.

They were very good. I remember that my first teacher was Jennifer Tennison. Oh my God! She is a love, that woman. She's so good. She's great. I took a lot of classes with her of grammar. Yeah and reading and writing. She's really helpful. She's always pushing you in a good way but to do work, and if you do it bad, she's always there helping you. She gives the work back to you so that you can do it.

Sara took several courses with the same instructor and appreciated how the instructor pushed her to learn the material and do her best as a student.

Like Sara, Aracelis stated that the teachers were nice and helped students enough.

She described her grammar teacher as being very helpful in class.

My relationships with my professors are good. They help a lot. My grammar teacher is a person who 50,000 times you ask her, "I didn't understand."

She says, "I am here." She goes again and explains it. You go again and get confused. She goes again and explains it to you. She is good teacher. She helps me a lot. Any doubt, there she is. What she tells us is "I came here to teach you. I want you to leave here knowing. Not that you come and pass my class and don't learn anything," so she is a very good teacher." 
The most impressive instructor for Aracelis was the teacher who was willing to teach her students and refused to let them only pass a course without learning the material.

The Hispanic Generation 1.5 participants, especially the older returning students, appreciated teachers who were willing to work with students and push them beyond the basic expectations of being in a course, as was evident with Sara's description of Jennifer and Aracelis's description of her evening grammar teacher. However, other ESL instructors were not ignored by the students. Aracelis explained that she had a positive perception of her other instructors as well even though that perception was not as high or as positive as her perception of the grammar teacher. She stated, "The grammar teacher is Puerto Rican. And I understand really well [her] speaking. The other is American and she is comprehensive. She explains to you enough the problems that you have with writing and that. I am satisfied." Aracelis was satisfied with having an instructor who could identify the students' writing problems and help them improve.

Like Aracelis, Juan appreciated similar qualities in his instructors. He mentioned that all his teachers were nice and he liked them all. However, when discussing positive instructors, he focused on his former ESL instructors who helped him with his reading and writing skills. When describing his Writing 4 teacher, he stated, "She was nice. She was very helpful. Anything you wanted, she would come early, stay late, between class. Whatever you need, a question, she would stop, and it wasn't a problem for her." When asked for an example of how a teacher had helped him, he explained:

I mentioned before the example "there, their." I used to make a lot of those mistakes and for my first essay, when I did it, she took me aside and I had a lot of mistakes with those two words that were confusing, and she showed me. I don't remember what she told me, but she told me, "The best way to remember which 
one to put in a sentence was something." I don't remember exactly what it was but she was nice.

Juan appreciated the instructor who was willing to identify students' English language weaknesses and help students understand and apply the necessary knowledge to improve those areas. Juan remembered how he perceived his instructors because of his engagement experiences with them, but he did not remember the actual engagement experiences well enough to give specific examples.

Like Juan, Anthony appreciated how his ESL writing instructor focused on isolating and articulating his areas for improvement and provided him with targeted instruction based on his learning needs. Anthony explained:

Ralph, his mentality, was different from the other teachers.... He's a really smart guy. That's what I think. I see him, and he's like really smart, like the way you do things. He gives me a paper. [He says,] "Correct this."

All right. [I say,] "This is wrong. This is wrong. This is wrong." wrong."

And he says, "All right. You missed all this, so this is what you have

I was like "Wow that's really clever." I would have never thought of that. And he was showing me stuff, and I was like "I'm gonna stay in this class," even though like it was easy, and I got lazy in one way, but it was good. It was good for me. I was feeling [like] I was learning.

Ralph was perceived as an effective instructor because he isolated students' writing strengths and weaknesses, and he helped students improve in those weak areas. Anthony saw that Ralph's instructional style and patience were unique and that this particular ESL teacher had a strength that he did not find in other instructors outside of the ESL courses.

\section{Personal Connections with Faculty}

Some students developed positive perceptions of their faculty through emotional connections that emerged out of their engagement experiences. G had been a community 
college student in New York prior to moving to Massachusetts and attending CMCC.

His perception of the faculty members was based on how much they cared for their

students, and he constantly compared his experiences at CMCC with his experiences at a

New York community college.

Down here, Ralph and Melinda actually care. Like they give you a chance. They warn you. They're like "Hey look. You're failing. Come on." Over there you fail, and they give you an F, and you don't pass, and that's it. And here if you are failing, what do you do? What happens? They actually try to pull you aside and say "Look, try to catch up. Do this work. Do this tutorial. Try to do it." But over there in New York I feel like if you don't do it, nobody is there to help you. If you're not paying attention or you don't understand, you're forgotten. You stay with the rest.

$\mathrm{G}$ appreciated the effort that the instructors at $\mathrm{CMCC}$ took in order to make sure that he was successful in his courses. These instructors did not just focus on teaching within the classroom but on touching base with each student and making sure that the students understood their academic skill levels within these two courses.

His engagement experiences with Ralph and Melinda, his writing and computer applications instructors, affected his perception of the school and his sense of academic duty. When $\mathrm{G}$ was not very successful in school, he felt guilty because he realized that Ralph and Melinda cared about his learning and well-being, and they were taking extra measures to help him succeed, which made him value CMCC even more. He described some of his instructors' attempts at helping him when he slacked off.

They're good, but I've been slacking. Like I haven't been going to a lot of them. He tries to catch me and be like "Hey, look. Where have you been? You missed our appointment." And it kind of makes you feel like, "Oh, look. He actually cares," me coming from an environment where nobody cares. If it's not your parents or someone related to you, they're not gonna care. 
G valued his instructors' acknowledgement of his presence as a member of the class and his instructor's openness about missing class sessions or assignments. This acknowledgement by his instructors made $\mathrm{G}$ feel that the institution and its instructors cared about him because the faculty held him accountable. Therefore, out of a sense of duty and positive self concept, he developed a stronger sense of commitment to his courses and the institution.

Some participants focused their perceptions of the ESL faculty on how well the faculty understood the students' non-academic needs and how non-academic needs affected classroom learning and success. Stephanie tied her perceptions of the ESL faculty to their understanding of her time constraints as a single mom. She explained:

I have Mr. Ronald. He is a good professor. I see him like a good professor. If you need anything, he is there and he understands because sometimes like one has a son, he know that sometimes one has an emergency. He says, "Don't worry. You can give me later the work. Don't worry because of that. I will grade you later."

Mr. Ronald understood that sometimes Stephanie had responsibilities that kept her out of the classroom, and he expressed his willingness to accommodate her needs. However, not all of her instructors understood her circumstances. Like G, Stephanie developed a sense of commitment to these courses and instructors who understood her situation, acknowledged her as part of the course, and provided support that would allow her to be successful in the course.

Negative Perceptions of ESL Faculty and Classroom Engagement Experiences

While most of the comments about the CMCC instructors were positive, there were a few negative engagement experiences with some of the faculty at the school. For 
example, two participants had negative perceptions of the ESL faculty members at CMCC. While Awilda generally described her teachers as being overall good teachers within the classroom, she admitted that some of her teachers were lazy. She did not elaborate further on the point, so it is difficult to know whether she was referring to their general character or to specific teaching styles such as the use of group activities rather than lecturing. Awilda's perceptions of her ESL CMCC instructors were solely based on classroom experiences.

When discussing their ESL instructors, both Ingrid and Stephanie had suggestions for the improvement of instructional practices. Stephanie wanted teachers to explain things better. She did not want instructors to go too fast or to go too slow when teaching new topics in the class. Ingrid felt that teachers needed to take time out to see if students understood the lessons. She explained:

Well, check that one understands...because you don't do anything with explaining if no one understands you. Take a moment and talk with us. Like "Do you believe that you are doing well? Do you feel good?" And not speak so fast. There are some teachers who go "Blah blah blah." You talk too fast.

Ingridhad some negative experiences with an ESL instructor who did not interact with students during lectures in order to ensure that the students were following along and understanding the material. This lack of informal assessment affected her perception of those instructors.

Ingrid was the only participant who was taking a hybrid ESL course, and her main concern was that this particular ESL teacher was not clear during face-to-face instructional time. She explained:

With the only one that I have problems is with the reading teacher. I don't know if it's her or if it's me but I don't understand her. It's not only what one has to do, 
the computer, or writing, but there are many times that she puts things like in an English that sometimes I say it's a tangled English that sometimes I don't understand. I ask her something. For example, "I need help. I don't understand this or that or whatever." And when she is trying to explain it, she wants to explain it so well that she becomes a mess, and I don't understand anything. She confuses me. So no matter what, I stay confused but with the other instructors I do not have a problem.

One critical factor for Ingrid and many of the other Hispanic Generation 1.5 participants was having instructors who could interact with the students in an understandable manner. They needed reassurance that instructors could explain content in a manner that made it accessible to the students.

Negative Perceptions of Non-ESL Writing Instructors

Most participants described the teachers' interactions with the students during class with a focus on the delivery of information during lessons. Some participants explained how instructors tried to engage the students by telling stories related to the course learning activities, especially in writing classes. However, this type of engagement many times excluded students from the classdiscussion as was the case with Juan. Juan explained:

We didn't talk much. She usually one that do all the talking and try to get you related and tell you stories. Once in a while you would throw yours in there just not to make her feel bad.... and once in a while that class would get going and relate their own stories or their own experience or stuff like that.

This type of in-class engagement allowed Juan to relate more to the instructor and the course but not necessarily to become more engaged. While the instructor was trying to engage them with his/her stories, Juan felt he was being pushed away from the classroom learning. 
Like Juan, Anthony had a negative perception of his non-ESL writing instructors.

He viewed his Basic Writing instructor as lazy, and he felt that the classroom learning was not as challenging as his learning experiences in the ESL writing course. He explained:

Yeah like write a lot, add more details. To add more details. That's the only thing they teach you, to add more details and stuff. It depends on the teacher too. Like I think my teacher was lazy. A kid that is 10 years old, can walk into my class, the Basic Writing class, be there for a week, and next week he can teach it because he would say the same thing over and over again. "We're going to do this." Remind you about writing for next week. "Write about your favorite object."He just tells you what you need to do. In the sense that, "Oh. This is what we do in the Basic Writing. You have to do this." No specific way to do things, like to add details

Anthony had difficulty understanding different teaching styles across the different curricular areas and the importance of fluency development in the Basic Writing course.

Like Awilda, he viewed some of the teachers' instructional choices as evidence of laziness rather than seeing the instructional choices as attempts to help students achieve the desired learning outcomes. At the same time, the participants' stories showed how these instructors were not explicit about their instructional techniques and their reasons for completing certain activities, unlike the ESL writing instructors.

\section{Negative Perceptions of Content Faculty}

There were some negative engagement experiences in the non-ESL writing courses; however, most of the participants' negative engagement experiences with faculty took place within the math and science areas. While G only had positive comments about his ESL instructor, Ralph Langston, he did not have any positive anecdotes about his math instructor. 
Those math teachers. They don't care about us. And they sit there and eat. They say do this and this and they're eating. And you're like "I need help."

"I'll be right there." And you're like - I got kind of mean with her. I didn't mean to. I kind of called her a fat cow. She told me to get out and I said "Okay" and I called her a fat cow. I'm not disrespectful, but I'm asking for help and you rather sit there and eat. I mean, come on,Lady.

G struggled to work with this math instructor. He had found support in the ESL courses and responsive instructors who helped him with learning challenges both inside and outside of the classroom. When he got to his math course, he met an instructor who was not as willing to meet students' learning requests in class. The instructor's approach made $\mathrm{G}$ feel disrespected by the teacher and perhaps resembled some of his negative learning experiences in the community college in NewYork.

Juan also described negative engagement experiences with his math instructor, which focused on not getting the appropriate level of instruction needed to be successful in the course. He explained:

This teacher, he'd been teaching here for like 25 years, and every time he used to go to the board, we, all the students, used to tell him, "We don't know this class." He would just start writing or doing whatever he does and like if we knew what we were doing. It's just, to him, he'd been here so long that it was natural to him. We're like, "You need to slow down. That's why we are here. We don't know. You start writing and we don't know. We get lost. You need to slow down." He used to do it all the time, just like a habit, but he was a nice teacher... That was in Algebra 1 and Chemistry.

At the end of his anecdote, Juan noted that this instructional issue was evident in both his math course and his chemistry course. He felt that thesenon-ESL instructors did not relate the material enough to their students and did not teach to the students' content and English levels.

When asked about general instructional help during class time in the non-ESL courses, some participants agreed that the instructors sent students to the course textbook 
rather than explaining the content area further. G explained that when students needed help in a course, the instructors typically sent them to the textbook to do research and that students could rarely find the instructors outside of the course. He compared his nonESL instructors to the ESL and Computer Applications instructors from his learning community:

If you've got a problem, you go to the book or do research because these teachers they would not write on the board, "Oh I'm in this room. Come see me." No. If you didn't listen, there's the book. Do research. Like I just noticed that. [Melinda and Ralph], actually you can actually find them and bother then and "Oh. Hey." Sometimes I be loud in class, "No. Stop. Repeat it. Repeat it." And she just laugh, and she repeat it.

The aspect that $\mathrm{G}$ found disappointing in his non-ESL instructors' methods was that they were not as willing to work with students outside of the class time. From the interviews, it seems that the math instructors and many of the other content instructors were adjunct faculty members who did not have a physical space or the time to meet with students outside of class.

\section{Perceived Effects of Negative Engagement Experiences with Faculty}

Some of these negative engagement experiences with faculty members could affect students' decisions to stay or return to an institution. After one year away from CMCC, Aracelis wanted to return to school, but discovered that in order to continue at the school she had to retake her pronunciation course because her final course grade was lower than $\mathrm{C}+$. She explained:

My only frustration was when I took pronunciation with Adam Hoover. That was my only frustration. That was the only one. But after, everything fine. Because it was the only frustration that in that time I don't know if I failed or passed with a bad grade. I know that I got a low grade, like sixty something. I don't know if with that one fails. I know that when I one time thought about returning to school 
and I went to check, I was told that I had to repeat that course. That was one year after I left that I thought about returning.

Aracelis had a miscommunication with her instructor and did not know that she had received a grade that was too low to move on to other courses. While taking the course and completing assignments, she was not aware of the possibility of not passing the course or needing to retake the course based on how she was being assessed. This lack of communication with the instructor on the course learning activities, the final course grade, and the effects of that course grade on her future registration efforts affected Aracelis' ability and desire to enroll in ESL courses. Feeling rather surprised and deceived, she stayed away from CMCC for another eight to nine years. Her alienation was caused by a lack of communication between the instructor and the participant.

Aracelis reacted to her negative engagement experience and alienation through miscommunication by staying away from the institution for nearly a decade. Similar to Aracelis, Juan completed a course where he felt that the teacher's approach did not promote engagement with peers or the teacher within the classroom. However, unlike Aracelis, he completed and passed the course, and he stayed enrolled at that institution. $\mathrm{G}$, on the other hand, chose to drop out of Basic Math after experiencing negative engagement experiences with a faculty member. He never attempted to speak with the math instructor outside of class time, and he did not seek the advice of college advisors or other faculty members.

The lack of communication and the perceived lack of support inside the math classroom made $\mathrm{G}$ feel disengaged and alienated in the classroom. G continued to explain the effects of this particular negative classroom experience: 
The math teacher. I ask you for help and you keep eating. That's why I dropped it. I was like, "No. Forget about it." And it's during class time. I feel like everybody is struggling with the book and I'm like "For real? Really?" I just went to the office the other day and dropped it. Whatever.

This negative in-class engagement experience with the math faculty member led $\mathrm{G}$ to withdraw from a course that he was required to take in order to graduate. This negative engagement experience could threaten his success in the school, especially if he has negative engagement experiences with his future math instructor when he re-enrolls in Basic Math.

\section{Engagement with Faculty Outside of the Classroom}

While the participants most commonly engaged with faculty inside class in relation to classroom activities, they still communicated with faculty outside of the classroom. Sara talked with her teachers outside of class; however, their conversations focused on the classes that she was taking and the things that she did wrong in class. She never discussed anything personal with any of her teachers. Like Sara, Juan interacted with his instructors outside of class because some of his instructors arrived early to the classroom. Before the start of class, they would chat about essays and writing in general, but he never discussed anything personal with his instructors.

Aracelis, on the other hand, engaged with her instructors outside of class on both academic and personal topics, but only before the start of class sessions. She explained:

Sometimes before going to the class, she and I arrive at the same time. We don't sit down, instead we go walking to the class and we go talking about the class, of what she is going to do. Things like that. Sometimes she asks me of the kids. With the writing teacher not much because she is a bit more quiet. Sometimes she 
arrives, "Hi," and she starts writing on the blackboard what she is going to do in the class. But that's it. The other one is very communicative. She loves to talk about her stuff. She loves to ask us stuff.

Aracelis's only opportunity to interact with her instructors was before class and during class; therefore, she appreciated the instructors who took the opportunity to have conversations with her before class. From Aracelis's perspective, the quiet writing teacher might have been missing a valuable opportunity to interact with her students and make meaningful connections because she did not engage her students in conversation prior to class.

Anthony's instructors engaged with him outside of class often since they would see him during the daytime on the main campus. Anthony felt that instructors engaged with him to see how he was doing outside of class, especially as he transitioned out of ESL and developmental courses. When asked about how he interacts with instructors in the school, he responded, "It depends. Like they always ask "How is everything? How is your life?"I be like, "Oh I'm doing great as always." They like to hear that. Yeah. I just tell them what I'm doing in school and stuff."Anthony recognized unspoken social rules of interaction between teachers and students at the school. He understood that the instructors were checking on with him, and he provided responses that he believed would satisfy them even though he was not always completely open or honest with them.

Not all participants felt that they engaged or interacted with faculty members outside of class, especially the evening students. Ingrid did not mention any engagement experiences with faculty outside of class, except in relation to her hybrid ESL course, which required her to do activities online. She did not discuss interacting with her instructor online via chat, email, or discussion board. Stephanie did not interact with 
faculty outside of the classroom, because as a young mother, she had to rush home after class to relieve the babysitter and take care of her child. Carlos only interacted with his instructors inside the classroom during class time or during class breaks. Awilda confessed to not having interacted with her instructors outside of the class because she did not have the opportunity to do so. All four of these participants were evening students on the Lincoln campus,and their instructors were part-timers.

\section{One-on-One Time with Instructors}

Structured one-on-one time with instructors outside of the classroom provided a greater positive impact than any other type of engagement with faculty at the college, and the ESL instructors were more willing to work with students outside of the classroom than developmental and content instructors. For example, Tomas remembered a former CMCC instructor who always offered to help students during office hours or by appointment if students were unable to make any of his office hours.

Fred Davis. Remember Fred Davis? He left like in 2005, but he worked with me. He asked me to go to his office hours and if not he dedicate some other time to help me in some of the grammar skills that I needed to improve.

Fred always reminded students of his availability outside of class time to work with them on anything related to the grammar class or the school such as the campus layout and student life. The time he devoted to students outside of the classroom made a positive impact on Tomas and influenced his future learning experiences at the school.

Ralph, another ESL instructor, provided student support outside of the class meeting time. Herequired that students meet him once a week for a 15 -minute session, 
which they scheduled at the beginning of the semester. Anthony described those one-onone sessions with his writing instructor.

It was good.... He was mad. He was so mad at me all the time. "I can make you such a good writer. I can do this. I just need to change some things. I can change it. You can be such a good writer. We just need to change some little things, some silly mistakes that you make." Oh. This is good. I had fun with Ralph. It was good.

Anthony appreciated the personal investment that Ralph made in all of his students, proving that he cared about his students and their learning experiences. This perceived investment motivated Anthony to continue with his studies and focus on his goals regardless of his ESL placement.

Overall, the participants who experienced structured one-on-one time with faculty members appreciated the attention provided during that one-on-one time and how the instructors reached out to them for those sessions. The sessions provided students with a critical opportunity to focus on the types of writing and English language issues that are typical of many Hispanic Generation 1.5 students at CMCC. In addition, the individualized attention demonstrated the instructor's level of caring and investment, which the students could identify and appreciate. G explained how Ralph communicated with him and what happened when he missed any of his appointments. He explained: He'll [Ralph'll] call you. He'll be like, "Hey, remember your meeting." Mm hmm. I'm surprised he don't text. But nah like he makes you. I just noticed that. They are the only two that do care, that do that.... Ralph and Melinda. Yeah. Like out of that, out of all the courses in the two colleges I've been, that's rare.

G and most of the daytime Hispanic Generation 1.5 participants were impressed with the personal and persistent attention that they got from their ESL instructors, especially outside of the classroom. 
The structured one-on-one time provided a valuable engagement and learning experience for the students in the ESL courses and was available particularly to the students who took courses in the daytime. The instructors who engaged in structured one-on-one time with the Hispanic Generation 1.5 students were the full-time faculty members who mostly taught day courses on the Hawthornecampus. The evening students all had adjunct instructors since full-time faculty were contracted to work only up to 4 p.m. at $\mathrm{CMCC}$ based on union regulations. Also, all evening ESL courses were taught only at the Lincoln campus in Lincoln, Massachusetts; therefore, the evening students did not get to experience college life on the main campus until after they finished their ESL courses depending on their future certificate or associate's degree program.

The students who were most satisfied with their engagement and classroom learning experiences with faculty were the daytime students who took courses with the full-time faculty members on the main campus in Hawthorne, Massachusetts, and had access to structured one-on-one time with the faculty members outside of the classroom. The evening students were the ones who engaged less with faculty members inside and outside of the classroom and who were least satisfied with their experiences at CMCC. These findings on out-of-class engagement with faculty are supported by Umbach's and Wawrzynski's finding that students valued out-of-class faculty-student interactions more than in-class interactions (2005). Therefore, more of these valued one-on-one experiences could have enhancedthe participants' sense of membership and belonging at CMCC. 


\section{Integration Support for Students}

Fred Davis played a critical role in helping students develop a sense of belonging at $\mathrm{CMCC}$, beyond the area of ESL, by helping them learn about the physical spaces and meet key non-ESL faculty at the main campus.Tomas described how Fred took his ESL students on a tour of the college's main campus in Hawthorne. Tomas explained:

I remember one time that Fred took us on a tour to like in the Hawthorne [campus] because all the classes I was taking were at the Hawthorne campus. So that first semester he took us around the campus and he introduced [us] to all the professors. So it was like, I was already like knowing more like outside ESL circle. I was getting to know all the professors that some of them were my future professors.

During the tour, Fred showed his students all critical aspects of the institution, including the student center, and he introduced them to many developmental and content area faculty members. Understanding the physical layout of the college helped the students navigate the college campus and helped them feel more comfortable at CMCC.

\section{Work-based Engagement Experiences}

Another type of engagement experience with faculty was work-based engagement with faculty members through part-time employment and work study programs. This type of engagement was perceived by CMCC students and graduates as having a significant impact on their sense of belonging to the institution. Tomas had the opportunity to work at CMCC through the federal work-study program. As a work-study student, he worked for his former reading and writing instructors Gregory Winston and Jocelyn Foster. Working with them provided him with the opportunity to engage with them on a daily basis and to engage with other faculty members from the ESL, developmental, and credit programs as he completed his daily activities. However, he 
was the only participant who participated in the work-study program and one of the few who even knew of its existence.

\section{Involvement with Institutional Committees and Initiatives}

Having met many faculty members, deans, and department chairs through his work-study experience, Tomas was exposed to another type of engagement experience, which he felt had the greatest impact on his sense of belonging at CMCC. A faculty member invited him to sit on a committee with other faculty members for an appreciative inquiry project at the college. He explained:

So one day I found Tracy Cooper and I said hello to her, and she told me to sit down and how they were working on the appreciative inquiry project.... She told me that they were trying to gather a group to work on that and how they were thinking about finding four students. The goal was to have 40 to 44 members of that committee, and they wanted to have four students. I was so impressed. I am still so impressed of how she could think of me to represent the student bodycommunity of CMCC. There were three other students, which I don't know very well too. And I was during those meetings, I would look at the whole group and all of them would know me, and how any time it was my turn to talk, they would look at me.

The invitation to join the college committee was an honor for Tomas, and it provided him with an opportunity to have meaningful interactions with $\mathrm{CMCC}$ faculty about the institution and about ways of improving the college experience for other students. Those engagement experiences with faculty through the inquiry project helped Tomas develop a deep sense of belonging to the group of faculty members and the institution that lasted years after graduation. 
Engagement with Faculty and Belonging at the Institution

Faculty had the greatest impact on students' sense of belonging at the institution through the interactions and general engagement experiences with students inside the classroom as well as outside of the classroom. How faculty made the participants feel in the classroom was critical for the students' comfort and belonging in the classroom, which affected their general belonging at the institution. This finding is aligned with Chickering's first principle of good practice in higher education, which focuses on increasing interactions between faculty and staff (1987). Many of the ESL faculty members, in particular, Ralph, who was the upper level ESL writing instructor, played an instrumental role in helping studentsdevelop a sense of belonging in the classroom regardless of the students' initial perceptions of their ESL placement. All students who took writing with Ralph felt that they learned in the course, even though it was an ESL course, and they all expressed satisfaction with the instructors' level of interest inside and outside the classroom. They all believed that Ralph wanted them to succeed, and by the end of the semester, none of them felt that the writing course was a waste of time or that they did not belong in that course. Their positive engagement experiences in Ralph's ESL writing course and their developed sense of belonging through those experiences helped them develop a sense of belonging at CMCC as well.

The non-ESL instructors were not as effective in helping students develop a sense of comfort and belonging in the course, especially in reading, math, and the sciences. For example, Juan felt that some teachers made him feel uncomfortable in the courses even though they were nice. For Juan, the teachers were all nice, and they tried to engage him 
in the courses. However, not all his teachers could make him feel like he belonged in the course or likehe was getting something valuable from being in that course.

Unfortunately, all participants who had taken math and science courses were unsatisfied with their classroom learning and general engagement experiences. These content instructors did not help the participants develop a sense of belonging at the institution, and sometimes they help develop feelings of alienation, which led to at least one participant, G, withdrawing from his math course.

The most powerful type of engagement with faculty that could be made accessible to all students was structured one-on-one time with faculty members. In her dissertation, Oudenhoven (2006) found that Hispanic Generation 1.5 students desired more one-onone assistance from their faculty members, which supports the students' positive perceptions of their one-on-one time with faculty at CMCC. This out-of-class engagement experience with faculty provided students with an opportunity to discuss strengths and weaknesses of their own work and improve on their weaknesses. In addition, the faculty members used this one-on-one time to assist students with matters relevant to their academic survival and success at the institution.

The rarest engagement experiences had the greatest impact on developing a sense of belonging at the institution rather than just the courses or a specific group of people. However, only Tomas had an opportunity to engage in these rare experiences among all the interviewees. Participating in the federal work-study program allowed for a variety of engagement experiences with faculty and staff that helped students feel part of a group or community within the institution. Also, participating in institutional initiatives, projects, or committees gave students a feeling of being needed and appreciated by specific 
communities within the institution and those experiences and feelings had a great impact on developing a sense of belonging to the institution. Being on the inquiry project committee made Tomas feel that CMCC was a family and the students were the children. This feeling of family became the greatest contributor to his sense of belonging at the institution.

\section{Engagement with Faculty in Comparison to Other Immigrant Groups}

Like the Hispanic Generation 1.5 participants in this study, the interviewees in the other three groups (i.e., first generation, second generation, and Haitian Generation 1.5) had the most satisfying engagement experiences with the ESL faculty. The first generation Dominican interviewees felt that the ESL teachers were more interested in their classes and students than the developmental or credit instructors, and that they provided clearer and better structured instruction inside the classroom. The second generation interviewees expressed that their ESL writing instructor was invested in their success and acted as both teacher and guidance counselor unlike their non-ESL instructors. The Haitian Generation 1.5 interviewees appreciated the ESL writing instructor's method of identifying their errors and helping them become better writers through targeted instruction.

The interviewees had negative perceptions of non-ESL instructors just like the Hispanic Generation 1.5 participants. Some of the interviewees felt that the content instructors were difficult to find outside of the classroom and that they did not care for the students as much as the ESL faculty members. Laura mentioned that once students 
were in credit courses, they were on their own with faculty support. All interviewees in the three groups who were taking or had taken math had negative engagement experiences inside of the classroom with those math instructors, similar to the Hispanic Generation 1.5 participants' experiences.

\section{Engagement Differences among the Three Units of Analysis}

Most of the participants were not satisfied with their initial ESL placement at CMCC and the related exclusion from taking credit courses while completing ESL coursework. However, Hispanic Generation 1.5 students engaged more often with their ESL faculty and generally had more positive perceptions of their ESL faculty and their engagement experiences with those faculty members. The ESL faculty engaged more with students inside the classroom, and they created more intentional and sometimes required engagement experiences with students outside of the classroom as well. The ESL faculty members were unique in their development of intentional out-of-class engagement opportunities, such as Ralph's required weekly one-on-one meetings. The ESL faculty members also were unique in their use of office hours to interact with students on classroom topics and assignments and to provide assistance with personal matters and general college survival skills. Feelings of belonging to a group, program, or the institution developed most intensely within the ESL courses and the faculty members played a key role in helping students develop the necessary initial comfort with the institution and faculty. 
Negative engagement experiences shared during the study interviews occurred with faculty who taught developmental and credit courses. In developmental courses, students interacted very little with faculty members outside of the classroom. Students' negative engagement experiences with faculty within the classroom occurred mostly with the math and science instructors. The students did not interact with the math and science faculty members outside of the classroom, and they had negative perceptions of their engagement experiences with these faculty members inside of the classroom. Therefore, the students engaged with faculty inside and outside of the classroom the most while taking ESL courses. They engaged less with faculty while taking developmental courses, and they rarely engaged inside or outside of the classroom with their instructors while taking credit courses.

\section{Summary}

Engagement experiences with faculty played a powerful role in the students' sense of belonging at the institution; however, many students, especially the evening students, did not engage with faculty outside of the classroom. The first effective form of engagement was structured one-on-one time with course instructors outside of the classroom hours because students developed a sense of belonging within the classroom, through the relationship with the instructor and then a sense of belonging to the institution. However, only the full-time day students with limited or no family responsibilities had the opportunity to engage with faculty through these two forms of out-of-class engagement. All the other participants did not have the opportunity to 
participate in these two forms of engagement, especially the evening students who mainly had access to adjunct instructors.

Another effective form of engagement for the development of a sense of belonging was engagement with faculty outside of the context of coursework. Engagement experiences with faculty through work study programs and college initiatives forced students to interact with faculty on matters other than classroom learning and to develop significant relationships with faculty members. However, only one Hispanic Generation 1.5 participant knew about these opportunities. The following chapter will discuss the engagement experiences of Hispanic Generation 1.5 students with the staff at the college, particularly the academic support staff. 


\section{CHAPTER VII \\ ENGAGEMENT EXPERIENCES WITH STAFF}

All college students interact with college staff, particularly those in student services offices and academic support areas. Students' first interactions at an institution usually occur with a staff member, especially during the enrollment process. Generally, college students continuing engaging with college staff members throughout college for a variety of reasons including advising, registration, tutoring, financial aid, and career services. The purpose of this chapter is to present the findings on Hispanic Generation 1.5 students' engagement experiences with the staff at Commonwealth of Massachusetts Community College. First, the engagement findings with student services and academic support staff will be presented followed by students' perceptions of those engagement experiences. The chapter will end with findings on mentorships and one-on-one support as critical engagement experiences at the college and a discussion on how engagement experiences with staff relate to Hispanic Generation 1.5 students' development of a sense of belonging.

\section{Engagement with Student Services Staff}

Since most times student services staff members are the first to engage with students during the enrollment process, they play a critical role in students' initial perceptions of the institution and their overall feelings of comfort and belongingness. However, the study participants did not have much to say about the staff in the student 
registration areas. In general, most participants felt that the people were nice and helpful but could not share examples of their interactions. Even though the support services staff was available on both campuses during day and evening hours, the Hispanic Generation 1.5 participants who assessed into ESL courses rarely engaged in the same advising and registration processes as the other CMCC students.

The ESL faculty and staff advisednearly all students who assessed into ESL courses, including Hispanic Generation 1.5 English language learners, in one-on-one sessions or at one-stop registrations set up specifically for this population. Therefore, Generation 1.5 English Language Learners rarely engaged with student services staff while they were enrolled in ESL courses. If the participants wanted to engage with a student services staff member, they would see the bilingual advisor who worked on the Lincoln campus and focused on helping current and former ESL students. After completion of their ESL coursework, most of the participants, who were former ESL students, took advantage of other one-stop registration opportunities, returned to former ESL instructors for advice or worked with the bilingual advisor on the Lincoln campus.

\section{Engagement with Academic Support Staff}

The Hawthorne campus and Lincoln campus both had academic support facilities that offer tutoring services for students taking ESL, developmental, and credit courses. Students enrolled in ESL reading courses were required to complete lab hours with the academic support staff in the English Language Center (ELC). Students enrolled in developmental reading or writing courses were required to complete tutoring or lab hours 
with the Academic Support Staff at the Reading Center and the Writing Center. Therefore, the study participants had engaged extensively with the academic support tutors on their corresponding campuses, except for Aracelis who had yet to take the ESL courses that have a required lab or tutoring component.

Some instructors who taught other ESL courses besides reading included lab activities in their courses like Stephanie's Listening and Speaking instructor who had the students complete an oral English language assessment in the ELC and then asked the students to return to the ELC for instruction and practice on some of their weak areas. G was the only student who admitted to using two other types of academic support services: the newer content peer tutoring program and SmartThinking, which is an online tutoring service used mostly for writing and content courses.After a few negative engagement experiences with face-to-face tutors, he preferred using SmartThinking rather than working with the tutors in the traditional academic support areas including the ELC, and the Writing Center.

\section{Positive Perceptions of Staff and Engagement Experiences}

Generally, the participants found the academic support staff to be nice and helpful. ESL tutoring was offered from 9 a.m. to 2 p.m. on both campuses and in the evenings on the Lincoln campus. Developmental reading and writing academic support was offered on both campuses to day and evening students. The Lincoln campus participants who were capable of working withday or evening tutors preferred to work with the daytime tutors and described the daytime tutors and their interactions much more favorably than those participants who had worked with the evening tutors. 
The most significant engagement experiences with academic support staff occurred on the main campus's ELC with the full-time day students. All students who engaged with the academic support staff at the ELC on the main campus only had positive comments about the staff and their engagement experiences. Tomas enjoyed working with the ELC tutors and many times chose to interact with them rather than spend time with his peers. Even after completing his ESL coursework and moving on to credit courses, Tomas continued to work with the ELC staff. He explained:

That is what I like about the ELC staff, that even though you're not an ESL student anymore, they still welcome you into their doors. So I was still going to their center to ask for help. Every time I would write an essay, I would go to the ELC.

Tomas saw his interactions at the ELC as very important and the special engagement opportunities made him feel like the institution was providing him with tools and support to be successful.

Anthony enjoyed working with the same staff as Tomas, and he continued to work with them even after enrolling in credit courses. Sometimes he went to the ELC to seek assistance for his assignments. Most times he went to the ELC to chat with the staff, share ideas, ask for advice, and complete assignments on the center's computers. When asked why he continued to visit the ELC, he answered:

Because they're friendly. It's good. We talk about different things. House. Everything. We can talk about the news. I have something to talk about with them. They give me suggestions. They give me this. If I just walk in - I don't need them. It's not that I don't need them in one way, like "Yes. I need this. I need to be here." No. I go. I just go. I'm not supposed to be there, but I just go. It's fun. They're nice people.

Anthony enjoyed the company of the ELC staff and stopped by whenever he had free time. He also stoppedby the ELC in the early morning, before regular tutoring hours, to 
print his assignments and ask them for advice about the wording or presentation of his ideas.

Negative Perceptions of Staff and Engagement Experiences

The Hispanic Generation 1.5 participants sometimes had negative perceptions of the academic support staff. Sometimes those negative perceptions reflected onto the academic support staff were based on the students' attitudes and perceptions of the academic support activities rather than the staff members themselves. For example, Sara, Anthony, and Juan did not enjoy the required reading lab activities, which consisted mainly of reading passages and answering related questions. Juan found the reading activities to be boring because the passages were outdated, and many times, he did not see applicability in his life or could not make connections with the text. Anthony saw the reading activities as part of a silly but required game in which he had to get through the reading cards as fast as possible, one card at a time. He did not find educational value in the required reading lab activities. Sara did not enjoy working in the ELC reading lab because the reading activities were tiring. These students reflected their perceptions of the activities onto their relationships with the academic support staff. They rarely spoke with the reading tutors unless it was part of the reading activity, and they did not have much to say about them during the interviews.

The students had different perceptions of the writing tutors. Writing tutorials were not required for the ESL courses, but all developmental writing students were required to work with a tutor on every single essay, with a minimum of 12 essays in a semester. Similar to his perceptions of the reading activities, Juan found the writing 
tutorials boring, and he had very little to share about his experiences with the writing tutor for developmental writing. However, he was in support of more writing tutorials and felt that the ESL writing courses should require writing tutorials as well because writing was a critical area for the ESL students.

Anthony preferrednot to have writing tutorial requirements for developmental writing courses. He found the writing tutors to be annoying and the requirement to be useless. He explained:

For the writing, it was annoying. Because like if I have the work... there was one way that I had to check it. But like "Ah I have it done. Good. Wait a minute, I have to bring it to the lab so that they can check it, so that they can just...sign it. Oh no!" So I'd be like "I have it done. It's good. I think it's good. You [the teacher] should check it." But no. They [the teachers] needed a signature from them [the tutors], and it was annoying. Because what you do you guys do? You guys correct it? Change some things? ....For the Basic Writing...I think they [the tutors] just want to have something to do. I don't know. They just want a job.

Anthony did not value his work with the Basic Writing tutors and was upset over the curriculum requirement to see a Basic Writing tutor for each assigned essay. He preferred to skip the required Writing Center step and simply submit his assignment to the developmental writing instructor.

Part of Anthony's frustration stemmed from how the tutors interacted with him on his almost weekly visits. He explained:

And for the Basic Writing, I used come in, "Here. Sign in." And it was like they were just cold.... Like too strict. Like you get next. "Any questions? Next." I was mad. Okay. I just want to get out of here. Sign it, please. I'm out.

Anthony presented the mismatch between the tutor's intention or situation and the students' perception of the tutor's intention. The developmental writing tutors at CMCC were trying to work with all the students enrolled in developmental writing courses, 
which totaled over 20 sections in the fall semester. There were about three to four writing tutors for the Basic Writing students on both campuses combined, and the curriculum required that each Basic Writing student meet with a tutor for every single essay, which averaged to 12 essays in one semester. The tutor intended to assist all the students with their papers, and sometimes she would get up to 20 students in a 5-hour workday. Anthony interpreted the swift process as the tutor not caring about the students and their work. Her attempt to help all her students diminished her ability to have meaningful interactions with the students.

Some participants described certain tutors as disrespectful, cold, or uncaring based on their own interpretations of the tutors' intentions and how they believed the tutors perceived them during tutorials. For example, Ingrid found that the evening ELC tutor on the Lincoln campus had a negative attitude and was bored with her job. The tutor did not provide Ingrid with explanations for incorrect answers and did not answer questions about the reading activities with enough depth, unlike the daytime tutors at the same location. Therefore, Ingrid missed some of her required lab sessions because she did not want to work with the evening tutor, and eventually took extra trips to the campus to work with the daytime tutor instead. The initial negative interactions with this English language tutor affected Ingrid's desire to attend required tutoring and seek any additional academic support that she needed to be successful in her ESL reading courses.

G refused to work with the college's tutors whenever possible because he had had negative engagement experiences with the non-ESL tutors, which had left him feeling uncomfortable and embarrassed. He explained: 
Yeah 'cuz like it's a little bit embarrassing because let's say I get some words wrong, and like I tried it, and they look at you like "My god you don't know how to spell that." That made me feel uncomfortable. Like "My bad. You know? I thought you were here to help me." ...That was in Lincoln. So since that day I do the online tutoring for my writing.

He explained that the negative comments about his writing from an academic support person could "get to students" and affect how students feel about their academic abilities and their sense of belonging at the institution. Since he was not required to see a face-toface tutor for his courses, he used SmartThinking for his tutoring whenever possible.

\section{Structured One-on-One Support}

The most significant engagement experiences with CMCC staff members, outside of academic support centers, occurred through one-on-one interactions provided by structured engagement programs or experiences. For example, Tomas was provided with a mentor at the college as part of his presidential scholarship award. Through this type of engagement, he acclimated more successfully to the institution.

It was my mentor, Danny Gomez. He was my mentor because when I applied for the scholarship, the scholarship that I received that it was from $\mathrm{CMCC}$, that scholarship I had a mentor. I was able to have a mentor through that scholarship as well. So Danny Gomez, he's no longer there. He was the person I would turn to during my first year, and during my second year. So he the one who wouldtook me for lunch, asked meanything I was concerned with. "Tell me about your intentions after the ESL curriculum." So having him as a mentor was the most, it was made my first year easier because I was being told like expectations after ESL. How to live, you know, like the student life at CMCC. How could I take advantage of the different sources, different opportunities like being part of student activities and things like that.

Having a mentor through a structured program was a key factor in Tomas's success at

CMCC. During that first year, he received support, advice, and information about 
various aspects of college life, including study habits and how to balance multiple responsibilities.

However, not all mentorship models were successful with the students. Some of the college staff might have tried to provide students with advice and help them set some goals, but the students did not always perceive these interactions as being supportive of their success. For example, $G$ felt that he was targeted by a potential mentor to join the army because he had some setbacks in life and was trying to move forward by studying at CMCC. G explained:

And why is that like when the army visits the colleges, they always choose the kids or the people that are like be looking down, "Oh I wish I could just drop out, move back." That's what they do in Lincoln. I'm telling you, there are some advisors there, they've got the pens, they've got the things, like promoting that because they are getting a cut for each kid they put in. Cuz I lost a brother in Iraq. And like - Not to say names. But there's a male, like he promotes it like "Damn! How much are they paying him?" And like he tried to give me that bullshit, I just backed up. I just got Dominican on him. I was like "Mira. I already lost a brother. Remember me and get another kid."

$\mathrm{G}$ interpreted the potential mentor's advice about army life as discriminatory because he was a low income Hispanic at a community college living on his own in a poor factory town. With his frustration, G felt a need to "get Dominican on him," by giving the advisor his honest perspective on how the army had already negatively impacted his family. G felt that he had not received advice on various options or ways to move forward with his academic goals from the staff and potential mentors outside of the ESL faculty and staff. Therefore, he found that the ESL faculty members were more open to listening to him and guiding him than the college's advisors and enrollment staff.

The college's TRIO program was a DOE grant-funded program for first generation college students. It provided many engagement opportunities for the students 
at $\mathrm{CMCC}$ and was the source of mentors for some of the students. Anthony had been admitted into the college's TRIO program, and through this membership, he was invited to social field trips as well as field trips to 4-year institutions in NewEngland. Tomas also worked with the TRIO program and engaged in their various activities. He described one activity with a mentor from the TRIO program.

Okay. Kathy Moore. We developed a very close relationship. She was a very good mentor to me. She started working with me and like writing the essay and applying for giving the commencement speech. I was focusing on my classes because I wanted to get the best GPA I could get, but I was also focusing on that because that was going to be my goal at graduation, for the time of my graduation. And Kathy Moore, she looked online and found out the things that I wanted to say during commencement. And I didn't get to be the commencement speaker, but she was still helping me in getting the outstanding student award, and I was so proud that I was, I received the outstanding student award in 2007. And Kathy Moore, she dedicated so much time in me receiving that award. So that is one moment that I think of now being at CMCC.

The TRIO program provided Anthony and Tomas with opportunities to interact with college staff and potential mentors. Through this program, they engaged in various academic activities and interacted with key personnel who became his mentors on various projects.

Unlike the daytime students, the evening students in the study did not describe any mentorship opportunities at the college. None of the Lincoln campus students (day or evening) described any mentors or mentorship opportunities even though the TRIO program was on the Lincoln campus as well. With the exception of Anthony and Tomas, who were both day students on the Hawthorne campus, none of the Hispanic Generation 1.5 participants were aware of the TRIO program even though the TRIO program was on both campuses and all the participants were first generation college students. 
Engagement with Staff and Belonging at the Institution

Generally, all the study participants had engaged with the academic support staff at $\mathrm{CMCC}$, except for Aracelis who had not taken an ESL course with a required lab component. At CMCC, the Hispanic Generation 1.5 ELLs had a high level of academic support usage and a high amount of interactions with the academic support staff because the initial encounters were required for certain ESL courses. This academic support requirement forced students to interact with the tutors while completing ESL coursework, and most of these engagement experiences were positive for the study participants. Positive engagement experiences with the academic support staff led to continuous engagement with them outside of curricular requirements throughout their college experiences as was the case with Tomas and Anthony.

Having positive engagement experiences in an academic support center helped the participants develop a sense of belonging through the positive interactions within that physical space. For Anthony and Tomas, the ELC was a critical factor in their development of a sense of belonging to the institution, and they continued to engage at the center even while completing credit coursework. They had a stable environment with a group of people who were highly involved in their students' learning outside of the classroom and who were part of the advising and registration team during one-stop registrations for ESL students. The ELC and its staff served as a central home physically located near classrooms in a space conducive to individual and group work with computer areas along the sides. Unfortunately, the evening students did not have these choices or opportunities for finding a home within their college setting and they did not 
have as much access to the staff with whom to engage for matters of coursework, academic goals, and life.

\section{Engagement with Staff in Comparison to Other Immigrant Groups}

The Hispanic Generation 1.5 participants generally had positive engagement experiences with the ESL academic support staff, especially with the daytime tutors on the Hawthorne campus. Their engagement experiences with the ESL academic support staff are similar to those of the first generation Dominican interviewees, who had positive engagement experiences with the ELC employees. However, the second generation and Haitian Generation 1.5 interviewees had not worked with any of the ESL academic support staff members.

In developmental courses, all students are required to work with the developmental academic support staff. The Hispanic Generation 1.5 participants did not enjoy their engagement experiences with the developmental academic support staff members, and they focused their interactions only on the required assignment. Like the Hispanic Generation 1.5 participants, the first generation Dominican interviewees only used the academic support services when required for a course. The second generation interviewees did not use the developmental academic support services. The Haitian Generation 1.5 interviewees sometimes sought assistance from the academic support staff, but they preferred to get help from peers unlike the Hispanic Generation 1.5 participants. 
Like the Hispanic Generation 1.5 participants, the interviews in the three groups preferred not to use any of the voluntary academic support services for students enrolled in credit courses. As mentioned earlier, $\mathrm{G}$ used SmartThinking, a virtual academic support service, whenever he needed assistance. The second generation students were not comfortable using the academic support services offered to students enrolled in credit courses. The Haitian Generation 1.5 participants preferred to work with peers. The only exception was with the math lab. Two interviewees (Kevin, a second generation immigrant, and Yesenia, a first generation Dominican) described positive experiences in the math lab and saw the math lab as a comfortable place where they could get tutoring on any aspect of math.

\section{Engagement Differences among the Three Units of Analysis}

The most significant engagement experiences with staff occurred in the English Language Center, an academic support area for students taking ESL courses. Those students who engaged with the staff at the ELC on the main campus in Hawthorne found the experiences to be rewarding and continued to visit the center and ask for academic and personal advice even after completing their ESL coursework. The ELC staff in that physical lab space helped the participants develop a sense of belonging, which the other academic support areas were not able to do for the Hispanic Generation 1.5 participants in the study. The participants did not express positive engagement experiences with nonESL staffwhile completing their developmental and credit coursework. Again, as was discovered with the interactions with the ESL faculty, the interactions with the ESL staff 
at the main campus were the most critical for the development of a sense of belonging for the Hispanic Generation 1.5 participants regardless of how they felt about their ESL placement.

The Hispanic Generation 1.5 used the ESL academic support services extensively. They completed lab and tutoring sessions on both campuses. However, while engaging with the ESL academic support staff, the participants moved beyond the required worked and discussed school, work, and life issues with the staff members. The engagement experiences stemmed out of the academic requirement, but blossomed into broader engagement experiences through which students could have genuine discussions with someone else at the campus while getting advice on different matters.

When the participants moved on to developmental courses, they were required to use the developmental academic support centers. The students completed their academic obligations, but the engagement experiences with the academic support staff focused solely on the reading and writing assignments. The participants felt uncomfortable engaging with the developmental academic support staff on matters other than the required reading and writing activities. In the credit-bearing courses, the participants rarely if ever used the academic support areas for credit courses, and when needed, some preferred to use virtual academic support labs such as SmartThinking.

\section{Summary}

This chapter presented the findings on student engagement experiences with the college staff, and revealed that the Hispanic Generation 1.5 students who assessed into 
ESL courses rarely had interactions with the college advisors and enrollment staff. They were advised and registered by the ESL faculty and the ELC academic support staff, limiting their engagement opportunities with non-ESL staff members. However, the participants' most positive engagement experiences were with the ELC staff on the main campus and the daytime ELC tutors on the Lincoln campus. While most of the engagement opportunities were initially required as part of the ESL coursework, the students who had positive engagement experiences with the ELC tutors continued to visit the center even after completing all ESL coursework. The ELC on the main campus played a critical role in helping some of the participants develop a sense of belonging at the institution.

Another critical type of engagement experience with staff members took place with mentors. Mentorships were very critical in developing a sense of belonging for Tomas, and he was able to engage with a mentor throughout his entire college experience at $\mathrm{CMCC}$, first with his presidential scholarship mentor, Danny Gomez, and then with his TRIO program mentor, Kathy Moore. The TRIO program provided students with access to staff members and mentors. Tomas took advantage of his TRIO resources and worked closely with a TRIO staff member who he viewed as a mentor. As a fellow member of the TRIO program, Anthony had not taken advantage of the program's mentorship services, but was already engaging in various activities and interacting with the staff members. However, most participants had never heard of the TRIO program at CMCC. The following chapter will focus on factors that affected engagement at CMCC. 


\section{CHAPTER VIII}

\section{FACTORS THAT AFFECT ENGAGEMENT AND BELONGING}

Chapters 5, 6, and 7 presented findings on Hispanic Generation 1.5 students' engagement experiences at Commonwealth of Massachusetts Community College. However, through the course of the study, data emerged demonstrating that students' engagement experiences at $\mathrm{CMCC}$ were affected by numerous factors outside of the college, and, therefore, outside of college engagement initiatives. The purpose of this chapter is to present the findings on the factors that affect Hispanic Generation 1.5 student engagement and belonging at $\mathrm{CMCC}$.

\section{K-12 U.S. Engagement Experiences}

Because Generation 1.5 students come out of U.S. high schools and move straight into the college setting, their U.S. high school engagement experiences and their perceptions of those experiences could affect their willingness to engage at the college. The findings showed that the Hispanic Generation 1.5 participants who were highly engaged in high school were highly involved at CMCC. For example, Anthony was a highly engaged student in high school. He studied and ran for the track team, becoming captain of the team his senior year. He was friendly, outgoing, and social with his peers and teachers inside and outside of school. He often even brought friends home. In a similar fashion, Anthony was highly engaged at $\mathrm{CMCC}$ with his teachers, tutors, and 
peers, and he continued his athletic tradition by joining the $\mathrm{CMCC}$ track team and becoming both team captain and main recruiter.

Unlike Anthony, the other Hispanic Generation 1.5 participants were not very involved in high school sports. However, some of them were involved in academic activities outside of class time. Even though Tomas was in a U.S. high school for only one year, he was highly engaged in academic activities and spent a significant amount of time with teachers and tutors outside of the classroom setting. When he was at CMCC, he did not spend much time with his peers, but just like in high school, he spent a significant amount of time with his instructors and tutors outside of the classroom.

On the other hand, those participants were rarely engaged in high school except when necessary (e.g., classroom activities, academic work) were not highly engaged at CMCC outside of the classroom. For example, in high school, Awilda and Stephanie were isolated from the mainstream population for approximately one year through a transitional program, and then they were integrated with the rest of the population. In high school, they were not very engaged with their instructors or their peers, and they rarely had opportunities to get involved at their school. Now at CMCC, they both barely engaged with teachers and staff, including their ELC tutors. They rarely engaged with their peers, and their minimal peer engagement experiences were mainly within the classroom.

Sara was in a transitional high school program as well, and did not discuss engagement at her high school, focusing mostly on the curriculum. She struggled to fit into her high school her first year and ended up returning to the Dominican Republic for her sophomore year in order to get back on track. After returning to the U.S., she focused 
on learning the English language, passing her courses, and graduating. At CMCC, she seemed a bit removed from her peers, and she rarely interacted with her peers except within the classroom.

Some participants did not have positive engagement experiences in U.S. high schools and felt isolated in the school setting. These participants were engaged within the classroom with the instructor, but not outside of the classroom with faculty, staff, or peers. For example, Aracelis had many negative engagement experiences in high school, and in CMCC, she did not think much about being engaged and did not demonstrate willingness or desire to be more engaged at the college.

Ingrid did not recall any positive engagement experiences while she lived and studied in Lincoln, Massachusetts as a teenager. She did not feel comfortable in the school and her peers made fun of her. Ingrid explained:

When I started school it was kind of hard cuz you know some students laugh at you. "Ah she doesn't know the language." You know? It was a little bit difficult. I know but there a lot of people who show off once they learn English, "Oh I don't know Spanish." You know? Knowing that they are Hispanics. And I had an experience with a girl in Addison that supposedly, like when I first started there, I was in regular classes but there were students who were Hispanic. So one time the teacher put us to work with a girl. I think she was Puerto Rican. But she, instead of helping us, laughed. I felt bad. "I have to learn English." You know? That is what one would say but anyways.

Ingrid referred back to her negative engagement experiences at Addison throughout the interview. The negative experiences surrounding her oral English skills in Addison high school made her feel uncomfortable among Hispanic and non-Hispanic peers at CMCC. She did not try to engage with her peers unless necessary during classroom group activities. 


\section{Family Responsibilities}

The type and numberof family responsibilities was another factor that related to students' level of engagement at CMCC. Students with children engaged much less than students without children. Among the Hispanic Generation 1.5 participants, female participants with children engaged less outside of the classroom than male participants with children. The female participants who had children or were pregnant were not involved in the school outside of required curricular activities such as attending courses and participating in required tutoring sessions. They rarely engaged with peers outside of the classroom and never engaged with their peers outside of theschool.

Aracelis, a mother of three children, felt that she was sacrificing her children by attending classes at night, and she did not want to further sacrifice them by getting involved in any activities or engaging outside of the classroom. She explained:

Little by little one goes [to school] because it's three kids that I have, it's three, and it's a lot of work for me. And the job. Leave fast from my job. I get out at four from my job. My husband picks them up. They wait for me here. I have to prepare them something to each and take them to the babysitter. Sometimes I get here at 10. Sometimes I get here at seven depending on the class so it's difficult for me and for them because I am sacrificing them as well.

By going to school, Aracelis felt that she was making her children's lives uncomfortable. She tried to complete her duties as a mother, which includedfeeding her children and spending time with them, but at the same time, she was sending them to a babysitter in the evenings so that she could take night courses. They were rarely in their homes as a family during the weekdays except to eat dinner and sleep. Overall, Aracelis felt guilty about the sacrifices that her children had to make so that she could go to school. 
Stephanie was the mother of a two-year-old boy, and she did not engage outside of the classroom except for required tutoring through the English Language Center. Sara was preparing for the birth of her first child, and as an expecting mother, she was restructuring her life so that she could devote the appropriate amount of time to her child. Before her pregnancy, Sara engaged with the English Language Center and the Writing Center tutors as required by her ESL reading and development writing courses. With her pregnancy, she was only engaging with student services staff members for registration assistance.

Age as a Factor

Age was another factor related to the Hispanic Generation 1.5 students' type and amount of engagement at CMCC. Older students engaged less than younger students. One reason could be because of age differences with the mainstream population. Juan was taking credit courses, and he described a 15-year age difference with most of his peers in the credit courses, which made him feel uncomfortable in some of his classes. The interview data revealed that generally the older returning students were less engaged than the traditional-aged Hispanic Generation1.5 students who went from high school straight to college. Both Juan and Aracelis were returning students after being out of school for 10 or more years. They were less interested in being involved with their traditional-aged college peers.

The younger participants who did not have children engaged much more than the older participants. Anthony was highly involved in the school through his work with the 
track team and his local engineering group. He engaged with peers, faculty, and academic support staff almost every day. Carlos socially engaged with many of peers before and after classes, and outside of the school, especially on the weekends and weekday evenings when he did not have a class. Ingrid spent a significant amount of time with at least one other classmate within the school. They met at the college almost every night that they had class, and they worked together in the computer lab on Friday afternoons.

\section{Motivators and Goals}

The participants were motivated to be successful at school by different factors or motivators. The common motivators were the desire to learn academic English, obtain a certificate or college degree, move into a new career, satisfy family members or responsibilities, and be "somebody" in life. Many of these immediate motivators, such as an immediate need to learn English, initiated the enrollment process for the participants, but also served as short-term and long-term goals. Some participants had more than one motivator and/or goal.

\section{Learn Academic English}

Participants who were focused solely on improving their academic English skills were mostly engaged with peers and instructors within the classroom while taking ESL courses. They rarely engaged with anyone outside of the classroom, and they did not desire to get involved in any of the school activities or engagement opportunities. For 
example, Aracelis was mostly interested in improving her English skills, which motivated her to go back to school and complete her courses. She stated, "My greatest motivation is that I can speak and understand when a person speaks to me only in English; speaks to me well, that I can answer." This language goal originated from a realization that she needed stronger English language skills for her new position, after being promoted.

When asked why she chose to attend $\mathrm{CMCC}$ to enhance her English language abilities, Aracelis explained:

Honestly, because my job changed. Well, I changed positions. Because since I function a bit more in English and I learned many things in my job, I changed from position. I used to work in production. Then they put me doing quality. So from there I went [to a new position] because I was the one who spoke the most and could write and learn the job faster. Now they put me as secretary so I have to speak English; it's obligated to speak. So then that like frustrates me, the not understanding. Then mostly because of that I went back to school.

Her immediate need to learn English in order to perform well in her new position motivated her to return to school. The desire to learn academic English then became a primary motivator and a short-term educational goal or step towards a certificate or associate's degree. With this goal in mind, she rarely engaged with anyone outside of the classroom unless necessary because she only focused on her schoolwork while at CMCC. However, she did speak with her peers inside the classroom about classroom topics or assignments.

Many of the participants expressed previous knowledge of CMCC's positive reputation in the community for excellent instruction of academic English and preparation for academic coursework. Stephanie knew that the ESL courses were good at $\mathrm{CMCC}$, which was one of the reasons she chose to attend CMCC. The participants who had first attended CMCC under the high school bridge program had already experienced 
the English language courses. These students appreciated the higher quality English language instruction and described it as being much better than their high school English language instruction. Other local high school graduates who were not part of the bridge program recognized CMCC's English language courses as being superior to their high school English courses.

Carlos and Tomas both purposely chose CMCC so that they could acquire academic English and move on to academic careers at other higher education institutions. Carlos wanted to obtain a position as a mechanic for a car dealership, but he needed to attain a certain level of academic English in order to enroll at the institution that would prepare him that type of position. Therefore, he chose to take his ESL courses at CMCC so that he could enroll at the private technical college upon attainment of the appropriate level of English reading, writing, listening, and speaking skills. In a similar fashion, Tomas wanted to improve his academic English skills in order to obtain a bachelor's degree at a state university. He chose to complete his ESL coursework at CMCC so that he may be more successful in the challenging college courses that require a high level of English language knowledge and skills.

\section{Get a Degree and a Career}

Another primary motivator or goal for the participants was studying towards a career, which included completing a program and obtaining a certificate or degree. Stephanie, Sara, Awilda, and Ingrid had a primary goal of completing ESL and then studying towards the completion of a major, which they associated with a career. They had some ideas of majors and careers that were interesting to them, but they were not 
fully committed to a specific career goal. For example, Ingrid stated that she wanted to be a child psychologist, but she could not explain why she chose that career. Instead, she explained that she wanted to be somebody in life and have a successful career.

Stephanie's primary goal was to finish ESL, and then perhaps continue with something involving medicine. She stated:

First it's to finish English. Then, I am not too sure of what I want to do but I did a course in CNA [certified nursing assistant] and that is interesting me, the branch of medicine, things like that. Perhaps when I finish with English, I will continue with medicine. But for now, it is English.

Stephanie identified an area of interest (medicine) but was not sure of a specific job or career in that area. She could only identify CNA as a possibility because it was the only area she had experienced through a CNA course. Like Stephanie, Sara was not too sure about the most appropriate career choice, but she knew she wanted to be in the field of medicine or psychology. Her primary goal was to never work in a factory again. Instead she wanted to move into the field of nursing assistant after completing her ESL and math coursework.

As mentioned in an earlier section, Aracelis'first goal was to learn English and then to complete a degree in a field where she could graduate in a short period of time and obtain a job afterwards. She explained:

The career that interests me now, for the time, the little time that I have to study, something like medical assistant. Something that has to do with radiology, that deals with x-rays. That because it's less, it's shorter than the others. Before,to me, what I like, because what I liked is business. I like to deal with money, with papers, with math, with everything. That is what I like but business [major] is quite big. Because my friend who studied with me who used to go to CMCC at the same time before had a lower level than me. When I left she continued because she still had not gotten married. She is younger than me. So right now she graduated last year. She graduated. She did her degree, her master's, everything. How much time? Almost 12 years. So it's a lot. If I take 12 years 
now with 32 years of age, I would end up finishing like at 42 . No. It's better to take something short that gives me something and that gives me time for my kids.

While Aracelis desired a degree in the field of business, her family always came first, and the academic credentials in business would mean sacrificing her children and her time with her children for at least another decade. Therefore, she compromised by looking into fields where she could complete her education in at least half the time, such as CMCC's radiology program.

More than half of the Hispanic Generation 1.5 participants were motivated to enroll in CMCC and complete college courses because of career goals, whether a specific type of job or a desire to work within the field. Juan wanted to get into the radiology program in order to get a job in that area and eventually obtain a master's degree. G was in college because he wanted to become a police officer, which required at least an associate's degree. He stated:

Like I want to start my career as a police officer. But my main goal is to become a detective. I have to spend a year or two in the force. When I reach that level to detective, I want to transfer to New York.

$\mathrm{G}$ and many of the participants desired work in specific fields or had envisioned specific jobs that they hoped to obtain in the future, and like G, they understood that they could not get those desired positions without a college education. Therefore, specific career goals, whether a specific position or a desire to work within a specific field, motivated over half of the participants to enroll and complete school.

Tomas's main goal was to become a reconstructive surgeon, and that career goal kept him motivated to move up into medical school. First he was motivated to become a reconstructive surgeon because of a personal experience as a child. He explained: 
Since age 11, I've been having this feeling inside of me of wanting to help people and some experiences have also taught me how going to medical school and being a doctoris something that will give me that satisfaction of helping people.

$\mathrm{Cuz}$ when I was like 10 years old, I had a lazy eye for like a couple of years for maybe, no like 6 years I had a lazy eye. And I had the surgery when I was 10 years old, and my eye got corrected. And it was a change of life that I experienced by having this eye corrected. I interacted with people. I could not interact with people much when I had the lazy eye because Ireceive these comments of like, "Who are you looking at?" because of the lazy eye.

But after this surgery, I was able to look at people straight in the face, and show how, show like that I am paying attention, showing my good manners, being educated.

This surgery improved his overall quality of life and inspired him to look at medicine as a possible career.

Because of his experiences, Tomas turned to reconstructive surgery as a possible

career where he could help improve the quality of life for other people. He explained:

So after I had that change in life, I decided that I want to do something in life where I can change people's lives too, not in that sense, not in the eyes, not by being an optometrist, but by being a reconstructive surgeon where I can help people feel better about their image.

That's what I want to do. I want to work with people who are poor or have this disfigurations so they can value life more and they can have a better selfesteem and all the reasons that I can spend days telling you about. But all I want to do is help change people's lives. It feels great and emotional because people can be healthy but they can also feel depressed or miserable. So my goal in being a physician, being a surgeon is to help people going through a change in their lives both physically and emotionally so that they don't feel depressed. So they feel good, as good as I feel being alive, I want to say.

His experiences and main career goal kept Tomas focused throughout his studies at $\mathrm{CMCC}$ and at the state university where he obtained his bachelor's degree. At the time of the study, his goal was to continue working as an EMT and to get an appropriate MCAT score for his medical school applications.

Anthony desired a career that was not related to sports or athletics, especially after being involved in competitive track teams in high school and now in college. He 
discovered his career goal through an unexpected interest in certain areas related to engineering while taking required math and chemistry courses in high school. $\mathrm{He}$ explained:

I didn't want something else like go to the Olympics or do that. And I wanted to be an engineer because I like to make things. I see things and ah "You can do this with this." I'm creative so I was like I want to be an engineer and I like math, I love math,so I was like I'll be an engineer. Then senior year, I was taking chemistry, and I was like "This is easy." Like "I can do this." Not that it was easy. I liked it. It was hard, but I liked it. "This is good. I like chemistry." So I was like, I will be an electrical engineer.... First I wanted to be a mechanical engineer, and then I was like an electrical engineer sounds good.

Anthony had spent a good amount of time in high school and college reflecting on his school activities and his future options. He recognized his weaknesses, his strengths, and his passions including creativity and math, and he had identified not just a field of interest (i.e., engineering), but where he could naturally fit into that field. Therefore, from the moment he first step onto the CMCC campus, he was focused on getting a bachelor's degree in electrical engineering

\section{Make the Family Proud or Help the Family}

The strongest and most common motivator across gender and age groups was family, which motivated the participants to go to college and do well in their studies. Aracelis and Juan, both of whom returned to college in their 30s, were motivated by their children to go back to college. When asked why he returned to college, Juan explained that one day his son pushed him to go to college. The message to their children in Juan's household was that getting good grades in school gives him the privilege of going to college in the future. Therefore, Juan's son asked his father why he had not gone to 
college and taken advantage of that privilege like other members of their family. Juan's son motivated him to return to college because the household message was that attending college was a privilege and they should all take advantage of any opportunities. That message was relayed back to Juan by his son, which motivated Juan to return to college. Juan's family-based motivations helped him return to school and stay in school. When asked what kept him in college, he explained:

Well, I would like to think my son. But he's part of it, but once I got in here, I don't think I need any motivation. I just want to do better. It's kind of late, but they say it's never too late. I just want to better myself, I guess.My wife and son, I guess.

Juan's motivation then became his desire to do better in life for himself and his family. All his siblings had gone to college and were successful in their careers in various states. His wife had completed her bachelor's degree and had about one more semester left before graduating with her master's degree from a state university. He wanted to do something meaningful for himself having seen how his wife and siblings had done so for themselves. Completing a college degree was something meaningful for himself and a great example for his children.

Like Juan, Aracelis' principle motivation was her oldest son who pushed her to go back to school. She explained:

When I had the homework, writing well, perfect, my oldestson told me, "Mom, you have to go back to the school because you have to learn English."

I said, "Papi, but I understand."

"Yeah, but you have to speak more. You hardly know anything." So I said, damn, my son, for whom I left school, is sending me to school.

She had dropped out of college to raise her children, but then her children became her greatest motivators for returning to college after she had been promoted to a position that 
required more daily usage of English. Then her children became her greatest supporters while he took classes.

While Juan and Aracelis were first motivated to go to college by their children, and then motivated by degree or career goals, Carlos was motivated first by his mother. He explained:

My mother. My mother... because my mother tells me that she is here [in the U.S.] but that she is here for us. If not, she would not be here. So she does not want like to leave us like that, that we don't study or that because she wants to leave us on a good path. That was what made me start [school] again.

Carlos was motivated to return to school because of his obligation to help fulfill his mother's goal of making sure that her children got an education and decent careers. He listened to his mother's words and compared her desires with the advice that his coworkers gave him. His coworkers advised him to go to school and graduate while he was still young rather than work for a decade and find himself in the same place as them, still at the same job, not fully satisfied with what they have accomplished in their lives, and wishing they could go back to school.

However, Carlos' sister was the person who physically helped him through the enrollment process ensuring that he completed all necessary steps to become a student at CMCC. He explained:

My sister brought me... She helped me enter this school. Because she never left school. She always is studying since we got here [to the U.S.] So she was like an example. Because she always also works a lot and studies. So she helped me enter school because she also started by taking ESL, the same class that I am taking now. She changed colleges. She went to Cambridge, but I don't know what she is taking now. She is in Boston now.

Carlos' sister helped him make all the necessary preliminary steps including the application and assessment processes at CMCC. 
Rather than being pushed to go to school by family members, some participants wanted to go to college in order to help their family membersin the future. For example, Sara was pregnant at the time of the interview and had just moved in with her boyfriend. When asked about her goals, she replied that she wanted to be able to support her family in the future. Some participants had parents who they wanted to help. Ingrid had to leave her mother in order to study in middle school and high school in the United States. She said, "I don't live with my mom. She lives in the Dominican Republic. So I would like in the future like to bring her. That she have a place where to live, for example, me have my own place." Ingrid wanted to live with her mother in the United States. She saw a college degree as a step towards a career that would allow her to establish a comfortable life and complete the appropriate steps to bring her mother to the United States.

Anthony also wanted to bring his mother to the United States from the Dominican Republic. He explained:

I want to help my mom in the Dominican Republic. I want her to be here because over there is a lot of crime. It's a lot of...it's bad. So I want to help my mom, want to help my family. I want to help my dad.

Since his mother was not married and did not have parents living in the United States, her best chances of eventually getting a visa to enter the country, even if it was just to visit, was through one of her biological sons. One her biological sons had to become a citizen, obtain an appropriate job with a certain minimum salary, and complete her visa paperwork, essentially sponsoring her visa. As her oldest boy, Anthony felt that his mother's visa was his responsibility, and this responsibility also motivated to pursue an education and a career in the United States. 


\section{Be Somebody in Life}

Many of the participants stressed that their primary goal was to be somebody in life. For example, Sara stated, "Well, I really want to do something in the future. I want to be, you know, I want to have a career." While Anthony's primary goal was to bring his mother to the United States, he also expressed the desire to be somebody in life. He explained:

And I want to help myself. I don't want to depend on everybody. I don't want to have a boss to be like "This this and that" for not enough money. You know what I mean? So I don't want, I don't want to be nobody. I want to be something. That's what's pushing me.

Anthony refused to be a nobody in life. He wanted to be somebody and he defined that as a person with an education and a career, not just a job. Juan also defined the notion of being somebody in a similar manner, including have a career, not just a job, and being a good example for his son like his siblings and his wife. He also said, "I just want to do better. It's kind of late, but they say it's never too late. I just want to better myself I guess." This abstract notion of being "somebody" in life was usually not a clear, measureable goal, but it was a very strong motivator for these participants.

\section{Summary}

The Hispanic Generation 1.5 English language learners at CMCC had many precollege factors that influenced their perceptions, desires or willingness, and abilities to be academically and socially engaged at the college. The participants' background information revealed that immigration patterns, age, motivators, and pre-college 
engagement experiences influenced how they perceived themselves in college as well as the type and amount of engagement that they perceived as important for their success. The participants' willingness to engage with certain groups was related to their language, degree, or career goals and how those engagement experiences might help them attain those goals. Therefore, while the dissertation is focused on Hispanic Generation 1.5 students' engagement and membership experiences at a Massachusetts community college, the data revealed factors to be considered while exploring students' perceptions of engagement at CMCC. The next chapter will provide an overall summary of key findings, present the study conclusions, and explain implications and suggestions for CMCC and similar institutions. 


\section{CHAPTER IX}

\section{DISCUSSION}

The purpose of this study was to describe Hispanic Generation 1.5 students' engagement and membership experiences at a Massachusetts community college. The dissertation data were coded and analyzed within the framework of engagement and membership in communities of practice, which could lead to the development of a sense of belonging at the institution. The findings were presented in chapters 4 through 8 by describing first the Hispanic Generation 1.5 population at the college, then their engagement experiences with peers, staff, and faculty, and finally, the various factors that affect their college engagement. This final chapter includes a summary of the findingsfor each of the research sub-questions, spoken and unspoken intricacies that relate to the participants' engagement experiences, suggestions for the enhancement of Hispanic Generation 1.5 students' experiences at $\mathrm{CMCC}$, and further research opportunities in the field.

\section{Hispanic Generation 1.5 Students at CMCC}

This dissertation study focused on the engagement and membership experiences of Hispanic Generation 1.5 students at CMCC. The first research sub-question was: Who are the Hispanic Generation 1.5 Students at Commonwealth of Massachusetts Community College (CMCC)?This section summarizes the findings of this first research sub-question. 
One finding in this study was that Hispanic Generation 1.5 English language learners at CMCC differed from the descriptions of Generation 1.5 students in the general literature. The literature suggests that when using English in oral communication, most Generation 1.5 students sound like native-speakers with signs of local pronunciations, slang, and colloquialisms. However, many of the Hispanic Generation 1.5 participants in this study preferred to use Spanish during their interviews because they could not express all their thoughts in English, were self-conscious of their oral English language usage, or simply felt more comfortable communicating in their native language. In her single-site case study of Hispanic Generation 1.5 students at a community college, Elizabeth Oudenhoven (2006) found a similar phenomenon. Her participants were self-conscious of their English verbal skills and were concerned about their English speaking abilities in college even though their English language challenges lied in their reading and writing skills (Oudenhoven, 2006).

Similar to the Generation 1.5 literature, another major finding was that English language ability was the major defining factor for this group of participants because this factor determined their status within school and their progress towards their goals. Participants described their initial levels of satisfaction with the institution based on the institution's perceptions of their English language abilities as demonstrated with ESL placement and the students' perceptions of their own language skills. However, the participants did not acknowledge the definition, associated labels, or future implications of being defined and defining themselves based on English language ability.

One unique feature of the Hispanic Generation 1.5 students at $\mathrm{CMCC}$ was that they had varying immigration patterns, which is not seen in the literature about this 
population. All the participants were Dominican, which reflects the immigration patterns of the participants' communities in Massachusetts. Some participants were actually born in the United States and raised in the Dominican Republic, which granted them American citizenship. However, the three U.S.-born participants viewed their home country as the Dominican Republic because they had no memories of life in the U.S. prior to their immigration during their adolescent and teenage years. These participants also lived and studied in the Dominican Republic prior to immigrating to the United States.

\section{Engagement Experiences of Hispanic Generation 1.5 Students}

The second research sub-question in this study was: What are these Hispanic Generation 1.5 students' social and academic engagement experiences while completing their (a) ESL coursework, (b) developmental coursework, and (c) credit-bearing coursework at Commonwealth of Massachusetts Community College?This section summarizes the findings that answer this second sub-research question. The summary is followed by a discussion of the engagement differences among the three units of analysis.

\section{Institution-level Engagement Opportunities}

Many institutional engagement opportunities focused on getting the students acquainted with services at the institution and involved in various groups or programs. Hispanic Generation 1.5 students in ESL might not be aware of any of these opportunities since they are involved with the faculty, staff, and support services provided by the ESL program and few times use services outside of the ESL arena. Of the study participants, 
the evening students were the ones least aware of college activities and opportunities, especially while enrolled in the ESL courses. The daytime students were a bit more aware because they witnessed some activities while taking courses, and they worked with full-time faculty and staff who were more aware of campus activities and shared that information with students. However, none of the study participants talked much about engagement with support services staff because they preferred to continue working with the ESL faculty and staff or the bilingual advisor even after completion of ESL coursework.

One finding was that the Hispanic Generation 1.5 participants who began their academic careers in ESL courses did not perceive engagement as being critical to their academic success. They did not seek out engagement experiences and they did not participate in voluntary engagement opportunities offered through student services unless supported by their instructors. A few participants thought it would be nice to be involved in at least one activity, but could not participate because of time constraints or perceived conflicts with their education goals. Some participants did not even know how to get involved or how to participate in activities if they found something of interest.

Another study conclusion is that an institution's engagement opportunities might be irrelevant to Hispanic Generation 1.5 English language learners because there is a disconnection between the engagement opportunities and the students' willingness and ability to effectively engage. The participants who wanted to be involved searched for involvement opportunities at the college such as Anthony who joined the track team and the engineering club. Some were willing to be involved in college or institution-level activities but did not have knowledge of these activities or the ability to participate. 


\section{Engagement with Peers}

The study findings revealed that Hispanic Generation 1.5 English language learners perceive that in-class peer engagement was effective in helping them during class time. However, success of in-class peer engagement depended on the type of engagement (academic or social), the purpose of the engagement, and the structure of the engagement activity as designed by the instructors. Random peer engagement within the classroom was not perceived as being important or critical to academic success for the study participants. Critical peer engagement activities were those in which instructors purposefully picked group members, provided clear group tasks, and required that students engage only in English.

Another finding in this study was that contrary to the higher education peer engagement research, many of the study participants did not desire to engage with their peers except when working on tasks within the classroom. Some participants preferred not to engage with their peers outside of the classroom in order to devote more time to academic, family, and work responsibilities. Study participants engaged with peers outside of class, preferred to engage with non-Hispanic peers or non-Spanish speaking peers, which forced them to use English in everyday conversations. Also, many participants felt that engaging with Hispanic peers would deter them from reaching their goals.

\section{Engagement with Faculty}

The most critical form of faculty and student engagement for the study participants was in-class engagement on specific academic topics or tasks because all 
participants could devote time to coursework regardless of part-time/full-time status and other characteristics. The more the participants engaged within the classroom, the more satisfied they were with their teachers and their in-class engagement experiences with those faculty members. This finding supports the findings by Umbach and Wawrzynski (2005) on in-class faculty and student interactions where they found a positive correlation between faculty members' use of student-centered approaches and students' perceived engagement levels. The study's findings also support McClenney's community college engagement findings. He found that community college students were more engaged in the classroom (McClenney, 2007).

Similar to the Umbach and Wawrzynski (2005) findings, the study participants valued out-of-class interactions with faculty more than in-class interactions with faculty. A finding of this dissertation study was that the participants who were most engaged with faculty outside of the classroom were the ones who had the strongest sense of belonging to the institution and the ones who were more successful in moving towards graduation. Some full-time faculty members had structured one-on-one time with their students either during office hours or by appointment. Some instructors met with students a couple of times a semester, and Ralph, an ESL writing instructor, required that students meet with him once a week. The full-time day students on the main campus were the ones who had the most experiences with structured one-on-one time. They were also the ones most engaged with their faculty throughout their coursework and most satisfied with the institution. 


\section{Engagement with Academic Support Staff}

Engagement with academic support staff, particularly the support staff in the English Language Center, was the second most critical type of engagement experience for the Hispanic Generation 1.5 study participants, after engagement with faculty. The ELC support staff was always in the same location and available during specific hours. The staff members served as tutors, advisors, and sometimes even mentors to the students. The tutors helped students with their coursework, ensured that students completed their ESL lab requirements, and provided a space for students to do homework. The physical space with the academic support staff created a comfortable place for the students, especially on the Hawthorne campus. Some of the study participants spent a significant amount of time with the ELC tutors since ESL lab work was required for many courses. Therefore, aside from their classroom instructors, the ELC tutors had a great impact on the students' engagement and sense of belonging at the institution.

As the findings of this study show, academic support staff members became the most critical college members after the students were enrolled in courses at the college. They had the opportunity to engage with students in one-on-one and small group settings and focus on academic success through genuine high impact learning activities. These interactions allowed for the development of significant relationships between the academic support staff members and the students. Many of the study participants maintained these relationships throughout their years at the college. Participants who were enrolled in credit courses or had graduated from the college pointed to the 
importance of those relationships several times throughout the study and used the ELC on the main campus as a second home at the college.

\section{Engaging Hispanic Generation 1.5 English Language Learners}

While the participants perceived that their engagement experiences with faculty and academic support staff were the most critical to their sense of belonging and academic success, they did not initiate the engagement experiences with either faculty or staff. The participants engaged with faculty and academic support staff only when the initial engagement experiences were developed and required by the ESL faculty and staff. Through the mandatory engagement experiences, the students developed relationships with the faculty and staff as well as positive habits that they could carry out while studying in other areas of the college. Some of these habits included visiting the academic support centers for homework and general learning assistance, asking questions inside and outside of class, taking advantage of office hours, and asking for help when needed.

Another finding was that even though most of the participants were surprised and/or upset with their ESL placement, they engaged most while taking ESL courses and developed a sense of belonging to the institution or some aspect of the institution while completing ESL coursework. Therefore, all components of ESL at CMCC played a role in engaging students at the college and helping them develop a sense of belonging within the institution. This finding shows that while ESL placement could be a detractor for Hispanic Generation 1.5 students, positive high impact engagement experiences during 
the first semester with ESL faculty and staff could reverse the negative feelings from the placement and help students appreciate the ESL resources and overall experience.

Differences among the Three Units of Analysis

The third research sub-question was: What are the similarities and differences in the social and academic engagement experiences for these students within the three levels of coursework: (a) ESL, (b) developmental, and (c) credit-bearing in Commonwealth of Massachusetts Community College? There were differences in the Hispanic Generation 1.5 participants' engagement experiences while in ESL, developmental, and credit-bearing courses, and these differences were included as a separate section in Chapters 5, 6, and 7. This section provides a summarized answer to the third research sub-question by focusing on engagement with peers, faculty, and staff separately.

\section{Differences in Engagement Experiences with Peers}

Even though the Hispanic Generation 1.5 participants did not perceive peer engagement as critical for their academic success, they felt more comfortable in classes that had a high number of Hispanic students. Most of their peer engagement experiences were inside of the classroom. They mostly engaged with their peers in ESL courses where they had ahigh number of fellow Hispanic students sitting in the classroom as well. The Hispanic Generation 1.5 participants engaged with their peers mostly for academic purposes, which included helping each other with homework and classwork activities 
andtalking with each other during teacher-led group activities. When the Hispanic Generation 1.5 students moved into developmental courses, they had fewer Hispanic peers in their classes, and they engaged less with their peers inside the classroom. In their credit courses, the participants noticed that they had even fewer Hispanics, and they explained that they rarely engaged with their peers inside or outside the classroom. Overall, the Hispanic Generation 1.5 participants engaged less with peers as they progressed into credit-bearing courses.

\section{Differences in Engagement Experiences with Faculty}

The Hispanic Generation 1.5 participants valued their engagement with faculty members both inside and outside of the classroom; however, most of their positive engagement experiences were with the ESL faculty members. While taking ESL courses, the students engaged with the faculty inside of the classroom about course-based topics, and they participatedinclassroom discussions. The participants also engaged with faculty outside of the classroom during office hours and required one-on-one sessions, which the full-time faculty members sometimes required in their courses. While taking developmental writing courses, the participants engaged with the faculty members less in the classroom, and they rarely engaged with faculty outside of the classroom. While taking credit courses, the participants rarely engaged with the faculty members inside of the classroom and did not provide any examples of engaging with faculty outside of the classroom. Overall, engagement with faculty consistently decreased as the Hispanic Generation 1.5 participants progressedfrom ESL to developmental and later to creditbearing courses. 


\section{Differences in Engagement Experiences with Support Staff}

Generally, the Hispanic Generation 1.5 participants did not engage with the student services support staff unless necessary. However, all the Hispanic Generation 1.5 participants, except for Aracelis, engaged with the academic support staff, and they mostly enjoyed working with the ESL academic support staff in the English Language Center (ELC). The daytime students spent a significant amount of time with the ELC staff working on required homework and lab assignments for their ESL courses. These engagement experiences expanded beyond the content of the ESL courses, and the students engaged with the ELC tutors about other courses, life on campus, and life outside of school. Some of the participants continued engaging with the ESL academic support staff throughout their post-ESL coursework at the college because of their positive engagement experiences in the ELC while taking ESL courses.

While taking developmental courses, the students met with the academic support staff in the reading and writing centers because lab work was required for the developmental courses. The students did not engage with the tutors beyond the scope of the required tutorials and lab assignments. While taking credit-bearing courses, the Hispanic Generation 1.5 participants avoided using the appropriate academic support services for those courses because they did not want to engage with the non-ESL staff. As the Hispanic Generation 1.5 participants progressed from ESL to developmental and to credit-bearing courses, they engaged less with the academic support staff and eventually stopped using the services on campus while taking credit-bearing courses. 


\section{Developing a Sense of Belonging}

This study was built upon a conceptual framework of engagement and membership in communities of practice as a process that develops a sense of belonging in an institution and leads to long-term retention and eventual degree completion. Based on the literature review, engagement is the most critical aspect of this conceptual framework because it is the mechanism by which students participate in communities of practice, develop membership within the communities of practice, and develop a sense of belonging to the community of practice and the overall institution. This section addresses belonging as the critical aspect of the conceptual framework and presents the study's findings in relation to the conceptual framework.

\section{Belonging and Institution-level Engagement Opportunities}

Overall, CMCC's institution-level engagement opportunities (e.g., clubs and fairs) were not effective in helping the Hispanic Generation 1.5 English language learners develop a sense of belonging to the institution. The study participants did not perceive institution-level engagement opportunities as helping them develop a sense of belonging within the college. However, they perceived their engagement with faculty and academic support staff as being critical. Therefore, one study conclusion is thateffective institutional engagement opportunities are those that help students develop significant relationships with faculty and academic support staff in order to increase their sense of belonging and academic success. 


\section{ESL Placement and Belonging}

Supporting the Generation 1.5 literature, most of the Hispanic Generation 1.5 participants were upset or disappointed with their ESL placement, feelings which relate with disengagement and alienation in the literature. The process of starting college is one of the three critical points during which students could feel alienated (Case, 2008). The ESL placement and the initial days in the ESL courses developed negative feelings among the participants, except those who voluntarily immigrated to the United States to perfect their academic language skills and obtain at least a bachelor's degree. The participants' feelings of alienation and general disengagement from the institution increased as they sat with other non-native English speakers, who unlike them did not go to U.S. high schools. However, the classroom engagement experiences with the ESL faculty diminished these negative feelings and increased the participants' positive perceptions of their courses and the school.The study's findings demonstrated that relationships with faculty members through positive in-class and out-of-class engagement experiences had the greatest impact on the participants' sense of belonging to the institution, with the ability to reverse feelings of alienation that might result from an ESL placement.

The second most critical type of relationship was between the participants and the academic support staff. The participants who felt engaged and who expressed feelings of belonging or comfort at the institution had all worked with the ELC academic support staff and had significant interactions with the ELC tutors. The daytime participants saw their ELC tutors as advisors, mentors, and role models who cared for the students. While the faculty reversed feelings of alienation and helped the students develop a sense of 
belonging to the course, the ELC also had a great impact in developing a sense of belonging to the program and in some ways to the institution.

While the participants did not express peer engagement as being critical to their sense of belonging and academic success, most of them wanted to feel comfortable among their peers regardless of the campus. The study's Hispanic Generation 1.5 participants did not need significant relationships with their peers to feel like they belonged to the institution. They simply needed to feel that they fit in with the rest of the group, especially inside of the classroom. Sitting in classes with a higher number of Hispanic students increased their comfort and sense of belonging within those courses.

\section{Looking Behind the Curtains}

Looking at engagement experiences of Hispanic Generation 1.5 students at a Massachusetts community college revealed some hidden or unspoken intricacies about this population. The study also revealed intricacies about this region that relate to these students' identities and to their success factors in college. This section focuses on these unspoken messages that are hidden behind the curtains of language, race, and academic success.

\section{Caught in the Middle of Changing Language Policies}

The participants in this study lived in three specific neighboring cities with a population of 176,166 among the three cities combined. Forty-three percent of this population (over 76,000 residents) speaks a language other than English and many of 
these residents might not use any English at home (U.S Census Bureau, 2009). In Lincoln alone, $74.1 \%$ of the population speaks a language other than English, and Lincoln has become a primarily Spanish-speaking community with a Hispanics making up $71 \%$ of the city population (U.S Census Bureau, 2009).

Regardless of the large population of non-native speakers throughout the state, and clustered within some specific cities, Massachusetts passed an anti-bilingual education initiative in 2002 (Gándara, P., Losen, D., August, D., Uriarte, M., Gómez, M. C., \& Hopkins, M., 2010). With this initiative, bilingual programs (teaching and learning in the native language and in English) were replaced with Structured English Immersion programs (English-only instruction through appropriate content and interaction), and students were allowed to be in the immersion programs for no more than 1 year before taking mainstream courses with the rest of the school population(Gándara, et al., 2010). Most the study participants lived and studied in Lincoln, Massachusetts with a 71\% Hispanic population during the implementation of this English initiative in Massachusetts, and they got caught in the middle of the high school's struggle to provide the most appropriate curriculum in the face of this new language initiative.

Many of the participants attended Lincoln High School and all Lincoln High School graduates described transitional, bridge, and after school programs designed to help them learn, take mainstream courses, and/or pass the MCAS. The students in the transitional program at Lincoln were segregated from the rest of the high school population. Some of these participants took ESL or English language courses as well as the mainstream courses that the other students at that grade level were taking. For example, Awilda described her experience taking an ESL course in one class period and 
reading Romeo and Juliet for her English course another class period. This curricular and language mismatch did not allow the participants who graduated from Lincoln High School to acquire appropriate English language skills while working on high school content.

While most participants did not overtly place blame on any system, school, or instructor, all participants who graduated from Lincoln High School expressed a realization that they were cheated out of the language learning experiences that would have benefited them in college. Most of them recognized the higher quality English language instruction at $\mathrm{CMCC}$, and some offered curriculum and instructional improvement suggestions for the local high schools. The participants' stories point to one possible reason for the sudden increase of Hispanic Generation 1.5 students in CMCC's ESL courses - the curricular and language mismatch that occurred after the implementation of Massachusetts anti-bilingual education initiative in 2002.

\section{Visible and Invisible Masks}

While the participants did not overtly discuss racism throughout the interviews, many of their experiences and perceptions were tainted with both external and internal racism. The desire to not engage with Hispanic peers outside of the classroom revealed this group's internalized racism since they saw their Hispanic peers as deterrents to English language acquisition and general academic success. Internalized racism refers to the internalization of external negative perceptions of one's race, which manifests itself through actions and words or behavioral and verbal patterns (Padilla, 2001; Tatum, 1992, 2003). Being Dominicans in New England, all of the participants had experienced some 
form of external racism either at work or in the community. However, the most common place for them to experience external racism was in U.S. schools. In high school, some participants were segregated from the mainstream population for at least one year. At least one participant discussed the method of separating Hispanic students during testing, with only one Hispanic student at every other table to prevent cheating while the nonHispanic students sat in groups. Other instances of external racism were more discrete but still present both in high school and at the college as disclosed by the participants via their various engagement anecdotes.

The data from the field notes and interviews reveal that race was not discussed within the college, and the participants did not discuss race, racism, or their own perceptions of Hispanics (internalized racism) with their college peers, faculty or staff members. Even though most participants lived in Lincoln, with Hispanics being the majority, their perceptions of themselves and of other Hispanics in the town were sometimes negative. Some participants perceived that their Hispanic peers provided distractions and deterred them from their academic responsibilities and goals. One future step in this area of internalized racism among Hispanic Generation 1.5 students might be to understand the connections between internalized racism and how the participants feel about their engagement with peers, faculty, and staff at CMCC.

\section{Struggling to Survive in a Struggling City/Region}

The participants did not overtly discuss economics or how their financial situations related to their success in college and life. However, some connections were made through the interviews between academic success and life in the region. 
Specifically, the participants made connections between their ability and willingness to engage at the college and factors outside of the college that affected their everyday lives.

These Hispanic Generation 1.5 participants mostly struggled to survive in a city that was struggling to survive as well, especially with the loss of many jobs and companies to a variety of factors including migration patterns and outsourcing of products and services. Most participants had worked in factories or fast food restaurants and all had struggled financially at some point in their lives whether as children or teenagers living with their parents or as adults. Most participants lived in Lincoln, Massachusetts, where the per capita income was $\$ 16,080$, more than $\$ 10,000$ less than the per capita income of Hawthorne and Madison, the two neighboring cities (U.S. Census Bureau, 2009). Only 11\% of the over 71,000 Lincoln residents had a bachelor's degree or higher while $30 \%$ of Hawthorne's residents and $23 \%$ of Madison's residents had at least a bachelor's degree. Lincoln had 13,000 to 25,000 more residents than its neighboring cities, and the economic and educational differences between Lincoln and its neighboring cities were alarming.

Getting a public education in a city with such a low per capita income and such a low college degree attainment makes educational success much more complicated for the young residents of Lincoln, Massachusetts. Students might face challenges within the public school classroom with fewer resources than schools in other, more financially stable cities. As they get older, Lincoln students might face additional academic challenges from the need to work at least part-time in order to help out the family or to cover their own expenses. Living in a small city facing economic difficulties, these 
students have limited transportation options, limited employment options, and limited educational options.

Seen as all being a part of everyday life, the many challenges that these students face become silent and many times even invisible. The study participants provided hints and clues making connections between their lives as Lincoln residents and their ability to (a) acquire academic English, (b) make educational choices in terms of schools and courses, and (c) even decide on their own personal, academic, and career goals. Therefore, while these sometimes invisible realities of the Hispanic Generation 1.5 students at CMCC were not overtly discussed throughout the interviews these silent or invisible factors played a critical role in their academic, personal, and career success as well as in their everyday lives.

\section{Suggestions for CMCC and Similar Institutions}

As a qualitative case study, the research study is not necessarily generalizable to an entire population; however, the case study provides findings and specific details that readers could apply to their own educational settings. For these readers, this study has several implications and improvement suggestions in relation to college enrollment policies and the development of more appropriate student engagement opportunities throughout an institution. When brought together under one umbrella, these suggestions are all part of a larger plan of helping Hispanic Generation 1.5 students develop a sense of belonging in order to increase their overall retention and success. 


\section{Institutional Engagement Opportunities}

This study has demonstrated that engagement opportunities developed by student services might not be relevant for Hispanic Generation 1.5 English language learners. The first year of college is the most critical year for students, and many Hispanic Generation 1.5 students in community colleges could assess into ESL courses, which are not always included in institutional engagement opportunities. Therefore, student services personnel should collaborate with ESL faculty and academic support services staff to develop engagement opportunities that are tied to academic success with current

coursework. Sometimes the relevance of the engagement opportunities might need to be highly explicit for Hispanic Generation 1.5 students to willingly partake in the activities. Other times, the engagement opportunities might need to be part of the coursework or required by the faculty in order for the students to participate. If full-time faculty members do not teach evening students, then student services offices will need to reach out to adjuncts and create engagement opportunities with them for the evening Hispanic Generation 1.5 English language learners.

Engagement opportunities should be designed for specific college populations rather than using a one-size-fits-all approach. The institution should understand the various groups to be included in the engagement opportunities and the factors that affect a group's willingness or ability to engage in those activities. Regardless of the number and type of engagement opportunities developed by the institution, the students must want to be engaged and take the necessary risks to become engaged at the school. Therefore, $\mathrm{CMCC}$ and similar community colleges should explicitly state the benefits of 
each engagement opportunity so that students may make well-informed decisions about how to use their limited time on campus.

\section{Enrollment}

CMCCmight need to revise its application and enrollment forms in order to obtain more critical student information beyond middle school and high school demographics. Student enrollment data should include items or variables on the students' birthplace, their parents' birthplace(s), time in the U.S. (especially for cyclical immigrants), family education, and general language use in the home and community. At some institutions, this type of data is only collected during advising or intake interviews in ESL programs and at other institutions the information is never collected. Having this data within the institution's system allows advisors, instructors, and retention specialists an opportunity to identify the various groups of students attending the college so that appropriate engagement and retention measures may be implemented for the various groups. One size does not fit all when it comes to both engagement strategies and retention strategies, and more personal information about our students will allow for population or group specific strategies to be developed and implemented throughout the institution and within specific programs or courses.Hudson County Community College in New Jersey has used the Language Use Survey, a student intake form that includes background, education, home, and language information (Nehrebecki \& Skinner, 2007). Such data can be used to create engagement opportunities and to modify courses in order to address the needs of the changing ESL or ELL population. 


\section{ESL Enrollment}

Aside from collecting and using appropriate institutional data, student enrollment in ESL courses must be reconsidered in community colleges. While many Hispanic Generation 1.5 students might need additional English language assistance, placement in ESL courses designed for immigrant students provides initial negative engagement experiences. Institutions need to be explicit with Hispanic Generation 1.5 students about their English language skills and the benefits of taking specific ESL courses. The nonnative speakers of English in this study perceived that their ESL experience was very beneficial, but they perceived the experience as beneficial only after completing at least half of an ESL course.

Colleges with a high number of Hispanic Generation 1.5 English language learners might consider developing special ESL course sections designed just for this student population. These Generation 1.5 course sections could help reduce the students' feelings of disengagement and alienation while completing ESL coursework. These special course sections would allow instructors an opportunity to develop curricula that is appealing to this specific generation of recent U.S. high school graduates. At CMCC, Ralph was finding success with his writing course for Generation 1.5 students titled English Writing Skills because he could design a curriculum that specifically addressed the writing issues and the learning preferences of this particular population. At a larger scale, Bergen Community College in New Jersey has seen success with its ESL courses specifically for Generation 1.5 students (Miele, 2003). 


\section{Engagement with Peers}

Peer engagement could help Hispanic Generation 1.5 English language learners be more successful in their ESL, developmental, and credit courses if the initial peer engagement experiences are well-structured and supported by the institution. One suggestion from this study is to develop in-class peer engagement experiences for students that focus on specific learning tasks with clear measurable goals and can be completed within the classroom using English. The instructors should become aware of various cooperative learning strategies and incorporate those strategies in the ESL, developmental, and credit courses. One finding from this study was that peer engagement decreased as student moved from ESL to developmental courses and from developmental courses to credit courses. Therefore, faculty members in developmental and credit courses should increase the use of cooperative learning activities for the promotion of positive academic peer engagement in the classroom.

Student mentorship models could be very effective with this population because the relationship could be used to enhance college survival skills and academic skills while providing the newer student with a significant peer relationship. When first taking ESL courses, a Hispanic Generation 1.5 student could be paired up with another Hispanic student who started in ESL but is now taking credit courses. The relationship could allow the more expert student to help the more novice student navigate the college's system and choose strategies that will help with coursework and general college success. In addition, the more expert student would have a higher level of English language knowledge and skills and could help the ESL student develop oral and written English language skills through meaningful interactions. 


\section{Engagement with Faculty}

The study findings reveal that the Hispanic Generation 1.5 students at this community college perceived engagement with faculty members inside and outside of the classroom as the most critical type of engagement for their success at the institution. The main implication of these findings is that full-time and part-time faculty members need to take more responsibility for the students' sense of belonging within the institution by intentionally engaging students in strategic ways. For example, Ralph was the most successful ESL instructor in developing a sense of belonging among his Hispanic Generation 1.5 students because he required students to engage with him outside of the classroom, and he was explicit about their English language levels and about their progress within the course.

All instructors, full-time and part-time, should find specifics ways of engaging their students inside and outside of the classroom. To help faculty enhance their in-class engagement with students, the professional development officeat the colleges should develop engagement workshops in which faculty members could identify high impact engagement activities to be included in their teaching. Some faculty members might only be comfortable using in-class engagement activities to help students develop a sense of belonging within the classroom and then the program. These faculty members could use class-time to engage with students through the use of different instructional techniques that increase class discussion. Faculty members could use the time prior and after the class session as well as any short class breaks to engage with individual students.

Outside of the classroom, full-time faculty should take advantage of the built-in office hours in their weekly schedules. They could require that students visit them at 
least once a semester, or, like Ralph, they could require that students visit them once a week. These structured engagement experiences should first focus on students' academic needs based on classroom performance and could expand to address any questions or concerns with advising, registration, and life on campus.

Part-time instructors might only have class time to develop significant relationships with their students because of their adjunct status and limited time at the college. They could take advantage of the 10-15 minute transitional period before class and after class as well as class breaks to interact with individual students. Part-time instructors also could take advantage of online resources to require some type of weekly or biweekly academic engagement with their students. For examples, weekly "check-in" emails could be just as effective as required office visits for many of these students who might be internet natives, growing up with computers and online technologies. Students who are not too comfortable or familiar with email could use the weekly "check-in" emails as a way to become more efficient with emailing instructors. Blended or webenhanced courses might use learning management systems that allow instructors to chat with students and send emails within the online portion of the course.

\section{Engagement with Student Services Staff}

College staff members are usually the first people who students see when they first engage at the college. Potential students have to interact with college staff when they first apply at the college or complete the enrollment process. As the first interactions at the new college, these engagement experiences are critical for student success in that first semester because they frame the students' perceptions of the college 
and their possible belonging to the institution. If studentsare already afraid of college and feel that they might not be successful at the institution, then initial negative engagement experiences with staff might result in those potential students not returning to complete the enrollment process, which might include placement tests.

College staff members who work in enrollment, registration, advising, financial aid, and career services have the opportunity to engage potential and new students in a positive manner and to build a positive relationship between the student and the institution. Therefore, institutions should work with these key staff members to help them provide optimal customer service to both potential and newly admitted students. They should be knowledgeable of the various academic programs, including ESL and developmental studies. They should be knowledgeable of the school, including the various involvement opportunities and academic support or learning centers. Professional development offices should take on the task of developing and offering customer service and engagement oriented workshops to student services staff in order to help them make connections with the students and create positive initial engagement experiences.

Engagement with the ESL academic support staff was a critical type of engagement for the development of a sense of belonging and the success of the Hispanic Generation 1.5 students. The study findings show that this school might need to require various engagement opportunities for their students through the academic support center. First, high risk courses and ESL courses that enroll a high number of Hispanic Generation 1.5 students could include a lab component or a specific number of required tutoring sessions to be completed in the actual academic support area, especially for first 
year courses. At the beginning of the academic semester, faculty could take their students to the academic support area for an orientation with the staff so that students are exposed to the space and the people and so that they develop initial feelings of comfort.

At this particular institution, non-ESL academic support staff members might need to be trained to work with a variety of students, including Hispanic Generation 1.5 students. This training would give the non-ESL support staff members the tools necessary for them to provide the best instructional services to the different populations they serve, especially for the improvement of English language skills. The school might choose to cross-train its academic support staff so that writing center tutors for credit courses are trained by ESL tutors on how to work with non-native speakers, who have unique language and academic needs than the native speakers in the developmental and credit courses. The staff could be presented with theory and pedagogy for working with Hispanic Generation 1.5 students and provided with an opportunity to apply the knowledge and reflect on practices. This form of reflective professional development could have more significant effects for the academic support staff members and the students they serve.

\section{Further Research}

This study has revealed several themes about the lived engagement experiences of Hispanic Generation 1.5 English language learners at a Massachusetts community college. With this exploratory information, various studies could be designed to gather more generalizable data on Hispanic Generation 1.5 engagement and membership 
experiences across the country.This section focuses on areas and methods for further research so that additional findings may be added to this discussion of Hispanic Generation 1.5 students' engagement experiences and academic in community colleges.

There are many engagement quantitative tools used to determine engagement needs across an institution. Engagement and Hispanic Generation 1.5 research studies should look at triangulating this quantitative data by using a variety of related instruments including the Community College Survey of Student Engagement (CCSSE), the Survey of Entering Student Engagement (SENSE), the Beginning College Survey of Student Engagement (BCSSE), and the Faculty Survey of Student Engagement (FSSE). Researchers should add survey items and sampling methods that allow a college to look at its different populations, including ESL and non-ESL Hispanic Generation 1.5 students. Then the surveys can yield comparable data that institutions can use to pinpoint areas for improvement in the arena of student engagement and belonging at the institution.

Data beyond simple engagement perceptions and activities are needed to look at the relationship among engagement, membership, belonging, and degree completion. Mixed methods research might be the next step to look at these relationships so that the quantitative data can be analyzed from the students' perceptions of their lived engagement and membership experiences. Particularly, research is needed in the areas of language and engagement differences by region, the role that immigration experiences play on high school and college engagement, motivational factors, and the role that motivation plays in engagement and academic success. Further research is needed to compare this dissertation study's findings to similar studies looking at other college 
populations so that each college can create a student engagement profile that should be updated at least every 5 years.

If I were to continue on this path of inquiry, I would continue to analyze the data as three units of analysis, since the students' experiences differed when in ESL, developmental, and credit courses. However, I would include non-completers to this study in order to include the perspective of those Hispanic Generation 1.5 students who left the institution while completing ESL coursework or shortly after completing it, and, unlike Juan and Aracelis, never returned. If given time and resources, I would follow a group of Hispanic Generation 1.5 students from the first semester of enrollment for 6 years or until graduation to grasp a complete picture of their engagement experiences and how they perceived that those experiences related to their academic success. Finally, I would love to complete the same study, with the just mentioned improvements, but across multiple community colleges in order to compare Hispanic Generation 1.5 students' engagement experiences across colleges within the same state and perhaps across different states. This embedded cross-analysis case study approach would allow for findings that are attributed to regional intricacies and that might vary not just from state to state but from county to county.

\section{Coming Full Circle with Some Valuable Answers}

As an instructor, I always integrated community building strategies within my courses to help students develop a sense of belonging to least my own course. I also required that students work with me outside of class at least twice a semester. Knowing 
what I know now, after the completion of my dissertation study, I plan tobe more explicit with my students about my intentions inside and outside of the classroom. I plan to create more intentional, well-structured out-of-class engagement experiences with my own students in order to foster stronger relationships with them, and I plan to teach them how to build relationships with future faculty members, especially outside of ESL.

From the administrative perspective, I plan to integrate more professional development opportunities for my faculty and staff so that they can create more significant engagement opportunities and relationships with their students. I plan to work more closely with the student services staff to ensure that our engagement work is supported by their interactions with our students. Whenever possible, I plan to collect and share students' stories as well as success data to help all program employees see how we are doing and where we could improve our engagement and student success efforts.

Janet was the case study participant who opened this path of inquiry for me after I spent years of frustration not knowing if what I was doing with my students was helping them succeed in college and not knowing what else I could do to enhance their success. Previous Generation 1.5 students motivated me to go back to school and obtain a doctoral degree. However, Janet was the one Hispanic Generation 1.5 student who helped me develop questions that opened up new doors of inquiry and shaped the overall dissertation. Now, when I meet future Hispanic Generation 1.5 students in my classroom or within my department, I can develop intentional engagement plans that could help the students learn more, learn better, and more importantly stay within the institution and reach their educational and career goals. 


\section{References}

(2006). 2006 performance measurement report: Performance goals for state and community college in the commonwealth of Massachusetts. Access, affordability, student success, fiscal efficiency. Massachusetts Board of Higher Education.

(2007). 2007 performance measurement report: Performance goals for state and community college in the commonwealth of Massachusetts. Massachusetts Board of Higher Education.

Achieving the Dream. (2008). State Profile: Massachusetts. Retrieved June 1, 2008, from

http://www.achievingthedream.org/_pdfs/_publicpolicy/massachusetts_state_profi le.pdf

Allison, H. A. (2006). Immigration + new literacy studies + digital technologies $=$ ESL for a new South. In C. Machado (Series Ed.) \& M. Spaventa (Vol. Ed.), Perspectives on community college ESL series: Vol. 1. Pedagogy, programs, curricula, and assessment (pp. 47-60). Alexandria, VA: Teachers of English to Speakers of Other Languages, Inc.

Astin, A. W. (1977). Four critical years. San Francisco: Jossey-Bass.

Benjamin, M., Earnest, K., Gruenewald, D., \& Arthur, G. (2007, spring). The first weeks of the first year. New Directions for Student Services, 13-24.

Blumenthal, A. (spring 2002). English as a second language at the community college: An exploration of context and concerns. New Directions for Community Colleges, No 117, 45-53.

Bogdan, R. C., \& Biklen, S. K. (2003). Qualitative research for education: An introduction to theories and methods ( $4^{\text {th }}$ ed.). Boston, MA: Allyn \& Bacon.

Bryson, C., \& Hand, L. (2007). The role of engagement in inspiring teaching and learning. Innovations in Education and Teaching International, 44(4), 349-362.

Case, J. M. (2008). Alienation and engagement: Development of an alternative theoretical framework for understanding student learning. Higher Education, 55(3), 321-332.

Caspi, A., Chajut, E., Saporta, K., \& Beyth-Marom, R. (2005). The influence of personality on social participation in learning environments. Learning and Individual Differences, 16, 129-144. 
Chickering, A. W., \& Gamson, Z. F. (Eds.). (1987, March). Seven principles for good practice in undergraduate education. AAHE Bulleting, 3-7.

Chickering, A. W., \& Gamson, Z. F. (1991). Applying the seven principles for good practice in undergraduate education. San Francisco: Jossey-Bass.

Chickering, A. W. \& Reisser, L. (1993). Education and identity (2 ${ }^{\text {nd }}$ edition). San Francisco: Jossey-Bass.

Commonwealth of Massachusetts Community College. (2009). Mission Statement and Core Values. Retrieved January 3, 2009, from http://www.CMCC.mass.edu/administration/mission.php

Community College Survey of Student Engagement. (2006). Act on fact: Using data to improve student success. Austin, TX: Community College Leadership Program, The University of Texas at Austin.

Community College Survey of Student Engagement. (2007). Committing to student engagement: Reflection on CCSSE's first 5 years. Austin, TX: Community College Leadership Program, The University of Texas at Austin.

Community College Survey of Student Engagement. (2008). Commonwealth of Massachusetts Community College. [Data file]. Retrieved January 3, 2009, from http://www.ccsse.org

Corbin, J. \&Strauss A. (1990). Grounded theory research: Procedures, canons, and evaluative criteria. Qualitative Sociology, 13(1), 3-21.

Creswell, J. W. (1998). Qualitative inquiry and research design: Choosing among five traditions. Thousand Oaks: Sage.

Cummins, J. (1989). Empowering minority students. Sacramento, CA: California Association for Bilingual Education.

Cummins, J. (2000). Language, power, and pedagogy: Bilingual children in the crossfire. Clevedon, England: Multilingual Matters LTD.

Cummins, J. (2001). An introductory reader to the writing of Jim Cummiins. Clevedon, England: Multilingual Matters LTD.

Erlandson, D. A., Harris, E. L., Skipper, B. L., \& Allen, S. D. (1993). Doing naturalistic inquiry: A guide to methods. Newbury Park, CA: Sage.

Excelencia in Education. (n.d). Hispanic serving institutions. Retrieved March 11, 2009, from http://www.edexcelencia.org/research/hsi 
Filkins, J. W., Doyle, S. K. (2002, June). First generation and low income students: Using the NSSE data to study effective educational practices and students. Paper presented at the Annual Forum for the Association for Institutional Research, Toronto, Ontario, Canada.

Flowerdew, J. (2000). Discourse community, legitimate peripheral participation, and the nonnative-English-speaking scholar. TESOL Quarterly, 34(1), 127-150.

Fosnot, C. T., \& Perry, R. S. (2005). Constructivism: A psychological theory of learning. In C. T. Fosnot (Ed.) Constructivism: Theory, perspectives, and practice $\left(2^{\text {nd }}\right.$ ed.) (pp.8-38). New York: Teachers College Press.

Fry, R. (2004). Hispanic youth finishing college: The role of selective pathways. Retrieved July 25, 2007, from the Pew Hispanic Center Web site: http://www.Pewhispanic.org

Gándara, P., Losen, D., August, D., Uriarte, M., Gómez, M. C., \& Hopkins, M. (2010). Forbidden language: A brief history of U.S. language policy. P. Gándara\& M. Hopkins (Eds.) Forbidden language: English learners and restrictive language policies pp. 20-33). New York: Teachers College, Columbia University.

Gawienowski, M. F., \& Holper, K. (2006). A portrait of generation 1.5 students. In C. Machado (Series Ed.) \& A. Blumenthal (Vol. Ed.), Perspectives on community college ESL series: Vol. 2. Students, mission, and advocacy (pp. 117-130). Alexandria, VA: Teachers of English to Speakers of Other Languages, Inc.

Gee, J. P. (1989a) What is literacy? Journal of Education, 171(1), 18-25.

Gee, J. P. (1989b) Dracula, the vampire Lestat, and TESL. Journal of Education, 171(1), 116-134.

Gee, J. P. (1996). Social linguistics and literacies: Ideology in discourses. New York: Routledge/Falmer.

Gee, J. P., Hull, G., \& Lankshear, C. (1996). The new work order: Behind the language of the new capitalism. Boulder, $\mathrm{CO}$ : Westview.

Gee, J. P. (2000). New people in new worlds: Networks, the new-capitalism and schools. In B. Cope \& M. Kalantzis (Eds.), Multiliteracies: Literacy learning and the design of social futures. London: Routledge.

Gee, J. P. (2002). Teenagers in new times: A new literacy studies perspective. Journal of Adolescent \& Adult Literacy, 43(5), 412-420. 
Gee, J. P. (2003). What video games have to teach us about learning and literacy. New York: Palgrave Macmillan.

Graunke, S. S., \& Woosley, S. A. (2005). An exploration of the factors that affect the academic success of college sophomores. College Student Journal, 39(2), 367376.

Graves, D. H. (2004). Teaching day by day: 180 stories to help you along the way. Portsmouth, NH: Heineman.

Greenslade, E. (2008, November). College as part of national report on student success. U.S. Fed News. Retrieved December 15, 2008, from http://www.lexisnexis.com/us/Inacademic/returnTo.do?returnToKey=20_T54118 57021

Gubrium, J. F., \& Holstein, J. A. (1997). The new language of qualitative method. New York: Oxford University Press.

Handelsman, M. M., Briggs, W. L., Sullivan, N., \& Towler, A. (2005). A measure of college student course engagement. Journal of Educational Research, 98(3), 184191.

Haneda, M. (1997). Second language learning in a 'community of practice': A case study of adult Japanese learners. Canadian Modern Language Review, 54, 11-27.

Hara, N., \& Schwen, T. M. (2006). Communities of practice in workplaces: Learning as a naturally occurring event. Performance Improvement Quarterly, 19(2), 93-114.

Harklau, L., Siegal, M., Losey, K. M. (1999). Linguistically diverse students and college writing: What is equitable and appropriate? In L. Harklau, M. Siegal, \& K. M. Losey (Eds.), Generation 1.5 meets college composition (pp. 1-16). Mahweh, NJ: Lawrence Erlbaum Associates.

Hispanic Association of Colleges and Universities. (n.d). Hispanic serving institution definition. Retrieved March 11, 2009, from http://www.hacu.net/hacu/HSI_Definition_EN.asp?SnID=2022802811

Hung, D., Chen, D. V., Koh, T. S. (2006). The reverse LPP process for nurturing a community of practice. Educational Media International, 43(4), 299-314.

Karp, M. M., Hughes, K, L, \& O'Gara, L. (2008). An exploration of Tinto's integration framework for community college students (CCRC Working Paper No. 12). New York: Community College Research Center, Teachers College, Columbia University. 
Keup, J. R. (2006, summer). Promoting new-student success: Assessing academic development and achievement among first-year students. New Directions for Student Services, 27-46.

Krause, K., McInnis, C., \& Welle, C. (2003, November). Out-of-class engagement in undergraduate learning communities: The role and nature of peer interactions. Paper presented at the Annual Meeting of the Association for the Study of Higher Education, Portland, OR.

Kuh, G. D., Kinzie, J., Buckley, J. A., Bridges, B. K., \& Hayek, J. C. (2007). Piecing together the student success puzzle: Research, propositions, and recommendations. ASHE Higher Education Report, 32(5), 1-182.

Kuh, G. D., Kinzie, J., Schuh, J. H., Whitt, E. J. (2005, July/August). Never let it reset: Lessons about student success from high-performing colleges and universities. Change, 44-51.

Kuh, G. D., Gonyea, R. M., \& Palmer, M. (2001). The disengaged commuter student: Fact or fiction? Commuter Perspectives, 27(1), 2-5.

Kulm, T. L., \& Cramer, S. (2006). The relationship of student employment to student role, family relationships, social interactions and persistence. College Student Journal, 40(4), 927-938.

Kuo, E. W. (1999, winter). English as a second language in the community college curriculum. New Directions for Community Colleges, 108, 69-80.

Laird, T. F. N., Bridges, B. K., Morelon-Quainoo, C. L., Williams, J. M., \& Holmes, M. S. (2007). African American and Hispanic student engagement at minority serving and predominantly White institutions. Journal of College Student Development, 48(1), 39-56.

Lave, J. \& Wenger, E. (1991). Situated learning: Legitimate peripheral participation. New York: Cambridge University Press.

Lincoln, Y. S., \& Guba, E. G. (1985). Naturalistic inquiry. Newbury Park, CA: Sage.

Mann, S. J. (2005). Alienation in the learning environment: A failure of community? Studies in Higher Education, 30(1), 43-55.

Mann, S. J. (2001) Alternative Perspectives on the Student Experience: alienation and engagement. Studies in Higher Education, 26(1), 7-20.

Maslow, A. H. (1970). Motivation and personality (2 ${ }^{\text {nd }}$ ed.).New York: Harper. 
Massachusetts Department of Elementary and Secondary Education. (n.d.).

Massachusetts Comprehensive Assessment System. Retrieved September 7, 2010, from http://www.doe.mass.edu/mcas/overview.html

McClenney, K. M. (summer, 2006). Benchmarking effective educational practice. New Directions for Community College, 134, 47-55.

McClenney, K. M. (2007). Research Update: The Community Survey of Student Engagement. Community College Review, 35(2), 137-146.

Miele, C. (2003). Bergen Community College Meets Generation 1.5. Community College Journal of Research and Practice, 27(7), 603-612.

National Center for Education Statistics. (2005). Graduation rate survey. Retrieved June 15, 2007, from http://nces.ed.gov

National Commission on the Future of Higher Education. (2006). A test of leadership: Charting the future of U.S. higher education. Washington, DC:U.S. Department of Education.

National Survey of Student Engagement. (2006). Engaged learning: Fostering success for all students. Bloomington, IN: Center for Postsecondary Research, School of Education, Indiana University, Bloomington.

National Survey of Student Engagement. (2007). Experiences that matter: Enhancing student learning and success. Bloomington, IN: Center for Postsecondary Research, School of Education, Indiana University, Bloomington.

Nehrebecki, E., \& Skinner, R. (2007). Building on “other” literacies: Instruction for Generation 1.5. Paper presented at the annual meeting of the National Council of Teachers of English, New York.

Newman, I., \& Benz, C. R. (1998). Qualitative-quantitative research methodology: Exploring the interactive continuum. Carbondale, IL: Southern Illinois University Press.

Ortmeier-Hooper, C. (2008). English may be my second language, but I'm not ESL. College Communication and Composition, 59(3), 389-419.

Osterman, K. F. (2000). Students' need for belonging in the school community. Review of Educational Research, 70(3), 323-367.

Oudenhoven, E. D. (2006). Caught in the middle: Generation 1.5 Latino students and English language learning at a community college (Doctoral dissertation). Available from Proquest database. 
Padilla, L. M. (2001). But you're not a dirty Mexican: Internalized oppression, Latinos \& Law. Texas Hispanic Journal of Law and Policy, 7(1), 59-118.

Patton, M. Q. (2002).Qualitative research and evaluation methods. Thousand Oaks, CA: Sage.

Pike, G. R., \& Kuh, G. D. (2005). First- and second-generation college students: A comparison of their engagement and intellectual development. The Journal of Higher Education, 76(3), 276-300.

Rambaut, R. G., \& Ima, K. (1988). The adaptation of Southeast Asian refugee youth. A comparative study. Final report to the Office of Resettlement. San Diego: San Diego State University. (ERIC Document Reproduction Service No. ED299372)

Rubin, H. J., \& Rubin, I. S. (2005). Qualitative interviewing: The art of hearing data $\left(2^{\text {nd }}\right.$ ed. $)$. Thousand Oaks, CA: Sage.

Schuetz, P. (2008). A theory-driven model of community college student engagement. The Community College Journal of Research and Practice, 32, 305-324.

Schwandt, T. A. (2001). Dictionary of qualitative inquiry $\left(2^{\text {nd }}\right.$ ed. $)$. Thousand Oaks: Sage.

Stake, R. E. (2000). The case study method in social inquiry. In R. Gomm, M Hammersley, \& P. Foster (Eds.), Case study method: Key issues, key text (pp. 1926). Thousand Oaks: Sage.

Stasinopoulos, J. (2006). The power of personal narrative: What we can learn from our students. In C. Machado (Series Ed.) \& A. Blumenthal (Vol. Ed.), Perspectives on community college ESL series: Vol. 2. Students, mission, and advocacy (pp. 117-130). Alexandria, VA: Teachers of English to Speakers of Other Languages, Inc.

Swail, W. S., Cabrera, A. F., \& Lee, C. (2004). Hispanic youth and the pathway to college. Retrieved July 25, 2007, from The Pew Hispanic Center Web site: http://www.Pewhispanic.org

Swail, W. S., Redd, K. E., \& Perna, L. W. (2003). Retaining minority students in higher education: A framework for success. ASHE Higher Education Report, 30(2). San Francisco: Jossey-Bass.

Swales, J. M. (1990). Genre analysis: English in academic and research settings. Cambridge: Cambridge University Press. 
Tatum, B. D. (1992). Talking about race, learning about racism: The application of racial identity development theory in the classroom. Harvard Educational Review, 62(1), 1-24.

Tatum, B. D. (2003). “Why are the Black kids sitting together in the cafeteria?” and other conversations about race. A psychologist explains the development of racial identity. New York: Perseus Books.

Tarquin, K., \& Cook-Cottone, C. (2008). Relationships among aspects of student alienation and self concept. School Psychology Quarterly, 23(1), 16-25.

Tinto, V. (1975). Dropout from higher education: A theoretical synthesis of recent research. Review of Educational Research, 45, 89-125.

Tinto, V. (1993). Leaving college: Rethinking the causes and cures of student attrition ( $2^{\text {nd }}$ ed.). Chicago: The University of Chicago Press.

Umback, P. D., \& Wawrzynski, M. R. (2005). Faculty do matter: The role of college faculty in student learning and engagement. Research in Higher Education, $46(2), 153-184$.

U.S. Census Bureau. (2000). Quick facts. Retrieved May 26, 2008, from http://www.quickfacts.census.gov

U.S. Census Bureau. (2005a). Current population survey. Retrieved July 27, 2007, from http://www.census.gov

U.S. Census Bureau. (2005b). 2005 American community survey. Selected Social Characteristics: Massachusetts. Retrieved July 22, 2008, from http://www.census.gov/acs/www

U.S. Census Bureau. (2006). Educational attainment. Retrieved July 27, 2007, from http://www.census.gov/population/www/socdemo/educ-attn.html

U.S. Census Bureau. (2009). 2006-2008 American Community Survey 3-Year Estimates. Retrieved November $4^{\text {th }}, 2010$, from http://factfinder.census.gov

Vernez, G., \& Abrahamse, A. (1996) How immigrants fare in the U.S. education. Institute on Education and Training Center for Research on Immigration Policy. Santa Monica, CA: RAND Corporation.

Vygotsky, L. M. (1978). Mind in society: The development of higher psychological processes. Cambridge, MA: Harvard University Press. 
Wenger, E., McDermott, R., Snyder, W. M. (2002). Cultivating communities of practice. A guide to managing knowledge. Boston: Harvard Business School Press.

Wenger, E. (1998). Communities of practice: Learning, meaning, and identity. Cambridge: Cambridge University Press.

Ybarra, R. E. (2004). Learning to write as a hostile act for Hispanic students. New York: Peter Lang.

Yin, R. K. (2003a). Application of case study research ( $2^{\text {nd }}$ ed.). Thousand Oaks: Sage.

Yin, R. K. (2003b). Case study research: Design and methods ( $3^{\text {rd }}$ ed.). Thousand Oaks: Sage. 
Appendix A

Consent Form

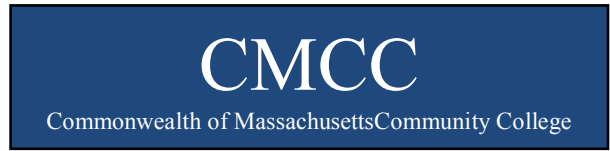

\section{FIU}

\section{INFORMED CONSENT TO PARTICIPATE IN A RESEARCH STUDY}

Title of the Study: Engagement and Membership Experiences of Hispanic Generation 1.5 English Language Learners in a Massachusetts Community College

Principal Investigator: Jacqueline Peña (cell phone: 978-569-6093) (email: jpena@fiu.edu)

You are invited to be a part of a research study about Hispanic students' experiences during and after taking ESL (English as a Second Language) at Commonwealth of Massachusetts Community College.

You were chosen for the study because you attended high school in the United States, and you are taking or have taken at least 6 credits of ESL courses at CMCC.

The study: The purpose of this study is to learn about Hispanic students' engagement experiences with their teachers, other students, and college employees during and after taking ESL classes in CMCC. You will be interviewed in a small group or by yourself for $1 \frac{1 / 2}{2}$ to 2 hours. The interviews will be tape recorded. You will be asked questions about your experiences in school before attending Commonwealth of Massachusetts Community College. You mostly will be asked questions about your experiences with teachers, staff, and other students at CMCC.

The information obtained from this study will be shared with others in written and oral formats.

Risks: There is no known risk involved in this study.

Benefits: Participants will be provided with food and refreshments at the interviews. In addition, participants will receive a $\$ 10$ gift certificate to the college bookstore at the end of each interview. You will receive a copy of the written study when it is completed. 
Confidentiality: All information will be handled in a strictly confidential manner so that no one will be able to identify you when the results are recorded and reported. Only the researcher will have access to the interview tape-recordings, and none of the participants' real names will be used in the transcripts or in any of the writings associated with the study. The transcripts and study reports will utilize the participants' aliases, which the participants will choose at the time of the interviews.

Voluntary nature/questions: You can choose not to do the study, and there will be no negative consequences. If you participate, you can choose to stop participating at any time with no negative consequences. If you want to withdraw from the study, let Jacqueline know, and she will destroy any information about you.

If you would like more information about this research after you are done, you can contact me at 978-569-6093 or ipena@fiu.edu. If you feel that you were mistreated or would like to talk with someone about your rights as a volunteer in this research study, you may contact Dr. Patricia Price, the Chairperson of the Florida International University Institutional Review Board at 305-348-2618 or 305-348-2494. You also may contact Mr. Tom Fallon, the Director of Institutional Planning and Research at Commonwealth of Massachusetts Community College (978-556-3866).

I understand the study described above and have been given a copy of the description as outlined above. I am 18 years of age or older and I agree to participate. 
Appendix B

Student Information Checklist

\section{Student Information Survey}

The purpose of this questionnaire is to obtain information that will help with the overall study about the academic and social experiences of Hispanic students in this community college. Only I, the researcher (Jacqueline Peña), will view these questionnaires. Your real name will not be on this questionnaire so that the information can remain confidential.

1. How old are you?

2. Where were you born (city and country)?

3. How old were you when you first came to the United States to live?

4. Did you go back home to live for more than 3 months after you first came to the U.S. (yes or no)?

5. What was the first grade that you attended in the United States (e.g. fifth grade, sixth grade)?

6. While you were in the K-12 public school system, before entering college, were you ever in any of the following. Please check all that apply.

a) English-only classes (all of the teaching is in English)?

b) A bilingual program (part of the teaching is in Spanish and part of the teaching in in English)?

c) English pull-out program (all of the teaching is in English and a teacher pulled you of class to work on your language skills)?

d) An ungraded classroom (where you were not aware of your grade or level)? 
7. Please list all the schools and colleges that you have attended here in the United States.

8. Did you take English or ESL courses at another place before coming to this college (yes or no)?

9. Please circle all the courses that you have taken at CMCC.

\begin{tabular}{|cccc|}
\hline ESL Grammar 1 & Listening/Speaking 1 & Reading 1 & Writing 1 \\
ESL Grammar 2 & Listening/Speaking 2 & Reading 2 & Writing 2 \\
ESL Grammar 3 & Listening/Speaking 3 & Reading 3 & Writing 3 \\
ESL Grammar 4 & Listening/Speaking 4 & Reading 4 & Writing 4 \\
Advanced Integrated Reading Skills & Basic Reading & Basic Writing \\
Advanced Integrated Writing Skills & College Reading & $\begin{array}{c}\text { Freshmen } \\
\text { Composition }\end{array}$ \\
\hline
\end{tabular}

10. What other courses have you taken at CMCC? Please list them all below.

11. Why did you become a student at CMCC? 
Appendix C

Interview Guide \#1

\section{Interview Guide}

\section{Hispanic Generation 1.5 Students in ESL}

*Note that these questions will be presented in English since Generation 1.5 students have oral language abilities that resemble those of their native English-speaking peers. However, the researcher is bilingual and can maneuver the discussion in both languages as needed.

\section{Main Questions and Possible Follow-up Questions:}

1. Tell me about yourselves and your school experiences before coming to this college.

2. Describe your first experience at this college.

3. Could you describe your first semester in ESL?

a. Describe your classes (what you did in them and what you learned)

b. How do you feel while taking ESL classes?

4. Tell me about your relationship with your ESL peers.

a. How do you feel around them?

b. What do you do with them inside and outside of class?

c. Describe your most significant friendship with someone in your ESL classes.

d. Describe one unforgettable moment with your ESL peers.

5. Could you describe your relationship with your teachers?

a. How do you feel around them?

b. What do you talk about with your teachers inside and outside of class?

c. Describe one unforgettable moment with a teacher.

6. Describe any other people you worked with at the college (e.g. the ESL lab tutors).

a. What activities did you complete with these people?

b. How do you feel around them?

c. Describe one unforgettable moment with one of these college employees.

7. What else do you do in this school when you are not taking classes?

8. Could you describe one moment when you felt that you did not belong in this school?

a. Could you describe the most negative experience that you have had at this school?

9. Could you describe one moment when you felt happy and comfortable in this school?

a. Could you describe the most positive experience that you have had at this school?

10. What are some recommendations, suggestions, or ideas that you would like to give to this school so that they can help other students, like you, succeed? 
Appendix D

Interview Guide \#2

\section{Interview Guide}

\section{Hispanic Generation 1.5 Students in Developmental Courses}

*Note that these questions will be presented in English since Generation 1.5 students have oral language abilities that resemble those of their native English-speaking peers. However, the researcher is bilingual and can maneuver the discussion in both languages as needed.

\section{Main Questions and Possible Follow-up Questions:}

1. Tell me about yourselves and your school experiences before coming to this college.

2. Describe your first experience at this college.

3. Could you describe your experiences in ESL and your relationships with people?

a. Describe your classes (what you did in them and what you learned)

a. How did you feel while taking ESL classes?

4. Could you describe your first semester in Basic Writing?

a. Describe your classes (what you did in them and what you learned)

b. How did you feel while taking these classes?

5. How did you feel when you moved from ESL to Basic Writing?

6. What are some differences or similarities between your experiences in the ESL classes and your experiences in Basic Writing and Reading?

7. Describe your relationship with your peers.

a. Tell me about your closest friend at the college.

b. Describe the people you talk to in class and out of class and what you talk about.

8. Describe your relationship with your teachers.

a. How do you feel around them?

b. What do you talk about with your teachers inside and outside of class?

c. Describe one unforgettable moment with a teacher.

9. Describe any other people you worked with at the college (e.g. the ESL lab tutors).

a. What activities did you complete with these people?

b. How did you feel around them?

c. Describe one unforgettable moment with a college employee (not a teacher).

10. What else do you do in this school when you are not taking classes?

11. Could you describe one moment when you felt that you did not belong in this school?

a. Could you describe the most negative experience that you have had at this school?

12. Could you describe one moment when you felt happy and comfortable in this school? 
a. Could you describe the most positive experience that you have had at this school?

13. What are some recommendations, suggestions, or ideas that you would like to give to this school so that they can help other students, like you, succeed? 
Appendix E

Interview Guide \#3

\section{Interview Guide}

Generation 1.5 Students in Credit-bearing/Mainstream Courses

*Note that these questions will be presented in English since Generation 1.5 students have oral language abilities that resemble those of their native English-speaking peers. However, the researcher is bilingual and can maneuver the discussion in both languages as needed.

\section{Main Questions and Possible Follow-up Questions:}

1. Tell me about yourselves and your school experiences before coming to this college.

2. Describe your first experience at this college.

3. Could you describe your experiences in ESL and your relationships with the people in the program?

a. Describe your classes (what you did in them and what you learned)

b. How did you feel while taking ESL classes?

c. What did you talk about with your peers and how often did you see each other?

4. Could you describe your first semester in Basic Writing?

a. Describe your classes (what you did in them and what you learned).

b. How did you feel while taking ESL classes?

5. How did you feel when you moved from ESL to Basic Writing and then when you moved to Composition?

6. What are some differences and similarities among the three types of courses (ESL, developmental, and credit-bearing courses)?

7. Describe your relationship with your peers.

a. Tell me about your closest friend at the college.

b. Describe the people you talk to in class and out of class and what you talk about.

8. Describe your relationship with your teachers.

a. How do you feel around them?

a. What do you talk about with your teachers inside and outside of class?

b. Describe one unforgettable moment with a teacher.

9. Describe any other people you worked with at the college (e.g. the lab tutors, advisors).

a. What activities did you complete with these people?

b. How did you feel around them?

c. Describe one unforgettable moment with a college employee (not a teacher).

10. Describe any other people you worked with at the college (e.g. the ESL lab tutors).

a. What activities did you complete with these people? 
b. How did you feel around them?

11. What else do you do in this school when you are not taking classes?

12. Could you describe one moment when you felt that you did not belong in this school?

a. Could you describe the most negative experience that you have had at this school so far?

13. Could you describe one moment when you felt happy and comfortable in this school?

a. Could you describe the most positive experience that you have had at this school so far?

14. What are some recommendations, suggestions, or ideas that you would like to give to this school so that they can help other students, like you, succeed? 


\section{Appendix F \\ Interview Guide \#4 \\ Interview Guide \\ Generation 1.5 Students Program Completers/Graduates}

\section{Introductory Questions:}

1. Tell me about yourself and your educational experiences before coming to this college.

2. Describe your first experience at this college.

\section{ESL Experiences:}

3. Could you describe your experiences in ESL and your relationship with the people in the program?

a. Describe your classes (what you did in them and what you learned).

b. How did you feel while taking ESL classes?

c. What did you talk about with your peers and how often did you see each other?

4. Tell me about your relationship with your ESL peers.

a. How did you feel around them?

b. What did you do with them inside and outside of class?

c. Describe your most significant friendship with someone in your ESL classes.

d. Describe one unforgettable moment with your ESL peers.

5. Could you describe your relationship with your ESL teachers?

a. How did you feel around them?

b. What did you talk about with your teachers inside and outside of class?

c. Describe one unforgettable moment with a teacher.

\section{Developmental Education Experiences:}

6. Could you describe your first semester in Basic Writing?

a. Describe your classes (what you did in them and what you learned).

b. How did you feel while taking Basic Writing classes?

7. Tell me about your relationship with the other Basic Writing students.

a. How did you feel around them?

b. What did you do with them inside and outside of class?

c. Describe your most significant friendship with someone in your ESL classes.

d. Describe one unforgettable moment with your ESL peers.

8. Could you describe your relationship with your Basic Writing teacher?

a. How did you feel around them?

b. What did you talk about with your teachers inside and outside of class?

c. Describe one unforgettable moment with the Basic Writing teacher. 


\section{Credit Coursework Experiences:}

9. Could you describe your first semester in Composition?

a. Describe your classes (what you did in them and what you learned).

b. How did you feel while taking Basic Writing classes?

10. Tell me about your relationship with the other Composition students.

a. How did you feel around them?

b. What did you do with them inside and outside of class?

c. Describe your most significant friendship with someone in your ESL classes.

d. Describe one unforgettable moment with your ESL peers.

11. Could you describe your relationship with your Composition teacher?

a. How did you feel around them?

b. What did you talk about with your teachers inside and outside of class?

c. Describe one unforgettable moment with the Basic Writing teacher.

12. Besides Composition, could you describe the courses that you take after Basic Writing?

a. How did you feel while taking these courses?

b. Describe one unforgettable moment in one of these courses.

\section{General Engagement Experiences across Programs:}

13. Could you describe one teacher who you feel influenced you in some way?

14. Could you describe at least one student who helped you or influenced you in some way?

15. Could you describe one college employee (e.g. an advisor or a tutor) who helped you or influenced you in some way?

\section{Engagement Experiences at the College:}

16. What else did you do in this school when you were not taking classes?

17. Could you describe one moment when you felt that you did not belong in this school?

a. Could you describe the most negative experience that you had at this school so far?

18. Could you describe one moment when you felt happy and comfortable in this school?

b. Could you describe the most positive experience that you had at this school so far?

\section{Final Thoughts:}

19. What are some recommendations, suggestions, or ideas that you would like to give to this school so that they can help other students, like you, succeed? 
Appendix G

Contact Summary Sheet

\section{Contact Summary Sheet}

Type of Contact:

Location:

Date:

1. What was the reason for the contact?

2. Summarize the information from this contact.

3. What was the most informative aspect or what new information was obtained from this contact?

4. What are some new or follow-up questions for this site, document, person, or group?

5. What are some new data collection activities as a result of this contact (if any)?

6. List all concerns, questions, comments, or notes about or from this contact:

7. What research question(s) or theoretical component does this contact address? 
Appendix $\mathrm{H}$

Coding Map

\begin{tabular}{|c|c|c|}
\hline Concept & Theme/Category & Code \\
\hline \multirow{11}{*}{$\begin{array}{l}\text { Pre-College } \\
\text { Factors }\end{array}$} & \multirow[t]{8}{*}{ Immigration Patterns } & Immigration to U.S. \\
\hline & & Return to DR \\
\hline & & Return to U.S. \\
\hline & & Long stays in DR \\
\hline & & Birthplace (DR or U.S.) \\
\hline & & Perceived effects on education \\
\hline & & $\begin{array}{l}\text { Perceptions of (cyclical) immigration } \\
\text { patterns }\end{array}$ \\
\hline & & National belonging (confusion/feelings) \\
\hline & \multirow{3}{*}{$\begin{array}{l}\text { Dominican Schooling } \\
\text { Experiences }\end{array}$} & Perceptions of curriculum \\
\hline & & Perceptions of structure \\
\hline & & Student habits \\
\hline \multirow{17}{*}{$\begin{array}{l}\text { U.S. Schooling } \\
\text { Experiences }\end{array}$} & \multirow{4}{*}{$\begin{array}{l}\text { General U.S. } \\
\text { Schooling } \\
\text { Experiences }\end{array}$} & Perceptions of curriculum \\
\hline & & Structure of schooling \\
\hline & & Perceptions of structure of schooling \\
\hline & & Student habits \\
\hline & \multirow{3}{*}{$\begin{array}{l}\text { U.S.high school } \\
\text { Testing }\end{array}$} & Testing experiences \\
\hline & & Testing perceptions \\
\hline & & Testing curriculum = prep work \\
\hline & \multirow[t]{4}{*}{ Language Programs } & Type \\
\hline & & Perceptions of language program \\
\hline & & Language learning experiences \\
\hline & & Suggestions for improvement \\
\hline & \multirow[t]{6}{*}{ HS Bridge Programs } & Type \\
\hline & & Program Activities \\
\hline & & Perceptions of program \\
\hline & & Peer engagement in program \\
\hline & & f-s engagement in program \\
\hline & & s-s engagement in program \\
\hline \multirow{9}{*}{$\begin{array}{l}\text { CMCC } \\
\text { Experiences }\end{array}$} & \multirow[t]{6}{*}{ Selecting CMCC } & Location \\
\hline & & Comfort level \\
\hline & & Convenience \\
\hline & & Prior Exposure \\
\hline & & Finances \\
\hline & & Reputation \\
\hline & \multirow[t]{3}{*}{ Assessment Process } & Assessment experiences \\
\hline & & Perceptions of assessment \\
\hline & & Alternative assessments \\
\hline
\end{tabular}




\begin{tabular}{|c|c|c|}
\hline Concept & Theme/Category & Code \\
\hline & \multirow{2}{*}{ Placement Process } & Actual placement \\
\hline & & Placement experiences \\
\hline & \multirow[t]{2}{*}{ Credit Coursework } & Perceptions of placement \\
\hline & & Learning experiences \\
\hline & \multirow[t]{2}{*}{ Math Coursework } & Perceptions of math curriculum \\
\hline & & Learning experiences \\
\hline & \multirow{2}{*}{ WRT Coursework } & Perceptions of WRT curriculum \\
\hline & & Learning experiences \\
\hline \multirow{9}{*}{$\begin{array}{l}\text { Faculty-student } \\
\text { Engagement }\end{array}$} & \multirow{3}{*}{$\begin{array}{l}\text { Faculty-student in- } \\
\text { class engagement }\end{array}$} & Perceptions of f-s engagement \\
\hline & & F-S engagement examples \\
\hline & & Perceptions of instructor/instruction \\
\hline & \multirow{3}{*}{$\begin{array}{l}\text { Faculty-student out- } \\
\text { of-class engagement }\end{array}$} & Perceptions of $\mathrm{f}$-s engagement \\
\hline & & F-S engagement examples \\
\hline & & Perceptions of instructor/instruction \\
\hline & \multirow{3}{*}{$\begin{array}{l}\text { General faculty- } \\
\text { student engagement }\end{array}$} & Perceptions of f-s engagement \\
\hline & & F-S engagement examples \\
\hline & & Perceptions of instructor/instruction \\
\hline \multirow{6}{*}{$\begin{array}{l}\text { Staff-Student } \\
\text { Engagement }\end{array}$} & \multirow{6}{*}{$\begin{array}{l}\text { General S-S } \\
\text { Engagement }\end{array}$} & Types \\
\hline & & Area \\
\hline & & Perceptions of service or engagement \\
\hline & & Perceptions of staff \\
\hline & & Levels of awareness \\
\hline & & Engagement examples \\
\hline \multirow{8}{*}{$\begin{array}{l}\text { Peer- } \\
\text { Engagement }\end{array}$} & \multirow{2}{*}{$\begin{array}{l}\text { In-class Peer } \\
\text { Engagement }\end{array}$} & Perceptions of peer engagement \\
\hline & & Peer engagement Examples \\
\hline & \multirow{2}{*}{$\begin{array}{l}\text { Out-of Class Peer } \\
\text { Engagement }\end{array}$} & Perceptions of peer engagement \\
\hline & & Peer engagement Examples \\
\hline & \multirow{4}{*}{$\begin{array}{l}\text { General Peer } \\
\text { Engagement }\end{array}$} & Perceptions of peer engagement \\
\hline & & Peer engagement Examples \\
\hline & & Significant relationships \\
\hline & & Language related to peer engagement \\
\hline
\end{tabular}




\begin{tabular}{|c|c|c|}
\hline Concept & Theme/Category & Code \\
\hline \multirow[t]{9}{*}{ Belonging } & \multirow{3}{*}{$\begin{array}{l}\text { Belonging at the } \\
\text { Institution }\end{array}$} & Feelings of belonging \\
\hline & & Feelings of not belonging \\
\hline & & Lack of belonging feelings \\
\hline & \multirow{2}{*}{$\begin{array}{l}\text { Factors that Affect } \\
\text { Belonging }\end{array}$} & Belonging facilitators \\
\hline & & Belonging detractors \\
\hline & \multirow[t]{4}{*}{ Involvement } & Involvement examples \\
\hline & & Involvement perceptions \\
\hline & & Lack of involvement \\
\hline & & Desire to be involved \\
\hline \multirow{8}{*}{$\begin{array}{l}\text { Language } \\
\text { Factors }\end{array}$} & \multirow{3}{*}{$\begin{array}{l}\text { Experiences with the } \\
\text { English Language }\end{array}$} & Language experiences in U.S. \\
\hline & & $\begin{array}{l}\text { Differences between English and } \\
\text { Spanish }\end{array}$ \\
\hline & & Perceptions of the English language \\
\hline & \multirow[t]{5}{*}{$\begin{array}{l}\text { English Language } \\
\text { Abilities }\end{array}$} & $\begin{array}{l}\text { Perceptions of general English language } \\
\text { abilities }\end{array}$ \\
\hline & & Perceptions of spoken language abilities \\
\hline & & Perceptions of written language abilities \\
\hline & & Perceptions of language learning \\
\hline & & Language learning tips \\
\hline \multirow{18}{*}{$\begin{array}{l}\text { Other Factors } \\
\text { that Could Affect } \\
\text { Engagement }\end{array}$} & \multirow{2}{*}{\begin{tabular}{|l|} 
Individual \\
Characteristics
\end{tabular}} & Personality traits \\
\hline & & Attitudes \\
\hline & \multirow[t]{3}{*}{ Employment } & Part-time/full-time \\
\hline & & On-campus/off-campus \\
\hline & & Perceptions of employment and school \\
\hline & \multirow{3}{*}{$\begin{array}{l}\text { Home } \\
\text { Responsibilities }\end{array}$} & Children \\
\hline & & Spouse \\
\hline & & Parents \\
\hline & \multirow[t]{4}{*}{ Language Usage } & Home language \\
\hline & & Work language \\
\hline & & Community language \\
\hline & & School language \\
\hline & \multirow[t]{6}{*}{ Motivators } & Career/employment goal \\
\hline & & Learn English goal \\
\hline & & Personal \\
\hline & & Family \\
\hline & & Financial support \\
\hline & & Desire to be involved \\
\hline
\end{tabular}


Appendix I

Sample Coded Transcript

\begin{tabular}{|c|c|c|c|c|c|c|c|c|c|c|c|}
\hline Group & Status & $\begin{array}{l}\text { Yrs.i } \\
\mathrm{n} \\
\text { U.S. } \\
\text { K- } \\
12\end{array}$ & $\begin{array}{l}\text { Parti- } \\
\text { cipant } \\
\#\end{array}$ & $\begin{array}{l}\text { Line } \\
\#\end{array}$ & Speaker & Text & UoA & Concept & Theme & Code & Notes \\
\hline $\begin{array}{l}\text { DR - } \\
\text { Gen } 1.5\end{array}$ & Credit & 3.5 & 12 & 232 & Jackie & What were your teachers like? & & & & & \\
\hline $\begin{array}{l}\text { DR - } \\
\text { Gen } 1.5\end{array}$ & Credit & 3.5 & 12 & 233 & Sara & They were very good. & ESL & $\begin{array}{l}\mathrm{f}-\mathrm{s} \\
\text { engagemen } \\
\mathrm{t}\end{array}$ & $\begin{array}{l}\text { general f- } \\
\mathrm{s} \\
\text { engagem } \\
\text { ent }\end{array}$ & $\begin{array}{l}\text { perceptions of } \\
\text { instructor/instr } \\
\text { uction }\end{array}$ & Good \\
\hline $\begin{array}{l}\text { DR - } \\
\text { Gen } 1.5\end{array}$ & Credit & 3.5 & 12 & 234 & Sara & $\begin{array}{l}\text { I remember that my first teacher } \\
\text { was Jennifer Tennison. }\end{array}$ & ESL & $\begin{array}{l}\mathrm{f}-\mathrm{s} \\
\text { engagemen } \\
\mathrm{t}\end{array}$ & $\begin{array}{l}\text { general f- } \\
\mathrm{s} \\
\text { engagem } \\
\text { ent }\end{array}$ & $\begin{array}{l}\text { perceptions of } \\
\text { instructor/instr } \\
\text { uction }\end{array}$ & $\begin{array}{l}\text { First = Jane } \\
(\mathrm{a} \\
\text { love/sweeth } \\
\text { eart) }\end{array}$ \\
\hline $\begin{array}{l}\text { DR - } \\
\text { Gen } 1.5\end{array}$ & Credit & 3.5 & 12 & 235 & Sara & $\begin{array}{l}\text { Oh my God! Es un amor, esa } \\
\text { señora. }\end{array}$ & ESL & $\begin{array}{l}\mathrm{f}-\mathrm{s} \\
\text { engagemen } \\
\mathrm{t}\end{array}$ & $\begin{array}{l}\text { general f- } \\
\mathrm{S} \\
\text { engagem } \\
\text { ent }\end{array}$ & $\begin{array}{l}\text { perceptions of } \\
\text { instructor/instr } \\
\text { uction }\end{array}$ & $\begin{array}{l}\text { Love and } \\
\text { admiration } \\
\text { for Jane }\end{array}$ \\
\hline $\begin{array}{l}\text { DR - } \\
\text { Gen } 1.5\end{array}$ & Credit & 3.5 & 12 & 236 & Jackie & $\begin{array}{l}\text { You know she did the nursing } \\
\text { program here? }\end{array}$ & & & & & \\
\hline $\begin{array}{l}\text { DR - } \\
\text { Gen } 1.5\end{array}$ & Credit & 3.5 & 12 & 237 & Sara & Yeah. & & & & & \\
\hline $\begin{array}{l}\text { DR - } \\
\text { Gen } 1.5\end{array}$ & Credit & 3.5 & 12 & 238 & Jackie & $\begin{array}{l}\text { She wants to be a nurse when she } \\
\text { retires. }\end{array}$ & & & & & \\
\hline $\begin{array}{l}\text { DR - } \\
\text { Gen } 1.5\end{array}$ & Credit & 3.5 & 12 & 239 & Sara & I know. & & & & & \\
\hline $\begin{array}{l}\text { DR - } \\
\text { Gen } 1.5\end{array}$ & Credit & 3.5 & 12 & 240 & Sara & She's so good. & ESL & $\begin{array}{l}\mathrm{f}-\mathrm{s} \\
\text { engagemen } \\
\mathrm{t}\end{array}$ & $\begin{array}{l}\text { general f- } \\
\text { s } \\
\text { engagem } \\
\text { ent }\end{array}$ & $\begin{array}{l}\text { perceptions of } \\
\text { instructor/instr } \\
\text { uction }\end{array}$ & \\
\hline
\end{tabular}




\begin{tabular}{|c|c|c|c|c|c|c|c|c|c|c|c|}
\hline Group & Status & $\begin{array}{l}\text { Yrs.i } \\
\text { n } \\
\text { U.S. } \\
\text { K- } \\
12\end{array}$ & $\begin{array}{l}\text { Parti- } \\
\text { cipant } \\
\#\end{array}$ & $\begin{array}{l}\text { Line } \\
\#\end{array}$ & Speaker & Text & UoA & Concept & Theme & Code & Notes \\
\hline $\begin{array}{l}\text { DR - } \\
\text { Gen } 1.5\end{array}$ & Credit & 3.5 & 12 & 241 & Sara & She's great. & ESL & $\begin{array}{l}\mathrm{f}-\mathrm{s} \\
\text { engagemen } \\
\mathrm{t}\end{array}$ & $\begin{array}{l}\text { general f- } \\
\text { s } \\
\text { engagem } \\
\text { ent }\end{array}$ & $\begin{array}{l}\text { perceptions of } \\
\text { instructor/instr } \\
\text { uction }\end{array}$ & \\
\hline $\begin{array}{l}\text { DR - } \\
\text { Gen } 1.5\end{array}$ & Credit & 3.5 & 12 & 242 & Sara & $\begin{array}{l}\text { I took a lot of classes with her of } \\
\text { grammar. Yeah. }\end{array}$ & ESL & $\begin{array}{l}\mathrm{f}-\mathrm{s} \\
\text { engagemen } \\
\mathrm{t}\end{array}$ & $\begin{array}{l}\text { general f- } \\
\text { s } \\
\text { engagem } \\
\text { ent }\end{array}$ & $\begin{array}{l}\text { perceptions of } \\
\text { instructor/instr } \\
\text { uction }\end{array}$ & \\
\hline $\begin{array}{l}\text { DR - } \\
\text { Gen } 1.5\end{array}$ & Credit & 3.5 & 12 & 243 & Jackie & Okay. & & & & & \\
\hline $\begin{array}{l}\text { DR - } \\
\text { Gen } 1.5\end{array}$ & Credit & 3.5 & 12 & 244 & Sara & Yeah and reading and writing. & ESL & $\begin{array}{l}\text { f-s } \\
\text { engagemen } \\
t\end{array}$ & $\begin{array}{l}\text { general f- } \\
\text { s } \\
\text { engagem } \\
\text { ent }\end{array}$ & $\begin{array}{l}\text { perceptions of } \\
\text { instructor/instr } \\
\text { uction }\end{array}$ & \\
\hline $\begin{array}{l}\text { DR - } \\
\text { Gen } 1.5\end{array}$ & Credit & 3.5 & 12 & 245 & Sara & She's really helpful. & ESL & $\begin{array}{l}\text { f-s } \\
\text { engagemen } \\
t\end{array}$ & $\begin{array}{l}\text { general f- } \\
\text { s } \\
\text { engagem } \\
\text { ent }\end{array}$ & $\begin{array}{l}\text { perceptions of } \\
\text { instructor/instr } \\
\text { uction }\end{array}$ & $\begin{array}{l}\text { Jane }= \\
\text { helpful = } \\
\text { Students } \\
\text { keep taking } \\
\text { classes with } \\
\text { same } \\
\text { teacher once } \\
\text { they find a } \\
\text { teacher they } \\
\text { like }\end{array}$ \\
\hline $\begin{array}{l}\text { DR - } \\
\text { Gen } 1.5\end{array}$ & Credit & 3.5 & 12 & 246 & Jackie & Tell me what's so great about her. & & & & & \\
\hline $\begin{array}{l}\text { DR - } \\
\text { Gen } 1.5\end{array}$ & Credit & 3.5 & 12 & 247 & Jackie & Give me an example. & & & & & \\
\hline
\end{tabular}




\begin{tabular}{|c|c|c|c|c|c|c|c|c|c|c|c|}
\hline Group & Status & $\begin{array}{l}\text { Yrs.i } \\
\mathrm{n} \\
\text { U.S. } \\
\text { K- } \\
12\end{array}$ & $\begin{array}{l}\text { Parti- } \\
\text { cipant } \\
\#\end{array}$ & $\begin{array}{l}\text { Line } \\
\#\end{array}$ & Speaker & Text & UoA & Concept & Theme & Code & Notes \\
\hline $\begin{array}{l}\text { DR - } \\
\text { Gen } 1.5\end{array}$ & Credit & 3.5 & 12 & 248 & Sara & $\begin{array}{l}\text { Um well she's always like not, like } \\
\text { pushing you in a good way but to } \\
\text { do work, and if you do it bad, } \\
\text { she's always there like helping } \\
\text { you. }\end{array}$ & ESL & $\begin{array}{l}\mathrm{f}-\mathrm{s} \\
\text { engagemen } \\
\mathrm{t}\end{array}$ & $\begin{array}{l}\text { general f- } \\
\text { s } \\
\text { engagem } \\
\text { ent }\end{array}$ & $\begin{array}{l}\text { perceptions of } \\
\text { instructor/instr } \\
\text { uction }\end{array}$ & $\begin{array}{l}\text { want } \\
\text { teachers } \\
\text { who push } \\
\text { them when } \\
\text { they can't } \\
\text { push } \\
\text { themselves } \\
\text { and who } \\
\text { help them } \\
\text { not just } \\
\text { when asked }\end{array}$ \\
\hline $\begin{array}{l}\text { DR - } \\
\text { Gen } 1.5\end{array}$ & Credit & 3.5 & 12 & 249 & Sara & $\begin{array}{l}\text { She gives the work back to you so } \\
\text { that you can do it. }\end{array}$ & ESL & $\begin{array}{l}\mathrm{f}-\mathrm{s} \\
\text { engagemen } \\
\mathrm{t}\end{array}$ & $\begin{array}{l}\text { general f- } \\
\text { s } \\
\text { engagem } \\
\text { ent }\end{array}$ & $\begin{array}{l}\text { perceptions of } \\
\text { instructor/instr } \\
\text { uction }\end{array}$ & $\begin{array}{l}\text { appreciates } \\
\text { feedback }\end{array}$ \\
\hline $\begin{array}{l}\text { DR - } \\
\text { Gen } 1.5\end{array}$ & Credit & 3.5 & 12 & 250 & Jackie & $\begin{array}{l}\text { Okay. And when you are with her } \\
\text { and with your other teachers, I'm } \\
\text { interested in, did you talk to them } \\
\text { a lot in class and outside of class? }\end{array}$ & & & & & \\
\hline $\begin{array}{l}\text { DR - } \\
\text { Gen } 1.5\end{array}$ & Credit & 3.5 & 12 & 251 & Sara & Yes. & ESL & $\begin{array}{l}\mathrm{f}-\mathrm{s} \\
\text { engagemen } \\
\mathrm{t}\end{array}$ & $\begin{array}{l}\text { general f- } \\
\text { s } \\
\text { engagem } \\
\text { ent }\end{array}$ & $\begin{array}{l}\text { f-s engagement } \\
\text { examples }\end{array}$ & $\begin{array}{l}\text { talk with } \\
\text { teachers in } \\
\text { and out of } \\
\text { class }\end{array}$ \\
\hline $\begin{array}{l}\text { DR - } \\
\text { Gen } 1.5\end{array}$ & Credit & 3.5 & 12 & 252 & Jackie & $\begin{array}{l}\text { And what did you talk about with } \\
\text { your teachers? }\end{array}$ & & & & & \\
\hline $\begin{array}{l}\text { DR - } \\
\text { Gen } 1.5\end{array}$ & Credit & 3.5 & 12 & 253 & Sara & $\begin{array}{l}\text { About the classes that I was } \\
\text { taking, about the things that I did } \\
\text { wrong in the class. Yeah. Work. }\end{array}$ & ESL & $\begin{array}{l}\mathrm{f}-\mathrm{s} \\
\text { engagemen } \\
\mathrm{t}\end{array}$ & $\begin{array}{l}\text { general f- } \\
\mathrm{s} \\
\text { engagem } \\
\text { ent }\end{array}$ & $\begin{array}{l}\text { f-s engagement } \\
\text { examples }\end{array}$ & \\
\hline
\end{tabular}




\begin{tabular}{|c|c|c|c|c|c|c|c|c|c|c|c|}
\hline Group & Status & $\begin{array}{l}\text { Yrs.i } \\
\text { n } \\
\text { U.S. } \\
\text { K- } \\
12\end{array}$ & $\begin{array}{l}\text { Parti- } \\
\text { cipant } \\
\#\end{array}$ & $\begin{array}{l}\text { Line } \\
\#\end{array}$ & Speaker & Text & UoA & Concept & Theme & Code & Notes \\
\hline $\begin{array}{l}\text { DR - } \\
\text { Gen } 1.5\end{array}$ & Credit & 3.5 & 12 & 254 & Jackie & $\begin{array}{l}\text { Okay. Did you ever talk about } \\
\text { anything personal or something } \\
\text { that's not about class with your } \\
\text { teachers? }\end{array}$ & & & & & \\
\hline $\begin{array}{l}\text { DR - } \\
\text { Gen } 1.5\end{array}$ & Credit & 3.5 & 12 & 255 & Sara & No. & ESL & $\begin{array}{l}f-s \\
\text { engagemen } \\
t\end{array}$ & $\begin{array}{l}\text { general f- } \\
\text { s } \\
\text { engagem } \\
\text { ent }\end{array}$ & $\begin{array}{l}\text { f-s engagement } \\
\text { examples }\end{array}$ & $\begin{array}{l}\text { doesn't talk } \\
\text { about } \\
\text { personal } \\
\text { stuff }\end{array}$ \\
\hline $\begin{array}{l}\text { DR - } \\
\text { Gen } 1.5\end{array}$ & Credit & 3.5 & 12 & 256 & Jackie & $\begin{array}{l}\text { Okay. Did you ever work with the } \\
\text { tutors in the language centers? }\end{array}$ & & & & & \\
\hline $\begin{array}{l}\text { DR - } \\
\text { Gen } 1.5\end{array}$ & Credit & 3.5 & 12 & 257 & Jackie & The reading lab tutors? & & & & & \\
\hline $\begin{array}{l}\text { DR - } \\
\text { Gen } 1.5\end{array}$ & Credit & 3.5 & 12 & 258 & Sara & $\begin{array}{l}\text { No. I used to go cuz I needed to } \\
\text { do the reading lab and stuff like } \\
\text { that. But- }\end{array}$ & ESL & $\begin{array}{l}\mathrm{s}-\mathrm{s} \\
\text { engagemen } \\
\mathrm{t}\end{array}$ & $\begin{array}{l}\text { general s- } \\
\text { s } \\
\text { engagem } \\
\text { ent }\end{array}$ & $\begin{array}{l}\text { s-s engagement } \\
\text { examples }\end{array}$ & reading lab \\
\hline
\end{tabular}


VITA

\section{JACQUELINE PEÑA}

2000

2002

1998-2000

2000-2002

2001-2005

2005-2008

2006-2008

2008-2010

2010-Present
B.A., English

Herbert H. Lehman College, CUNY

Bronx, New York

M.A., English

Boston College

Newton, Massachusetts

Language and Literacy Tutor (Spanish, English, and Italian)

Herbert H. Lehman College, CUNY

Bronx, New York

English Tutor and Teaching Assistant

Boston College

Newton, Massachusetts

Faculty, ESL and Developmental Studies

"Commonwealth of Massachusetts Community College

Hawthorne, Massachusetts

Graduate Research Assistant,College of Education

EMBERS, MURMSI, and Early Reading First Grants

Florida International University

Miami, Florida

Adjunct, College of Education

Florida International University

Miami, Florida

Institutional Effectiveness Coordinator, Institutional Effectiveness

Florida International University

Miami, Florida

Department Chairperson, College Prep

Miami Dade College, Wolfson Campus

Miami, Florida 


\section{PUBLICATIONS AND PRESENTATIONS}

Peña, J. (2001). Getting students through the text and to the paper: Reading strategies for the writing tutor. Paper presented at the annual conference for the New England Peer Tutoring Association, Dudley, MA.

Peña, J. (2004, March). Within these walls: Building community in the classroom. Paper presented at the Conference on College Composition and Communication, San Antonio, TX.

Peña, J. (2005, March). "Why ain't they getting' it rite?" Helping students get it right. Paper presented at the Conference on College Composition and Communication, San Francisco, FL.

Peña, J. (2005, March). Service-learning for ESL students. Paper presented at the Teaching Academic Survival Skills Conference, West Palm Beach, FL.

Peña, J. (2007, Nov.). The explicit construction of a teacher identity through reflexivity. Paper presented at the National Council of Teachers of English Convention, New York.

Peña, J. (2008, Feb.). Post-ESL student success in higher education through membership in communities of practice. Paper presented at the National Association of Bilingual Education, Tampa, FL.

Peña, J. (2008, Feb.). Language variations in the academic writing classroom. Paper presented at the National Association of Developmental Education, Boston, MA.

Peña, J. (2008). Moving to the front of the classroom: English graduate students as composition instructors. Proceedings of the College of Education Research Conference, Florida International University, Miami, FL.

Dinehart, L., Peña, J., \& Chae, C. (2008). The Effect of an early language and literacy intervention on the literacy skills of preschool students. Poster presented at National Association for the Education of Young Children, Dallas, TX.

Peña, J., Britt, Y., \& Lora, A. (2008). A mirror in the classroom: Teacher identity construction through reflective professional development processes and subsequent changes in teacher beliefs. Poster presented at the National Association for the Education of Young Children, Dallas, TX.

Pena, J. (2009, Feb.). A Generation 1.5 student stuck at the gates. Paper presented at the National Association of Developmental Education, Greensboro, NC. 